\title{
Geomorphic comparison of two Atlantic coastal rivers: toward an understanding of physical controls on Atlantic salmon habitat
}

Author: Benjamin Carleton Wilkins

Persistent link: http://hdl.handle.net/2345/674

This work is posted on eScholarship@BC, Boston College University Libraries.

Boston College Electronic Thesis or Dissertation, 2009

Copyright is held by the author, with all rights reserved, unless otherwise noted. 
Boston College

The Graduate School of Arts and Sciences

Department of Geology and Geophysics

GEOMORPHIC COMPARISON OF TWO ATLANTIC COASTAL RIVERS:

TOWARD AN UNDERSTANDING OF PHYSICAL CONTROLS ON

ATLANTIC SALMON HABITAT

a thesis

by

BENJAMIN C. WILKINS

submitted in partial fulfillment of the requirements

for the degree of

Master of Science

May 2009 
(C) copyright by BENJAMIN C. WILKINS 2009 


\begin{abstract}
Geomorphic comparison of two Atlantic coastal rivers: toward an understanding of physical controls on Atlantic salmon habitat

Benjamin C. Wilkins

Advisor: Dr. Noah P. Snyder
\end{abstract}

Substrate size and mobility are important to Atlantic salmon (Salmo salar) spawning and rearing success. Channel geometry is a control on bedload mobility in streams. It is believed that channel morphology in many Maine rivers has been altered by land use practices, creating wider and shallower channels, and lowering stream competence. If correct, these changes may be partially responsible for the limited number of returning salmon currently observed in Maine coastal rivers. To evaluate the magnitude of these changes, I performed a statistical comparison of channel morphology between two Atlantic coastal streams: the Narraguagus River in Downeast Maine and the Jacquet River in northern New Brunswick, Canada. Compared to the Narraguagus River, the Jacquet River has relatively healthy returns of adult salmon. Both watersheds have similar drainage areas (Narraguagus $588 \mathrm{~km}^{2}$; Jacquet $510 \mathrm{~km}^{2}$ ) and mean annual precipitation $(1244 \mathrm{~mm} ; 1200 \mathrm{~mm})$, but differing average channel gradients $(0.16 \%$; $0.51 \%$ ) and longitudinal profiles. During the summer of 2007, I surveyed a $13.6-\mathrm{km}$ section of the Narraguagus with a drainage area range of $129-247 \mathrm{~km}^{2}$, and a $10.4-\mathrm{km}$ section of the Jacquet with a drainage area range of $94-265 \mathrm{~km}^{2}$. I made measurements of active and bankfull width and depth, and channel gradient at 100-m intervals, and 
performed grain-size counts at 200-m intervals. I also measured gradient and width in a GIS-based analysis. Results of my analysis show that channel gradient is likely the most influential factor on Atlantic salmon habitat as it relates to sediment size. The two rivers exhibit no significant difference in width-to-depth ratio, when low-gradient outliers in the Narraguagus River are removed. Predicted median riverbed grain sizes were calculated using two methods: (1) from the empirical relationship between basal shear stress and measured grain size; and (2) using the Shields parameter and remote sensing data only. Measured and predicted grain sizes reveal finer river-bed sediments on the Narraguagus River, however, Shields parameter calculations show that sediment should be mobile in both streams. I compare these predictions to field-based habitat mapping on the Narraguagus River. Based on predicted grain sizes, I expect nearly continuous Atlantic salmon spawning (28-95\%) and rearing (95-100\%) habitat on the Jacquet, and much less spawning (47-62\%) and rearing (57-68\%) habitat on the Narraguagus. This is likely because the Narraguagus River is segmented into reaches of steeper gradient $(S>0.002)$ with potentially good habitat, and flatter reaches $(S<0.0005)$ of poor habitat. The long flat reaches (several $\mathrm{km}$ ) likely act as sediment sinks, preventing the continuity of downstream sediment transport and causing sediment to be sourced from localized glacial deposits. 


\section{Acknowledgments}

First of all to my parents for supporting me on the circuitous path that has led me to where I am today. And to my brother who thinks this work says something about what I'm made of.

To Noah P. Snyder for funding and guiding all of my scholarly activities here at BC, and for putting up with all of the trials and tribulations that I put him through.

To all those that went out in the field with me: (in the order I met them) Mike Castele, Eric Hazlinsky, Alan Kasprak, David Santaniello, Liz Johnson, Adam Pearson, Peter Snajczuk, and Billy Armstrong. Your help and camaraderie is what made this work enjoyable and memorable.

To everyone in 329 (and 311) who shared in all that time well spent: discussing the topic of the hour, solving crosswords, staying too late on Thursdays, and darts.

And finally, to my room (and roommates) with a view of the compost pile. 


\section{Table of Contents}

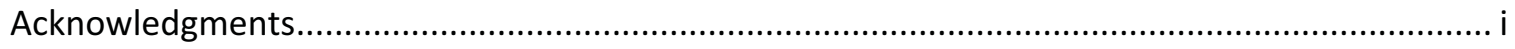

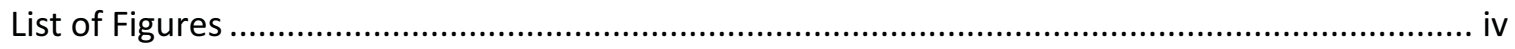

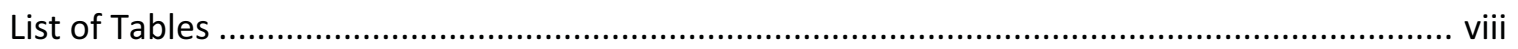

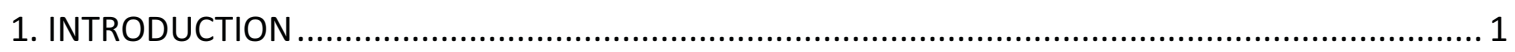

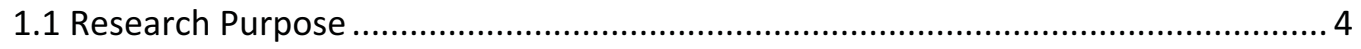

1.2 Study Area Locations and Environment ......................................................... 4

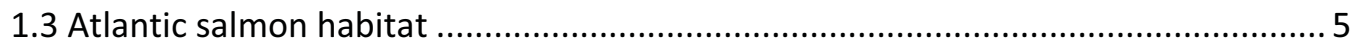

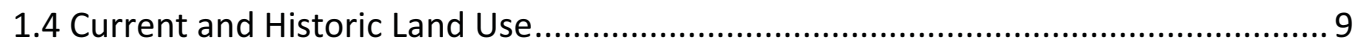

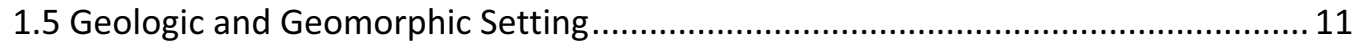

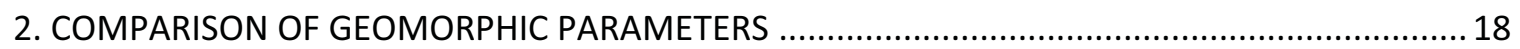

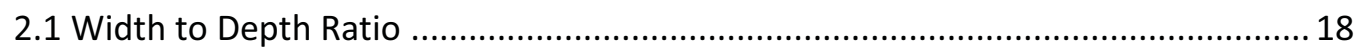

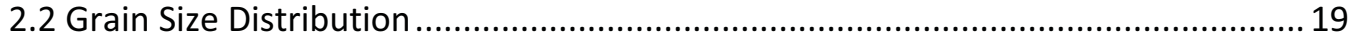

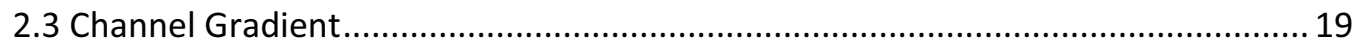

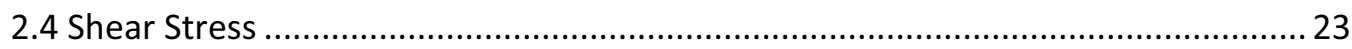

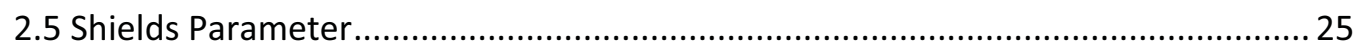

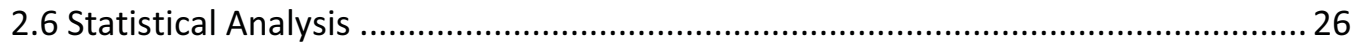

3. METHODS

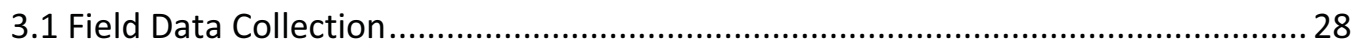

3.2 Geographic Information System (GIS) measurements ......................................... 34

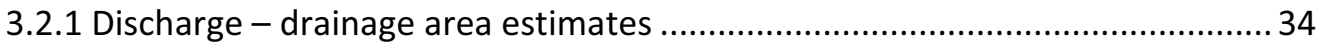

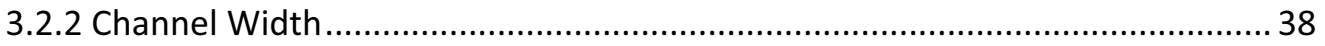

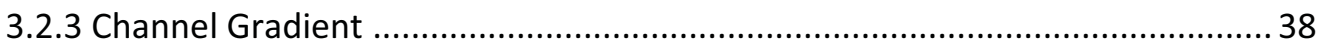

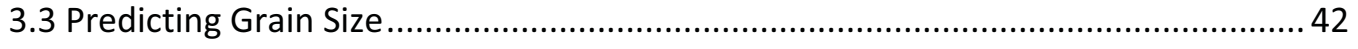

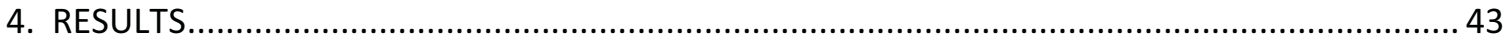

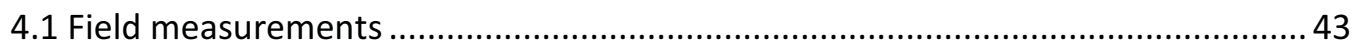

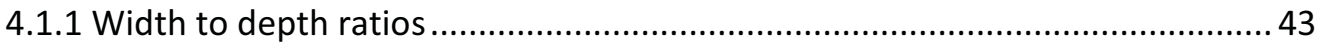

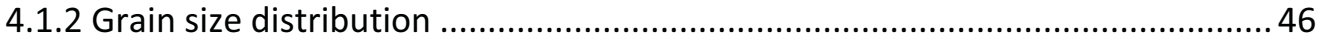




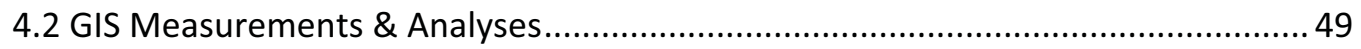

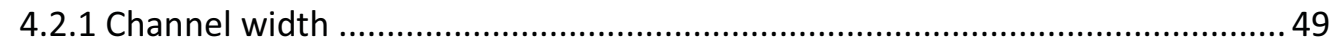

4.2.2 Channel gradient and river profiles............................................................. 51

4.2.3 Shear stress and Shields parameter calculations ..........................................5 54

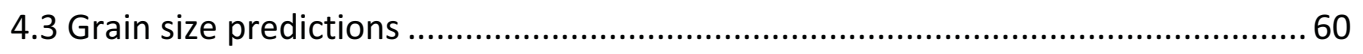

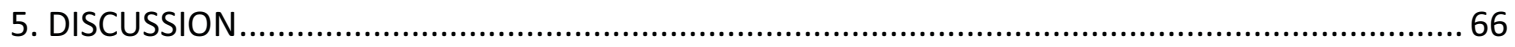

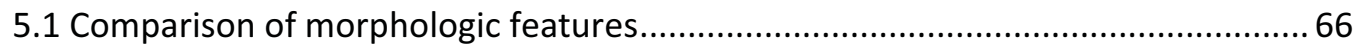

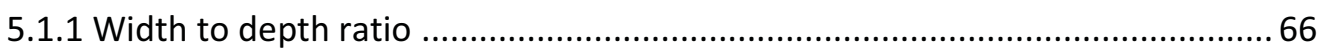

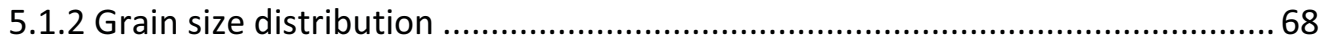

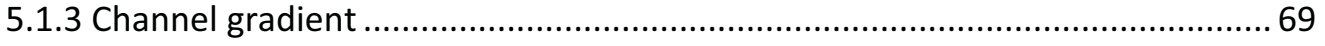

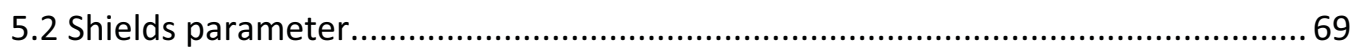

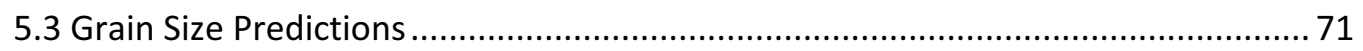

5.4 Comparison of grain-size predictions with mapped Atlantic salmon habitat ......... 74

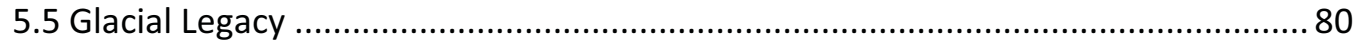

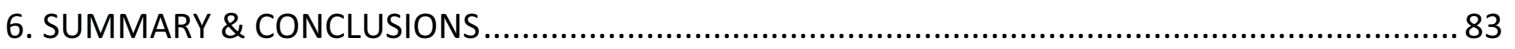

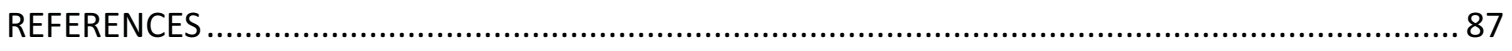

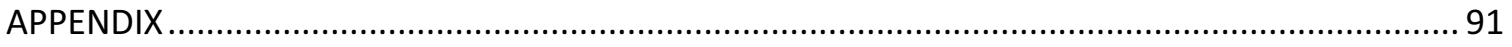




\section{List of Figures}

Figure 1. Locations of the two study river watersheds: the Narraguagus River in coastal Maine, USA, and the Jacquet River in northern New Brunswick, Canada. The Gulf of Maine Distinct Population Segment (GOM-DPS) watersheds are also displayed.

Figure 2. The lifecycle of Atlantic salmon (reproduced from Hendry and Cragg-Hine, 2003). The egg, alevin, parr and smolt stages take place in the fluvial environment. The physiological change called smoltification signals the ability of the juvenile fish to migrate to the saltwater environment where they can spend up to four years feeding. Adult salmon return to their natal streams to spawn

Figure 3. Watershed map of the Narraguagus River showing field surveyed reaches. Base map is a shaded relief image generated from a USGS 10-m digital elevation model. Cross section A to A' is shown in Figure 6a, Hemlock Dam area in Figure 27.

Figure 4. Examples of discrete sediment input to the Narraguagus River. 13

Figure 5. Watershed map of the Jacquet river showing field surveyed reaches. Base map is a shaded relief image created from an Environment Canada 30-m digital elevation model. Cross section B to B' is shown in Figure 6b.

Figure 6. Elevation profiles of representative cross sections for each of the study rivers from digital elevation models of each river. The location of cross section A to $\mathrm{A}^{\prime}$ is marked in Figure 3, cross section B to B' in Figure 5

Figure 7. Post glacial alluvial fill terraces along the Jacquet River

Figure 8. Longitudinal profiles of the Narraguagus and Jacquet rivers from digitized topographic maps. Field surveyed reaches are indicated in red.

Figure 9. Photographs of typical channel gradient in the two study rivers.

Figure 10. Examples of base images showing pre-selected survey points where field and GIS measurements were made (red numbers indicate kilometers from river mouth). (A) Base is a shaded relief image created from 1-m lidar elevation data collected in 2007. (B) Base is from 1-m digital orthophotograph quadrangle (DOQ) image taken in 1998. 
Figure 11. Photographs illustrating the survey method used to measure: (A) channel width; and (B) channel gradient.

Figure 12. Example photograph of grain size measurement in the field. 32

Figure 13. Example of typical grain size plots indicating: (A) cumulative grain size distribution; and (B) cumulative percent finer distribution.

Figure 14. Flood frequency plot for the study rivers displaying the relationship between the recurrence interval $(R I)$ and $k_{q}$, a coefficient that represents the normalized discharge to the channel during an event with a specified recurrence interval, calculated as discharge $(Q)$ divided by drainage area $(\mathrm{A})$. The discharge and associated $k_{q}$ during the two year recurrence interval event are $109 \mathrm{~m} / \mathrm{s}^{3}$ and $1.83 \times 10^{-7} \mathrm{~m} / \mathrm{s}$ on the Narraguagus, $113 \mathrm{~m} / \mathrm{s}^{3}$ and $2.02 \times 10^{-7} \mathrm{~m} / \mathrm{s}$ on the Jacquet.

Figure 15. Comparison of slope and elevation data from two distinct sources along a section of the Narraguagus River: (i) elevation data from digitized topographic maps, essentially the same as DEM data; and (ii) elevation data gathered from lidar (vertical offset interpolated at 1-m intervals). The vertical offset between these datasets is not important. This stream section is chosen because it is bracketed by two contour lines on the topographic map, therefore appearing to have one continuous slope throughout the reach.

Figure 16. Histograms representing the distribution of width to depth ratios on the study rivers using all data (dark colors) and also data that has had outlying values removed based on slope (light colors). A standard Z-test shows that there is no significant difference between the two data sets that have had outliers removed.

Figure 17. Histograms presenting the distribution of mean field-measured grain size $\left(D_{50 f i e l d}\right)$ on the study rivers.

Figure 18. Histograms presenting the distribution of the field-measured coarse fraction of the bed sediments $\left(D_{84}\right.$ field $)$ on the study rivers.

Figure 19. Comparison plots of field-measured active $\left(w_{a}\right)$ and bankful width $\left(w_{b f}\right)$ versus width measured on digital orthophotograph quadrangles $\left(w_{d o q}\right)$ and width measured from lidar data $\left(w_{\text {lidar }}\right)$. 
Figure 20. Comparison plot of: (A) longitudinal profiles created from digital elevation models; and (B) slope calculated from digitized topographic maps (and $S_{\text {field }}$ for the Jacquet river).

Figure 21. Comparison plots of $\tau_{b \text { field }}$ (calculated using field data and $S_{\text {topo }}$ with equation 4 ) and $\tau_{b \text { gis }}$ (calculated using only remote sensing data and equation 11) for the study rivers. 57

Figure 22. Comparison plot of $\tau_{\text {field }}$ (calculated using $h_{b f}$ and $S_{\text {topo }}$ ) and $\tau_{\text {gis }}$ (calculated using remotely-sensed data only) for the two study rivers. 58

Figure 23. Histograms displaying the distribution of Shields parameter values $\left(\tau_{\text {field }}^{*}\right)$ for the study rivers using all data (shown in dark blue) and also data that has had

Figure 24. Basal shear stress $\left(\tau_{b \text { gis }}\right)$ plotted against the observed mean grain size 62

Figure 25. Comparison of field measured median grain size $\left(D_{50 \text { field }}\right)$ and predicted median grain sizes $\left(D_{50 \text { gis }}\right.$ and $\left.D_{50 \text { lidar }}\right)$.

Figure 26 . Predicted median grain size $\left(D_{50 \mathrm{emp}}\right)$ at every survey point along the length of the study rivers. This method is based on the empirical relationship between basal shear stress calculated from digitized topographic maps $\left(\tau_{b g i s}\right)$ and observed mean grain size $\left(D_{50}\right.$ field $)$.

Figure 27. Predicted median grain size $\left(D_{50}\right.$ gis $)$ at every survey point along the length of the study rivers. This method is based on the Shields parameter equation directly ( $\tau^{*}$ is held constant at 0.04 and $\tau_{b \text { gis }}$ is used).

Figure 28. Hemlock Dam area on the Narraguagus River (location shown in Figure 3). Image is colored so that everything at an elevation above the top of the dam appears as red. This highlights the plausible extent of the reservoir created by the dam prior to it being breached. Base is a partially transparent shaded relief lidar DEM.

Figure 29. Atlantic salmon spawning and rearing habitat maps based on: A) the empirical relationship between basal shear stress $\left(\tau_{b \text { gis }}\right)$ and observed grain size; B) using the Shields parameter equation $\left(\tau^{*}=0.04\right)$ and basal shear stress $\left(\tau_{\text {blidar }}\right)$; and C) mapped Atlantic salmon habitat data (ashab) collected in 1991 by the USFWS-GOM Coastal Program 
Figure 30. Histograms comparing the distribution of $D_{\text {50lidar }}$ for spawning and rearing habitat on the Narraguagus River to habitat defined by the USFWS. 


\section{List of Tables}

Table 1. Catchment characteristics of the study rivers. Mean annual runoff is a measure of total yearly discharge divided by drainage area. ........................................ 5

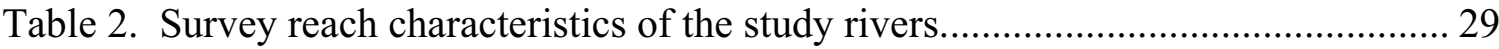

Table 3. List of all GIS coverages used including resolution and source....................... 35

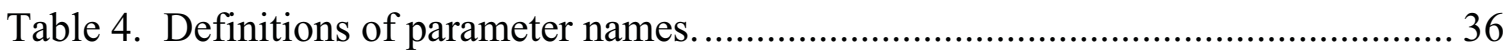

Table 5. Average values and standard deviations of active and high-flow width ( $w_{a}$ and $\left.w_{b f}\right)$ and depth $\left(h_{a}\right.$ and $\left.h_{b f}\right)$ at survey sites along the study rivers. The width to depth ratio is initially calculated using all data. Outlying values are then removed based on channel gradient (where $S_{\text {topo }}<0.002$ ) and a new width to depth ratio is calculated.

Table 6. Mean ( \pm 1 standard deviation) field-measured river bed grain sizes $\left(D_{16}, D_{50}\right.$, and $D_{84}$ ) along the surveyed reaches of the Narraguagus and Jacquet rivers.... 46

Table 7. Average channel gradients and standard deviations from field measurements $\left(S_{\text {field }}\right)$, digitized topographic maps $\left(S_{\text {topo }}\right)$, and airborne laser swath mapping $\left(S_{\text {lidar }}\right)$ for the surveyed reaches of the Narraguagus and Jacquet rivers.

Table 8. Average basal shear stress $\left(\tau_{b \text { gis }}\right)$ and standard deviation values for the Narraguagus and Jacquet rivers calculated using DEM-derived values for drainage area, channel width $\left(w_{\text {doq }}\right)$, and slope $\left(S_{\text {topo }}\right)$. Shear stress values $\left(\tau_{b}\right.$ lidar) are also shown for the Narraguagus based on lidar-derived width ( $w_{\text {lidar }}$ ) and slope $\left(S_{\text {lidar }}\right)$.

Table 9. Summary of observed and predicted median grain sizes for the surveyed reaches of the Narraguagus and Jacquet rivers. Predictions are made from: (1) the empirical relationship between observed grain size $\left(D_{50 \text { field }}\right)$ and basal shear stress $\left(\tau_{b \text { gis }}\right)$; and $(2)$ from the Shields parameter equation with the Shields parameter held constant at $\tau^{*}=0.04$.

Table 10. Grain size predictions as percent spawning and rearing habitat for the two study rivers, as well as habitat mapped by the USFWS 


\section{INTRODUCTION}

Atlantic salmon (Salmo salar) around the world have long been subject to intense anthropogenic pressures, both through over-fishing and numerous forms of habitat degradation. While some former Atlantic salmon habitats, such as those in many parts of northern Europe (Montgomery, 2003; Hendry and Cragg-Hine, 2003), are thought to be beyond repair, there is still much effort being put into the resurrection of Atlantic salmon populations in North America, including in coastal rivers in Maine. Current U.S. populations of anadromous Atlantic salmon are below one percent of historical estimates (Montgomery, 2004) and are geographically confined to a small number of rivers in Maine (NRC, 2004). Populations have seen such a dramatic decline that Atlantic salmon were listed under the federal Endangered Species Act in November 2000 (Lisles, 2000). These fish are now the focus of extensive research, with the goal of rebuilding the species to a sustainable population. Critical habitat has been designated for the Gulf of Maine Distinct Population Segment (GOM DPS) of Atlantic salmon as all watersheds from the Androscoggin River along the Maine coast to the Dennys River (Fay et al., 2006) (Figure 1). These are rivers where the salmon populations are critically low but still thought to be genetically diverse enough for restoration purposes. Much work is being done on these rivers, focused primarily on salmon restocking and habitat restoration, in order that we may better understand the complex interaction between habitat and species success.

An important component of any restoration project is having an understanding of the pre-disturbance environment (Kondolf and Wolman, 1993; Gottesfeld et al., 2004; 
Montgomery, 2004; Snyder et al., 2008). In the case of Maine rivers that have been modified by humans both intentionally and unintentionally over the last several hundred years, it is difficult to obtain an accurate picture of pre-European settlement conditions. Currently, quantitative data on geomorphic changes is a missing component that is key to better assessment of the effects on salmon reproduction and survival. In order to be effective, future salmon recovery requires a multi-disciplinary approach that will integrate geologic, geomorphic, and ecologic information into rehabilitation efforts (Montgomery, 2004). By comparing the Narraguagus River (one of the coastal GOMDPS rivers) to a nearby river in New Brunswick, Canada (Figure 1) that is thought to be in a less disturbed condition and has a relatively healthier salmon population, I endeavor to further our understanding of how the Narraguagus River has been altered and what can be done to facilitate restoration efforts that will put the river on a trajectory toward predisturbance conditions. 


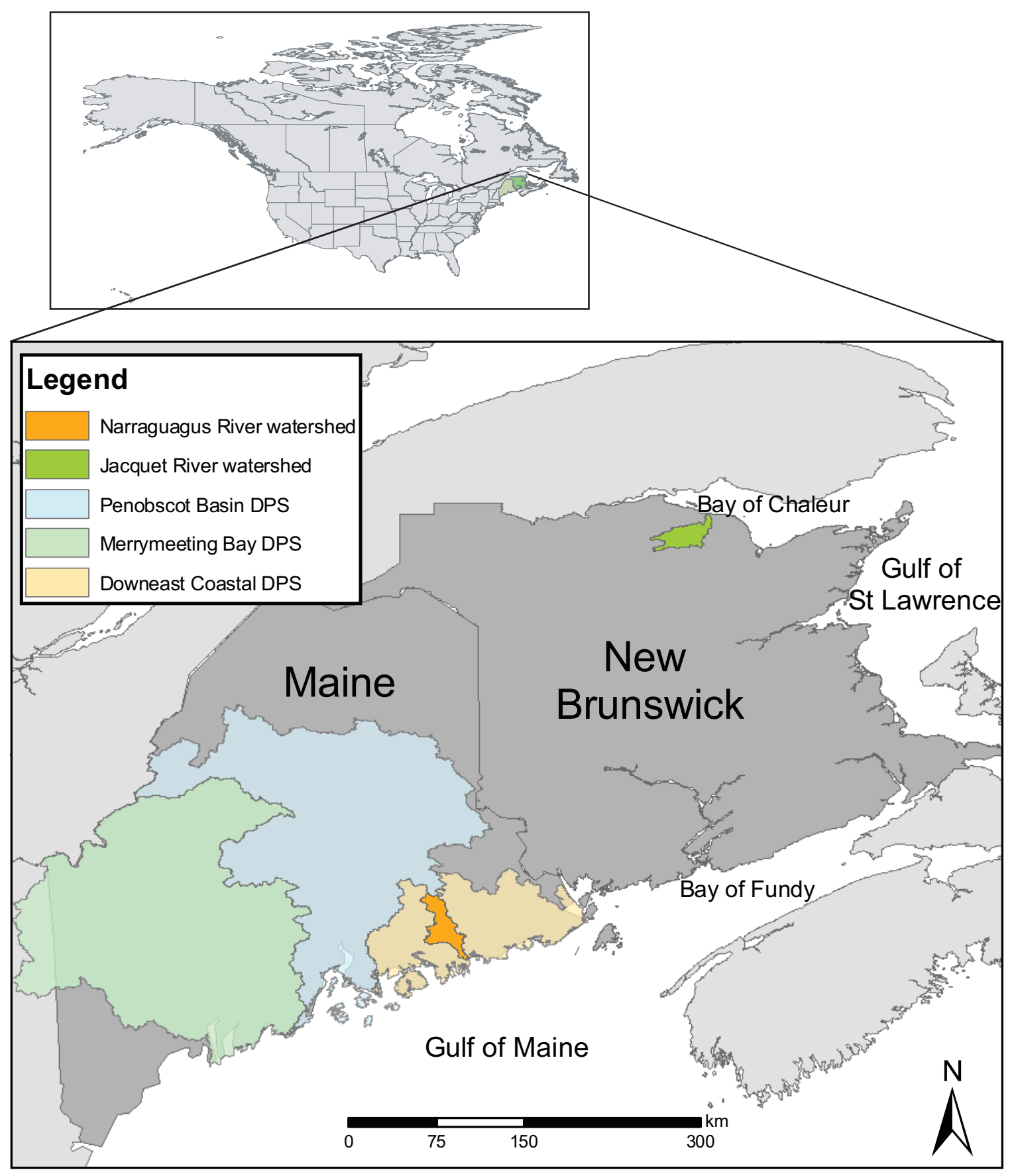

Figure 1. Locations of the two study river watersheds: the Narraguagus River in coastal Maine, USA, and the Jacquet River in northern New Brunswick, Canada. The Gulf of Maine Distinct Population Segment (GOM-DPS) watersheds are also displayed. 


\subsection{Research Purpose}

The goal of the project is to better understand the geomorphic responses of rivers to historic land-use changes, and attempt to relate these changes to Atlantic salmon habitat quality in two coastal rivers. Understanding how rivers respond to change is an important aspect of predicting and restoring good quality fish habitat (Dudley, 2004). While much work has been done on rivers in the mountainous terrain of the Pacific Northwest (e.g., Montgomery et al., 1999; Merz et al., 2006) and in small, steep watersheds in northern Europe (e.g., Gibbins, 2002; Moir, 2003), far less attention has been given to the low-relief rivers in paraglacial landscapes (previously covered by continental glaciers) along the north Atlantic coast of the US and Canada (Magilligan et al., 2008; Snyder et al., 2008). This study compares morphologic elements such as grain size, channel morphology and hydraulics between two Atlantic coastal rivers in an effort to better understand apparent differences in salmon habitat.

\subsection{Study Area Locations and Environment}

The two study rivers are located in sparsely populated areas of Maine and New Brunswick (Figure 1). Both rivers flow through a bedrock-dominated environment where transport sediment transport rate is limited by patchy sediment supply and low channel gradients. They both flow across terrain occupied by ice during the Wisconsinan glaciation. The two rivers are coastal, meaning that they flow directly into saltwater environments without first joining another river. The Jacquet River flows into the Bay of Chaleur, which is connected to the Gulf of St. Lawrence, and the Narraguagus River 
flows into the Gulf of Maine. Average annual precipitation is $1240 \mathrm{~mm}$ on the Narraguagus (Dudley \& Nielsen, 2000) and approximately $1200 \mathrm{~mm}$ in the Jacquet River area (Environment Canada, 2007a). The maximum recorded flood on the Narraguagus was $269 \mathrm{~m}^{3} / \mathrm{s}$ on May 28, 1961 (59 years of record), and $235 \mathrm{~m}^{3} / \mathrm{s}$ on May 4, 1991 on the Jacquet (42 years of record). The contributing drainage area of the Narraguagus River is $588 \mathrm{~km}^{2}$ and the Jacquet River watershed is $510 \mathrm{~km}^{2}$ (Table 1).

\begin{tabular}{|l|c|c|}
\hline & Narraguagus & Jacquet \\
\hline Watersheds & & \\
$\quad$ Contributing drainage area $\left(\mathrm{km}^{2}\right)$ & 588 & 510 \\
Hydrology & & \\
Period of record for gauging station data & $1949-2006$ & $1964-2005$ \\
Mean daily discharge $\left(\mathrm{m}^{3} / \mathrm{s}\right)$ & 13.98 & 10.15 \\
Mean annual runoff $(\mathrm{m} / \mathrm{yr})$ & 0.75 & 0.63 \\
Mean annual precipitation $(\mathrm{mm})$ & 1244 & 1200 \\
\hline
\end{tabular}

Table 1. Catchment characteristics of the study rivers. Mean annual runoff is a measure of total yearly discharge divided by drainage area.

\subsection{Atlantic salmon habitat}

Atlantic salmon are an anadromous species, meaning that they hatch in fresh water and spend two to four years in the fluvial environment before swimming out to sea where they grow and develop into adult fish. After one to four years at sea, adult fish return to their native rivers and streams to spawn (Figure 2). The distinct lifestyle of Atlantic salmon requires that specific conditions be met at different stages in their lifecycle. They require unimpeded migration routes up and downstream, mobile gravel beds for spawning, deep, cool pools to rest in and hide from predators, riparian vegetation 
and in-stream woody debris to provide shade and cover, and minimum water flows. All of these factors combine to provide sufficient complexity in the stream environment for salmon to thrive.

Salmon spawning and rearing habitat is directly linked to channel morphology. In this study, I focus on these conditions as key measures of habitat quality. In a natural state, good quality spawning habitat includes channel-bed gravel sediments that are frequently mobilized, both during high-flow events (i.e. bankfull conditions) and by adult fish that initiate gravel movement during redd construction (depressions dug in the river bed by adults where they lay their eggs) (Hassan et al., 2008). If the riverbed sediments are immobile, adult salmon will not be able to construct redds that will allow their eggs to survive and hatch. Sediment immobility may be due to either armoring of the channel bed, a situation where the bed material is too coarse to be mobilized by common high flow events (flows occurring every one to two years) but the fines get winnowed away, or when coarse sediments become embedded in finer material.

Returning adult Atlantic salmon construct their redds in riverbed gravels with a median grain size $\left(D_{50}\right)$ of approximately $16 \mathrm{~mm}$ (Warner, 1963), and possibly up to 64 mm (Hendry and Cragg-Hine, 1997). Kondolf and Wolman (1993) summarized the results of several studies of salmon species and show an average $D_{50}$ of $22 \mathrm{~mm}$, ranging from $5.4 \mathrm{~mm}$ for Coho salmon in Oregon (study by Koski, 1966) to $78 \mathrm{~mm}$ for Chinook salmon in Washington (study by Chambers et al., 1954). These numbers vary depending on fish species as well as other factors such as water depth and velocity, and the presence or absence of cover. 
During incubation, the composition of the riverbed (size and material) influences water quality around the eggs by affecting both flow rates within spawning beds and the exchange between intragravel and stream water (Danie et al., 1984). Throughout the following freshwater stages of their lifecycle (rearing), juvenile salmon live in water depths ranging from 17 to $26 \mathrm{~cm}$, flow velocities from 0.5 to $0.75 \mathrm{~m} / \mathrm{s}$, and where bed materials are loosely packed and moderately coarse (Hendry and Cragg-Hine, 2003). Median grain sizes of 16 to $256 \mathrm{~mm}$ are thought to provide appropriate rearing conditions (Kondolf and Wolman, 1993, Hendry and Cragg-Hine, 1997, Buffington et al., 2004). 


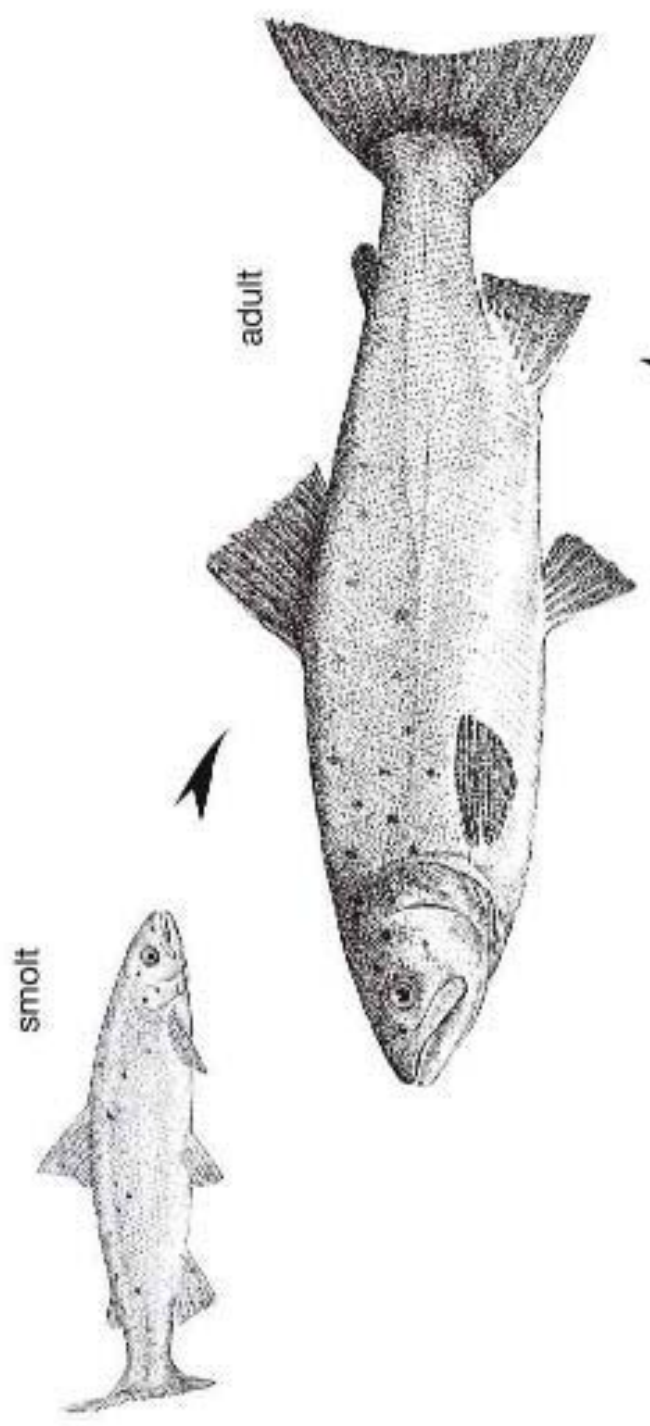

$\lambda$

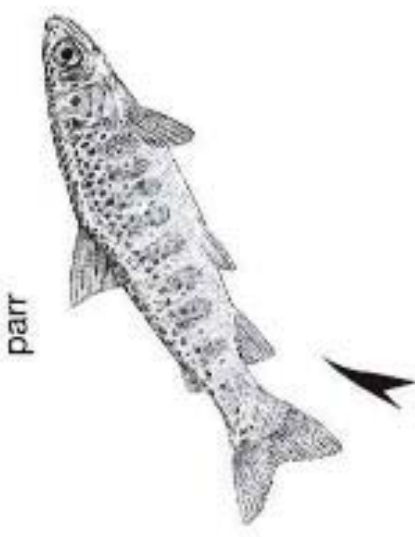

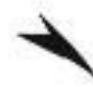
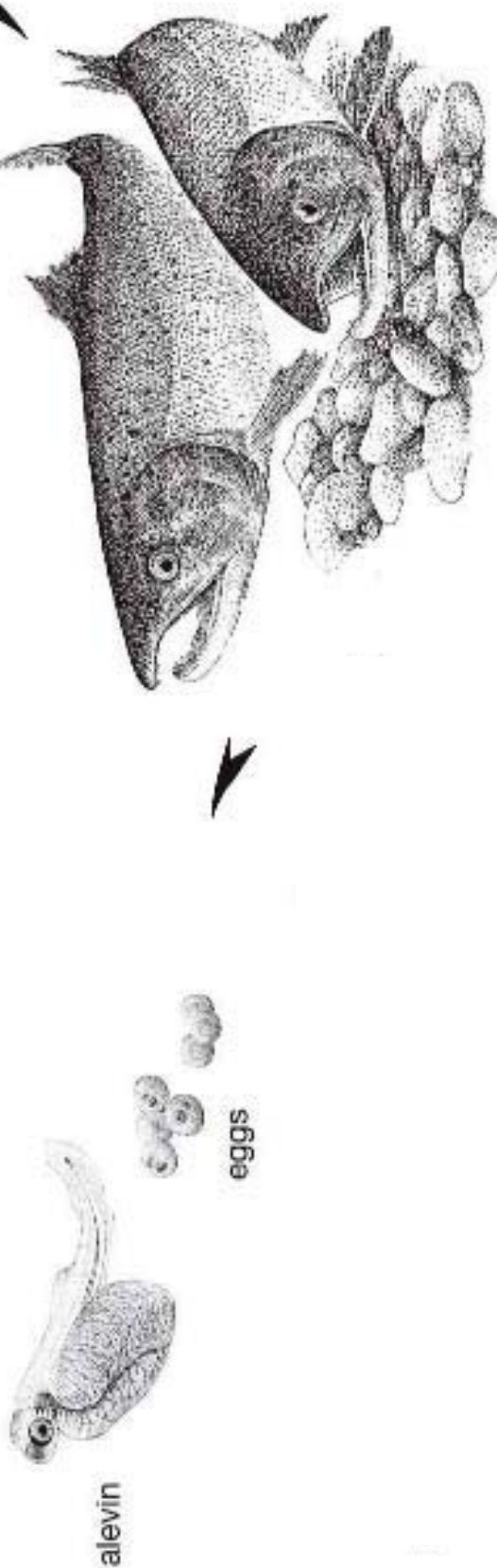

$+\frac{0}{\circ}$

ผ ฏ

응 웅

紊范产

흥

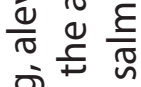

워늠

든 든 훈

ํ. 이

ํํㅇ 응

는

ฮั

주 ह ह

임 ఫ

讨 운

등 윽

긍 읃

눤 은

등 등

은 은 은

ष्ट

능 응 인

은 들

은 둥 둥

ठ है

है 을 을

늘 d

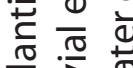

运引

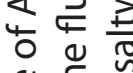

Q

ปั

幽 웅

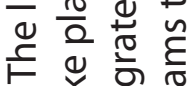

ค 힝

ญ艹

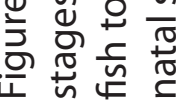




\subsection{Current and Historic Land Use}

For much of the $19^{\text {th }}$ and $20^{\text {th }}$ century intensive timber harvest occurred in both the Narraguagus and Jacquet watersheds. Until the mid $20^{\text {th }}$ century, common logging practices were to clear-cut an area up from the edges of a river and harvest all trees in the area (JRGNPA, 2007). This led to an increase in soil erosion throughout watersheds, delivering fine-grained sediment to the river. This sediment may have effectively choked the river and buried existing river-bed gravels with finer material. Cutting of riparian trees likely caused rivers to erode channel banks more efficiently, widening channels and lowering competence, defined as the ability of the river to transport sediment. Current practices include selective cutting as well as leaving a riparian buffer adjacent to river banks in an effort to reduce further bank erosion and delivery of fine sediment.

Historically, the harvested logs would be transported to the river where they would be stored in reservoirs created behind low-head, temporary dams colloquially referred to as splash dams. In addition to storing water and logs, splash dams created sections of slow-moving, flat water that would cause the river to deposit sediment, thus reducing the transport of sediment downstream. These dams would periodically be breached sending a pulse of water and logs downstream and into reservoirs created for mills located near the river mouth. At least six and possibly as many as nine mill dams are known to have existed on the main stem of the lower Narraguagus River, the last being removed in 1951 (Harriman, 1977). At least two splash dams existed on the upper Narraguagus main stem and several more were present on tributaries. There remains one ice-control dam at Cherryfield (located approximately $11 \mathrm{~km}$ from the mouth of the 
river), a roughly two meter high crib dam built by the Corps of Engineers in 1961 (Perham, 1983). In contrast, while some logging-related dams are known to have existed on tributaries of the Jacquet, no main stem dams are recorded in the literature (JRGNPA, 2007). This is likely because the steeper channel gradient of the Jacquet allowed for more frequent but potentially less damaging transport of logs downriver, due to transport occurring during normal high-flow conditions. Although logging still continues in both watersheds, current logging practices include trucking logs out of the area on gravel roads. This has eliminated the need for temporary splash dams.

During the times when the temporary dams were in existence, they would occasionally be breached sending a pulse of water and logs downstream. This mass movement of wood and water down the river would potentially cause serious erosion of the channel bed and banks (particularly because of the high potential for erosion due to deforestation of riparian areas), potentially widening and straightening the rivers. The widening of the channel would lead to decreased flow depths during periods of regular flow (i.e. not dam-influenced) and hence to higher width to depth ratios and lower stream competence. The decreased competence would in turn lead to increased deposition of sediment in the channel and therefore alteration of the composition of the bed material.

In-channel log drives also necessitated the removal of obstacles preventing the passage of logs downstream. Removal of natural logjams may have increased bank erosion in these areas, and changed the flow regime in the channel. It is now thought that channel-spanning debris created by deadfall into the river and other large woody debris (LWD) is an essential component of the salmon rearing environment (Dolloff and 
Warren, 2003; Montgomery, 2003; Magilligan et al., 2008). LWD creates pools where adult salmon can rest before spawning and juvenile salmon can hide from predators, and generally increase flow and channel complexity. Projects with a primary focus on reintroduction of LWD to channels are currently underway in Maine.

\subsection{Geologic and Geomorphic Setting}

The Narraguagus River watershed is underlain by Devonian-aged granites, small pockets of the Ordovician-Cambrian Penobscot Formation made up of carbonaceous pelites, and by the Devonian-Ordovician Bucksport Formation, which consists of interbedded sandstone and impure limestone (Osberg et. al, 1985). The Jacquet River is underlain by mid-Ordovician to Devonian marine and terrestrial sedimentary and volcanic rocks of the Dalhousie group (Williams, 1978).

The Narraguagus River watershed (Figure 3) is a landscape strongly imprinted with remnants of late Pleistocene glaciation. The river flows around resistant bedrock knobs and glacial features such as eskers and moraines in its upper reaches, and enters a glacial outwash plain downstream of Beddington Lake. The river has incised 1s to 10s of meters into these poorly sorted materials, which appear to be a primary source of sediment to the channel (Figure 4). 


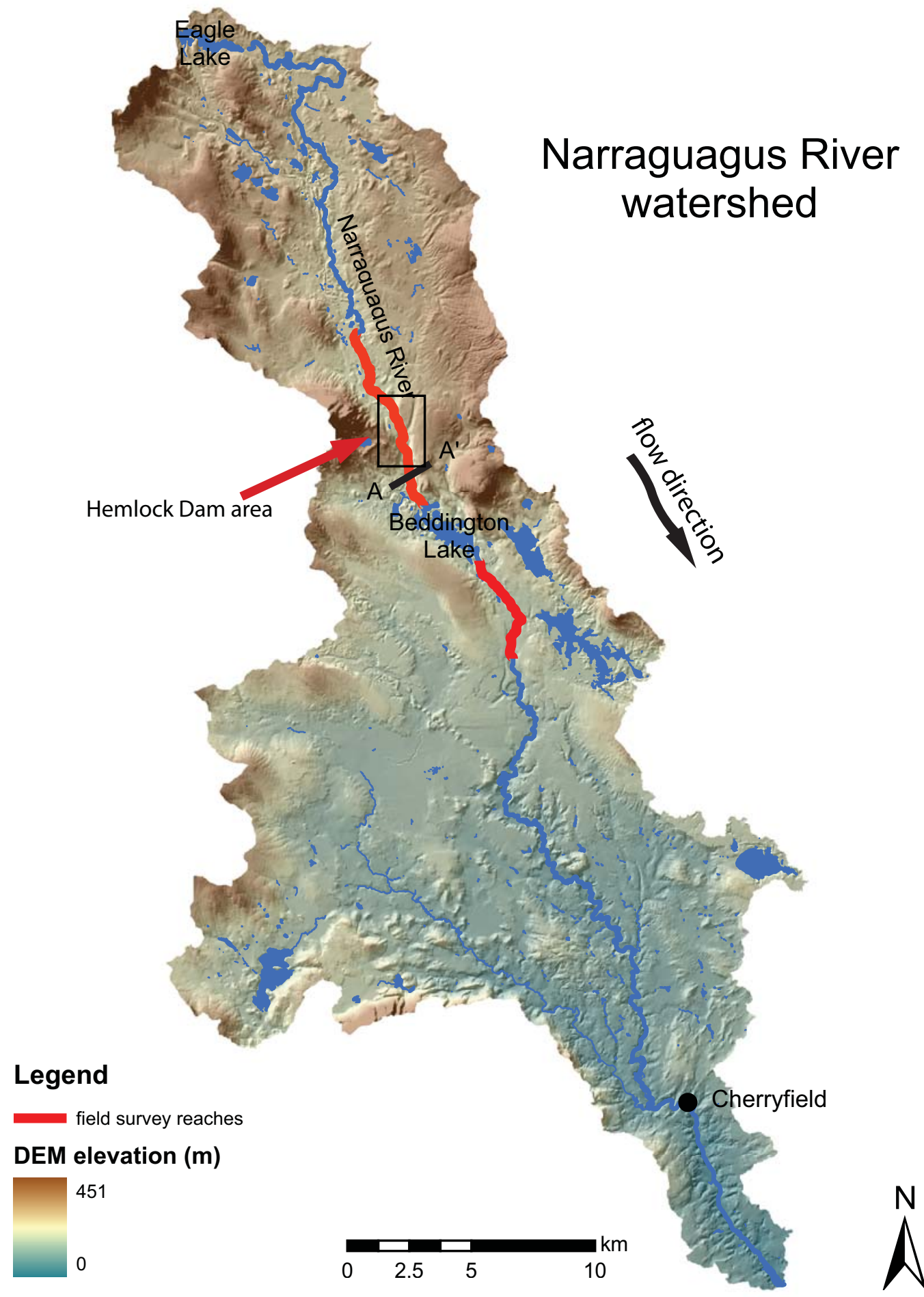

Figure 3. Watershed map of the Narraguagus River showing field surveyed reaches. Base map is a shaded relief image generated from a USGS 10-m digital elevation model. Cross section A to A' is shown in Figure 6a. Hemlock Dam area shown in Figure 28. 

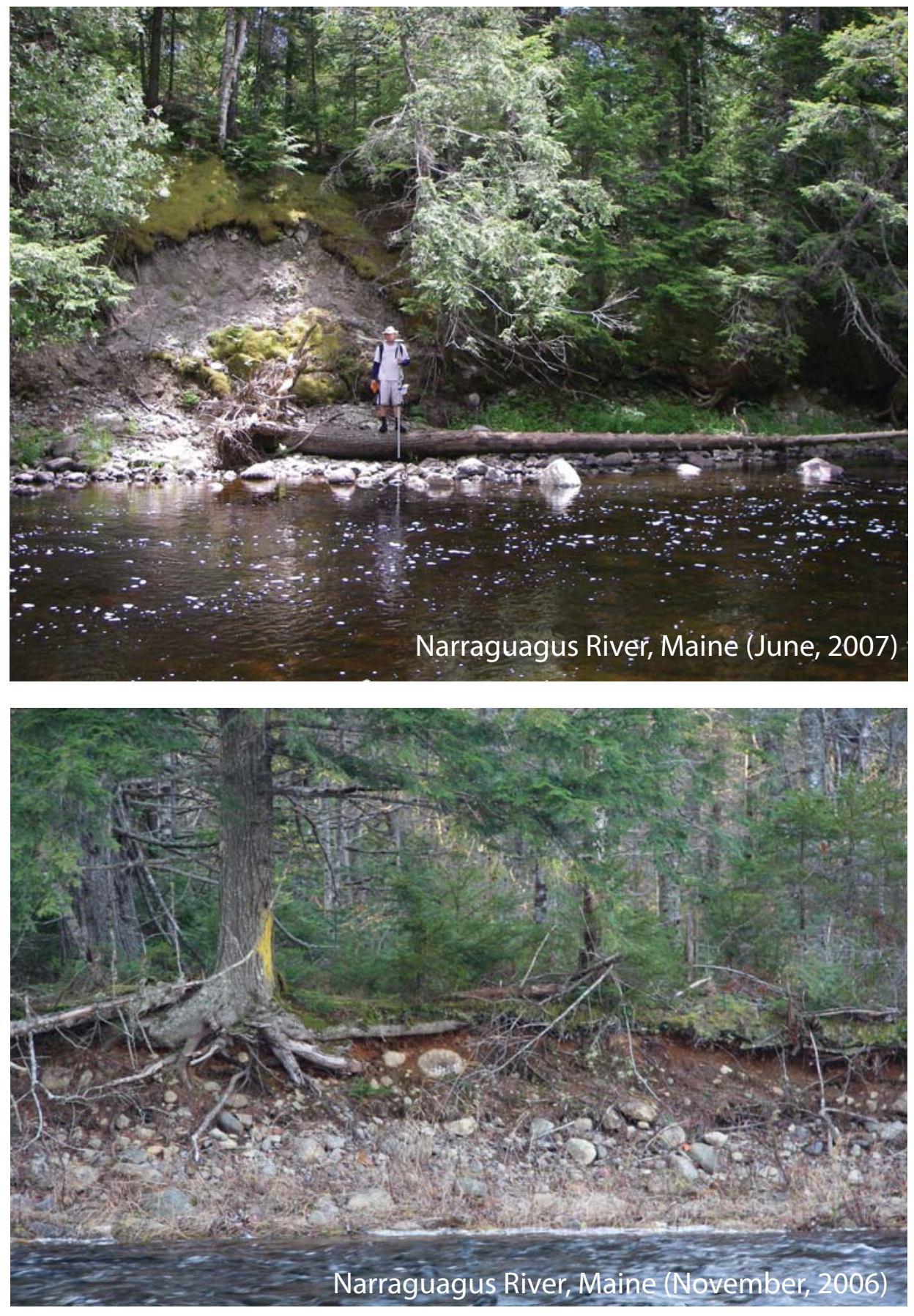

Figure 4. Examples of discrete sediment input to the Narraguagus River. 
The Late Pleistocene glaciation also influenced the Jacquet River landscape (Figure 5). The river flows through a canyon incised tens of meters into the sedimentary rocks of the surrounding plateau (Figure 6). Although published information regarding glaciation of this specific area is limited (Rappol, 1989), it is possible to speculate as to the conditions at the time of deglaciation and what implications this may have on current conditions. During the glacial retreat period, ice would have remained perched upon the plateau after the ice in the lower elevations had melted. Subsequent meltwater from the higher elevation ice on the plateau likely flowed through the incised river channels and flushed much of the glacial sediments in the channels downstream, out the mouth of the river and into the bay. There does not appear to be the large-scale remnant deposits such as moraines, eskers and fine grained glacial outwash adjacent to the Jacquet River channel that exist in the Narraguagus River watershed. There are however, alluvial fill terraces, likely deposited during deglaciation, bordering the river in multiple locations (Figure 7). 


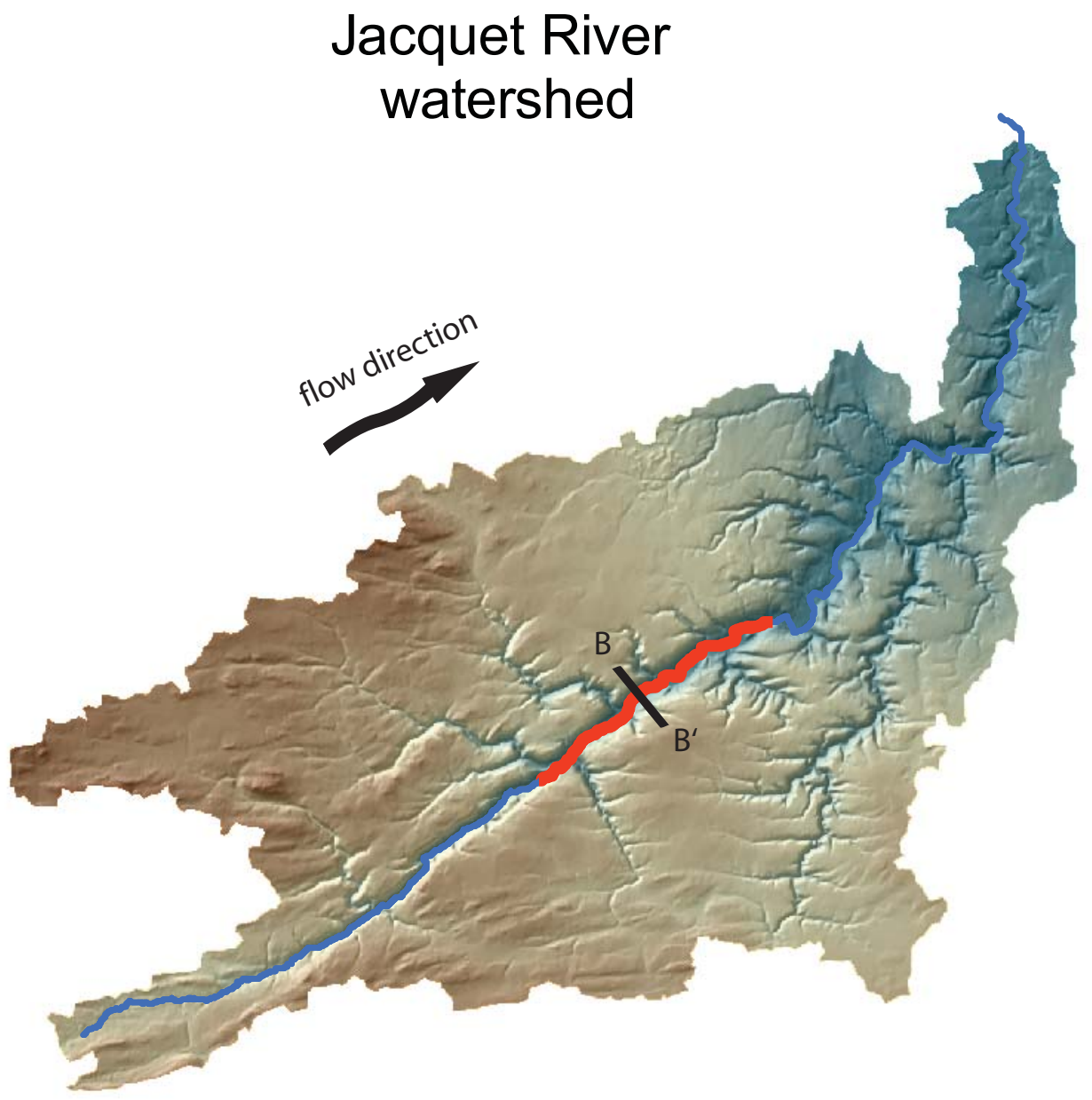

\section{Legend}
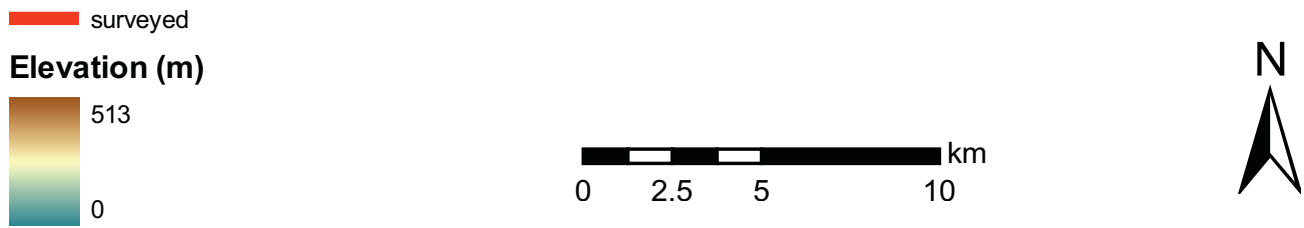

Figure 5. Watershed map of the Jacquet River showing field surveyed reaches. Base map is a shaded relief image generated from an Environment Canada 30-m digital elevation model. Cross section B to $B^{\prime}$ is shown in Figure $6 b$. 


\section{Narraguagus}

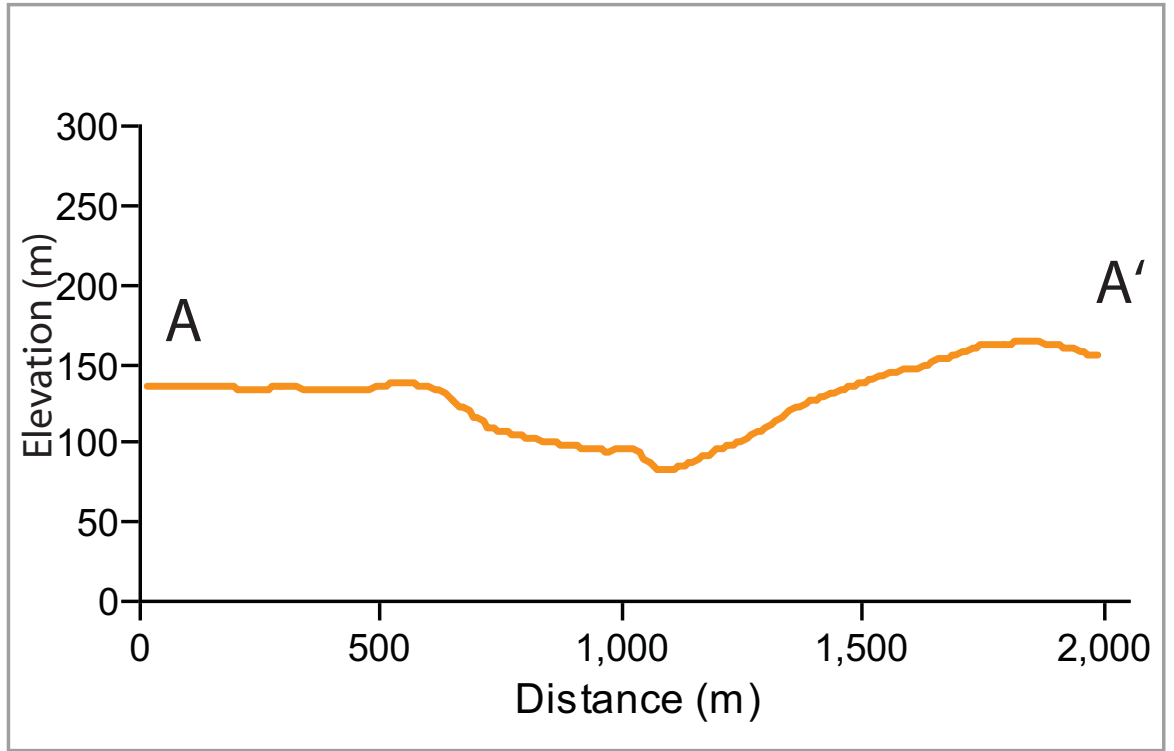

A.

\section{Jacquet}

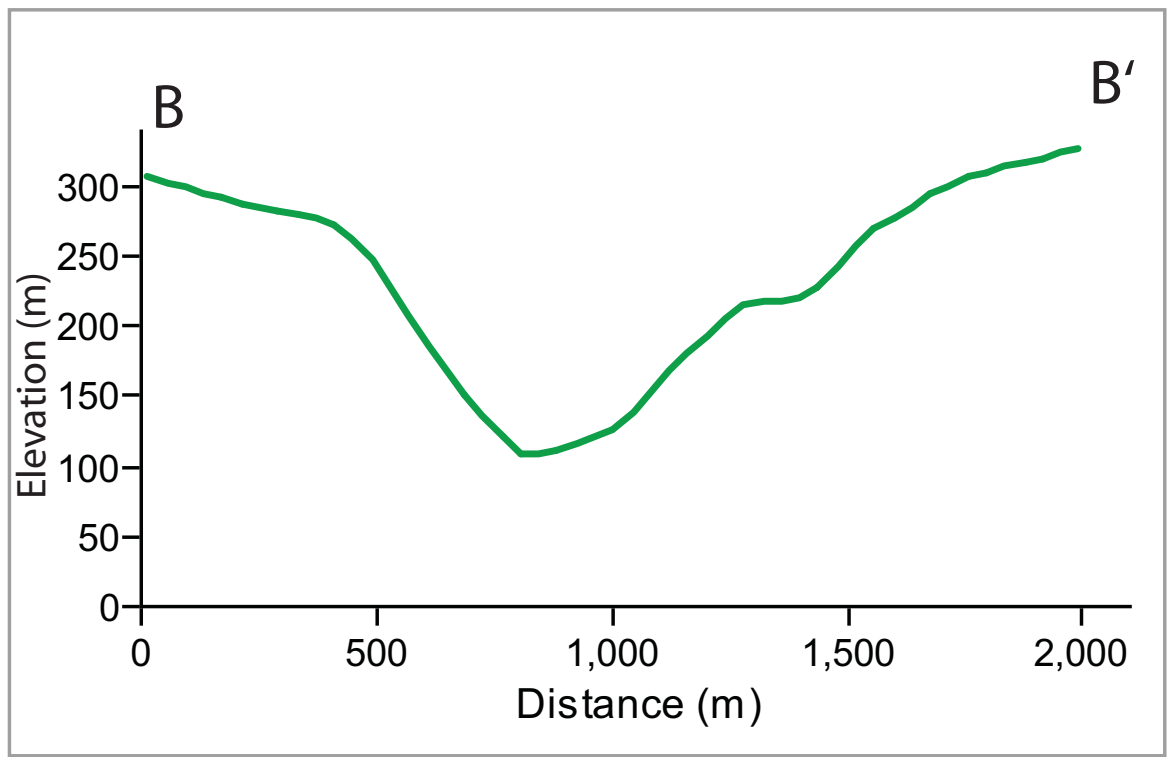

B.

Figure 6. Elevation profiles of representative cross sections for each of the study rivers from digital elevation models of each river. The location of cross section $A$ to $A^{\prime}$ is marked in Figure 3 , cross section $B$ to $B^{\prime}$ in Figure 5. 

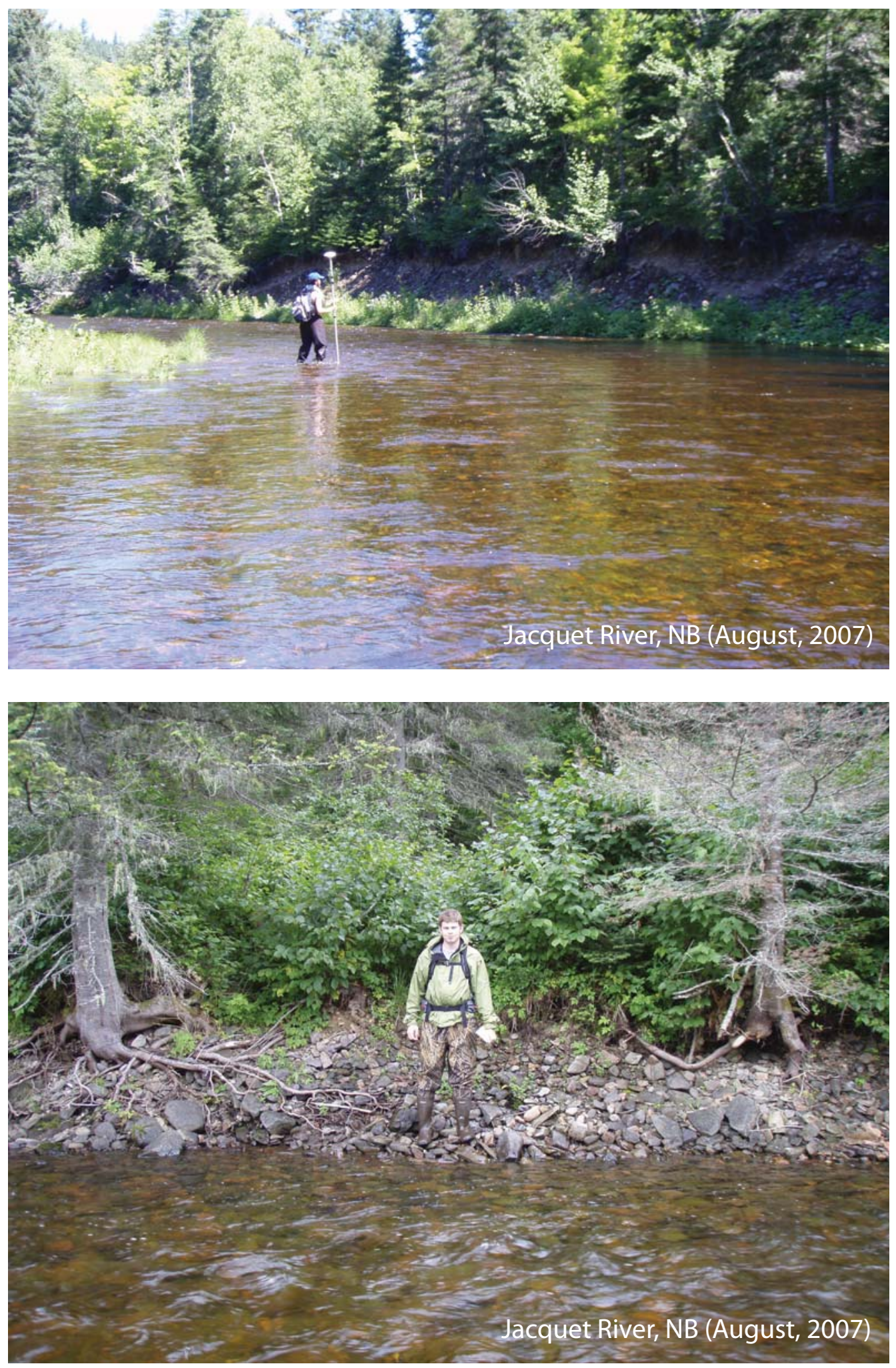

Figure 7. Post-glacial alluvial fill terraces along the Jacquet River. 


\section{COMPARISON OF GEOMORPHIC PARAMETERS}

This section addresses the specific geomorphic features used for the comparison between the study rivers: width to depth ratio, grain size distribution and channel gradient. I explain their significance, how numerical values are calculated for each feature, and how they combine to construct the equations that produce values also used for comparative purposes: basal shear stress, the Shields parameter and grain size predictions.

\subsection{Width to Depth Ratio}

Many resource managers and watershed groups concerned with habitat quality and restoration start from the viewpoint that Maine rivers are out of geomorphic equilibrium. This situation is believed to be the result of land uses (particularly timber harvest) that have widened and shallowed rivers since the onset of European settlement in North America. Increased width to depth ratio of the rivers in Maine has potentially created a situation where the rivers cannot transport their bed sediment, a requirement for good quality salmon spawning habitat (NRC, 2004). These assumptions, while likely valid, are presently untested in Maine rivers.

The ratio of width to depth is an indicator of the competence of the river (i.e. its ability to transport sediment). The outcome of a higher width to depth ratio (e.g., wide and shallow) will be reduced competence, effectively decreasing the maximum grain sizes transported (Ritter et al., 2002). The current belief among many resource managers, and one hypothesis going into this study, is that the Narraguagus River would exhibit a 
larger overall width to depth ratio than the Jacquet River. A potential reason for a larger range in width to depth values on the Narraguagus is the large discrepancy in channel gradient values between the steep and flat reaches observed on this river.

\subsection{Grain Size Distribution}

The composition of the riverbed is a primary factor to consider when assessing the suitability of a stream for spawning and rearing habitat. As discussed in section 1.3, Atlantic salmon require riverbed sediments that have a mean diameter $\left(D_{50}\right)$ of approximately 16 to $64 \mathrm{~mm}$ for spawning and 16 to $256 \mathrm{~mm}$ for rearing. One hypothesis of this study is that sediments in this grain size range in the Narraguagus River are too poorly sorted to support good spawning and rearing habitat. It is also possible that there are simply too few areas of appropriately sized sediments to support a healthy salmon population. A comparison of the measured grain sizes from the Narraguagus and Jacquet rivers will test these ideas.

\subsection{Channel Gradient}

The longitudinal profiles of the Narraguagus and Jacquet rivers (Figure 8) create an important distinction between the two rivers. The average channel gradient $\left(S_{\text {topo }}\right)$ on the Narraguagus is 0.0015 and is characterized by long flat stretches $(S<0.0005)$ (Figure 9a) with short steeper reaches $(S>0.002)$. The low-gradient sections are typically wider and deeper, with slow moving water. A probable result of this dichotomy is that the 
flatter sections contain finer bed material (sands and fine gravel) whereas the steeper sections contain coarser gravel and cobbles. The low gradient reaches likely act as sediment sinks because they lack the competence to transport the coarser materials mobilized in the steeper reaches. In contrast, the profile of the Jacquet River (Figure 8) is characterized by a more continuous steep slope (average $S_{\text {topo }}$ is 0.0051 ) (Figure 9b) and a more uniform bed material composed of coarse gravel and cobbles. The consistent nature of the Jacquet gradient likely allows for more continuous sediment transport and homogenous geomorphic conditions along the majority of the river length. In addition, the Jacquet flows through a gorge that has incised into the surrounding plateau, whereas the landscape bordering the Narraguagus is relatively flat (Figure 6). While the confined nature of the Jacquet limits the ability of the river to erode or shift laterally, the Narraguagus has no such constraints. Its ability to erode laterally, and therefore widen, is potentially greater. 


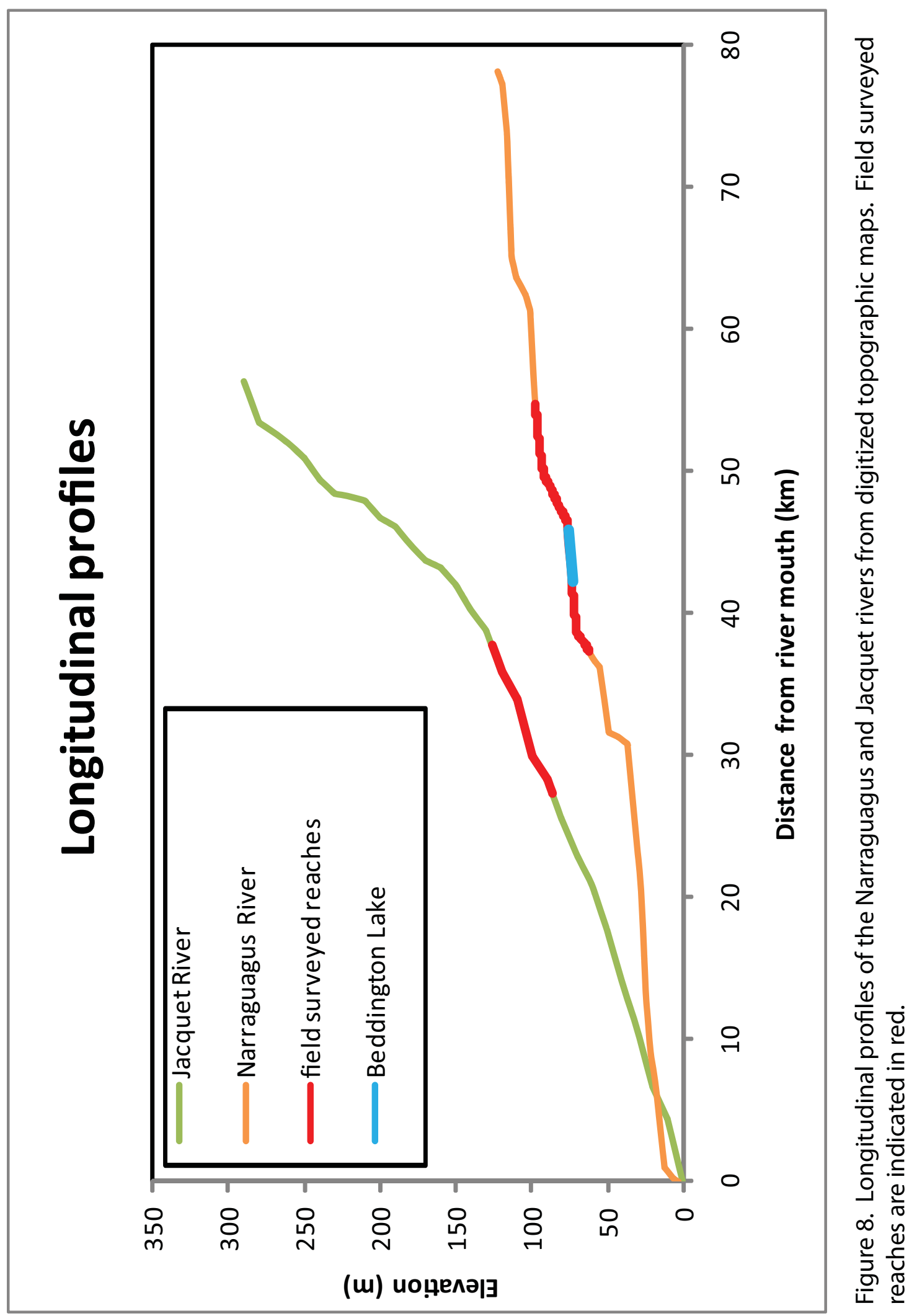




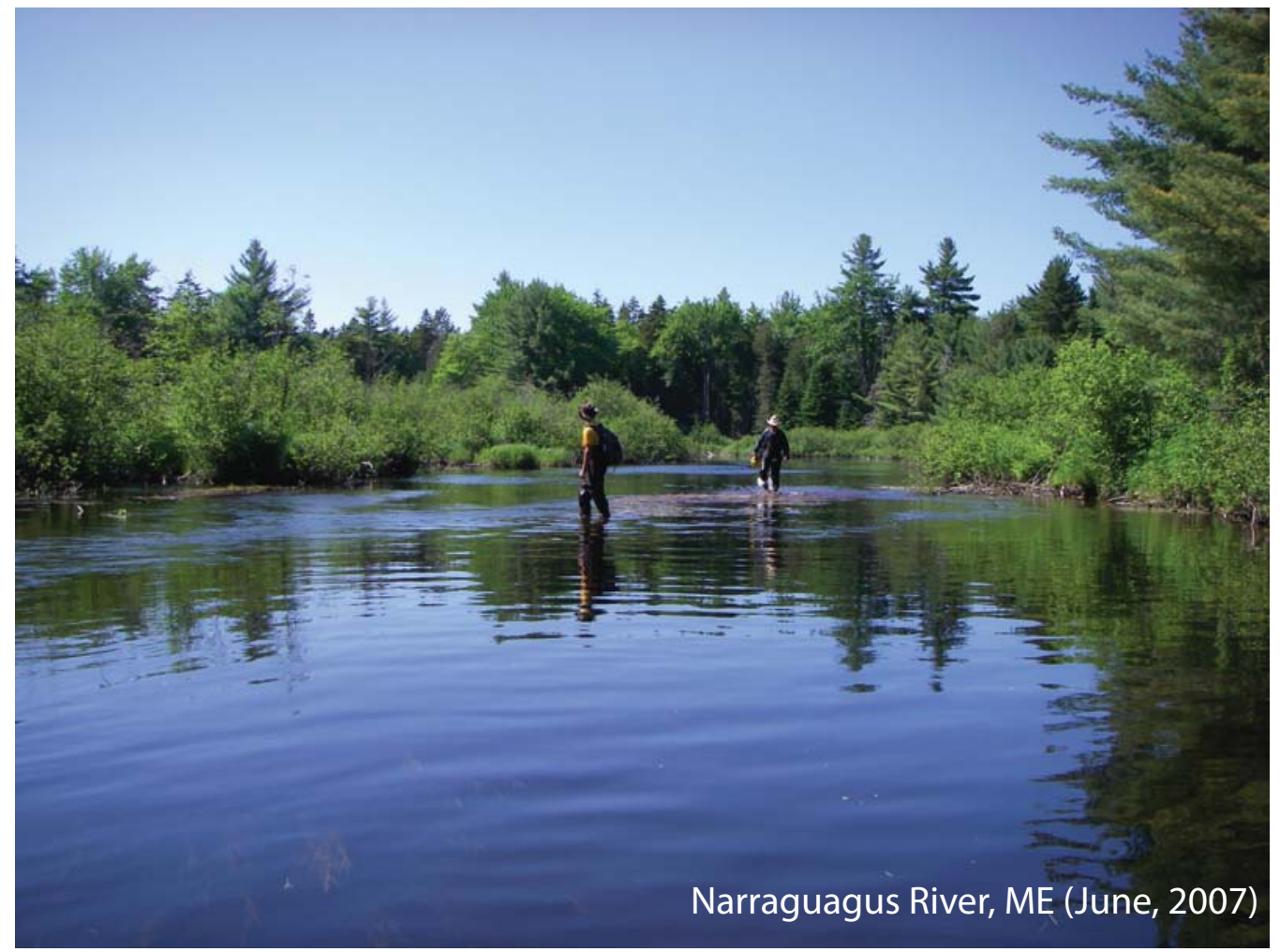

A.

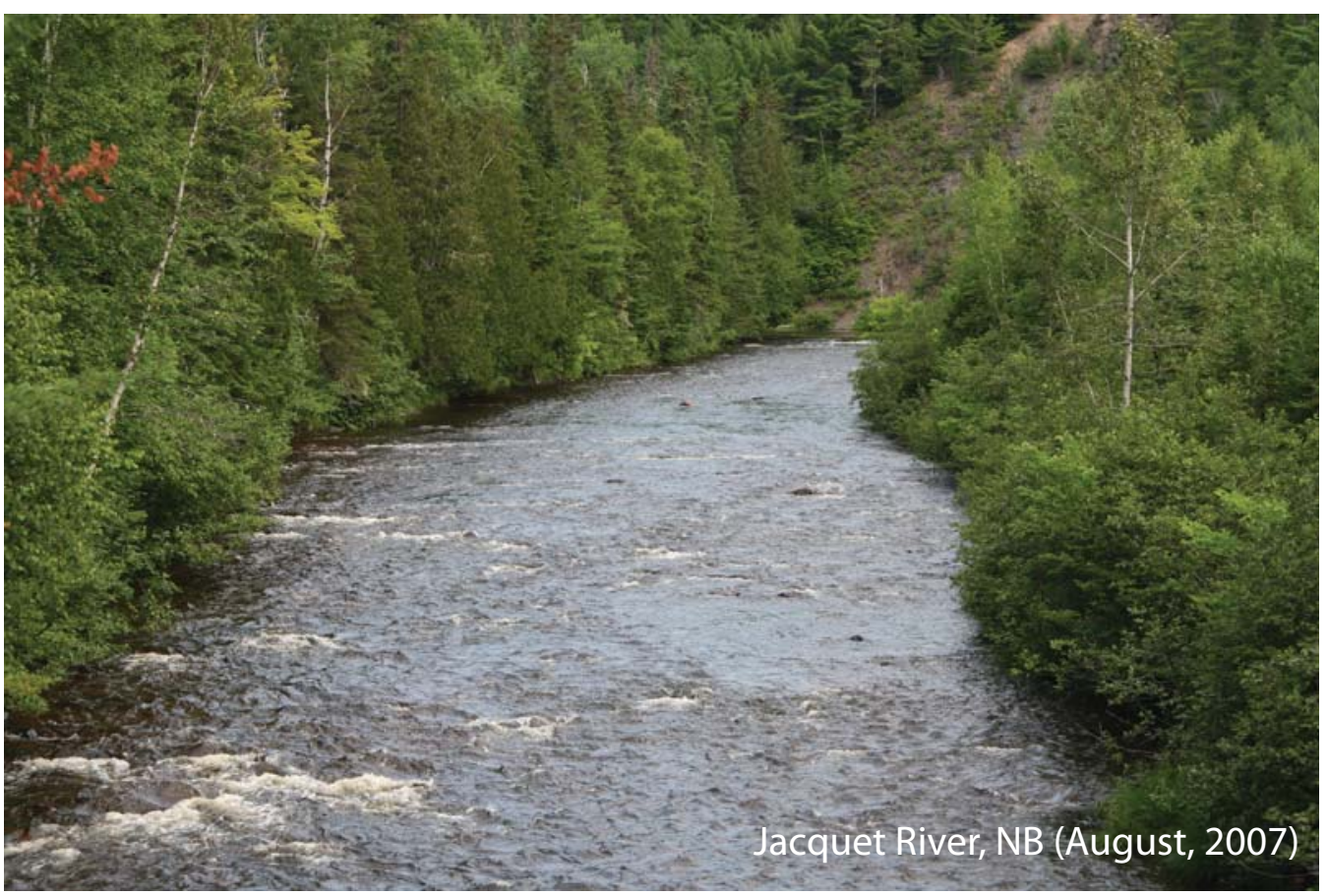

B.

Figure 9. Photographs of typical channel gradient in the two study rivers. 


\subsection{Shear Stress}

Shear stress at the river bed, also known as basal shear stress $\left(\tau_{b}\right)$, is the force per unit area acting to transport sediment in the channel. Calculating shear stress for a given flow is one way to determine what grain sizes will be transported during different flow conditions. Basal shear stress can be expressed as a force balance, obtained by setting the driving forces $\left(F_{d}\right.$; i.e. the downstream part of the density of water and gravity)

$$
F_{d}=\rho g h w \Delta x \sin \theta
$$

equal to the resisting forces $\left(F_{r}\right)$ (i.e. channel-bed area multiplied by $\left.\tau_{b}\right)$

$$
F_{r}=w \Delta x \tau_{b}
$$

where $\rho$ is the density of water (I use $\rho=1000 \mathrm{~kg} / \mathrm{m}^{3}$ ), $g$ is the acceleration of gravity, $h$ is the depth of the water, $w$ is channel width, $\Delta x$ is a unit length, and $\theta$ is the watersurface slope angle. Due to the low slopes in the two rivers in this study, I use the small angle approximation where $\sin \theta$ is equal to the channel gradient or slope $(S)$ (units are $\mathrm{m} / \mathrm{m})$

$$
\sin \theta \approx \tan \theta=\frac{d z}{d x}=S
$$

By setting $F_{d}$ equal to $F_{r}$ and including equation 3 , I obtain the depth-slope product:

$$
\tau_{b}=\rho g h S
$$

The depth-slope product allows me to calculate $\tau_{b}$ at survey points along the channel based on $S$ and $h$. In order to extrapolate this calculation of $\tau_{b}$ to the entire watershed it is necessary to replace $h$ with a quantity that can be estimated from geographic information 
systems (GIS) data. To do this it is first necessary to estimate the relationship between discharge and drainage area, calculated as:

$$
Q=k_{q} A^{c}
$$

where $Q$ is discharge, $k_{q}$ is an empirical, dimensional coefficient that represents discharge to the channel during an event with a specified recurrence interval, $A$ is the drainage area, and $c$ is a constant which depends on how much of the watershed contributes water to the channel during a rainfall event (Dunne and Leopold, 1978). In this case, with little development or artificial water catchment in either watershed, I assume that the entire watershed contributes water to the channel at the same rate, therefore $c=1$. This assumption is further justified by the relatively small size and low relief of both watersheds. I rearrange and solve for $k_{q}$ using the discharge of the two-year flood. I then use the Manning equation:

$$
\bar{u}=\frac{1}{n} R^{2 / 3} S^{1 / 2}
$$

where $\bar{u}$ is the cross-sectional average flow velocity, $S$ is slope, $n$ is the channel roughness coefficient, and $R$ is the hydraulic radius. For wide, shallow, rectangular cross sections, $R$ can be approximated by the water depth $(h)$ :

$$
R=\frac{A_{x}}{p_{w}} \approx \frac{h w}{w+2 h} \approx h,
$$

where $A_{x}$ is the cross sectional area, $p_{w}$ is the wetted perimeter, and $w$ is the channel width. Substituting $h$ for $R$ in equation 6, I obtain: 


$$
\bar{u}=\frac{1}{n} h^{2 / 3} S^{1 / 2}
$$

Next, I combine equation 8 with a simple expression of conservation of water mass in a channel, where $Q$ is estimated based on an approximately rectangular cross section,

$$
Q=h w \bar{u}
$$

and rearrange to get:

$$
h=Q^{3 / 5} n^{3 / 5} w^{-3 / 5} S^{-3 / 10}
$$

The next step is to substitute for $h$ in the depth slope product (equation 4) and combine with equation 5 to get:

$$
\tau_{b}=\rho g n^{3 / 5}\left[\frac{k_{q} A^{c}}{w}\right]^{3 / 5} S^{7 / 10}
$$

Equation 11 allows me to estimate $\tau_{b}$ at stations (every $100 \mathrm{~m}$ ) along each river based on GIS measurements of $A, w$ and $S$ for each station. Basal shear stress can then not only be used as an initial indicator of channel condition and therefore habitat suitability, but also as a variable in the Shields parameter calculations that are necessary to calculate predicted grain sizes.

\subsection{Shields Parameter}

The Shields parameter $\left(\tau^{*}\right)$ is a dimensionless variable used as an indicator of the onset of particle mobility in a river (Buffington and Montgomery, 1997). The Shields parameter can be described as the ratio of forces acting to mobilize the bed material, i.e. 
the shear stress exerted on the bed by the flow $\left(\tau_{b}\right)$, and the forces acting to keep the sediment in place, i.e. gravity, grain size, and material buoyancy. Because $\tau^{*}$ is dimensionless, it provides a good way to compare sediment mobility between rivers. I calculate $\tau^{*}$ using this relationship:

$$
\tau_{*}=\frac{\tau_{b}}{\left(\rho_{s}-\rho\right) g D}
$$

where $D$ is bed sediment particle diameter and $\rho_{s}$ is the density of the sediment (I use $\rho_{s}=$ $2650 \mathrm{~kg} / \mathrm{m}^{3}$, the density of quartz and feldspar). The boundary shear stress $\left(\tau_{b}\right)$ can be estimated using equations 4 or 11 .

In my analysis I used the median grain size $\left(D_{50}\right)$, which is a standard metric of bed mobility (Buffington and Montgomery, 1997). Prior field and experimental studies indicate that initiation of coarse gravel transport occurs at $\tau^{*}$ ranging from 0.03-0.07 (Buffington and Montgomery, 1997). Results presented by Snyder et al. (2008) show that the threshold of mobility at several sites on two coastal Maine rivers (including the Narraguagus River) occurs at $\tau^{*} \geq 0.04$. Values of $\tau^{*}$ within this range therefore indicate that the median fraction of the bed material will be set in motion during bankfull events.

\subsection{Statistical Analysis}

Statistical comparisons of geomorphic parameters from both rivers were made using a comparison of means test (Z-test). Results of the Z-test indicate whether or not the null hypothesis $\left(H_{0}\right)$ can be rejected. The null hypothesis is that the mean and 
standard deviation of one dataset is the same as those of the other dataset, i.e. no significant difference between the data sets. A rejection of the null hypothesis therefore implies that the two datasets are significantly different at a stated significance level $(p)$, in this case $p<0.05$. Specifically, the Z-test is computed by comparing a sample of a parameter from the Jacquet River with the mean and standard deviation of the sample from the Narraguagus. The reverse is also done in order to assess the validity of the results. In this study the specific parameters compared using the Z-test are: (1) the width to depth ratio; and (2) the Shields parameter. 


\section{METHODS}

\subsection{Field Data Collection}

During the summers of 2006 and 2007, I surveyed pre-selected reaches of the Jacquet and Narraguagus rivers. These reaches were chosen so that the contributing drainage areas covered would be similar in both rivers. The first step was to define a channel centerline along the length of both main stem rivers. This existed as a geographic information systems (GIS) coverage for the Narraguagus River, and I digitized a line based on topographic maps for the Jacquet River. I then divided each line into survey points at 100 meter intervals (Figure 10). In the field, the pre-selected survey points were located with handheld global positioning system (GPS) instruments displaying GIS coverages.

In total, a $13.6 \mathrm{~km}$ section of the Narraguagus River (from kilometer 37.3 upstream to $\mathrm{km} 42.3$ and from $\mathrm{km} 46.0$ to $\mathrm{km} 54.6$ ), and a $10.4 \mathrm{~km}$ section of the Jacquet River (from kilometer 27.4 upstream to kilometer 37.8) were surveyed (Table 2; Figure 3 and Figure 5). I collected a total of 240 width $(w)$ and depth $(h)$ measurements with the help of two field assistants by walking the selected sections of each river and measuring wetted (active) channel width $\left(w_{a}\right)$ and depth $\left(h_{a}\right)$, and bankfull width $\left(w_{b f}\right)$ and depth $\left(h_{b f}\right)$. Width and depth measurements were made using a Laser Tech 200 LR laser range finder (held by one person in the channel thalweg) targeting a survey rod held first on the left riverbank and then on the right bank by the other two people (Figure 11a). I also measured channel bed gradient $\left(S_{\text {field }}\right)$ at the same 100 meter intervals, using the laser 
range finder and survey rods. The actual measurements taken for the slope calculation were horizontal and vertical distance between one person with the laser range finder standing in the thalweg at the survey station and the other with the survey rod standing approximately 50 meters ( $\sim 3$ channel widths) downstream also in the thalweg (Figure $11 b)$.

My field assistants and I performed a total of 115 riverbed clast counts using the method described by Wolman (1954) at $200 \mathrm{~m}$ intervals (every second station) on the surveyed reaches of both rivers (Figure 12). At each location, we measured the intermediate axis of a minimum of 100 randomly selected clasts across the entire width of the channel. All clasts smaller than two millimeters were recorded as $1.5 \mathrm{~mm}$, those greater than two millimeters were approximated to the nearest millimeter. Statistical analysis of each sample was performed using a MATLAB code and cumulative grain size as well as $D_{16}, D_{50}$ and $D_{84}$ were determined and plotted (Figure 13; Appendix 1).

\begin{tabular}{|l|c|c|}
\hline & Narraguagus & Jacquet \\
\hline Surveyed Reaches & & \\
Length of field survey reach $(\mathrm{km})$ & 13.6 & 10.4 \\
Min drainage area surveyed $\left(\mathrm{km}^{2}\right)$ & 129 & 94 \\
Max drainage area surveyed $\left(\mathrm{km}^{2)}\right.$ & 247 & 265 \\
Number of data points & 136 & 104 \\
Number of grain size counts & 63 & 52 \\
\hline
\end{tabular}

Table 2. Survey reach characteristics of the study rivers. 


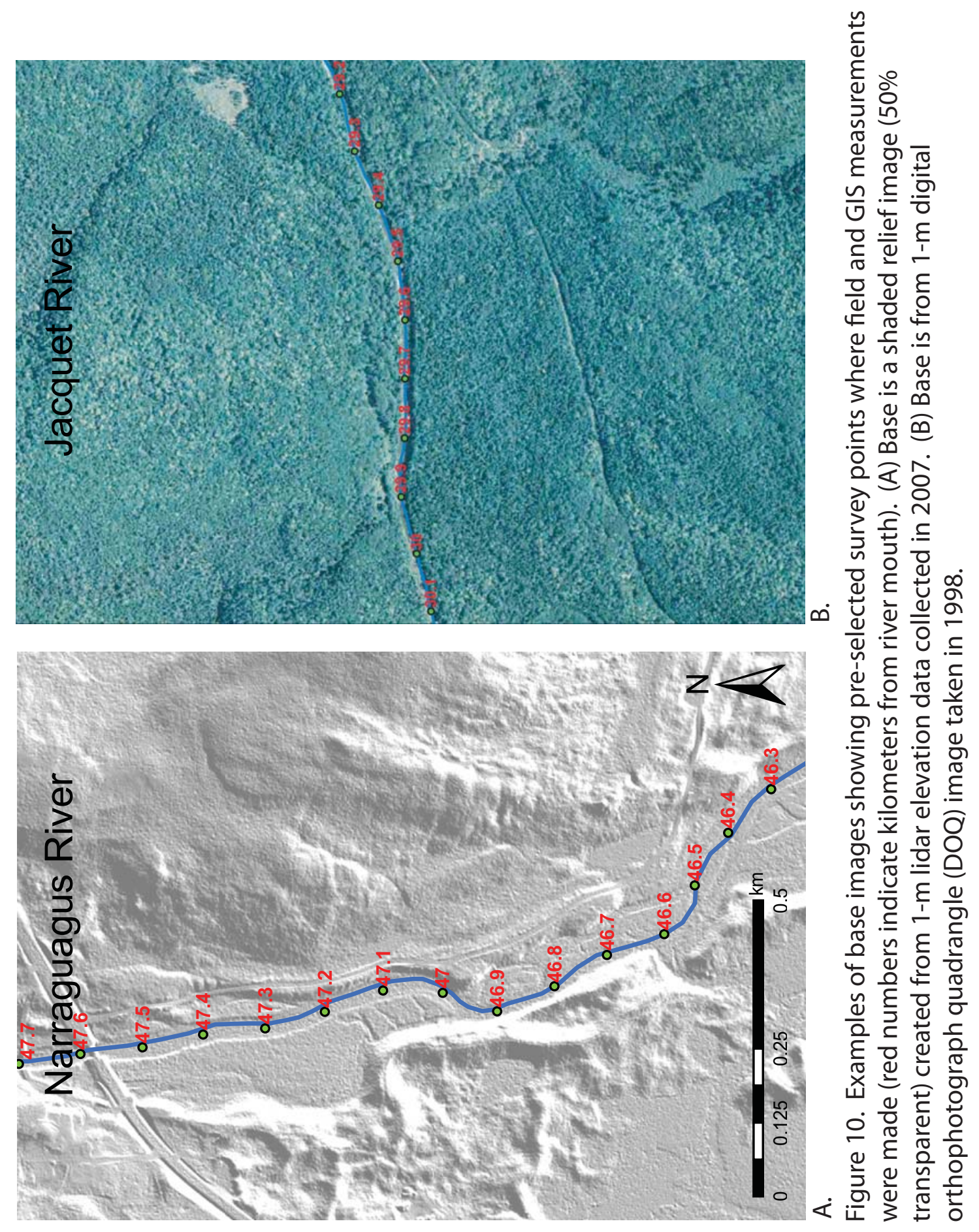




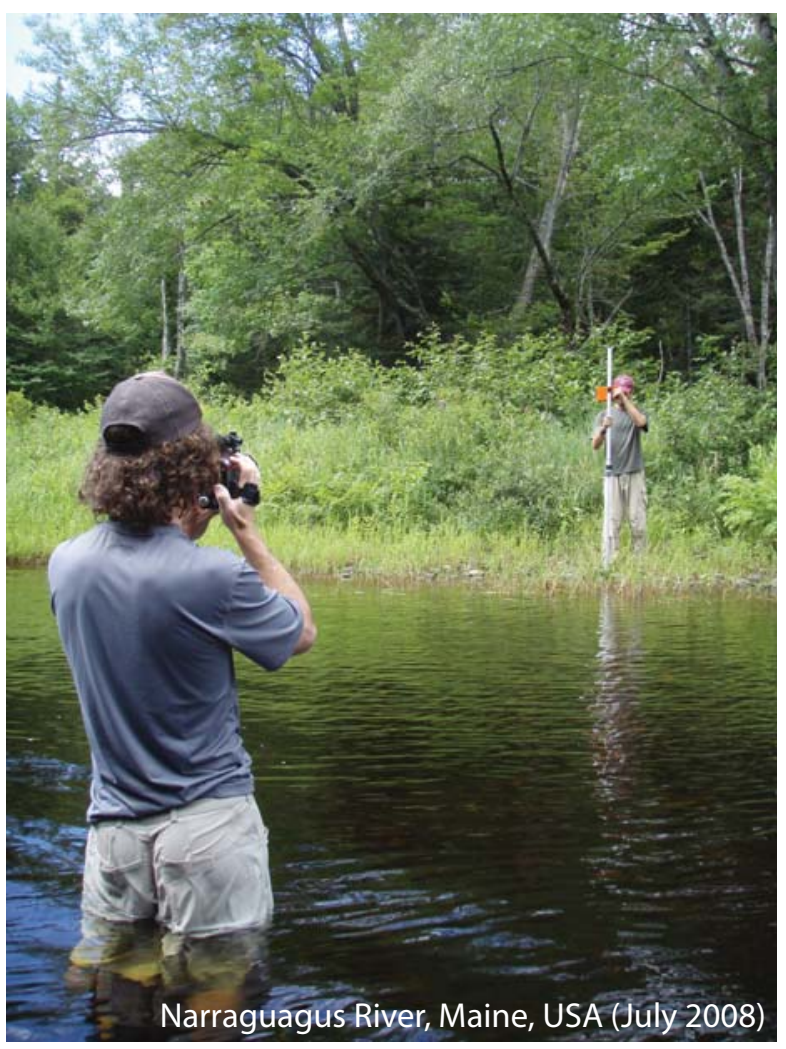

A.

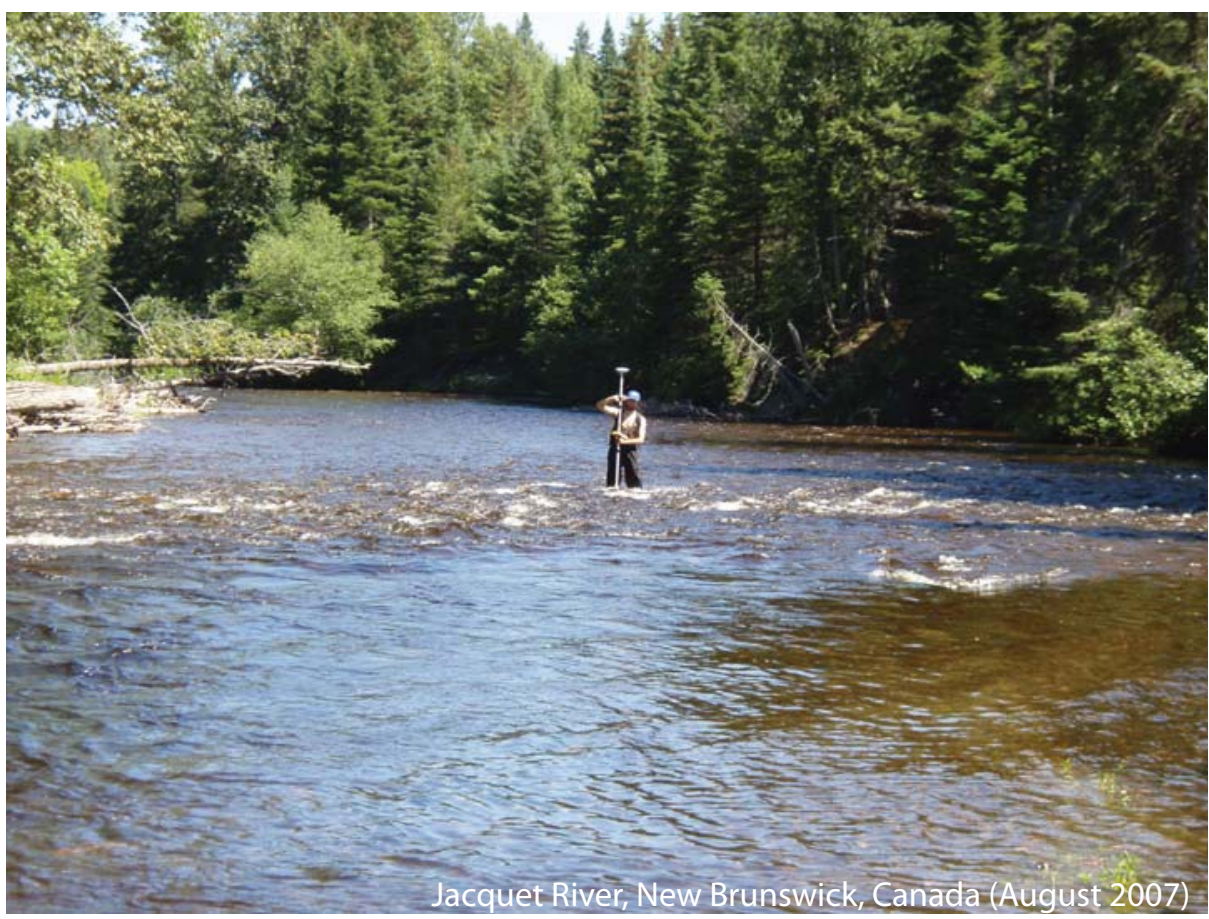

B.

Figure 11. Photographs illustrating the survey method used to measure: (A) channel width; and (B) channel gradient. 


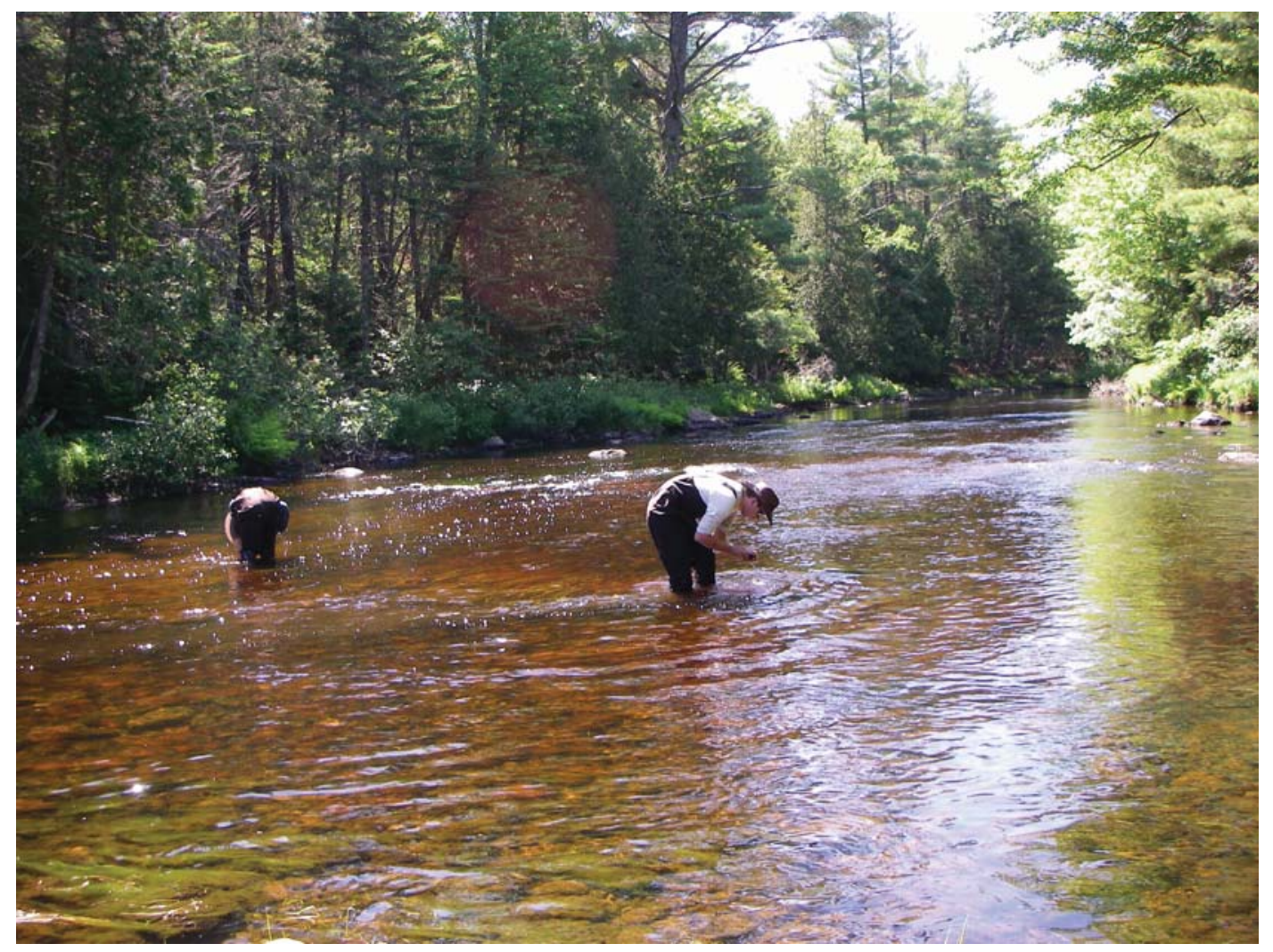

Figure 12. Example photograph of grain size measurement in the field. 

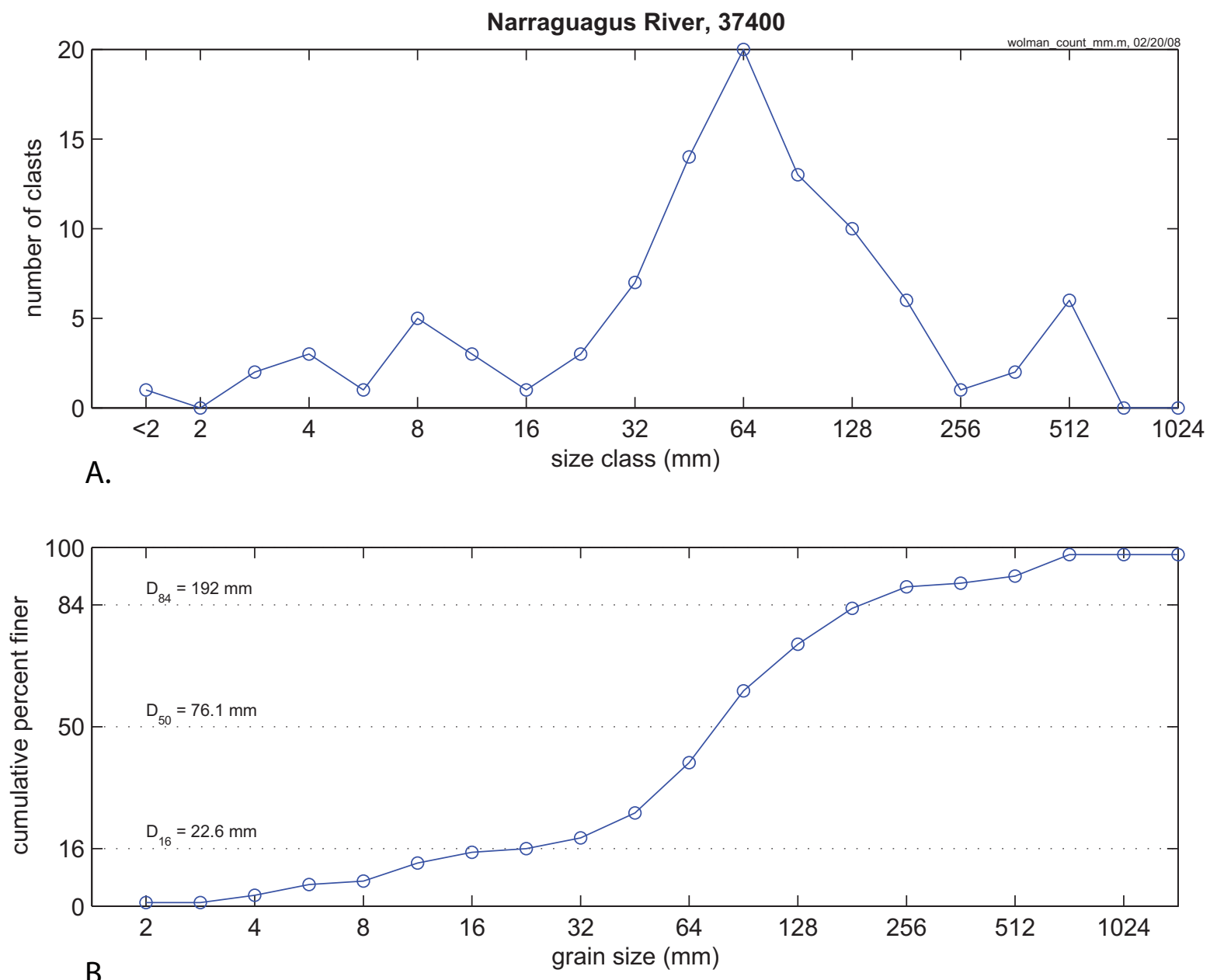

B.

Figure 13. Example of typical grain size plots indicating: (A) cumulative grain size distribution; and (B) cumulative percent finer distribution. 


\subsection{Geographic Information System (GIS) measurements}

Measurements using GIS methods are an integral part of this study. These techniques allow calculations of drainage area $(A)$, channel width $(w)$ and slope $(S)$ to be made easily and accurately, with much greater spatial coverage than is possible by fieldwork alone. Various measurements of these channel parameters were made using the datasets detailed in Table 3. Definitions of all parameters are in Table 4.

\subsubsection{Discharge - drainage area estimates}

I calculated drainage area $(A)$ for each survey station using standard GIS tools found in ArcMap 9.2 (specifically in the Spatial Analyst extension). I assumed a linear relationship between discharge and drainage area $(c=1)$, shown in equation 5 , and rearranged as:

$$
k_{q}=\frac{Q}{A_{c}}
$$

in order to determine a value for the coefficient $k_{q}$ based on a flow event with a recurrence interval $(R I)$ of two years (Figure 14). I use the two-year recurrence interval because it is thought to be the dominant channel forming flow (e.g. Andrews and Nankervis, 1995). The two-year flow on the Narraguagus River is $109 \mathrm{~m}^{3} / \mathrm{s}$ (USGS, 2008), which produces a $k_{q}$ value of $1.83 \times 10^{-7} \mathrm{~m} / \mathrm{s}$. The two-year flow on the Jacquet

River is $113 \mathrm{~m}^{3} / \mathrm{s}$ (Environment Canada, 2007b), which corresponds to a $\mathrm{k}_{\mathrm{q}}$ equal to 2.02 $\times 10^{-7} \mathrm{~m} / \mathrm{s}$ (Figure 14). 


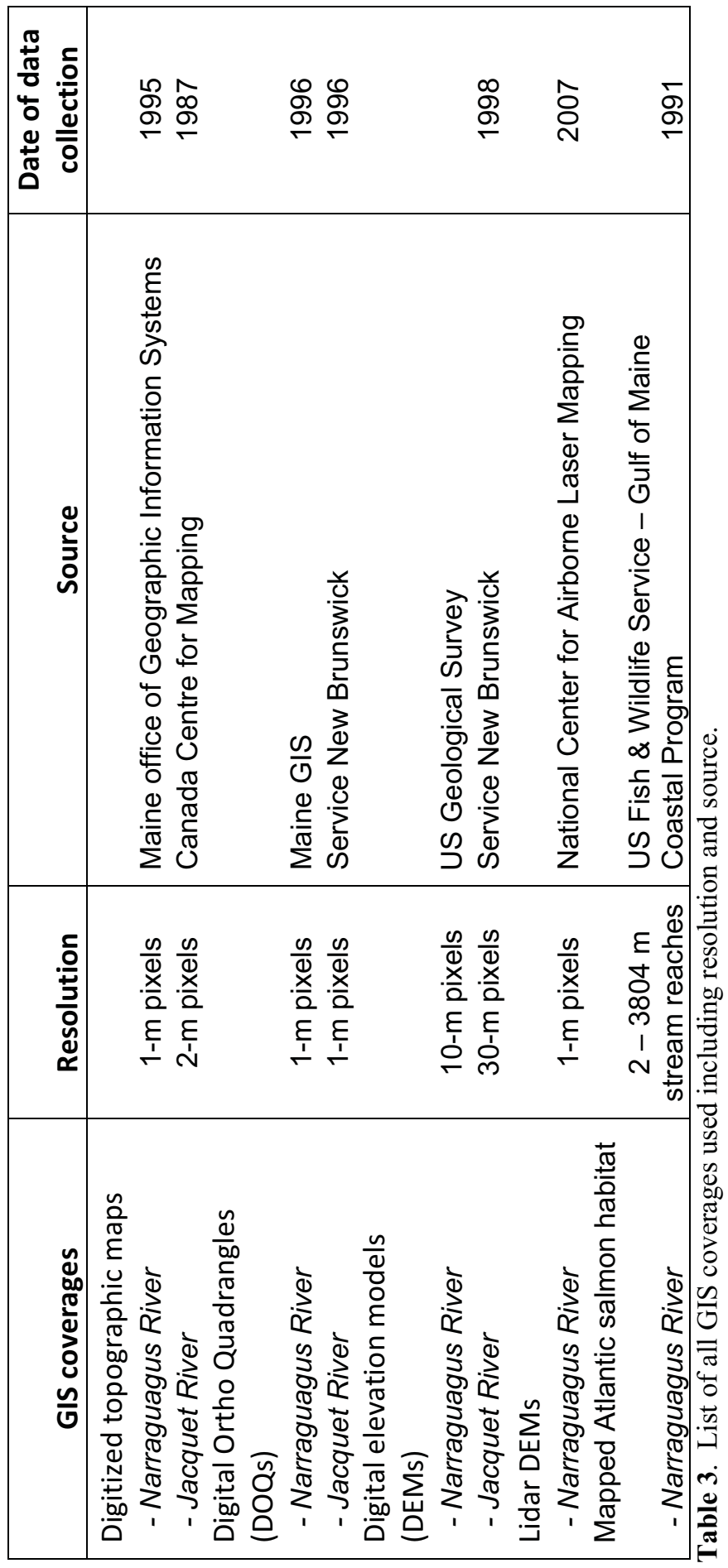




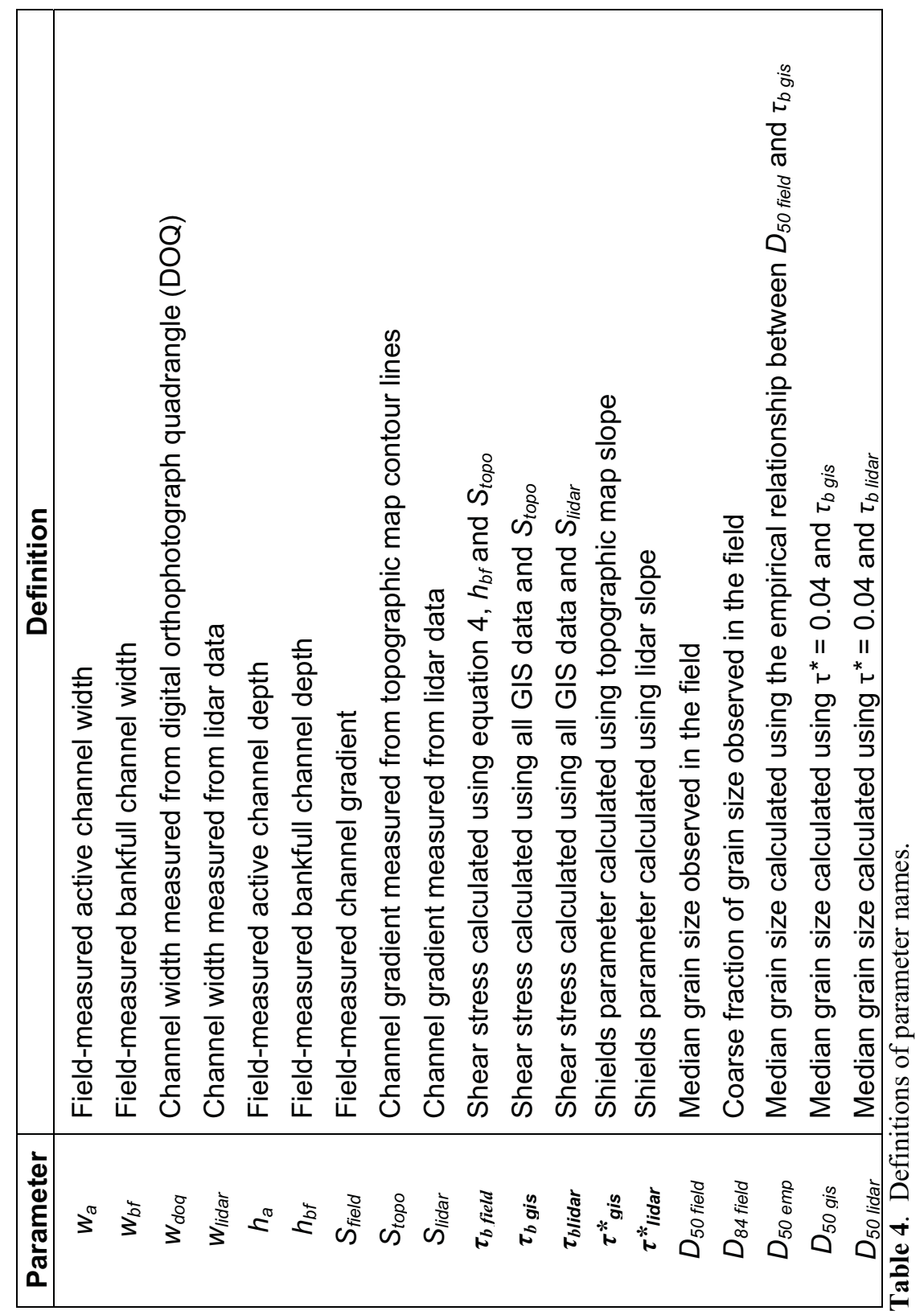




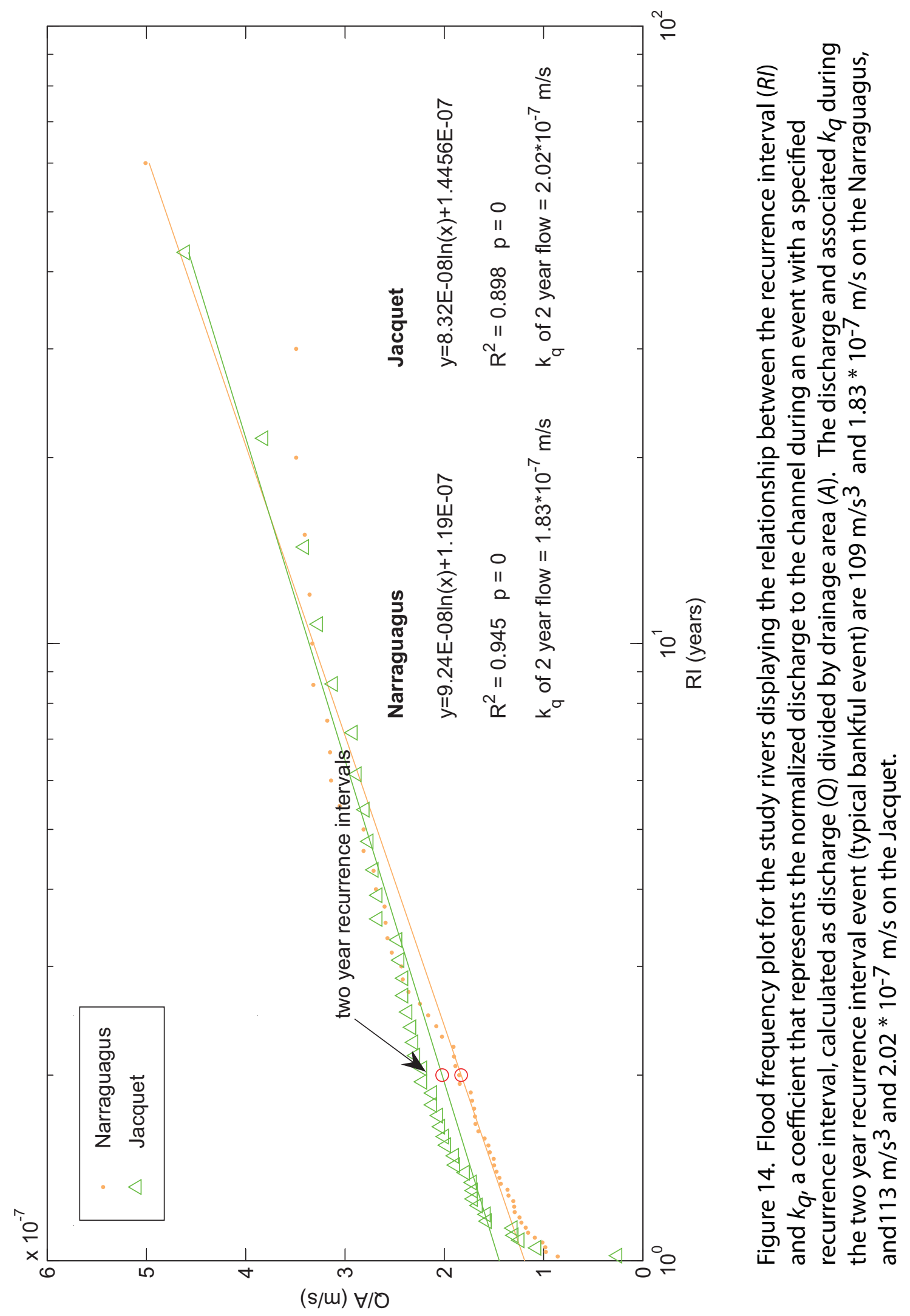




\subsubsection{Channel Width}

I measured channel width using digital orthophotograph quadrangles images (DOQs). The DOQs for the Narraguagus watershed are black-and-white photographs from 1996; the Jacquet images are in color, photographed in 1998. Both sets of images have 1 meter pixel resolution. I measured channel width $\left(w_{d o q}\right)$ at the pre-selected survey stations (100 m intervals) by drawing line segments across the channel in ArcMap 9.2 at a scale of 1:2,500 (Arc then calculates the length of each line segment). I compared the width measurements directly to measurements made in the field in order to assess the accuracy of the GIS-derived values.

In November 2007, a high resolution elevation survey was conducted on the Narraguagus River using light detection and ranging (lidar) technology. Also known as airborne laser swath mapping (ALSM), these data were used to create a digital elevation model (DEM) of the Narraguagus River and surrounding area. This DEM was then viewed as a shaded relief image, from which I subsequently made channel width measurements (Figure 10a). I measured lidar channel width ( $\left.w_{\text {lidar }}\right)$ using the same technique as with the DOQ images.

\subsubsection{Channel Gradient}

I calculated channel gradient using digitized topographic maps of each river. The digital elevation models (DEMs; Narraguagus 10-m pixels, Jacquet 30-m pixels) covering both watersheds, available from the U.S. Geological Survey (USGS) and Environment Canada, were created from these same topographic maps. Therefore, the 
results of calculating slope from a DEM are indistinguishable from those calculated directly from the original topographic map (Wobus et al., 2006; Snyder, 2009). I started at the mouth of the river (elevation zero) and measured the river distance between each contour line crossing of the channel. I then calculated a slope $\left(S_{\text {topo }}\right)$ between each set of contour lines and applied it to all survey stations located within the interval. With that slope, I interpolated the elevation at each survey station and created elevation profiles of the entire rivers (Figure 8).

The contour-line slope measurements give a good overall indication of the gradient in the river, however they group together the entire area enclosed between contour lines (frequently several kilometers in low slope rivers), and are therefore not able to reveal small-scale features contained in these groupings (Snyder, 2009). This can lead to an entire reach being classified as one slope whereas in reality there may be several different slopes included within the channel length (Figure 15). For this reason channel gradient was also calculated from the available high resolution lidar data by first extracting elevation values every 1 meter along the same channel centerline path as used for all the other analyses. The data were then smoothed using a 25-point moving average and interpolated between the minimum values to remove any non-fluvial highpoints such as bridges. Channel gradient $\left(S_{\text {lidar }}\right)$ was then calculated based on elevation values interpolated at 0.5-m intervals (Snyder, 2009). This technique was able to show much smaller scale changes in slope. Figure 15 shows channel gradient and elevation calculated using each method for a $6.2 \mathrm{~km}$ section of the Narraguagus River. The entire section is contained between two contour lines and therefore has a single value of $S_{\text {topo }}$. 
In comparison, the lidar data gives a more precise profile of the river and will therefore provide more accurate data with which to make grain size predictions. 


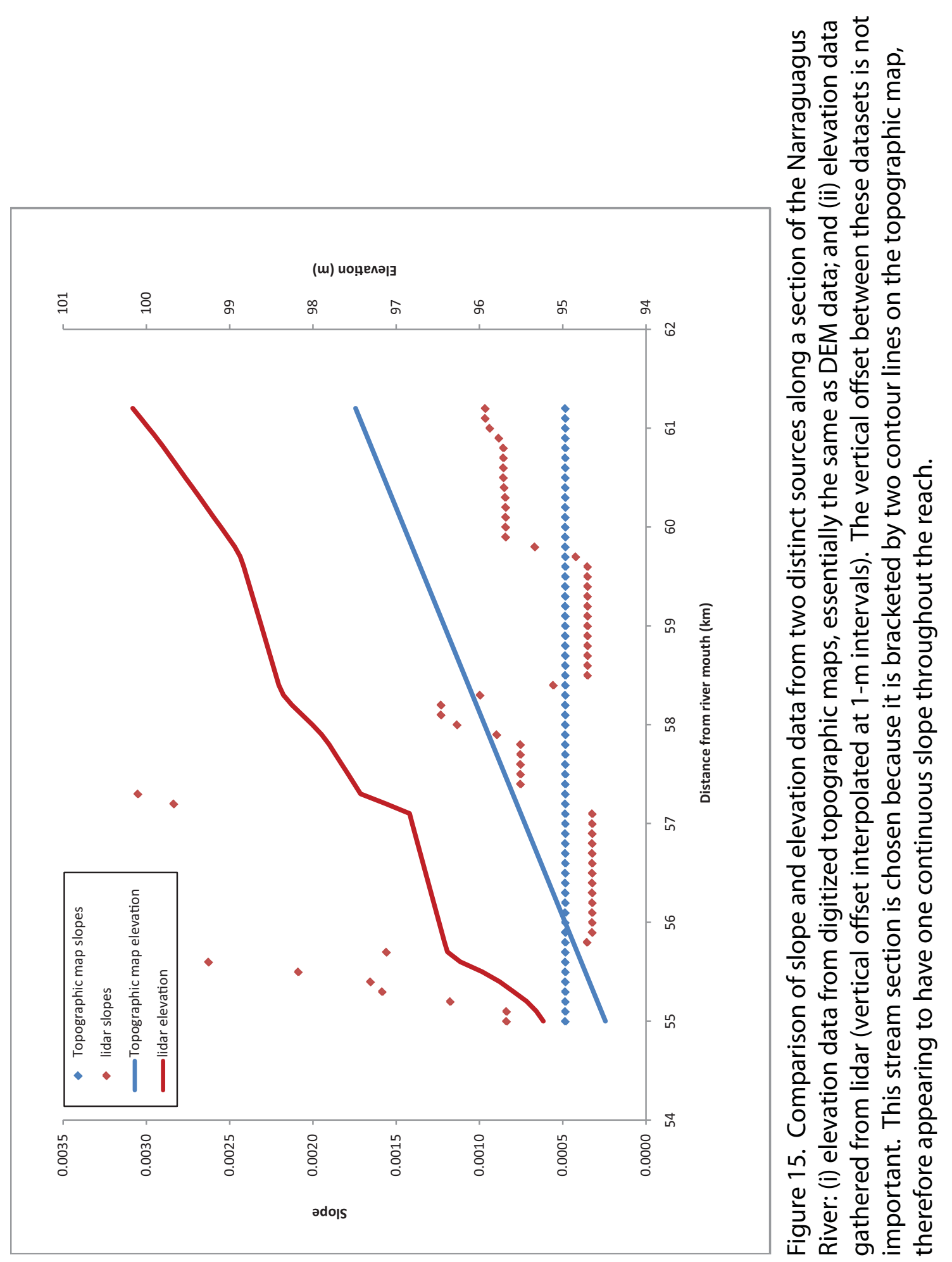




\subsection{Predicting Grain Size}

I have developed two basic models that I will use to predict grain size in the channel. The first method uses the empirical relationship between the basal shear stress $\left(\tau_{\text {bgis }}\right)$ and the observed grain size $\left(D_{50 f i e l d}\right)$. Once the necessary $\tau_{b}$ calculations have been made using equation 4 , I plot $\tau_{b \text { gis }}$ versus $D_{50 f i e l d}$ to determine the empirical relationship between the two. This relationship is then used to predict the median grain sizes $\left(D_{50 e m p}\right)$ throughout the remainder of the watershed (this same method can be used to calculate the coarse fraction $\left(D_{84 e m p}\right)$ of the bed material).

The second model uses only remote sensing data. The advantage of this method is that, because no field work needs to be done, it is possible to cover a much larger area in a shorter amount of time. This time I calculate $\tau_{b}$ using equation 11 , then determine grain size directly from equation 12 by setting the Shields parameter $\left(\tau^{*}\right)$ equal to 0.04 (based on observations by Snyder et al., 2008) and solving for grain size $\left(D_{50}\right)$. My GISbased model is comparable to the model developed by Buffington et al. (2004); however certain geomorphic factors considered in my study are simpler. Buffington et al. (2004) examined the effects of varying hydraulic roughness and multiple channel types (planebed, pool-riffle, wood-forced pool-riffle, step-pool, and cascade) in steep mountain catchments in the Pacific Northwest. My study does not vary hydraulic roughness or account for channel type due to the relatively uniform geomorphology of my study rivers. 


\section{RESULTS}

\subsection{Field measurements}

\subsubsection{Width to depth ratios}

I made width and depth measurements for both the active $\left(w_{a}\right.$ and $\left.h_{a}\right)$ and the high-flow channel $\left(w_{b f}\right.$ and $\left.h_{b f}\right)$ along the surveyed reaches of both rivers. Table 5 shows the averages and standard deviations of these measurements (all supporting data is shown in Appendix 2). In this study I focus on the high-flow measurements to make comparisons between the rivers. High-flow widths and depths, defined by bank vegetation and morphology, provide a reasonable basis for comparison because they do not depend on stage at the time measurements are made. I calculated a unitless width to depth ratio (averaged for survey reaches) of 29.65 \pm 12.48 for the Narraguagus River and $24.37 \pm 7.93$ for the Jacquet River (Figure 16). The comparison of means test (Z-test) shows that I can reject the null hypothesis, that each population cannot be described by the mean and standard deviation of the other.

Initial analysis of the data indicates that the difference in width to depth ratio between rivers is largely the result of several outlying data points, primarily on the Narraguagus River. In order to assess the difference between similar reaches of the two rivers, I remove outlying values based on two criteria: (1) where the channel is not a single thread (i.e., where mid-channel islands are present), and (2) where channel gradient $\left(S_{\text {topo }}\right)$ is less than 0.002 (only occurs on the Narraguagus). The choice of these criteria is based on: (1) a limited number of multi-thread channels exist on the 
Narraguagus only; and (2) the extremely low gradient reaches are only found on the Narraguagus and these "deadwaters" represent a channel type not found on the Jacquet River (the steeper reaches are more similar and therefore more comparable to the Jacquet). The unitless width to depth ratio for the data without outliers is $25.85 \pm 8.87$ for the Narraguagus and $24.13 \pm 7.97$ for the Jacquet River. Results of a Z-test on this dataset show that I cannot reject the null hypothesis (Figure 16).

\begin{tabular}{|l|c|c|}
\hline & Narraguagus River & Jacquet River \\
\hline Using all data & & \\
Active width $\left(w_{a}\right)(\mathrm{m})$ & $25.19 \pm 11.04$ & $17.73 \pm 5.04$ \\
High-flow width $\left(w_{b f}\right)(\mathrm{m})$ & $32.96 \pm 13.34$ & $21.66 \pm 6.65$ \\
Active depth $\left(h_{a}\right)(\mathrm{m})$ & $0.55 \pm 0.28$ & $0.52 \pm 0.21$ \\
High-flow depth $\left(h_{b f}\right)(\mathrm{m})$ & $1.13 \pm 0.30$ & $0.93 \pm 0.26$ \\
Active w/h ratio & $57.59 \pm 42.52$ & $39.59 \pm 19.68$ \\
High-flow w/h ratio & $29.65 \pm 12.48$ & $24.37 \pm 7.93$ \\
\hline Data with outliers removed & & \\
Active w/h ratio & $53.77 \pm 26.97$ & $39.66 \pm 20.08$ \\
High-flow w/h ratio & $25.38 \pm 8.49$ & $24.13 \pm 7.97$ \\
\hline
\end{tabular}

Table 5. Average values and standard deviations of active and high-flow width $\left(w_{a}\right.$ and $\left.w_{b f}\right)$ and depth $\left(h_{a}\right.$ and $\left.h_{b f}\right)$ at survey sites along the study rivers. The width to depth ratio is initially calculated using all data. Outlying values are then removed based on channel gradient (where $S_{\text {topo }}<0.002$ ) and a new width to depth ratio is calculated. 

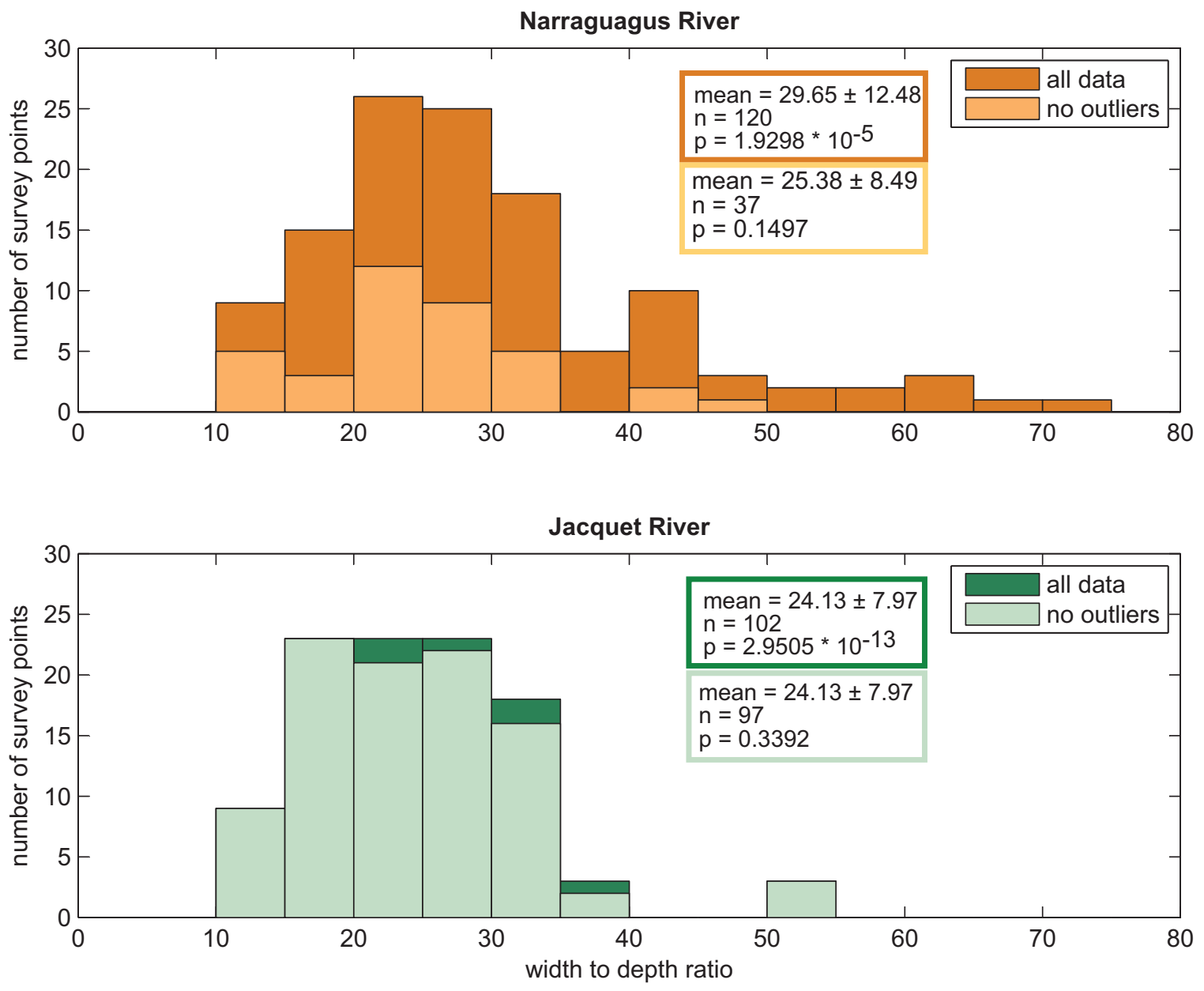

Figure 16. Histograms representing the distribution of width to depth ratios on the study rivers using all data (dark colors) and also data that has had outlying values removed based on slope (light colors). A standard z-test shows that there is no significant difference between the two data sets that have had outliers removed. 


\subsubsection{Grain size distribution}

Results of the Wolman pebble count show the average median $\left(D_{50 \text { field }}\right)$ and coarse fraction $\left(D_{84 \text { field }}\right)$ channel-bed grain size on the surveyed reaches of the two study rivers (Table 6; Figure 17 and Figure 18). A complete list of all calculated grain sizes at each survey site along both channels is in Appendix 3. Median grain size on the Narraguagus River is $32 \pm 27 \mathrm{~mm}$, finer than the $61 \pm 17 \mathrm{~mm}$ on the Jacquet River but with a greater standard deviation. The smaller $D_{50 \text { field }}$ on the Narraguagus River likely implies that sediment will be more easily mobilized than the coarser sediments in the Jacquet River.

\begin{tabular}{|l|c|c|}
\hline & Narraguagus River & Jacquet River \\
\hline $\boldsymbol{D}_{\mathbf{1 6} \text { field }}(\mathrm{mm})$ & $8 \pm 12$ & $25 \pm 10$ \\
$\boldsymbol{D}_{\mathbf{5 0 ~ f i e l d ~}}(\mathrm{mm})$ & $32 \pm 27$ & $61 \pm 17$ \\
$\boldsymbol{D}_{\mathbf{8 4} \text { field }}(\mathrm{mm})$ & $91 \pm 68$ & $126 \pm 31$ \\
\hline
\end{tabular}

Table 6. Mean ( \pm 1 standard deviation) field-measured river bed grain sizes $\left(D_{16}, D_{50}\right.$, and $\left.D_{84}\right)$ along the surveyed reaches of the Narraguagus and Jacquet rivers. 

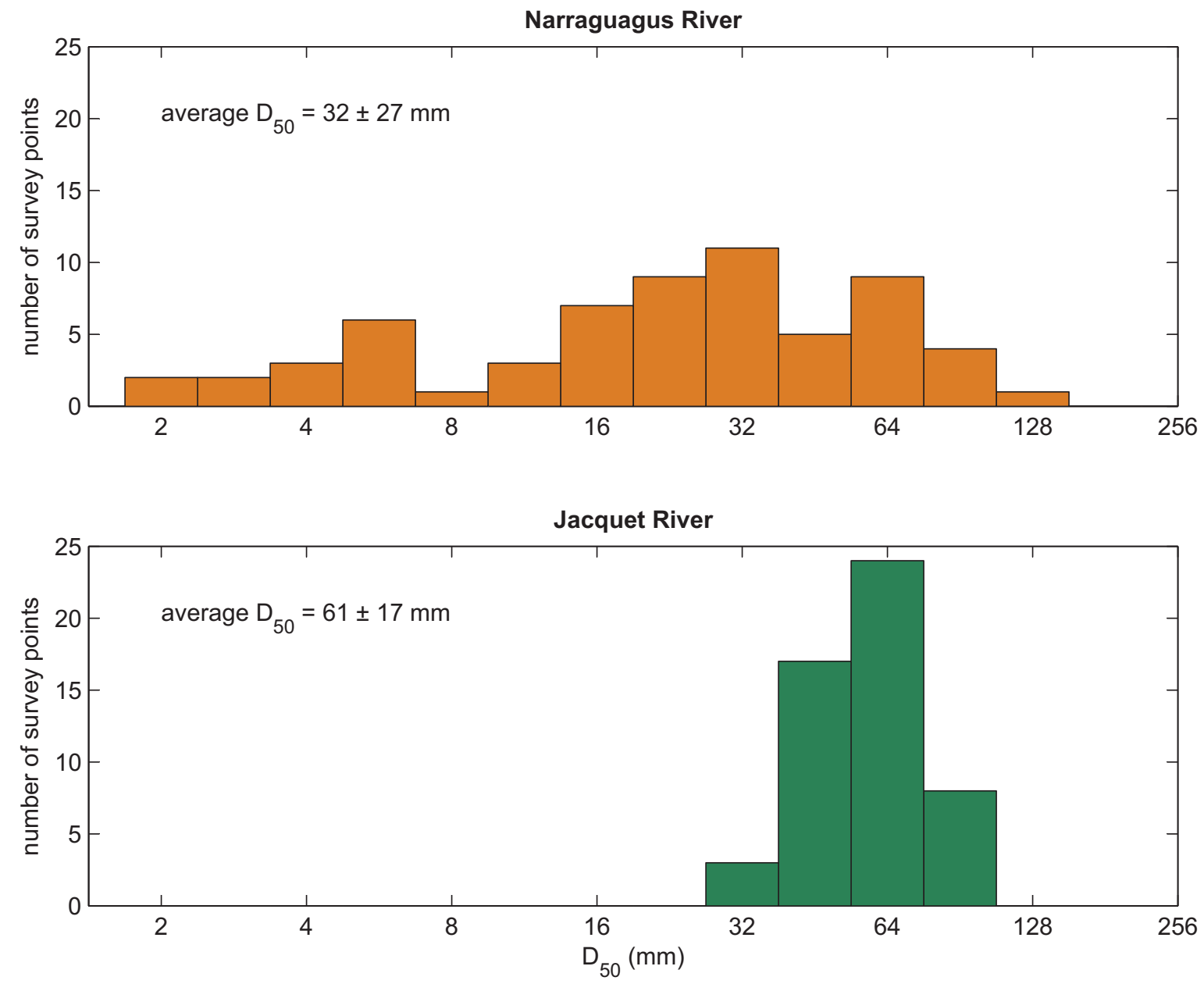

Figure 17. Histograms presenting the distribution of mean field-measured grain size $\left(D_{50}\right.$ field $)$ on the two study rivers. 

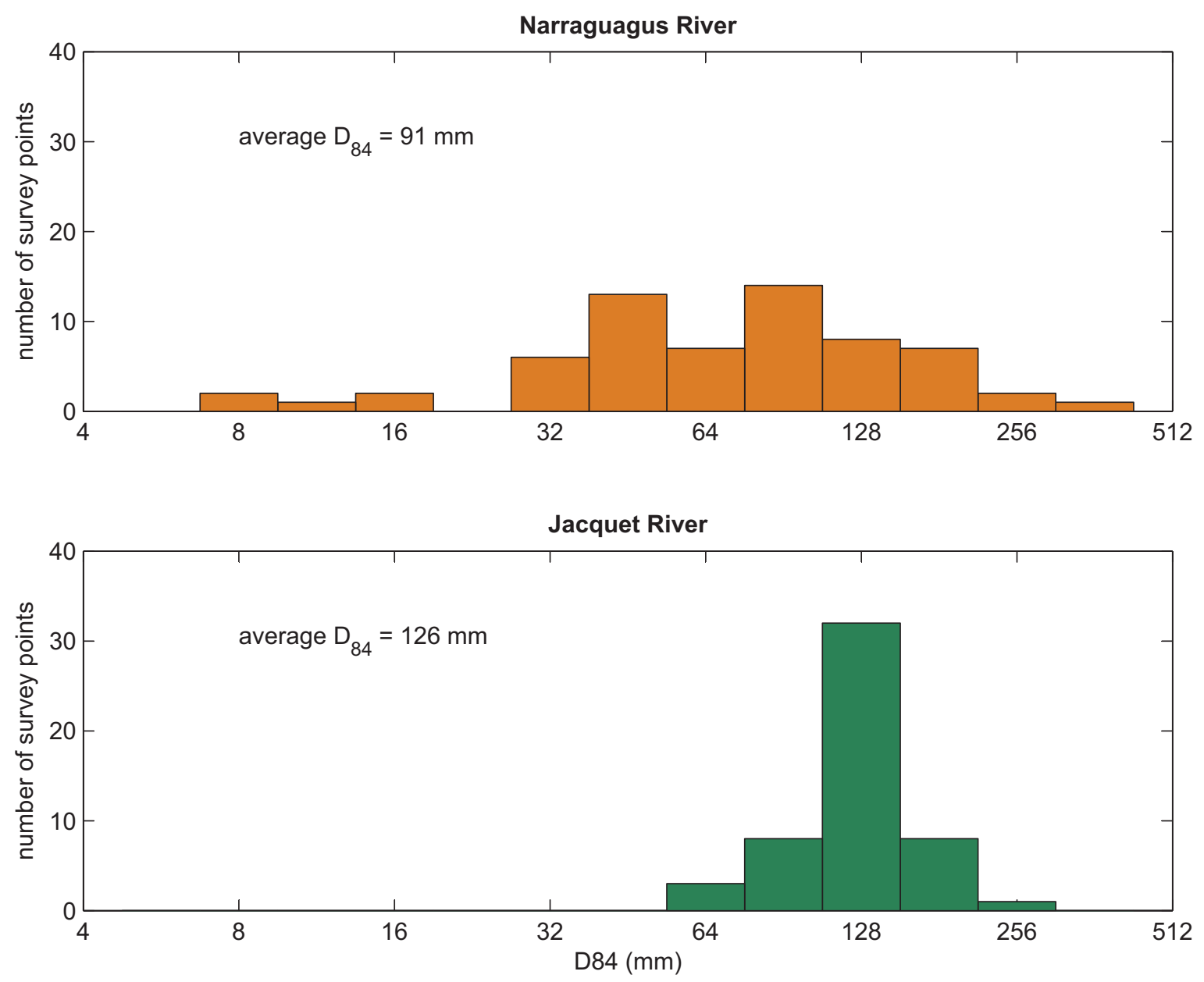

Figure 18. Histograms presenting the distribution of the field-measured coarse fraction of the bed sediments ( $D_{84}$ field) on the two study rivers. 


\subsection{GIS Measurements \& Analyses}

\subsubsection{Channel width}

In addition to field-measured channel widths ( $w_{a}$ and $\left.w_{b f}\right)$, I also measured channel width using GIS: (1) from DOQs $\left(w_{d o q}\right)$ for each of the study rivers: and (2) from lidar data $\left(w_{\text {lidar }}\right)$ for the Narraguagus only. Figure 19 shows the comparison between the field-measured and GIS-measured widths. In the majority of cases, GIS-measured widths are narrower than the field-measured widths. This is relatively easy to explain for $w_{d o q}$ : the tree cover in the riparian zone obscures the river banks making the river appear (in the DOQs) narrower than it actually is. The $w_{\text {lidar }}$ results match the field measurements better than $w_{d o q}$ because the lidar technology is able to remove vegetation cover from the data, thereby showing the river banks more clearly.

Another result that is apparent from Figure 19 is that a better correlation exists between the GIS-measured widths and $w_{a}$, than between GIS-measured widths and $w_{b f}$. High-flow width is thought to be a measure of the width of the channel during approximately the two year flood, therefore always larger than $w_{a}$, which is stage dependant, except during times of floods with recurrence intervals greater than two years (which did not occur during my field surveys). In the case of the two study rivers, the channel depth is consistent (very few mid-channel bars) and the river banks are relatively vertical, which combine to minimize the effect of stage on width. This implies that GIS techniques are more closely related to $w_{a}$. 

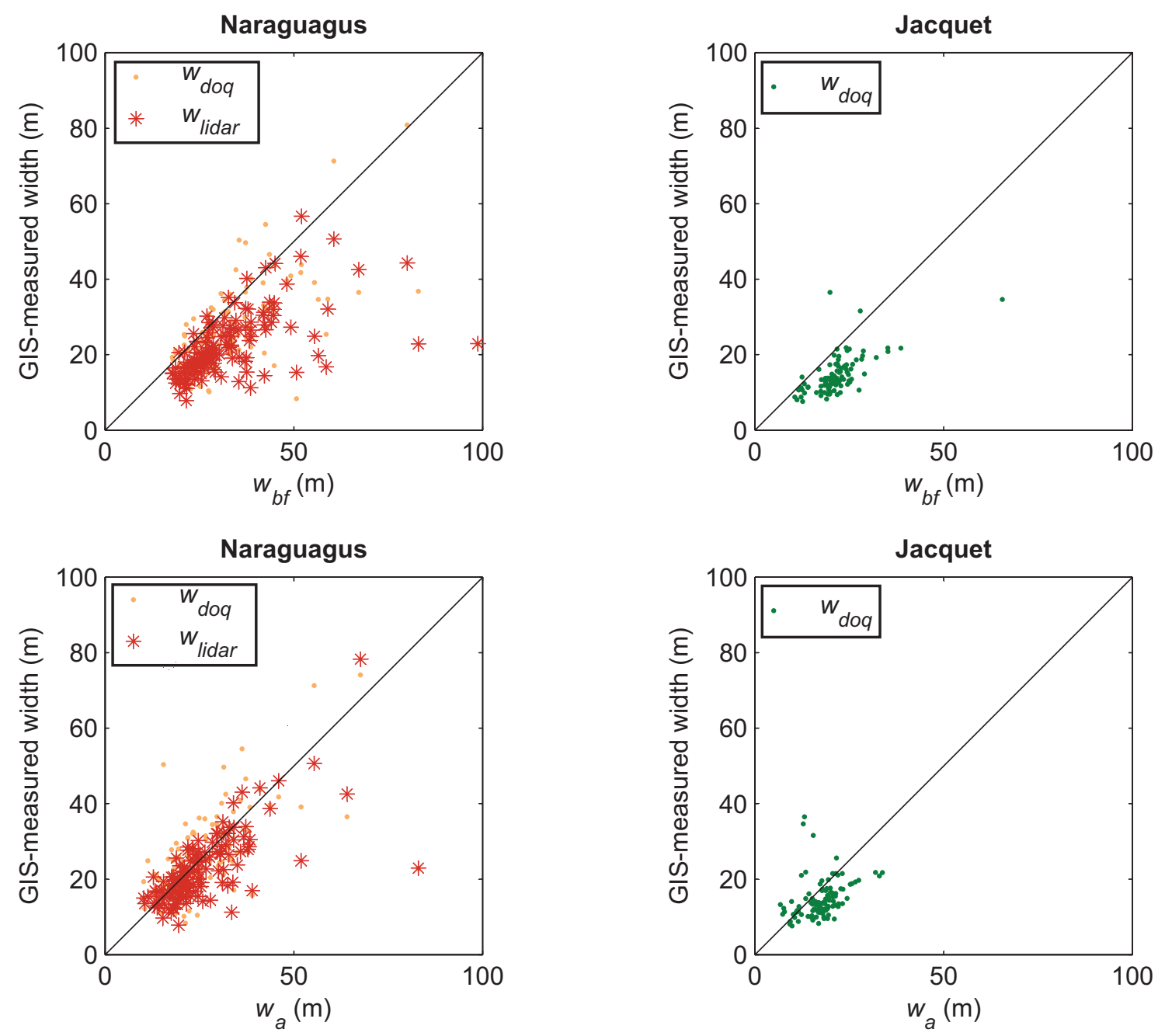

Figure 19. Comparison plots of field-measured active $\left(w_{a}\right)$ and bankful width $\left(w_{b f}\right)$ versus width measured on digital orthophotograph quadrangles $\left(w_{d o q}\right)$ and width measured from lidar data ( $w$ lidar). 


\subsubsection{Channel gradient and river profiles}

I measured channel gradient in three ways: (1) in the field $\left(S_{\text {field }}\right.$, on the Jacquet River only) using a hand held laser range finder; (2) in the lab using digitized topographic maps $\left(S_{\text {topo }}\right)$ to measure between contour lines; and (3) using a DEM generated from lidar data $\left(S_{\text {lidar }}\right)$ (on the Narraguagus River only; Table 7). Figure 20 shows elevation profiles created from these data. The two methods used on the Jacquet River $\left(S_{\text {field }}\right.$ and $\left.S_{\text {topo }}\right)$ give quite different results, while the two methods used on the Narraguagus River $\left(S_{\text {topo }}\right.$ and $\left.S_{\text {lidar }}\right)$ agree closely with each other.

The low gradients on both rivers made field measurements using hand-held equipment difficult and inaccurate. When comparing the field-surveyed slopes $\left(S_{\text {field }}\right)$ on the Jacquet River to those derived from the digitized topographic maps $\left(S_{\text {topo }}\right)$ it became evident that I had systematically overestimated the field measurements. This is a result of the error in the measurement being larger than the measurement itself (average slope on the Jacquet is $0.5 \%$ ). I therefore consider the measurements of channel gradient using a hand-held rangefinder to not be useful in rivers with slopes less than $\sim 2 \%$. Making accurate measurements of slope in the field is possible but would require using more precise surveying equipment such as a total station. This was not considered a viable option for this study because total station measurements require significantly more time (hours instead of minutes) at each survey station. 


\begin{tabular}{|l|c|c|}
\hline & Narraguagus River & Jacquet River \\
\hline Field gradient $\left(S_{\text {field }}\right)$ & $\mathrm{n} / \mathrm{a}$ & $0.0067 \pm 0.0043$ \\
Topographic map gradient $\left(S_{\text {topo }}\right)$ & $0.0015 \pm 0.0022$ & $0.0038 \pm 0.0014$ \\
lidar gradient $\left(S_{\text {lidar }}\right)$ & $0.0015 \pm 0.0028$ & $\mathrm{n} / \mathrm{a}$ \\
\hline
\end{tabular}

Table 7. Average channel gradients and standard deviations from field measurements $\left(S_{\text {field }}\right)$, digitized topographic maps $\left(S_{\text {topo }}\right)$, and airborne laser swath mapping $\left(S_{\text {lidar }}\right)$ for the surveyed reaches of the Narraguagus and Jacquet rivers. 


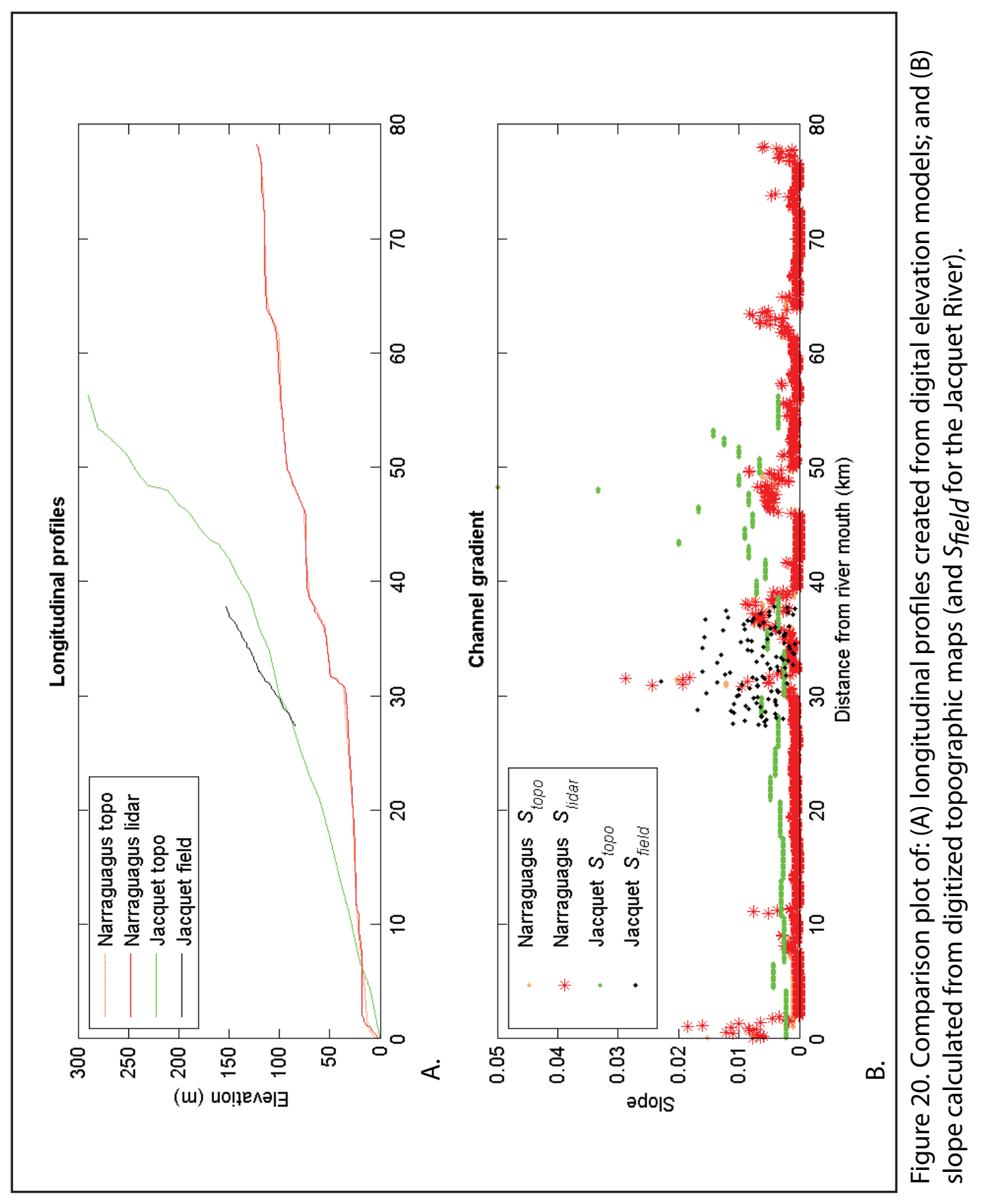




\subsubsection{Shear stress and Shields parameter calculations}

I used the coefficient $k_{q}$ in equation 11 in order to calculate basal shear stress $\left(\tau_{b}\right)$ at individual survey stations along the rivers. I did this in two ways: (1) using DOQ channel width $\left(w_{\text {doq }}\right)$ and topographic map slope $\left(S_{\text {topo }}\right)$; and $(2)$ for the Narraguagus River only, using the lidar channel width $\left(w_{\text {lidar }}\right)$ and slope $\left(S_{\text {lidar }}\right)$ (Table 8 and Appendix 4$)$. I used the GIS measured width so that calculations could be made at every survey station along the length of both rivers, and also to provide a comparable reference frame. In both cases I maintained the Manning roughness coefficient $(n)$ constant at 0.04 , a reasonable estimate for gravel-bedded rivers based on Barnes (1967).

The resulting values for the Narraguagus were notably lower indicating that the Jacquet is a higher energy system that can mobilize coarser bed sediments. Some differences exist between the basal shear stress calculated using equation 4 ( $\left.\tau_{b \text { field }}\right)$, using predominantly field-derived values, and equation 11 , in which all values used are derived from GIS analysis $\left(\tau_{b \text { gis }}\right)$ (Figure 21$)$. This is in part due to the fact that $\tau_{b \text { field }}$ is calculated using the bankfull depth $\left(h_{b f}\right)$ (used because it provides a better means of comparison between the two study rivers), while $\tau_{\text {bgis }}$ and $\tau_{\text {blidar }}$ are calculated using GISmeasured channel width, which is most closely related to active width $\left(w_{a}\right)$. Figure 19 shows that $w_{d o q}$ is consistently under predicted when compared to the Jacquet $w_{a}$, but not compared to the Narraguagus $w_{a}$. The inability to better measure $w_{d o q}$ on the Jacquet may be due to a thicker riparian vegetation cover, which lessens the apparent channel width on aerial images. The result of this lower $w_{d o q}$ for the Jacquet is a higher prediction of $\tau_{b \text { gis }}$ 
(equation 11) which in turn leads to higher values of $\tau^{*}{ }_{\text {gis }}$ (Figure 22) and to larger grain size predictions.

The primary reason for the similarity in the results from the two methods is that they both use the same GIS-derived value for channel gradient $\left(S_{\text {topo }}\right)$, which is the most important factor affecting shear stress in these low gradient rivers because: (1) it is raised to a higher power in equation 11; and (2) it varies over several orders of magnitude from 0.0003 to 0.0203 on the Narraguagus and 0.0023 to 0.0500 on the Jacquet (Appendix 4). Furthermore, systematic variations in the GIS width and drainage area $(A)$ tend to cancel each other out because both increase downstream.

\begin{tabular}{|c|c|c|}
\hline & Narraguagus River & Jacquet River \\
\hline $\boldsymbol{\tau}_{\boldsymbol{b} \text { gis }}$ & $18.1 \pm 19.2$ & $53.9 \pm 24.0$ \\
$\boldsymbol{\tau}_{\boldsymbol{b} \text { lidar }}$ & $17.6 \pm 23.7$ & $\mathrm{n} / \mathrm{a}$ \\
\hline
\end{tabular}

Table 8. Average basal shear stress $\left(\tau_{\boldsymbol{b} \text { gis }}\right)$ and standard deviation values for the Narraguagus and Jacquet rivers calculated using DEM-derived values for drainage area, channel width $\left(w_{\text {doq }}\right)$, and slope $\left(S_{\text {topo }}\right)$. Shear stress values $\left(\tau_{\boldsymbol{b} \text { lidar }}\right)$ are also shown for the Narraguagus based on lidar-derived width $\left(w_{\text {lidar }}\right)$ and slope $\left(S_{\text {lidar }}\right)$.

The Shields parameter is an indicator of the onset of sediment transport in the channel. Values between 0.03 and 0.07 indicate the initiation of sediment mobility (Buffington \& Montgomery, 1997). Figure 23 shows results from this study: values for the Narraguagus River $(0.073 \pm 0.079)$ have a higher mean and standard deviation than those for the Jacquet River $(0.038 \pm 0.022)$. Both sets of data do however suggest that sediment should be mobile during high-flow conditions in both rivers. It is readily apparent from Figure 23 that the high Shields values on the Narraguagus are due to the 
many high outliers $(\tau *>0.15)$. In an attempt to account for this, I removed all outlying values based on the same conditions as used with the width to depth ratio analysis (multithread channels and all locations where $S_{\text {topo }}<0.002$ ). The analysis of these data is also shown in Figure 23. Although all Shields values greater than 0.12 were removed on the Narraguagus, decreasing the mean Narraguagus Shields parameter value and bringing the results for the two rivers closer together, results of a revised Z-test for the data excluding outliers show that there still remains a significant difference between the two datasets. 

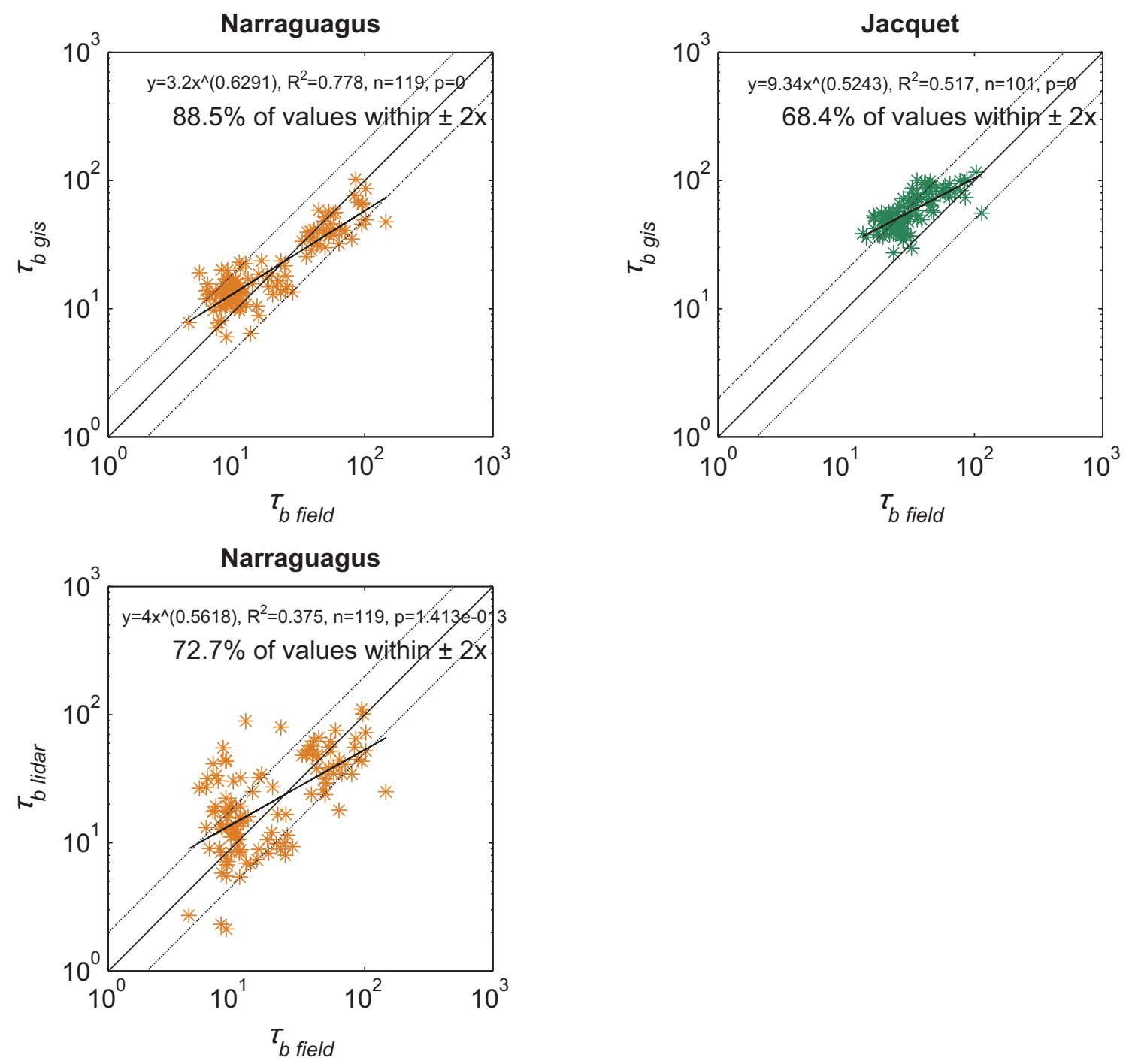

Figure 21. Comparison plots of $\tau_{b}$ field (calculated using field data and $S_{\text {topo }}$ with equation 4 ) and $\tau_{b}$ gis (calculated using remote sensing data only and equation 11) for the two study rivers. 

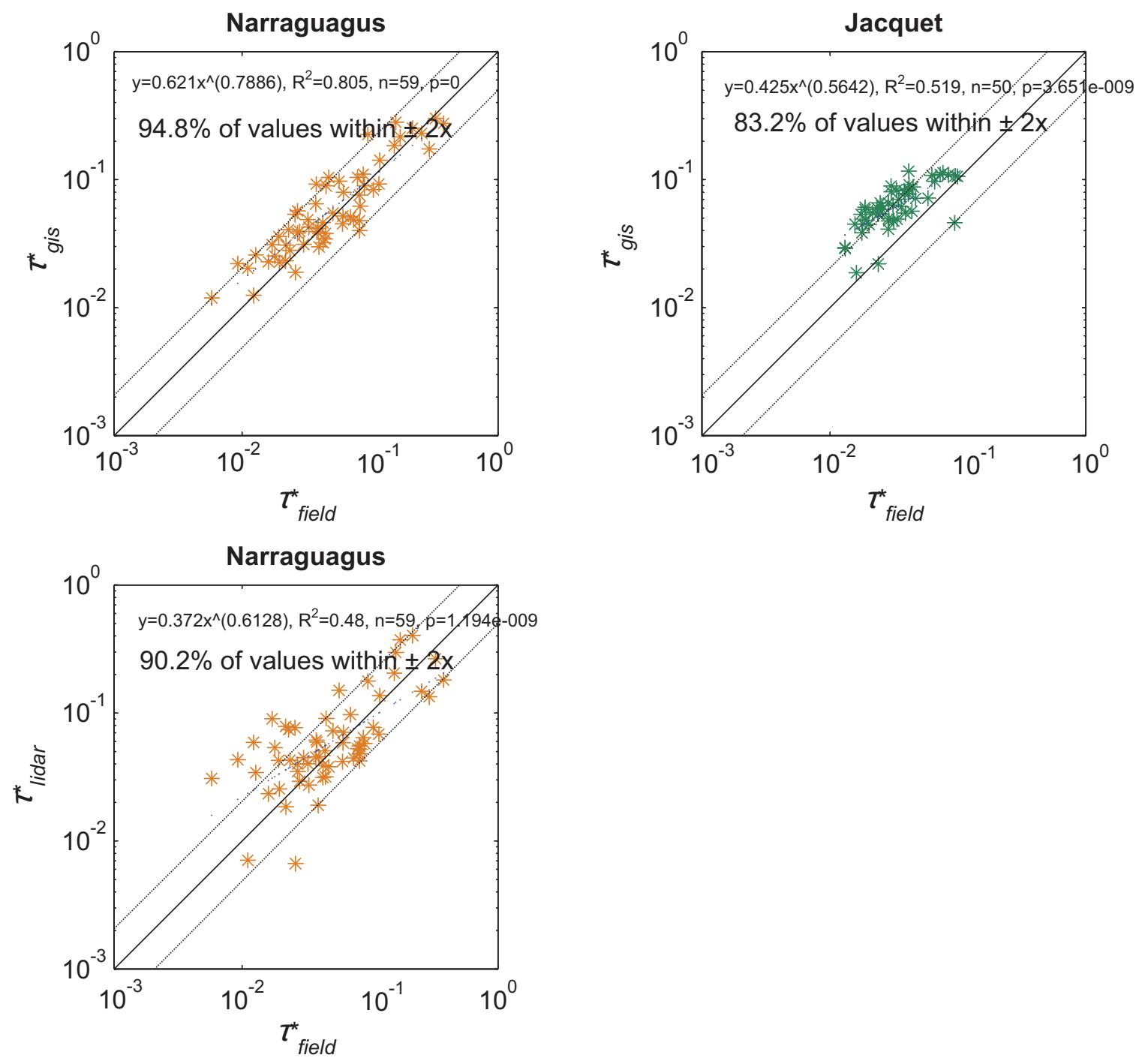

Figure 22. Comparison plot of $\tau *$ field (calculated using $h_{b f}$ and $S_{\text {topo }}$ ) and $\tau^{*}$ gis (calculated using remotely sensed data only) for the two study rivers ( $\tau *$ field versus $\tau *$ lidar for the Narraguagus only). 

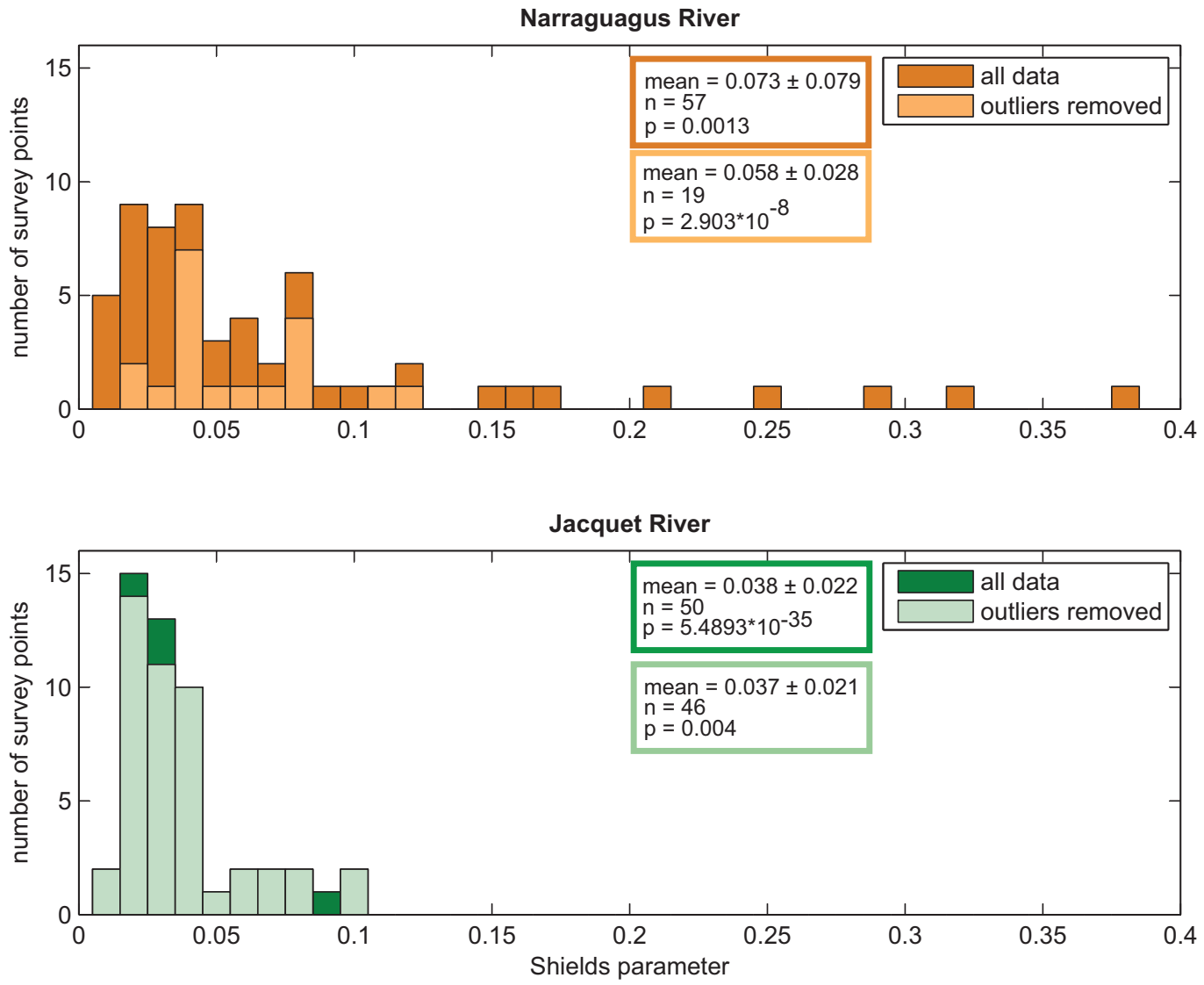

Figure 23. Histograms displaying the distribution of Shields parameter values ( $\tau *$ field $)$ for the study rivers using all data (shown in dark colors) and also data that has had outlying values removed (where $S_{\text {topo }}<0.002$ ) (shown in light colors). A standard $z$-test shows that the two data sets are significantly different in both cases. 


\subsection{Grain size predictions}

With the data that I collected during this study I have developed two basic predictive models of grain size for each study river. The first model uses the empirical relationship between observed grain size in the field $\left(D_{50 \text { field }}\right)$ and basal shear stress calculated from digitized topographic maps $\left(\tau_{b \text { gis }}\right)$ (the resulting equation for each river is shown in Figure 24$)$ to calculate a predicted grain size $\left(D_{50 \text { emp }}\right)$ at every station along the entire length of the study rivers.

The second model uses equation 12 to predict grain size using the Shields parameter equation directly, and therefore does not require the use of any field data. For this method I use a constant value of $\tau^{*}=0.04$ (based on the observations of Snyder et al., 2008), and $\tau_{b \text { gis }}$ (or $\tau_{b \text { lidar }}$ for the Narraguagus only). I justify the use of $\tau_{b \text { gis }}$ in Figure 21 where I show that $\tau_{b \text { field }}$ and $\tau_{b \text { gis }}$ agree within a factor of two more than $68 \%$ of the time. Predicted grain sizes noted in Table 9 are of the surveyed reaches only, so that comparisons with observed grain sizes are possible (Figure 25). Figure 26 and Figure 27, and Appendix 3 show the grain size predictions based on each of the two methods. 


\begin{tabular}{|l|c|c|}
\hline & Narraguagus & Jacquet \\
\hline$D_{50 \text { field }}$ - Observed mean grain size $(\mathrm{mm})$ & $32 \pm 27$ & $61 \pm 17$ \\
\hline $\begin{array}{l}D_{50 \text { emp }} \text { - Predicted from empirical relationship between } \tau_{\mathrm{b}} \\
\text { and observed grain size }(\mathrm{mm})\end{array}$ & $32 \pm 23$ & $61 \pm 2$ \\
\hline$D_{50 \text { gis }}$ - Predicted using $\tau^{*}=0.04 \& \tau_{\mathrm{b} \text { gis }}(\mathrm{mm})$ & $37 \pm 27$ & $57 \pm 33$ \\
\hline$D_{50 \text { lidar }}$ - Predicted using $\tau^{*}=0.04 \& \tau_{\mathrm{b} \text { lidar }}(\mathrm{mm})$ & $40 \pm 33$ & $\mathrm{n} / \mathrm{a}$ \\
\hline
\end{tabular}

Table 9. Summary of observed and predicted median grain sizes for the surveyed reaches of the Narraguagus and Jacquet rivers. Predictions are made from: (1) the empirical relationship between observed grain size $\left(D_{50 \text { field }}\right)$ and basal shear stress $\left(\tau_{b \text { gis }}\right)$; and $(2)$ from the Shields parameter equation with the Shields parameter held constant at $\tau^{*}=0.04$. 

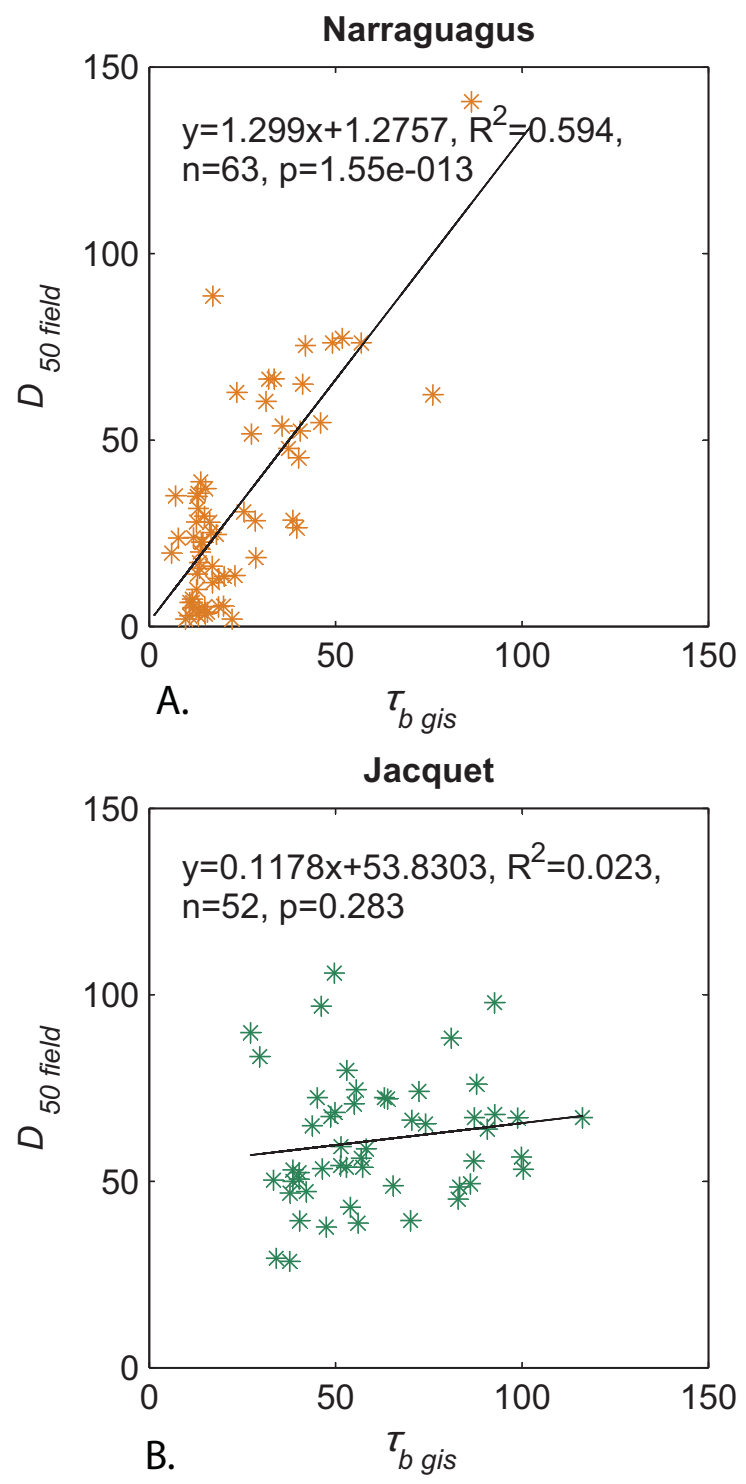

Figure 24. Basal shear stress ( $\tau_{b}$ gis $)$ plotted against the observed mean grain size $\left(D_{50}\right.$ field $)$ for the study rivers. The empirical relationship between the two variables is what is used to create a set of mean grain size predictions for the entire length (surveyed and unsurveyed) of the river . 


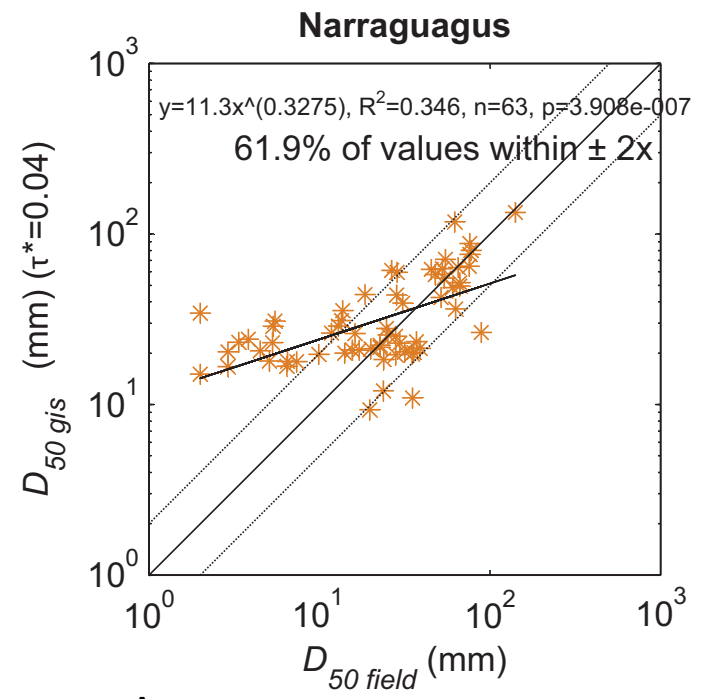

A.

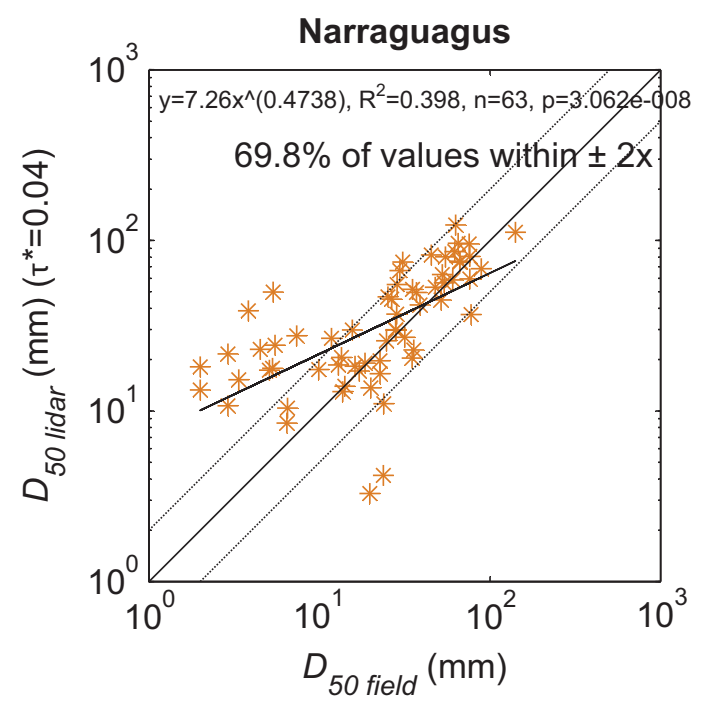

C.

Figure 25. Comparison of field measured median grain size ( $D_{50}$ field $)$ and predicted median grain size ( $D_{50}$ gis and $D_{50}$ lidar).

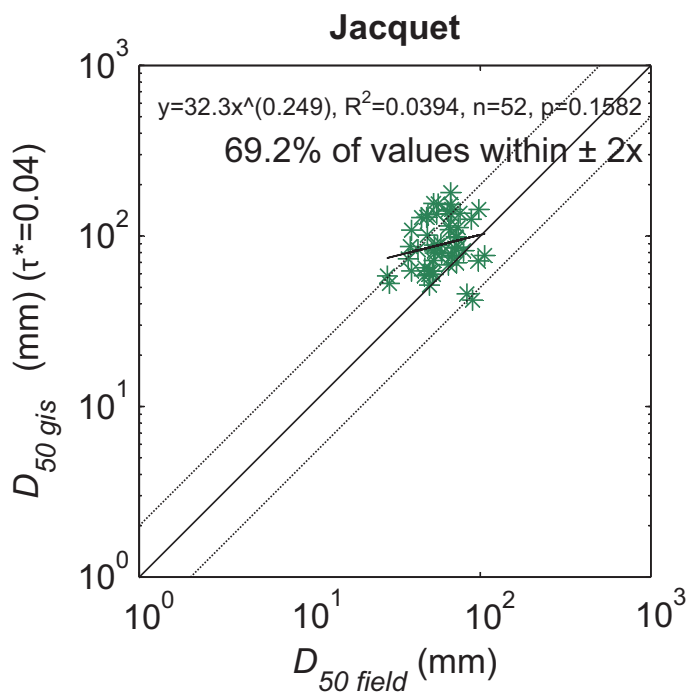

B. 


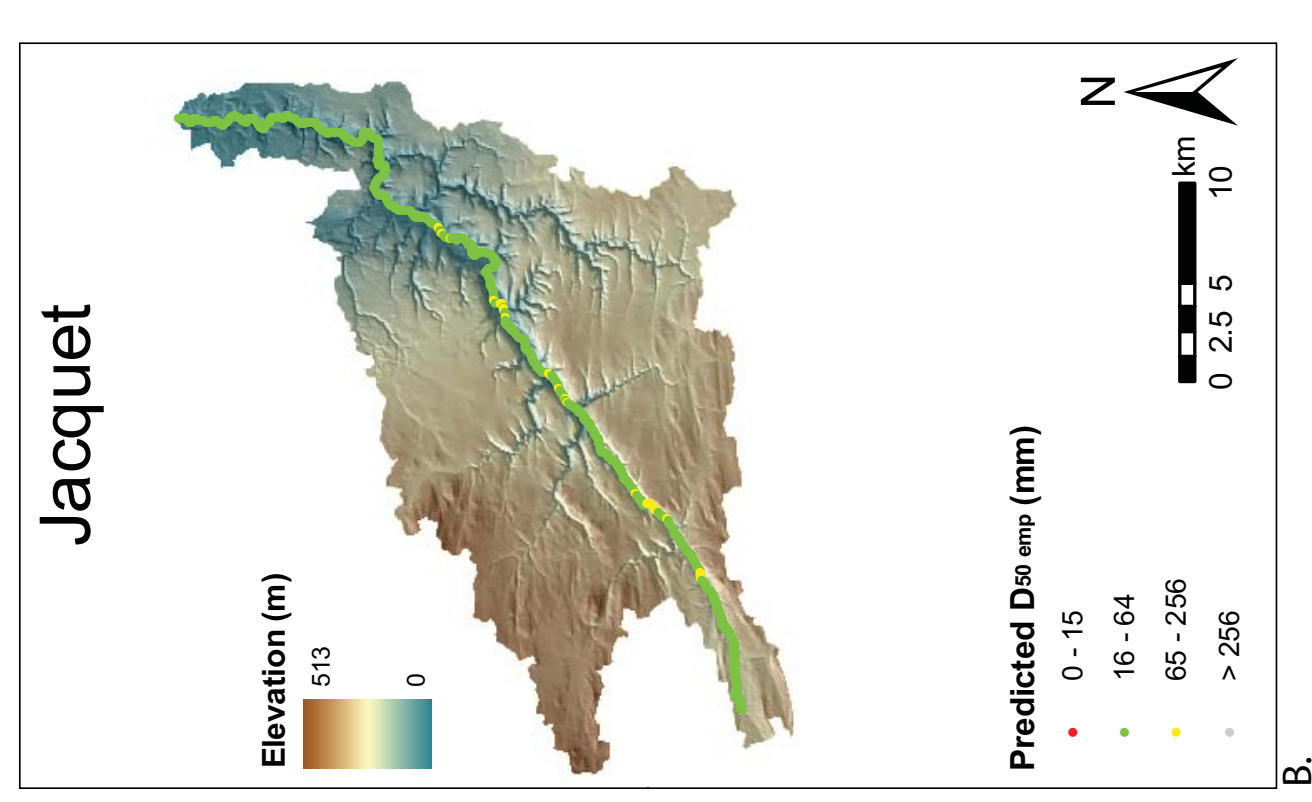

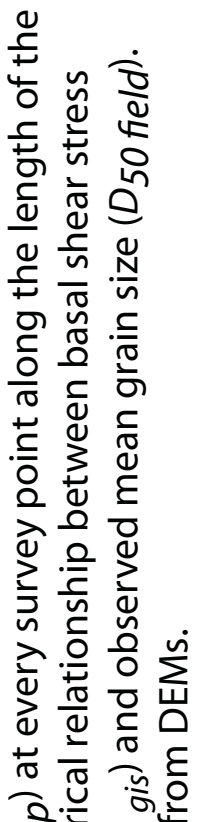

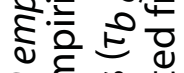

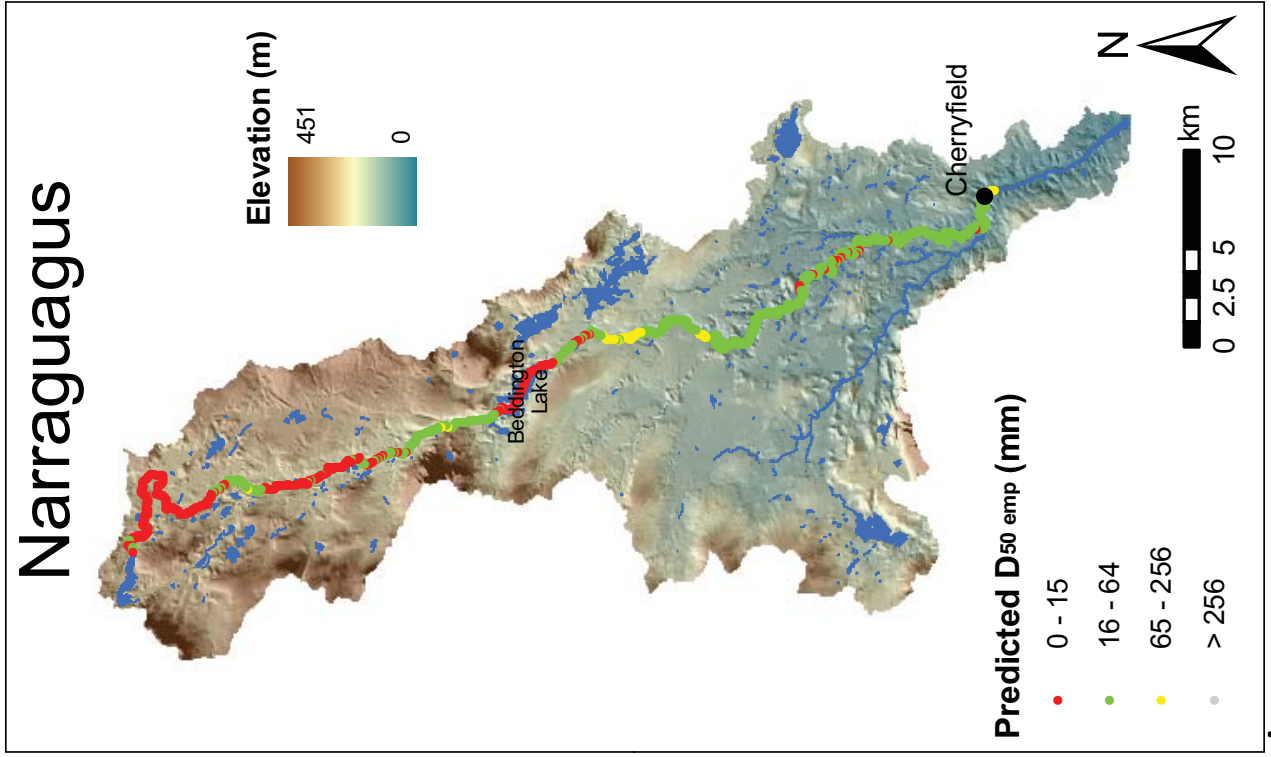

융 ڤ

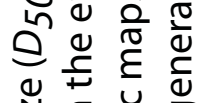

兴

$\cong \frac{0}{\circ}$ 崩

휴 윰

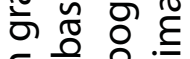

든. 응

응 훙ㅎㅇ

\&

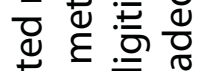

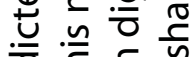

ญ्र

는 은

ํํㄹㅇㅝ 응

थ

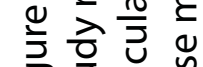

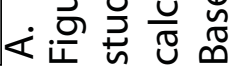




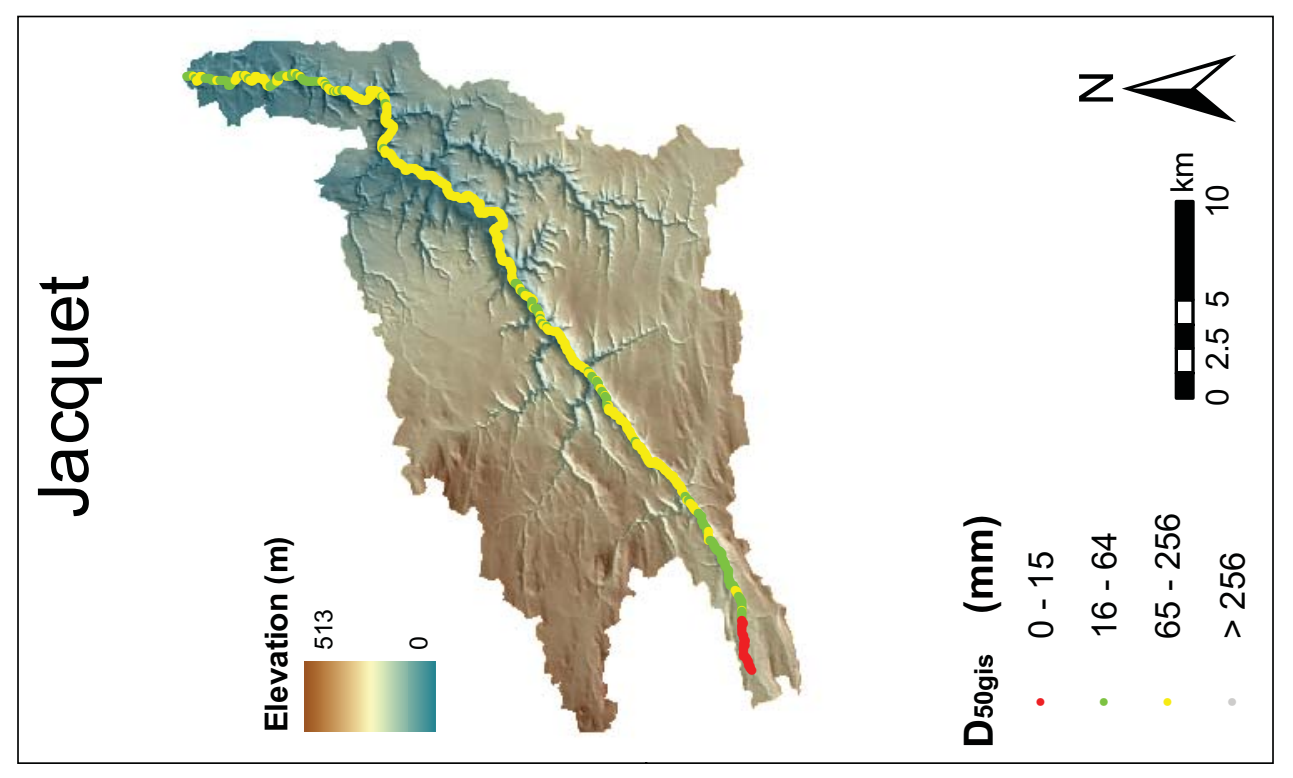

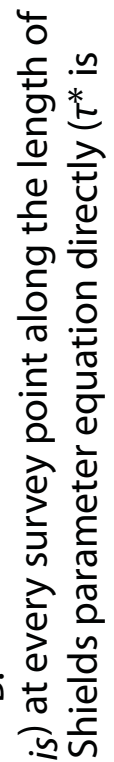

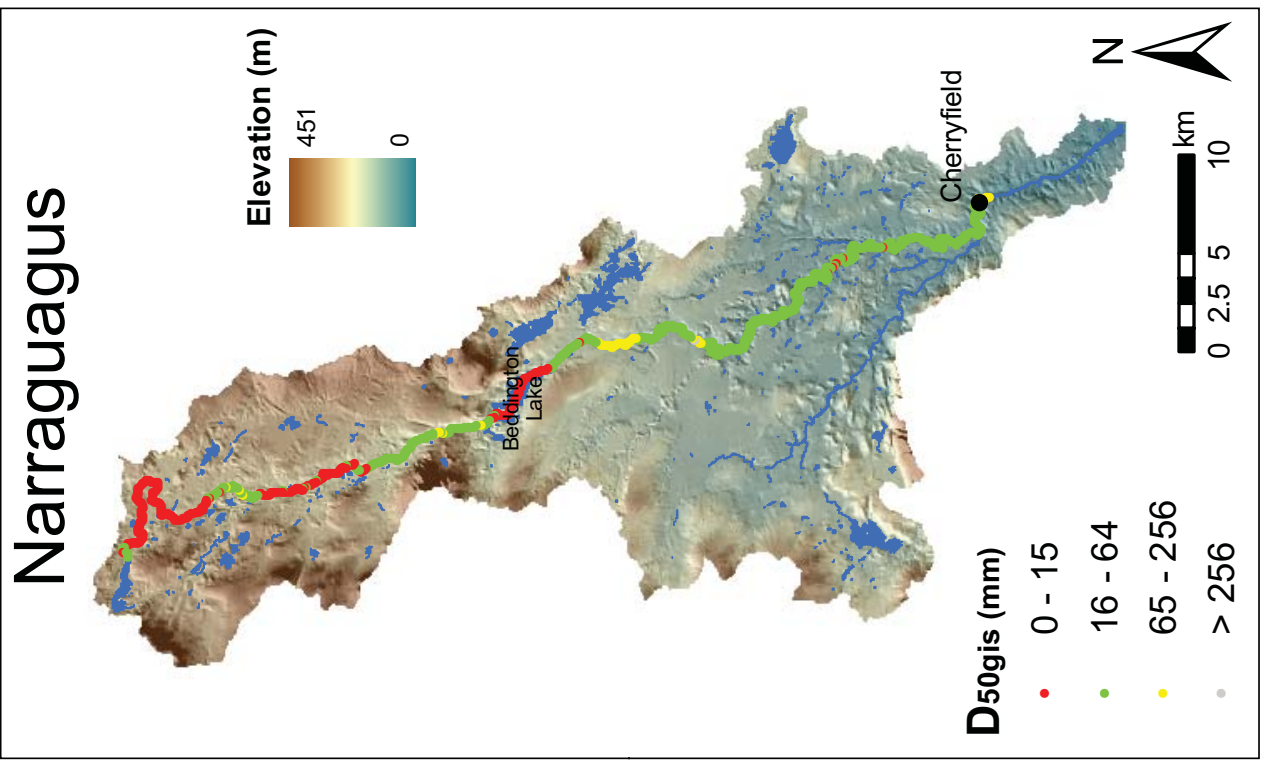

5)

ㄴำ

ํㅗㅇ 월

.

흔 뜨 $\frac{n}{\frac{\pi}{6}}$

든

ฮั

얼 웅

눈

ญ ญ

츨

월 눈

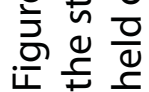




\section{DISCUSSION}

This study attempts to determine whether anthropogenic impacts may have led to morphologic differences between the Narraguagus and Jacquet rivers and whether these differences may be related to observed disparities in current Atlantic salmon populations. In this section, I first discuss on the comparison of morphologic features, followed by an analysis of the various transport calculations used and predictions of grain size and habitat. The grain size predictions are then compared with existing habitat maps created by the U.S. Fish and Wildlife Service (USFWS) in an attempt to determine whether riverbed grain size can be used as a proxy for Atlantic salmon spawning and rearing habitat. Finally, the possible influences of glacial legacy on habitat characteristics of each river are discussed.

\subsection{Comparison of morphologic features}

\subsubsection{Width to depth ratio}

The first of the morphologic features studied is the width to depth ratio of the two river channels. When looking at all data I found that, as hypothesized, the width to depth ratio on the Narraguagus River is significantly larger $(p<0.01)$ than the Jacquet River (Figure 16). However, upon inspection of the data it appeared that this difference was mainly due to a limited number of very high outliers on the Narraguagus River that were associated with the long, low-gradient sections of the river. Reanalysis of the data after the removal of these outliers provided a more focused comparison of similar sections, 
particularly in terms of channel gradient, of each river. The exclusion of the outliers resulted in the removal of 75 out of 112 data points on the Narraguagus, and 5 out of 102 removed from the Jacquet. Results of the Z-test on this reduced data set (Figure 16) showed that there is no significant difference between the two data sets, although this analysis is limited by the low number of data points on the Narraguagus once the outliers are removed. This suggests that the width to depth ratio on the Narraguagus is not significantly higher in areas where the slope values are similar between the two rivers. It therefore seems likely that the perceived differences in width to depth ratio are heavily influenced by differences in slope between the two rivers. This makes the impact of human land use practices such as logging difficult to quantify when looking solely at width to depth ratio. However, logging did occur in both watersheds, and perhaps the less frequent but more intense type of in-channel log drives practiced on the Narraguagus River did lead to higher rates of erosion of the channel bed and banks. This may have led to widening of the channel. The discrepancy in logging practices coupled with the higher overall channel gradient on the Jacquet River, may have led to the situation seen today because the Jacquet: (1) was less disturbed initially; and (2) has a steeper and more continuous profile that was better able to mobilize the sediments currently in its channel and thereby return to a more natural state. 


\subsubsection{Grain size distribution}

The second parameter that I looked at is the grain size distribution within the channel of each river. As Atlantic salmon require a specific gravel size for spawning and rearing purposes (Kondolf \& Wolman, 1993; Hendry \& Cragg-Hine, 1997) grain size provides a relevant means of comparison between the two study rivers. As anticipated, the results of the field data that I collected show an overall coarser bed in the Jacquet River (Table 6; Figure 17 and Figure 18). Also important is that the grain-size measurements for the survey stations on the Narraguagus River span a larger range than on the Jacquet River. The finer sediments present in the Narraguagus may be due in part to anthropogenic practices such as logging that can cause greater than normal amounts of fine-grained sediment to be delivered to the river. More likely, the finer materials observed on the Narraguagus are the result of the extremely low-gradient reaches within the surveyed channels. These reaches likely are depositional environments where fine grained materials transported through steeper upstream reaches build up on the channel bed, a process that does not occur to the same extent on the steeper Jacquet River (Figure 20). The lack of a continuum of sediment transport on the Narraguagus in turn affects the sourcing of sediment by the river. Potential bed sediments will not be dispersed uniformly throughout the river, but rather will need to be sourced locally by erosion of glacial deposits left behind by the Laurentide ice sheet. These deposits include a wide range of grain sizes: from the poorly-sorted till that makes up moraines, the sand and gravel that makes up eskers, and the outwash features that are composed of sand and silt. 


\subsubsection{Channel gradient}

The third, and possibly most important, attribute that I looked at in this study is channel gradient. Channel gradient appears to control the spatial distribution of sediment size, and is therefore likely a significant factor for the distribution of Atlantic salmon habitat. Slopes measured from digitized topographic maps $\left(S_{\text {topo }}\right)$ range from 0.0003 to 0.0203 on the Narraguagus, and from 0.0023 to 0.5000 on the Jacquet (Figure 20). It is possible that the channel gradient is too low $(S<0.0005)$ in the long flat reaches of the Narraguagus River (some are several kilometers in length) to generate the shear stresses required to mobilize the channel bed sediments. This results in some reaches becoming buried with fine grained sediments (embedding) while others become sediment starved over time as the finer-grained materials get winnowed away leaving a layer of coarser sediment armoring the channel bed. I explore this idea further and provide an example in conjunction with the grain size predictions discussion in section 5.3.

\subsection{Shields parameter}

The Shields parameter $\left(\tau^{*}\right)$ is an indicator of the initiation of sediment transport for a given grain size and flow event. Equation 12 shows that $\tau^{*}$ is essentially the ratio of forces propelling sediment downstream relative to the forces acting to keep sediment in place. It can be calculated using basal shear stress ( $\tau_{b}$; equations 4 and 11$)$ as the downstream force and grain size acting as the resisting force. Shields parameters of 0.03 to 0.07 (Buffington \& Montgomery, 1997) indicate the initial mobilization of gravel on 
the channel bed. A previous study on the Narraguagus and Sheepscot rivers in Maine (Snyder et al., 2008) found that gravel entrainment occurred during flow events that produced $\tau^{*}>0.04$

Differences in sediment transport potential between the two rivers, as calculated using the Shields parameter, are impacted primarily by the following factors: (1) grain size in the channel; and (2) overall channel gradient. My results show that the gradient is steeper (Figure 20), and the grain size is coarser on the Jacquet River (Figure 17 and Figure 18). Initially, I hypothesized that the Shields parameter calculated using the mean grain size and a flow event with a two year recurrence interval would be higher on the Jacquet River than on the Narraguagus River, indicating a lack of sediment mobility on the Narraguagus River. My results do indicate that the Shields parameter (Narraguagus $0.073 \pm 0.079$; Jacquet $0.038 \pm 0.022)$ is significantly different $(p<0.01)$ between the two rivers (Figure 22) but that sediment should be mobile in both during the common two year event. As with all of the other geomorphic features used to assess differences between the two rivers, the range of values for the Shields parameter is larger for the Narraguagus, with the Jacquet values more tightly clustered in the 0.03 to 0.07 range. This is because the Shields parameter data for the Narraguagus includes many high outliers $\left(\tau^{*}{ }_{\text {gis }}>0.15\right)$ that increase the overall mean and standard deviation. In order to further the analysis in a manner consistent with the width to depth ratio analysis, I removed all survey points with multi-thread channels, and also all points where topographic map slope $\left(S_{\text {topo }}\right)$ was lower than 0.002 (there are no slopes below this threshold on the Jacquet) and subsequently recalculated the Z-test. This did succeed in 
removing all data points on the Narraguagus where $\tau^{*}{ }_{\text {gis }}$ is greater than 0.12 , however it also removed two thirds ( 38 of 57) of all the data points. Although this results in bringing the mean values of the Shields parameter for the two rivers closer together, there still remains a significant difference between the two study rivers (Figure 22). This difference can likely be attributed to the finer grain sizes on the Narraguagus, which directly increase the calculated Shields parameter values.

\subsection{Grain Size Predictions}

I have predicted grain size distribution in two ways: (1) from the empirical relationship between the observed grain size $\left(D_{50 \text { field }}\right)$ and the basal shear stress calculated from digitized topographic maps ( $\left.\tau_{b \text { gis }}\right)$ (Figure 26$)$; and (2) directly from the Shields parameter equation (Figure 27). Results using the empirical relationship show similar numbers to the actual grain sizes measured in the field (Figure 25) despite the poor correlation $\left(R^{2}=0.023\right)$ for the Jacquet River data (Figure $24 \mathrm{~b}$ ), due to the relatively narrow range of grain sizes observed during the field survey (Figure 17 and Figure 18).

Although both models were able to predict grain size reasonably accurately (Figure 25), there is one important example where predicted grain size is much larger than $D_{50 \text { field. }}$ This occurs in an area where actual riverbed sediments are finer than is required for Atlantic salmon habitat $\left(D_{50 \text { field }}<<16 \mathrm{~mm}\right)$ : upstream of the breached Hemlock Dam on the Narraguagus River (Figure 28). At the time of its use as part of logging operations that took place in the area, the dam likely created an area of flat water 
that extended upstream more than one kilometer. The slow moving water in the reservoir would have increased the deposition of fine grained sediments being transported downstream, thereby burying the coarser sediments naturally in place in this reach. This supposition is supported by the predictive model of grain size that I have created. It is apparent from Figure 28, which shows the plausible extent of the reservoir and the relationship between observed $\left(D_{50 \text { field }}\right)$ and predicted grain size (for this high-resolution view, I use the prediction based on the Shields parameter $-D_{50}$ lidar $)$, that the grain sizes predicted in this reach are consistently coarser (most are more than $2 \mathrm{x}$ ) than those observed during the field surveys. In fact, ten of the nineteen high outliers in Figure 25c are located in the area immediately upstream of Hemlock Dam. It seems possible that the fine sediments in this area are stored legacy sediments that the river has not yet been able to remobilize since the dam was breached. 


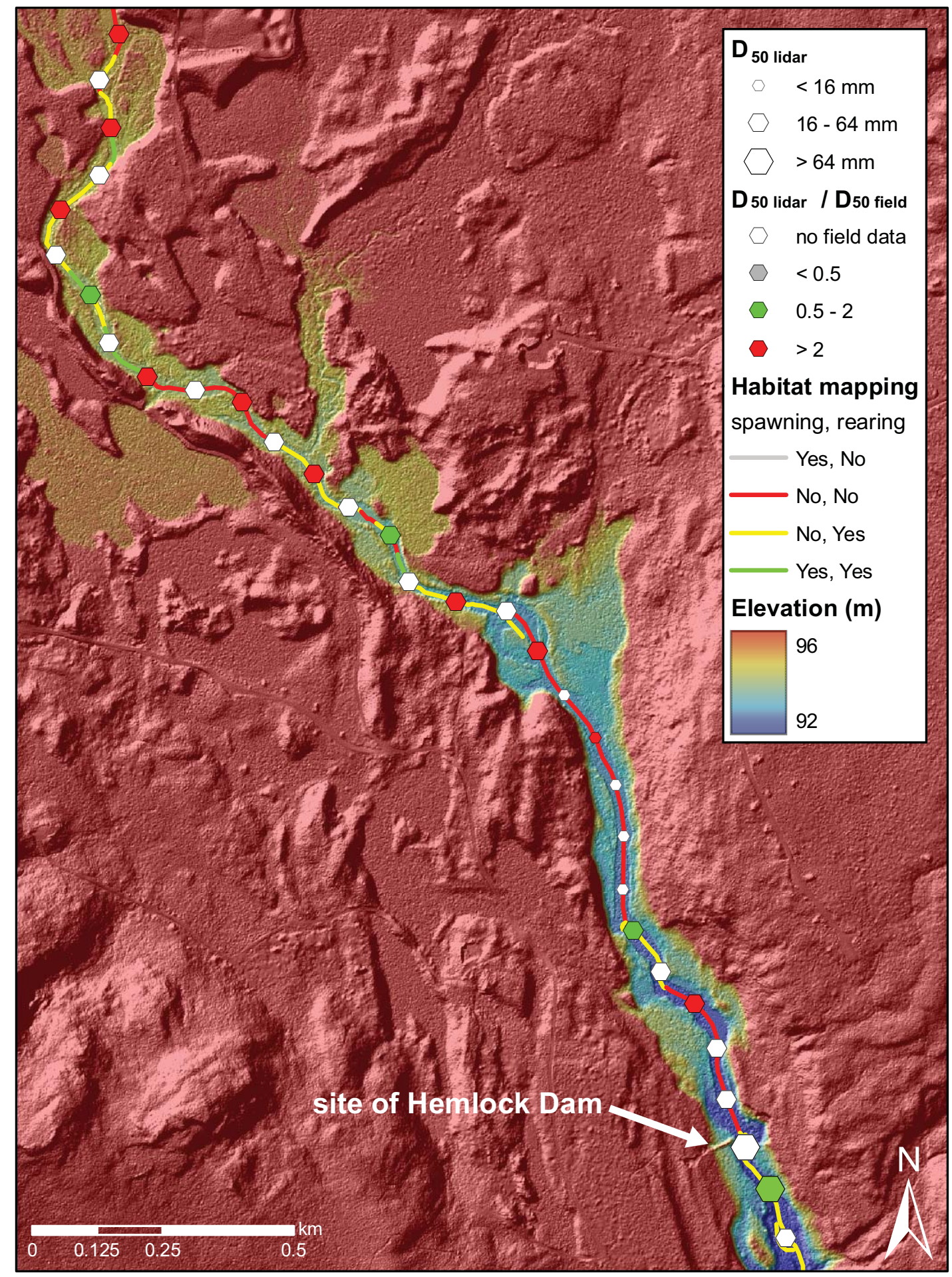

Figure 28. Hemlock Dam area on the Narraguagus River (location shown in Figure 3). Image is colored so that everything at an elevation above the top of the dam appears as red. This highlights the plausible extent of the reservoir created by the dam prior to it being breached. Base is a partially transparent shaded relief lidar DEM. 


\subsection{Comparison of grain-size predictions with mapped Atlantic salmon habitat}

One of the goals of this project was to determine the effectiveness of using riverbed grain size as a proxy for Atlantic salmon habitat. To this end I have associated specific values of mean grain size with habitat suitability based on work by Kondolf and Wolman (1993), Hendry and Cragg-Hine (1997), and Buffington et al. (2004), which suggest that a median grain size of 16 to $64 \mathrm{~mm}$ provides good spawning habitat, and 16 to $256 \mathrm{~mm}$ provides good rearing habitat for Atlantic salmon. In order to visualize the resulting grain sizes, I have grouped the grain size data by logarithmically spaced size classes and then assigned a qualitative color scheme for display purposes. The predicted spawning $\left(D_{50}=16\right.$ to $\left.64 \mathrm{~mm}\right)$ and rearing $\left(D_{50}=16\right.$ to $\left.256 \mathrm{~mm}\right)$ habitat on the Narraguagus is fragmented (47-62\% of the river predicted as spawning, $57-68 \%$ predicted as rearing habitat) compared to the nearly continuous habitat on the Jacquet River (28-95\% predicted as spawning, $95-100 \%$ predicted as rearing habitat) (Table 10). The low spawning habitat predicted by $D_{50 g i s}$ on the Jacquet $(28 \%)$ is due to the over prediction of $\tau_{b \text { gis }}$ as shown in Figure 21 and interpreted in section 4.2.3. 


\begin{tabular}{|l|c|c|}
\hline Grain size prediction types & Narraguagus & Jacquet \\
\hline$D_{50 \mathrm{emp}}$ predicted as spawning habitat (\%) & 59 & 95 \\
$D_{50 \mathrm{e} m p}$ predicted as rearing habitat (\%) & 64 & 100 \\
$D_{50 \text { gis }}$ predicted as spawning habitat (\%) & 62 & 28 \\
$D_{50 \text { gis }}$ predicted as rearing habitat (\%) & 68 & 95 \\
$D_{50 \text { lidar }}$ predicted as spawning habitat (\%) & 47 & - \\
$D_{50 l i d a r}$ predicted as rearing habitat (\%) & 57 & - \\
USFWS mapped as spawning habitat (\%) & 10 & - \\
USFWS mapped as rearing habitat (\%) & 33 & - \\
\hline
\end{tabular}

Table 10. Grain size predictions as percent spawning and rearing habitat for the two study rivers, as well as habitat mapped by the USFWS.

Although I have created maps of predicted grain size for both of the study rivers, there is currently no reach-specific assessment of Atlantic salmon habitat which I can use to evaluate the accuracy of my Jacquet River predictions. In contrast, the US Fish and Wildlife Service (USFWS) performed extensive field surveys in the Narraguagus River in 1991 to map the downstream distribution of Atlantic salmon spawning and rearing habitat. These habitat maps were created by walking the length of the river channel (and many tributaries) during low flow periods and recording (using hand-held GPS devices) separate habitat type locations "... on the basis of one or more physical characteristics that separated them from adjacent habitat types" (USFWS, 2006). This work is physically challenging and time consuming, and because it is based on field observations, not physical measurements of processes, it does not provide a direct means for developing predictions using remote-sensing data. In contrast, the field surveys for my study took only three weeks, and, as this study has shown, provide evidence that I am able to predict habitat suitability for the entire river relatively well using nothing but remote-sensing data. Figure 29 compares the USFWS mapping efforts along the Narraguagus River 
mainstem with predicted grain size based on: (1) $D_{50 \text { emp }}$ - the empirical relationship between field-measured grain size $\left(D_{50 \text { field }}\right)$ and basal shear stress calculated using digitized topographic maps ( $\tau_{b \text { gis }}$ ); and (2) $D_{50 \text { lidar }}$ - using the Shields equation directly.

Overall, the predictions for both median and coarse grain size agree moderately well with the mapped habitat classification and appear to provide a reasonable overview of habitat conditions in the watershed. Figure 30 divides the data points into spawning and rearing habitat and non-habitat based on the mapping efforts of the USFWS. Although I have over-predicted the total amount of suitable habitat compared to the amount mapped ( $\sim 33 \%)$, I have succeeded in correctly identifying approximately two thirds (65\%) of the habitat. In fact, the USFWS mapped habitat agrees almost completely with my predictions of grain size where the predicted median grain size is greater than 64 $\mathrm{mm}$ (there does appear to exist some correlation where sediment is between 16 and 64 $\mathrm{mm}$ ). Although further investigation is needed, it seems likely that areas where my model disagrees with the USFWS maps (i.e. where predictions of grain sizes are in the 16-64 $\mathrm{mm}$ range but no spawning or rearing habitat is identified) will be good candidates for habitat restoration projects such as large woody debris additions and other sitespecific projects.

Locations where my model does not match with surveyed habitat may be because the model predicts grain size based on 100 meter intervals. This may consolidate smaller reaches into larger ones, thereby limiting the ability of the model to predict habitat on as small a scale as the USFWS surveys were able to do (the average reach length for the USFWS surveys is $98 \mathrm{~m}$; the mode is $46 \mathrm{~m}$; and $85 \%$ of all USFWS reaches are less than 
$100 \mathrm{~m}$ ). The fact that the my predictions are at all similar to the USFWS mapped habitat is a good indication that Atlantic salmon habitat depends critically on grain size in the river. In sum, it appears that Atlantic salmon habitat mapping can be approximated without field data, using no more than grain size predictions based on GIS data derived from aerial photographs and DEMs. 


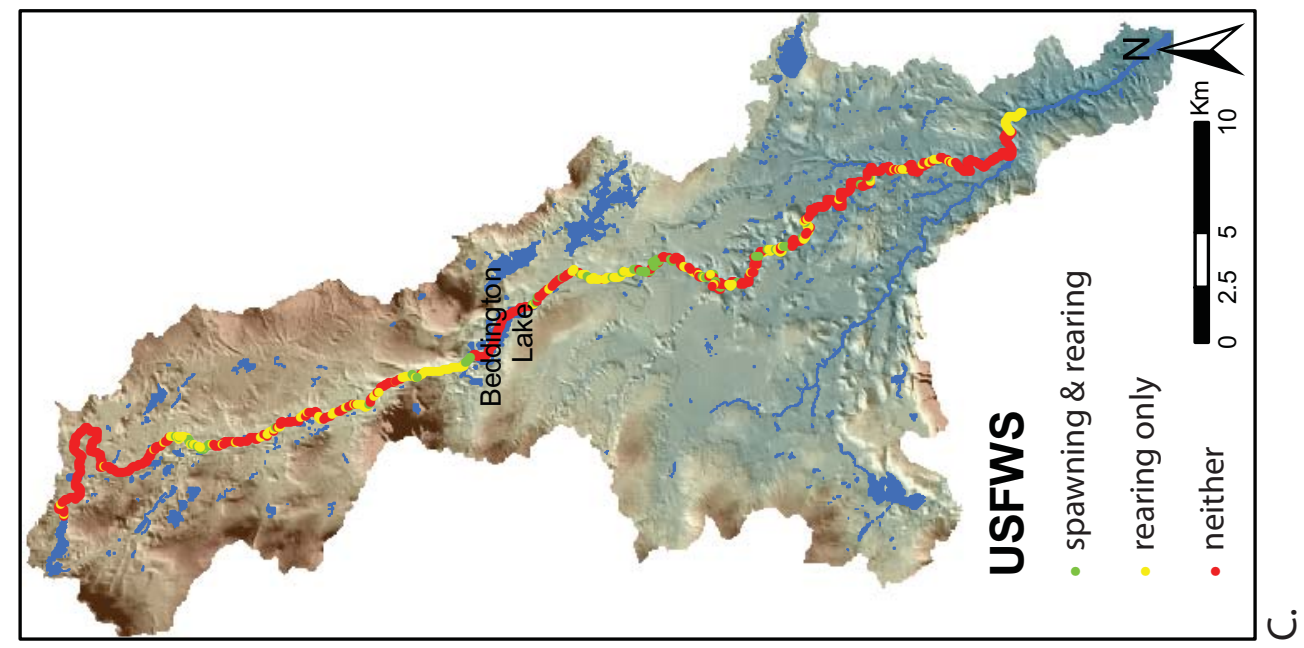

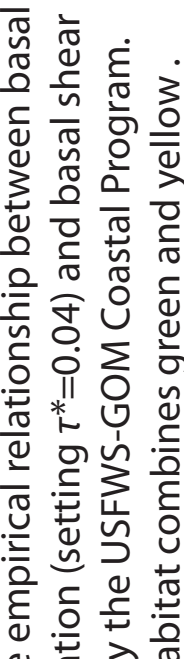

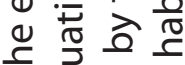

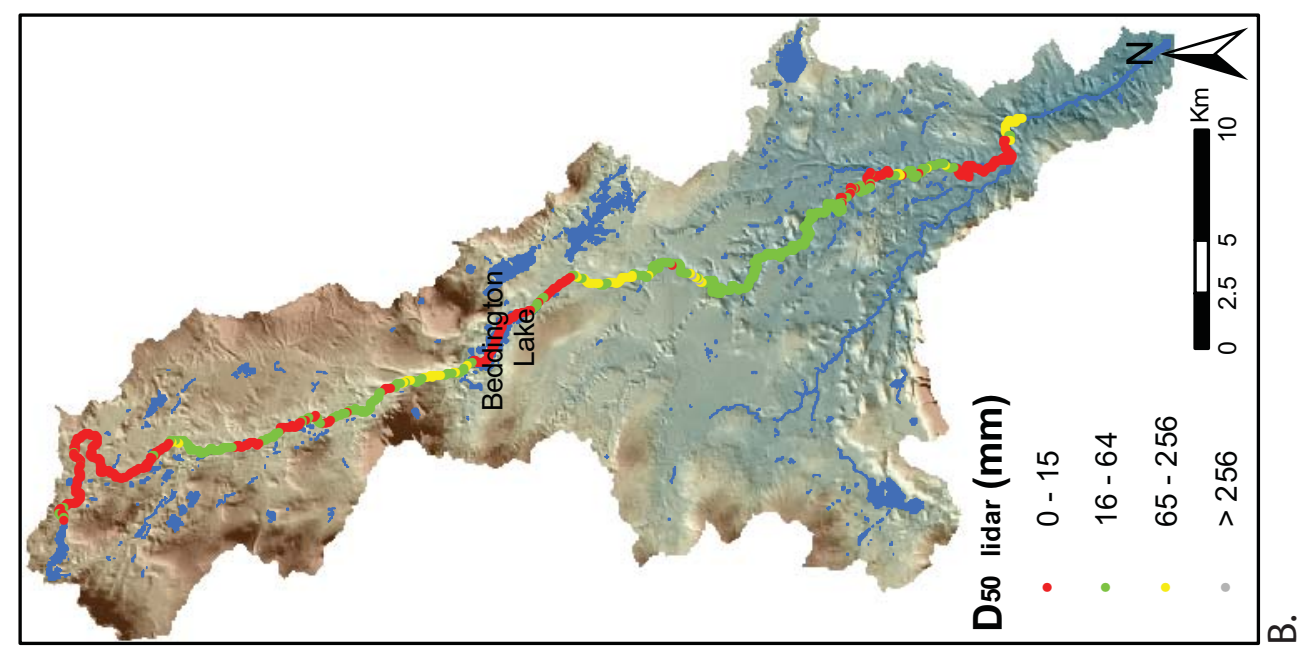

๘ 웡 б

ช ฮ

రัँ

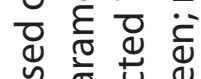

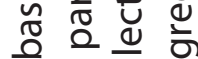

นั 능. 인

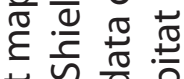

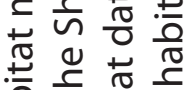

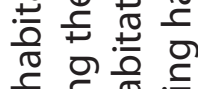

들. 들

旅

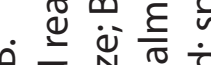
兄 $\frac{N}{\sim} \stackrel{0}{0}$

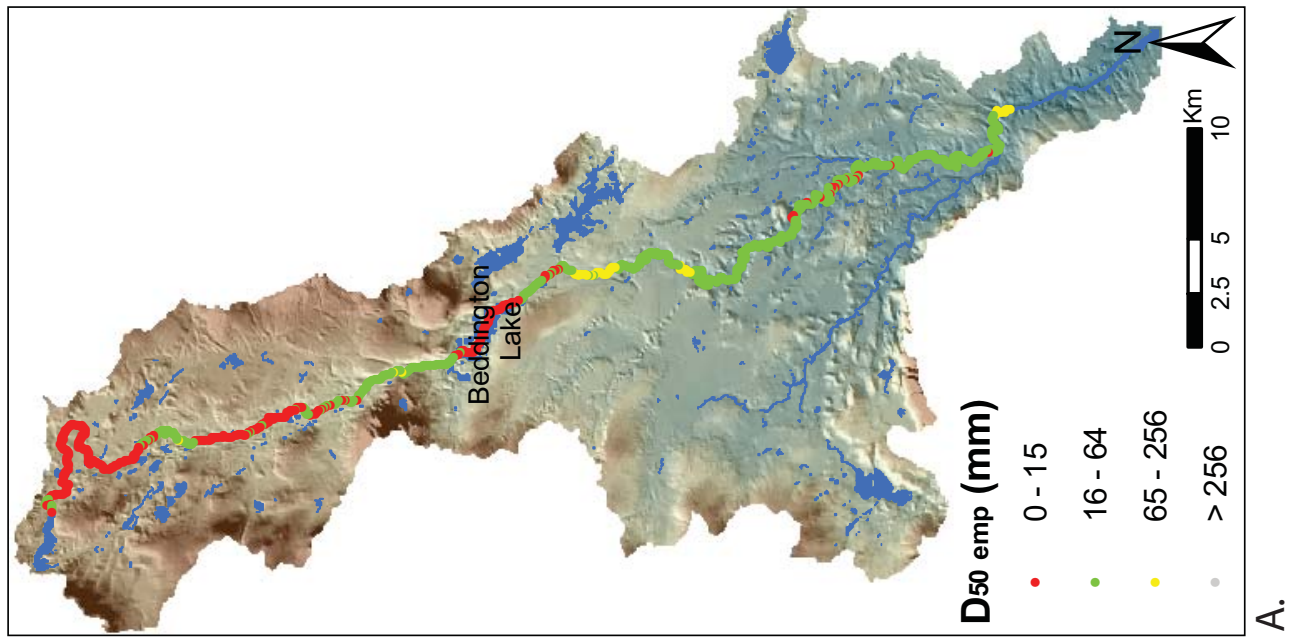

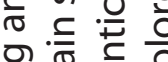
은 든 高盯专

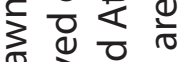
은 궁 ปิ ह 는 든 它 世 ํํㄴ른 Q

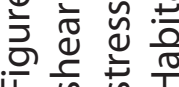



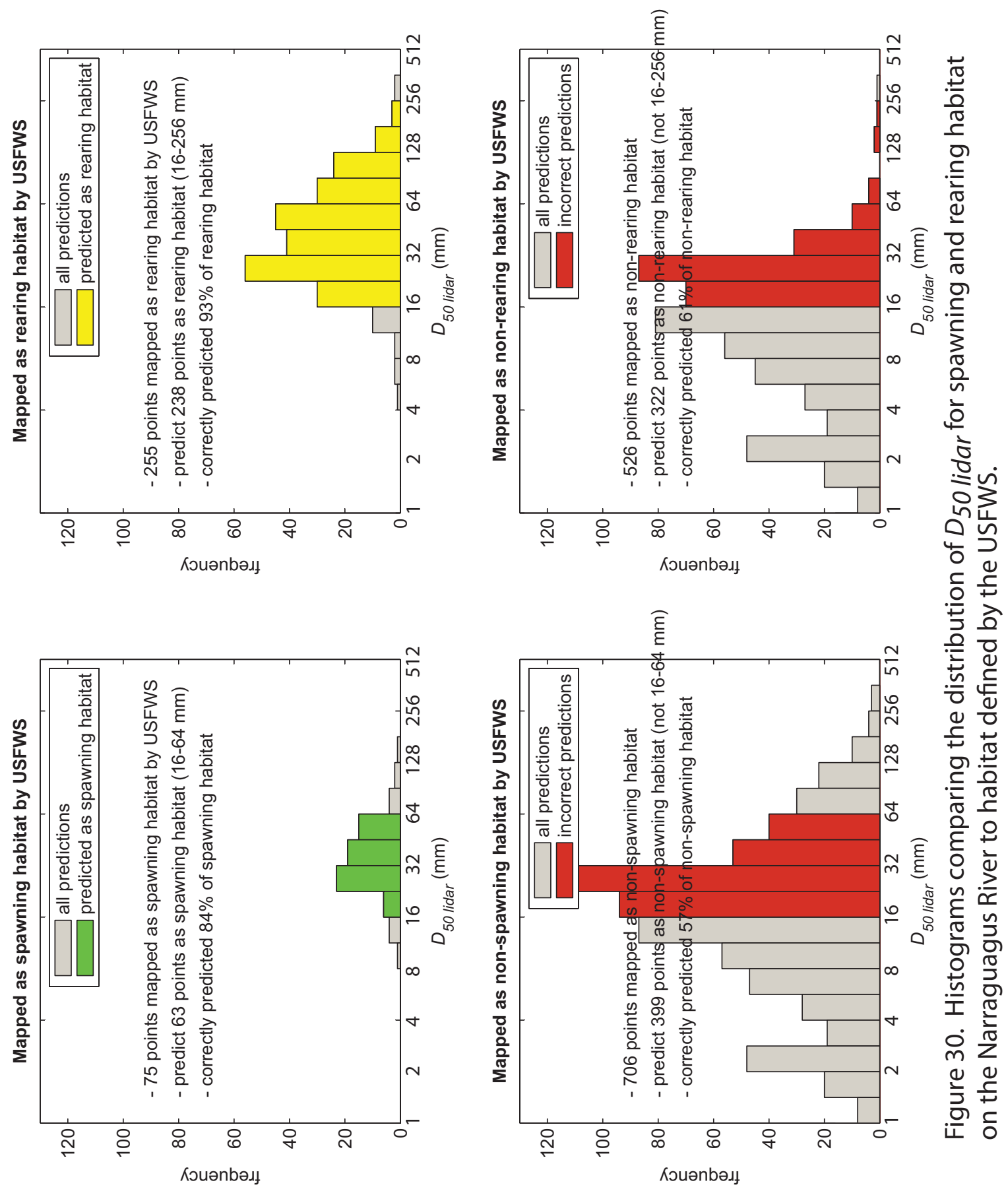


\subsection{Glacial Legacy}

The influence of the most recent glaciation (during the late Pleistocene) on the landscapes through which the two study rivers flow is undeniably important (Figure 3). The different resulting landscapes have an impact on the suitability of the rivers in terms of Atlantic salmon habitat but also in the way that the rivers respond to anthropogenic impacts. It is known that Atlantic salmon once flourished in both rivers. It also seems likely that both rivers have been negatively impacted by human land uses such as logging, however the responses of the rivers to these perturbations may be what differentiates them today.

The Narraguagus is an imposed form river, meaning that it flows through a landscape that it did not create (i.e. the resistant features within the landscape dictate the path of the river). It flows as a series of steeps and flats (Figure 20) through a lowgradient landscape strewn with bedrock knobs, eskers, moraines, outwash and other paraglacial legacy features. This setting creates a precariously balanced fluvial environment where a minor change in flow regime, sediment load, or other factor may lead to extensive and possibly irreversible change in the nature of the river. The many lake-like deadwater reaches, (extremely low channel gradient; Figure 20) that extend for hundreds of meters to kilometers, act as sediment sinks, preventing all but the finest materials from travelling downstream. The inability of the river to successfully move its coarser sediment load through these deadwaters means that the river is fragmented into reaches where bed morphology depends critically on local sediment supply. 
The Jacquet River flows through a gorge that existed prior to the Laurentide ice sheet advance and retreat across the area. The presence of this gorge confines the river to a narrow path where lateral erosion is possible only on a small scale. This has lead to a lack of wide and shallow areas, i.e. deadwaters or lakes, except in the upper part of the watershed where the river is not incised into the plateau surface (Figure 5). The resulting uniform nature of the present channel indicates that sediment is likely mobilized and transported through the entire system in a consistent manner.

Also of importance is that the area surrounding the river is a relatively high plateau where glacial ice likely would have remained after ice in the Bay of Chaleur melted. Meltwater from the plateau likely rushed down through the narrow gorge, where there is little room for sediment deposition, and flushed most of the finer sediment out to the bay. The remaining terrace deposits (Figure 7), likely deposited during deglaciation, are probably a more uniform and consistent source of coarse sediment than that supplied to the Narraguagus River.

These differences in slope (Figure 19) and confinement (Figure 6) indicate that the Narraguagus River likely has a limited ability to respond to land use impacts in a way that is conducive to good quality salmon habitat while the Jacquet River is much more able to do so. Although the Shields parameter indicates that sediment should be mobile in both rivers during high flows, the Narraguagus does not appear to be moving sediment through the entire river as evidenced by the wide variety of grain sizes presently in its channel (Figure 17 and Figure 18). The Jacquet on the other hand contains a more uniform grain size distribution as a result of its more uniform slope and ability to move 
sediment throughout the entire river (Figure 8 and Figure 22). As natural channel evolution takes place, the Narraguagus River becomes more distinctly divided into steeper areas of coarse sediment and flatter areas with finer sediments, resulting in increasingly localized sediment deposition and further degradation of spawning habitat. Channel migration on the Jacquet River however, will result in the addition of more sediment that the river is able to mobilize, resulting in a channel bed consisting mostly of gravels that are closer to ideal for spawning and rearing habitat.

Regardless of the reason for the differences in Atlantic salmon habitat between the two study rivers, the fractured nature of the sediment supply and transport along the Narraguagus is an important component of the current situation. Reaches with grain sizes appropriate for salmon habitat are scarce on the Narraguagus due to a prevalence of finer grained material in the low-gradient parts of the system. This situation does not appear to be conducive to good Atlantic salmon habitat, and both the USFWS survey and my predictive model of grain size as a proxy for habitat show relatively little expected highquality spawning habitat (Figure 26, Figure 27, Figure 29 and Table 10). 


\section{SUMMARY \& CONCLUSIONS}

This study addresses the geomorphic differences between the Narraguagus and Jacquet rivers, and the possible connection between these differences and current Atlantic salmon populations. It has been postulated that the declines in returning adult Atlantic salmon throughout the rivers of Maine are the result of land use changes, particularly logging, which may have widened and shallowed the rivers and also introduced large amounts of fine sediment to the rivers. Wider and shallower rivers produce lower basal shear stresses and are therefore thought to be less able to mobilize their channel bed sediments, leading to armoring with immobile clasts or an increase in fine sediment deposition between clasts and embedding. This study tests the hypothesis that channel morphology is different between the two study rivers by collecting and comparing field and remote sensing data.

Initial results show that the Narraguagus River is significantly wider (Figure 16) and contains a wider range of sediment sizes on the river bed than the Jacquet River (Figure 17). However, this difference is largely the result of a few wide and shallow sections of channel that are locations with mid-channel islands and low gradient. Further analysis shows that there is no difference in width to depth ratio between the two rivers when outlying data points are removed. Calculations of the Shields parameter $\left(\tau^{*}\right)$, an indicator of the initiation of bedload sediment transport, show a significant overall difference in sediment mobility potential between the two rivers during the common two year recurrence interval event (Figure 22). Both rivers have average values of $\tau^{*}$ in the 
0.03-0.07 range, indicating mobility during high flows (Buffington and Montgomery, 1997; Snyder et al., 2008). The high average value for the Narraguagus is due in part to many high outliers $\left(\tau^{*}>0.15\right)$; the distribution covering a much smaller range on the Jacquet River.

The different glacial history of the two rivers appears to be important. Although both watersheds were glaciated during the late Pleistocene, the two rivers are located in areas with different glacial sedimentary deposits. The Narraguagus River flows through a low-relief landscape (Figure 6a) dominated by eskers and moraines (consisting of poorly sorted glacial sediments) in the upper watershed, and through a glacial outwash plain in the lower part of the watershed. The fragmented nature of the river (into steeps and flats) does not allow for these poorly sorted sediments to be transported through the entire river, likely an important factor degrading Atlantic salmon spawning and rearing habitat. On the other hand the Jacquet River flows through a steeper gorge that is incised into the surrounding plateau (Figure 6b). The sediments supplying the river are likely more uniform in size, and combined with its steeper channel gradient, increase its ability to mobilize its sediment load, and create higher quality habitat.

During the analysis of my field data for this project it became apparent that channel gradients measured in the field were consistently higher than those calculated using topographic maps (Table 7; Figure 20). This error was due to the inaccuracy of measuring slope with a hand held device on rivers with slopes less than 1 to $2 \%$. Measuring channel gradient accurately in the field on low-gradient rivers could be done using stationary surveying tools such as a total station, however this would be impractical 
and time consuming. It was possible to calculate very precise values for channel gradient using the digital elevation model (DEM, with 1 meter pixel resolution) of the Narraguagus River watershed made from lidar data collected in November 2007.

For this project I used aerial photographs, traditional digital elevation models (DEMs), and a DEM generated from lidar data, to create a set of predictive grain size maps for the Narraguagus River (Figure 26b; Figure 27b; Figure 29b). Initially the primary use of the lidar data in my project was to increase the accuracy of channel gradient and channel width measurements. While this new data set did not significantly increase the overall accuracy of my grain size predictions (Figure 25c) it did permit a much more detailed view of the channel profile (Figure 20). This in turn did increase my ability to predict smaller, reach-scale habitat conditions with greater confidence. In future analyses of the sort undertaken in this study as well as others, the comprehensive and accurate nature of the lidar dataset will greatly improve our ability to identify small scale features as well as reduce the number of GIS datasets required for this type of study.

The grain size predictions were in turn correlated with habitat quality based on information from Kondolf \& Wolman (1993) and Hendry \& Cragg-Hine (1997). My predictions of spawning and rearing habitat suitability compared moderately well with maps of Atlantic salmon habitat prepared by the US Fish and Wildlife Service (I correctly identified $\sim 65 \%$ of the habitat) (Figure 29 ). This ground-truthing implies that my grainsize predictions based solely on GIS data give a good overall representation of actual habitat found in the field. This should enable future predictions of Atlantic salmon 
habitat on other rivers to be made with greater confidence; however a comprehensive habitat survey of the Jacquet River, such as the one for the Narraguagus, would improve confidence in the predictive value of this model. As it stands currently, my model will likely be useful in roughly assessing habitat conditions over large areas quickly, and with an eye to identifying specific reaches where habitat restoration projects may be promising.

Whether or not anthropogenic land use is the cause for the differences between the rivers, and thereby responsible for the decline in Atlantic salmon population, ideal conditions on the Narraguagus River with respect to grain size for Atlantic salmon habitat are sparse (predicted $47-62 \%$ spawning, $57-68 \%$ rearing habitat) while conditions on the Jacquet River appear to be better (predicted 28-95\% spawning, 95-100\% rearing habitat). This difference in habitat suitability is undoubtedly largely related to the steeper channel gradient of the Jacquet River, however further collection and analysis of morphologic data from other rivers with healthy Atlantic salmon populations would strengthen this claim. The model developed and used in my study will hopefully be a valuable tool used not only in the analysis of collected data, but also in the pre-selection of river reaches that potentially hold the most useful information. 


\section{REFERENCES}

Andrews, E.D. and Nankervis, J.M., 1995. Effective discharge and the design of channel maintenance flows for gravel-bed rivers, Geophysical Monograph, 89, pp. 151-164.

Barnes, H.H. Jr., 1967. Roughness Characteristics of Natural Channels, U.S. Geological Survey water supply paper 1849, United States Government Printing Office, Washington, D.C., 213 pp.

Buffington, J.M. and Montgomery, D.R., 1997. A systematic analysis of eight decades of incipient motion studies, with special reference to gravel-bedded rivers, Water Resources Research, 33(8), 1993-2039.

Buffington, J.M., Montgomery, D.R., and Greenberg, H.M., 2004. Basin-scale availability of salmonid spawning gravel as influenced by channel type and hydraulic roughness in mountain catchments. Canadian Journal of Fisheries and Aquatic Sciences, 61, 2085-2096. doi: 10.1139/F04-141

Chambers, J.S., Pressey, R.T., Donaldson, J.R., and McKinley, W.R., 1954. Research relating to study of spawning grounds in natural areas, annual report, Department of Fisheries, Washington State, Olympia.

Danie, D.S., Trial, J.G. and Stanley, J.G., 1984. Species profile: life histories and environmental requirements of coastal fish and invertebrates (North Atlantic), Atlantic salmon, U.S. Fish \& Wildlife Service, FW/OBS-82/11.22. U.S. Army Corps of Engineers, TR EL-82-4. 19 pp.

Dolloff, C.A. and Warren, M.L., 2003. Fish Relationships with Large Wood in Small Streams. America Fisheries Society Symposium, 37, 179-193.

Dudley, R.W. and Nielsen, J.P., 2000. Streamflow statistics for the Narraguagus River at Cherryfield, Maine, U.S. Department of the Interior, USGS Report.

Dudley, R.W., 2004. Hydraulic-geometry relations for rivers in coastal and central Maine, U.S. Geological Survey, Augusta, Maine.

Dunne, T. and Leopold, L.B., 1978. Water in Environmental Planning. W.H. Freeman and Company, New York, 818 pp.

Environment Canada, 2007a. Canadian Climate Normals 1971-2000, http://www.ec.gc.ca/ [accessed 24 October 2007] 
Environment Canada, 2007b. Real-Time Hydrometric Data, http://scitech.pyr.ec.gc.ca/waterweb/selectProvince.asp [accessed 14 March 2007]

Fay, C., Bartron, M., Craig, S., Hecht, A., Pruden, J., Saunders, R., Sheehan, T., and Trial, J., 2006. Status Review for Anadromous Atlantic Salmon (Salmo salar) in the United States. Report to the National Marine Fisheries Service and U.S. Fish and Wildlife Service, $294 \mathrm{pp}$.

Gibbins, C.N., Moir, H.J., Webb, J.H., Soulsby C., 2002. Assessing discharge use by spawning Atlantic salmon: A comparison of discharge electivity indices and phabsim simulations, River Research and Applications, 18, 383-395.

Gottesfeld, A.S., Hassan, M.A., Tunnicliffe, J.F., and Poirier, R.W., 2004. Sediment dispersion in salmon spawning streams: The influence of floods and salmon redd construction. Journal of the American Water Resources Association (JAWRA), 40(4), 1071-1086.

Harriman, P., 1977. Mills of the Narraguagus, self-published.

Hendry, K. and Cragg-Hine, D, 1997. Restoration of riverine salmon habitats. Fisheries Technical Manual 4 Environment Agency, Bristol.

Hendry, K. and Cragg-Hine, D, 2003. Ecology of the Atlantic salmon, Conserving Natura 2000 Rivers Ecology Series No. 7. English Nature, Peterborough.

Hassan, H.A., Gottesfeld, A.S., Montgomery, D.R., Tunnicliffe, J.F., Clarke, G.K.C., Wynn, G., Jones-Cox, H., Poirier, R., MacIsaac, E., Herunter, H., and Macdonald, S.J., 2008. Salmon-driven bed load transport and bed morphology in mountain streams. Geophysical Research Letters, 35.

Jacquet River Gorge Protected Natural Area Local Advisory Committee, 2007. Draft Management Plan for the Jacquet River Gorge Protected Natural Area, Department of Natural Resources.

Kondolf, G.M., Wolman, M.G., 1993. The sizes of salmonid spawning gravels. Water Resources Research, v. 29, p.2275-2285.

Koski, K.V., 1966. The survival of coho salmon (Oncorhynchus kisutch) from egg deposition to emergence in three Oregon coastal streams. M.S. thesis, Oregon State University, Corvallis, $84 \mathrm{pp}$. 
Lisles, G., 2000. Wild Atlantic salmon in Maine protected as endangered species, NOAA National Fish \& Wildlife Service 2000-1113, http://www.publicaffairs.noaa.gov/releases2000/nov00/noaanfws1113.html.

Magilligan, F.J., Nislow, K.H., Fisher, G.B., Wright, J., Mackey, G. and Laser, M., 2008. The geomorphic function and characteristics of large woody debris in low gradient rivers, coastal Maine, USA. Geomorphology, 97, 467-482.

Merz, J.E., Pasternack, G.B., Wheaton, J.M., 2006. Sediment budget for salmonid spawning habitat rehabilitation in a regulated river, Geomorphology, 76, 207-228.

Moir, H.J., Gibbins, C.N., Soulsby, C., Webb, J., 2003. Linking channel geomorphic characteristics to spatial patterns of spawning activity and discharge use by Atlantic salmon (Salmo salar L.), Geomorphology, 60, 21-35.

Montgomery, D.R., Buffington, J.M., 1997. Channel-reach morphology in mountain drainage basins, GSA Bulletin, 109, no. 5, 596-611.

Montgomery, D.R., Beamer, E.M., Pess, G.R., Quinn, T.P., 1999. Channel type and salmonid spawning distribution and abundance, Canadian Journal of Aquatic Science, $56,377-387$.

Montgomery, D.R., 2003. King of Fish: The thousand-year run of salmon, Westview Press, Boulder, CO, $290 \mathrm{pp}$.

Montgomery, D.R., 2004. Geology, geomorphology, and the restoration ecology of salmon. Geological Society of America Today, 14 (11), 4-12.

National Research Council, Committee on Atlantic Salmon in Maine, 2004, Atlantic salmon in Maine, 304 pages, PDF version available from National Academic Press at http://www.nap.edu/catalog/10892.html

Osberg, P.H., Hussey II, A.M., Boone, G.M., 1985. Bedrock Geologic Map of Maine, Maine Geological Survey.

Perham, R.E., 1983. Ice sheet retention structures. CRREL Report 83-80, U.S. Army Cold Regions Research and Engineering Laboratory, Hanover, NH, 39 pp.

Rappol, M., 1989. Glacial dispersal of Precambrian Shield and local Appalachian rocks in the lower St. Lawrence region in western Gaspesie, Quebec, and in adjacent New Brunswick. Geological Survey of Canada, Report 89-1B, pp 127 -136. 
Ritter, D.F., Kochel, R.C., Miller, J.R., 2002. Process geomorphology $-4^{\text {th }}$ edition, McGraw-Hill, New York.

Snyder, N.P., Castele, M.R., and Wright, J.R., 2008. Bedload entrainment in lowgradient paraglacial coastal rivers of Maine, USA: Implications for habitat restoration. Geomorphology, doi: 10.1016/j.geomorph.2008.07.013

Snyder, N.P., 2009. Studying stream morphology with airborne laser elevation data. Eos, 90 (6), 45-46.

US Fish and Wildlife Service (USFWS), Gulf of Maine Coastal Program (GOMP), 2006. Atlantic Salmon Habitat Survey (ashab3). Office of Geographic Information Systems (MEGIS), Augusta ME http://megis.maine.gov/catalog/

USGS Real-Time Water Data for the Nation. http://waterdata.usgs.gov/nwis/uv [accessed 2 January 2008]

Warner, K., 1963. Natural spawning success of landlocked salmon, Salmo salar. Transactions of the American Fisheries Society, 92, 161-164.

Williams, H., 1978. Tectonic lithofacies map of the Appalachian Orogen. Memorial University of Newfoundland, St John's, Newfoundland, Canada.

Wobus, C., Whipple, K.X., Kirby, E., Snyder, N., Johnston, J., Spyropolou, K., Crosby, B., and Sheehan, D., 2006. Tectonics from topography: Procedure, promise, and pitfalls, in Willett, S.D., Hovius, N., Brandon, M.T., and Fischer, D.M., eds., Tectonics, Climate, and Landscape Evolution: Geological Society of America Special Paper 398, Penrose Conference Series, p. 55-74.

Wolman, M.G., 1954. A method for sampling coarse river-bed material. EOS (Transactions, American Geophysical Union), 35, 951-956. 


\section{APPENDIX}

Appendix 1. Grain size plots for each survey point along the study rivers, created from pebble count data gathered and measured using the method described by Wolman (1954).................................................. 2

I. Narraguagus River..............................................

II. Jacquet River....................................................

Appendix 2. Field measurements of active and high-flow width and depth, as well as observed grain sizes $\left(D_{16}, D_{50}\right.$ and $\left.D_{84}\right)$ for the study rivers.............61

I. Narraguagus River.............................................. 62

II. Jacquet River...............................................66

Appendix 3. Predicted grain sizes for the study rivers.........................69

Appendix 4. Calculated basal shear stress $\left(\tau_{b}\right)$ and Shields parameter $\left(\tau^{*}\right)$ values for the study rivers................................................... 87

I. Narraguagus River........................................... 88

II. Jacquet River........................................... 105 


\section{Appendix 1.}

Grain size plots for each survey point along the study rivers, created from pebble count data gathered and measured using the method described by Wolman (1954). 

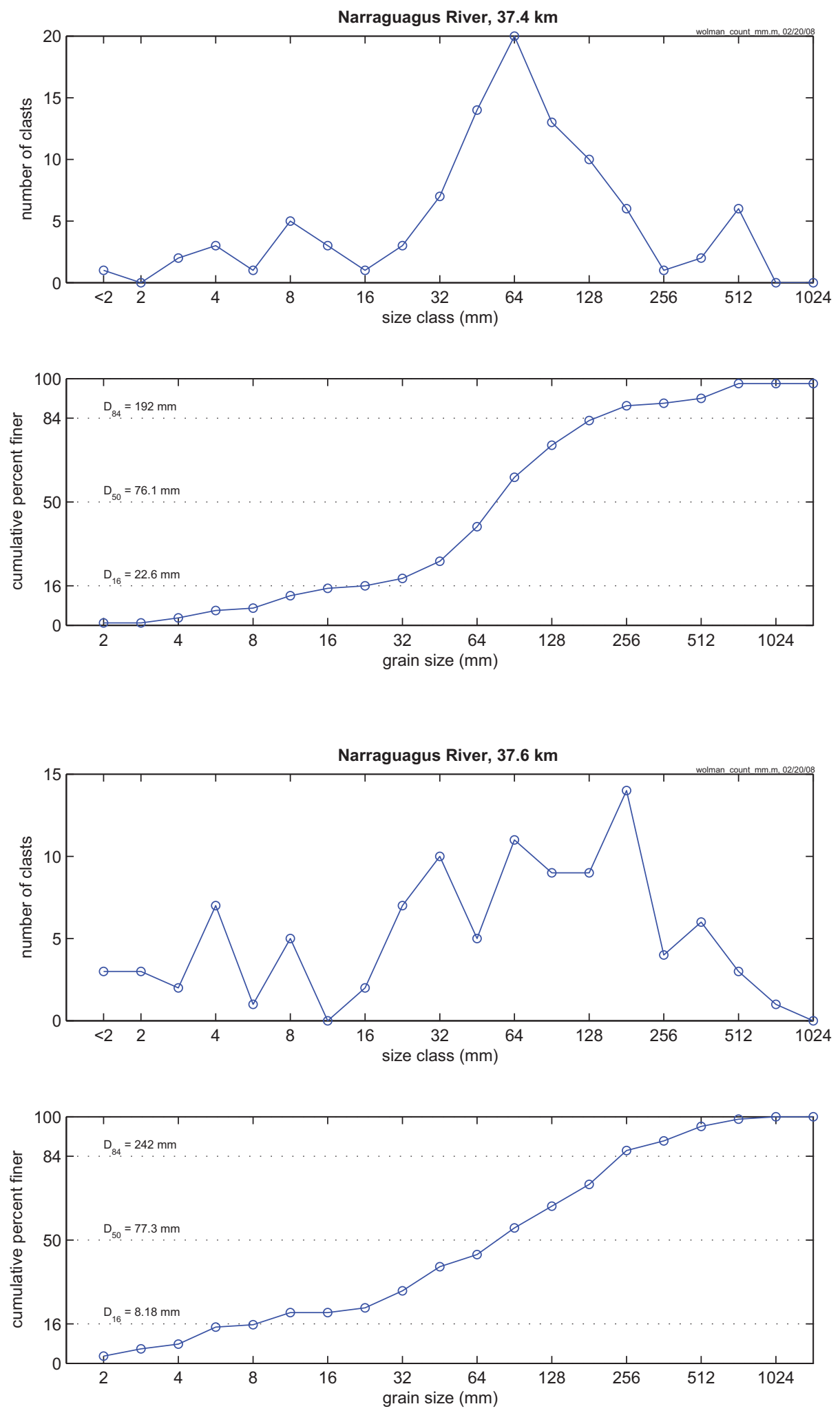

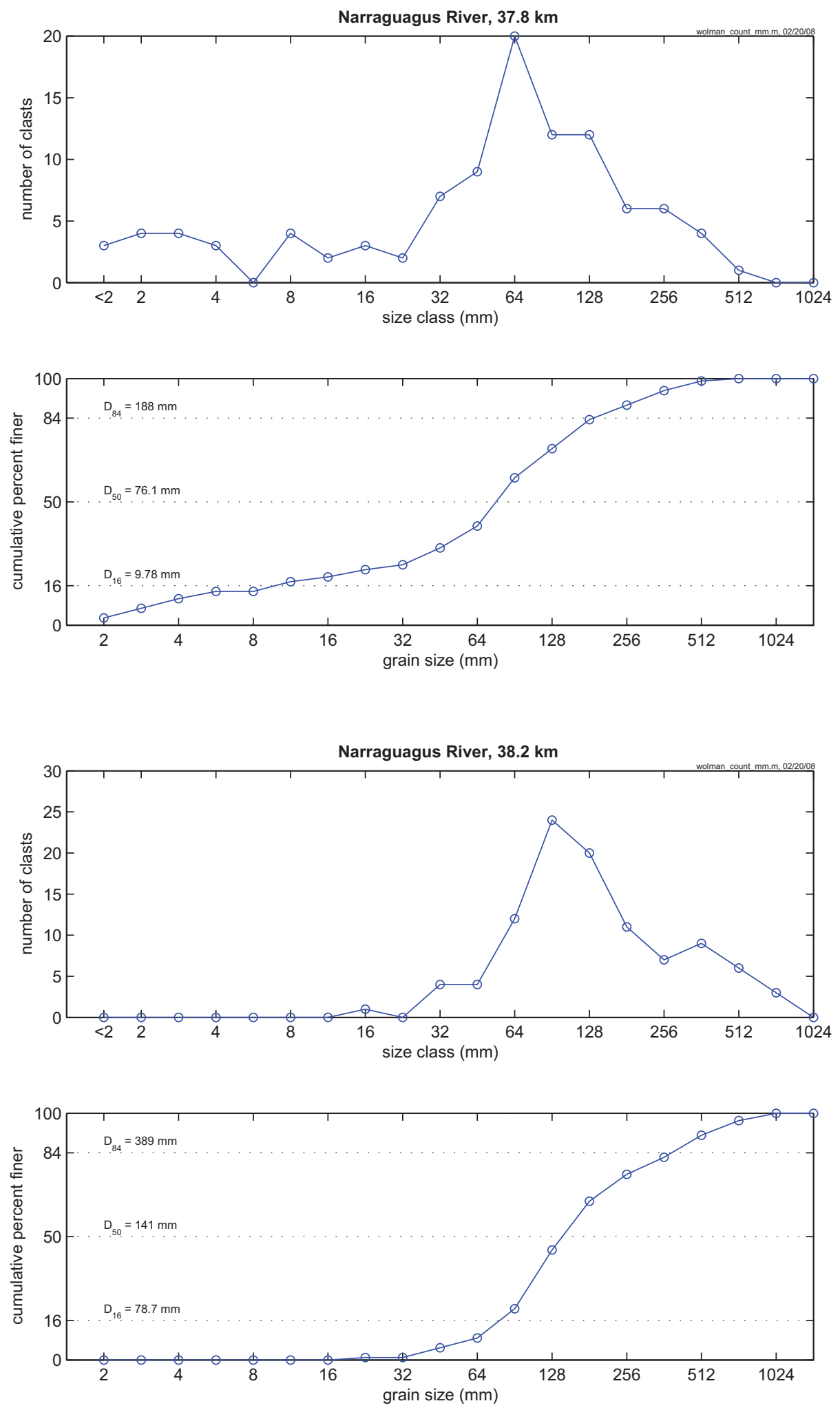

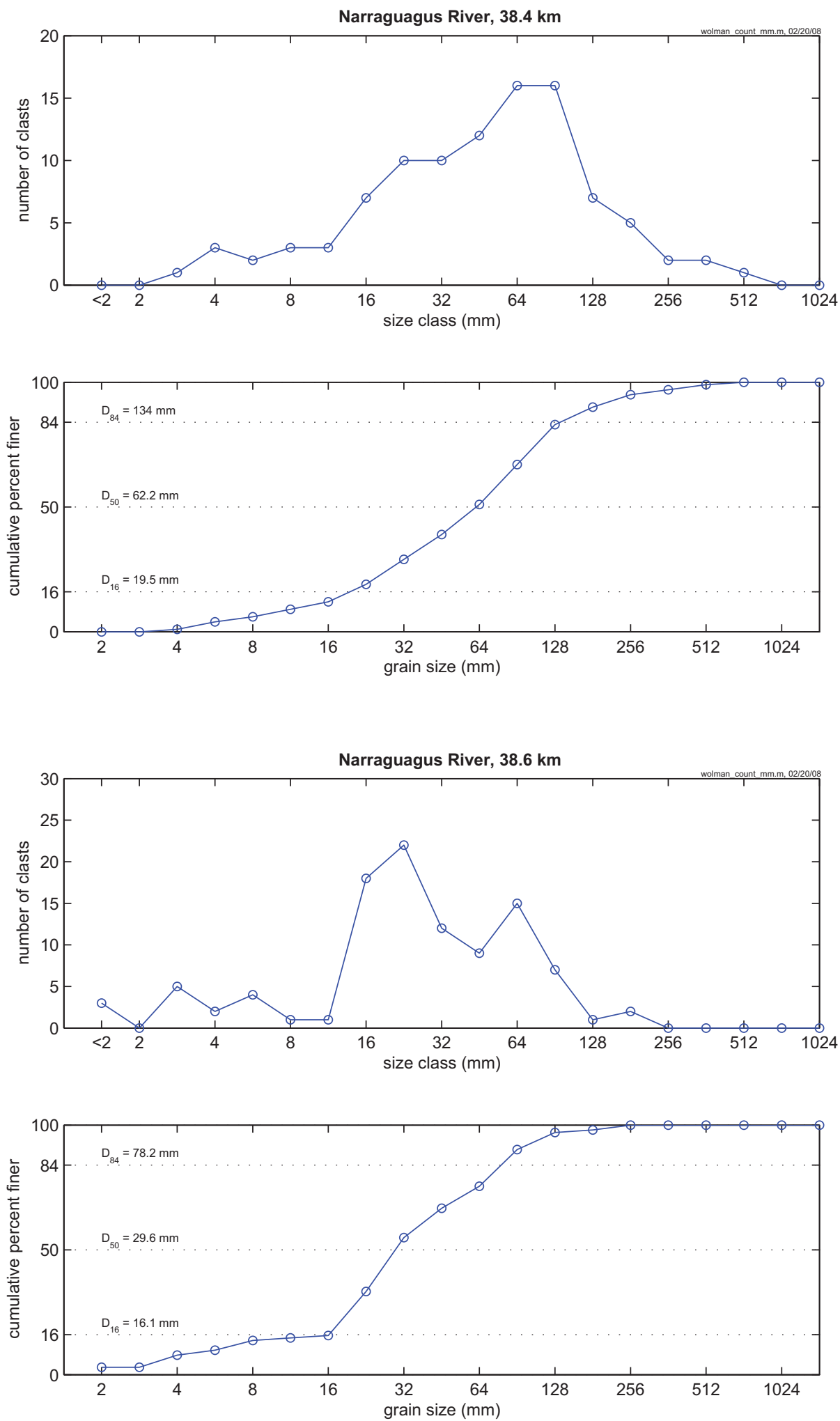

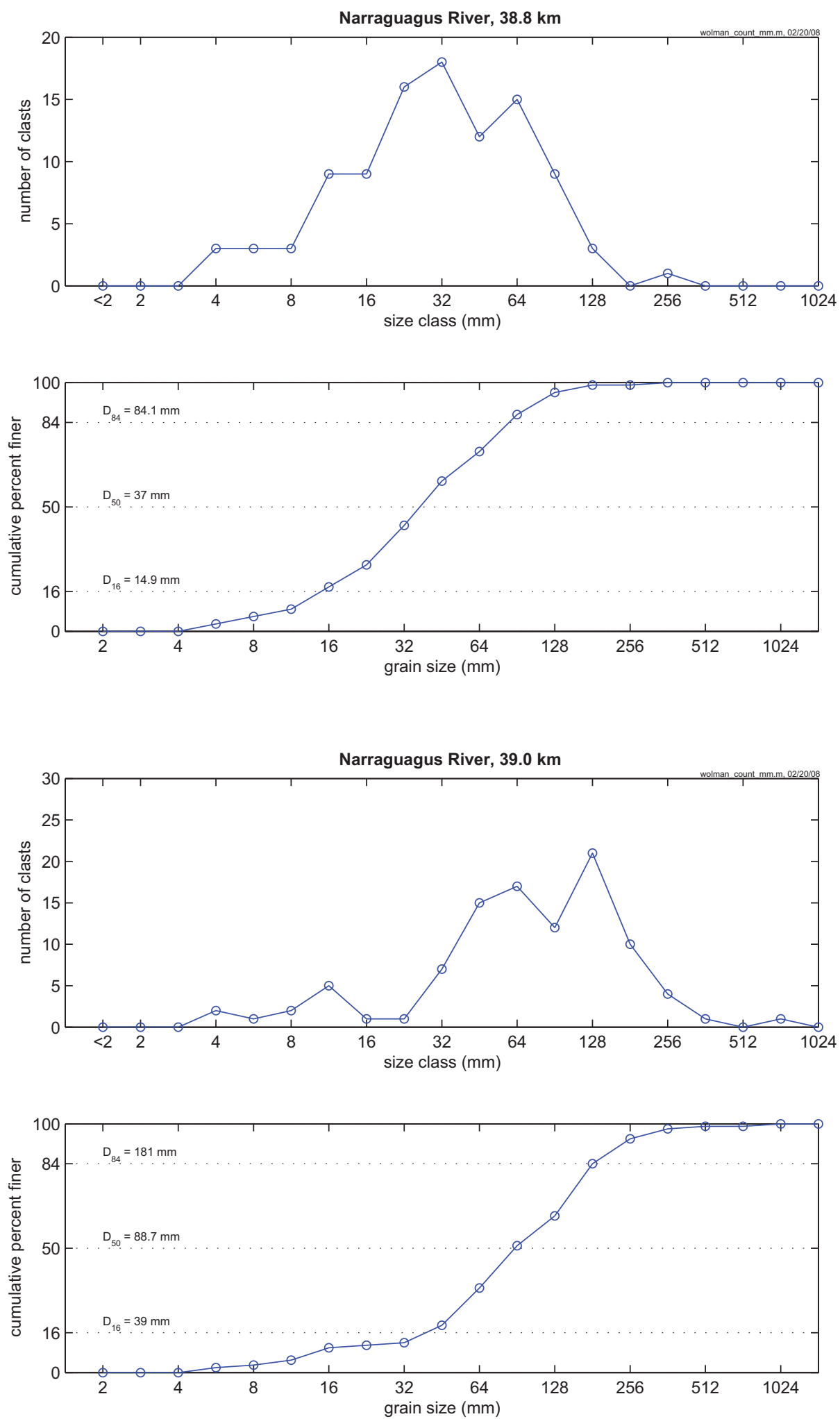

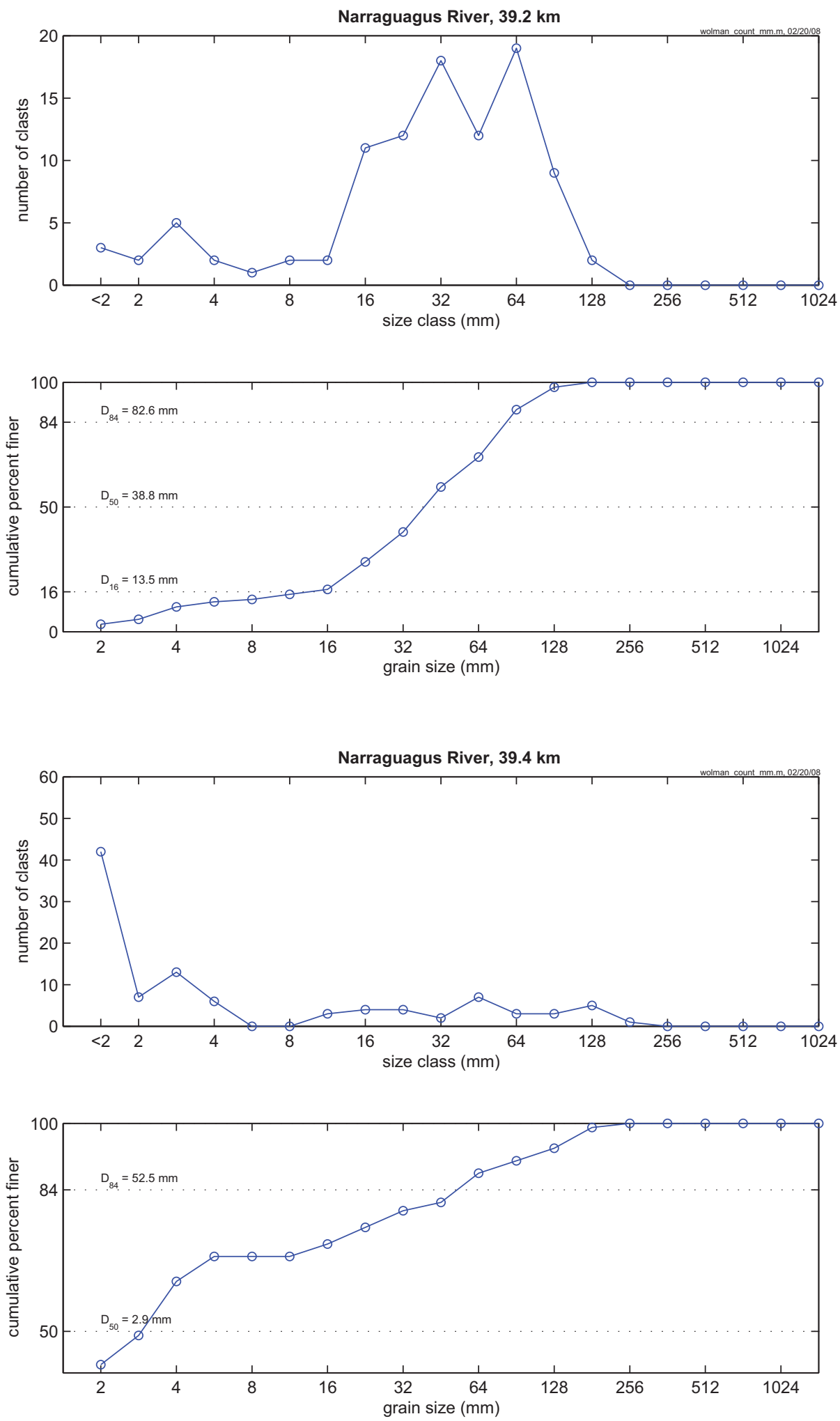

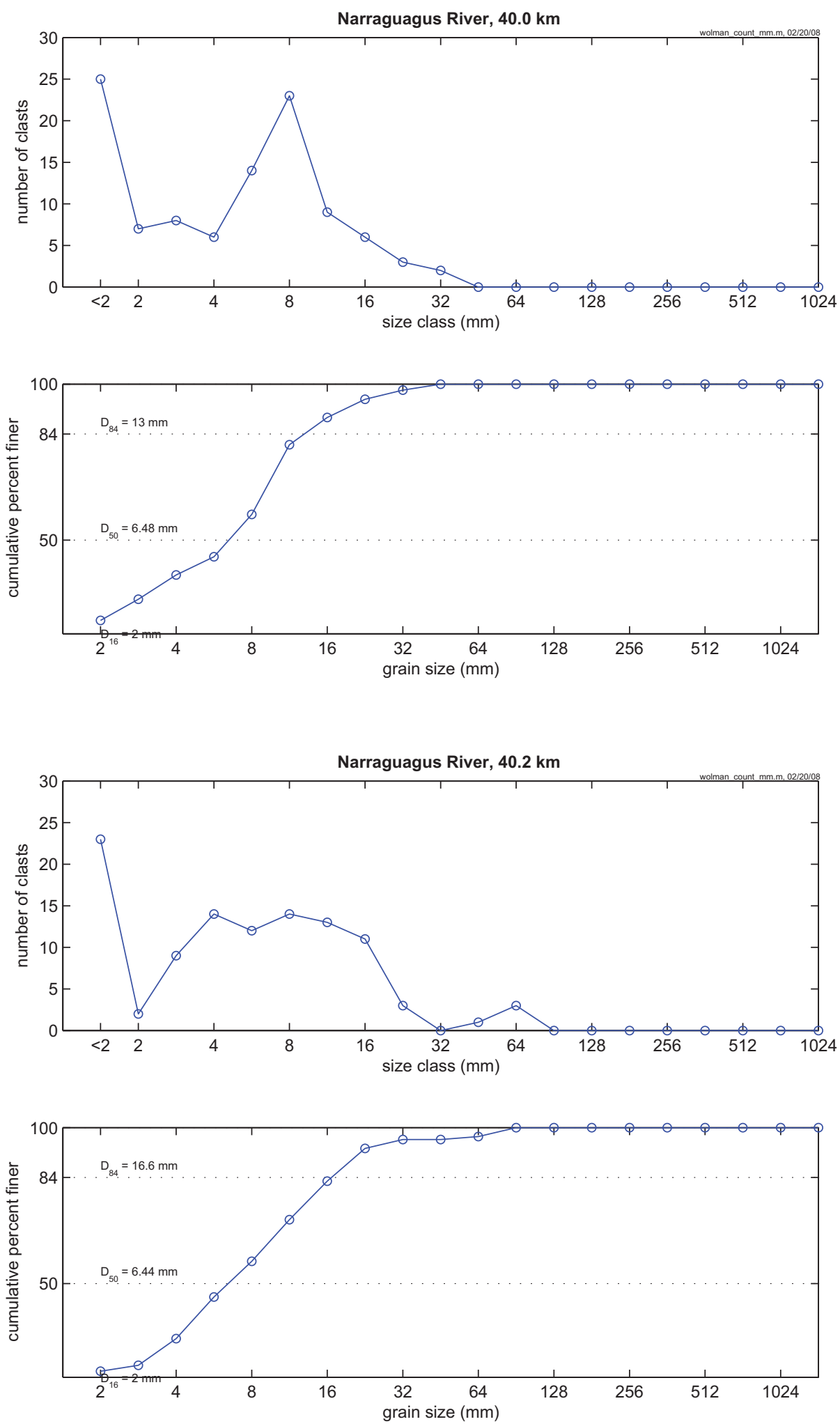

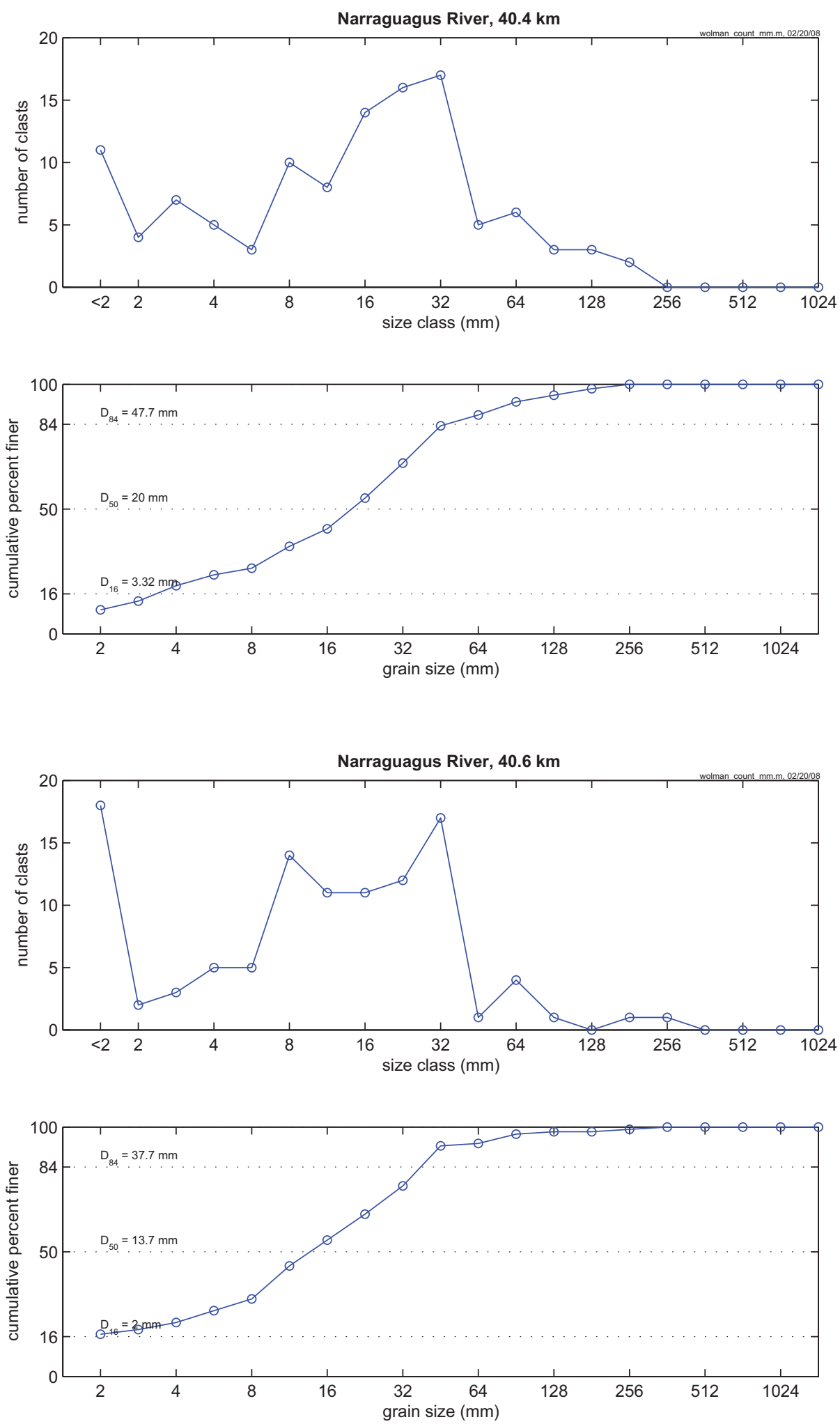

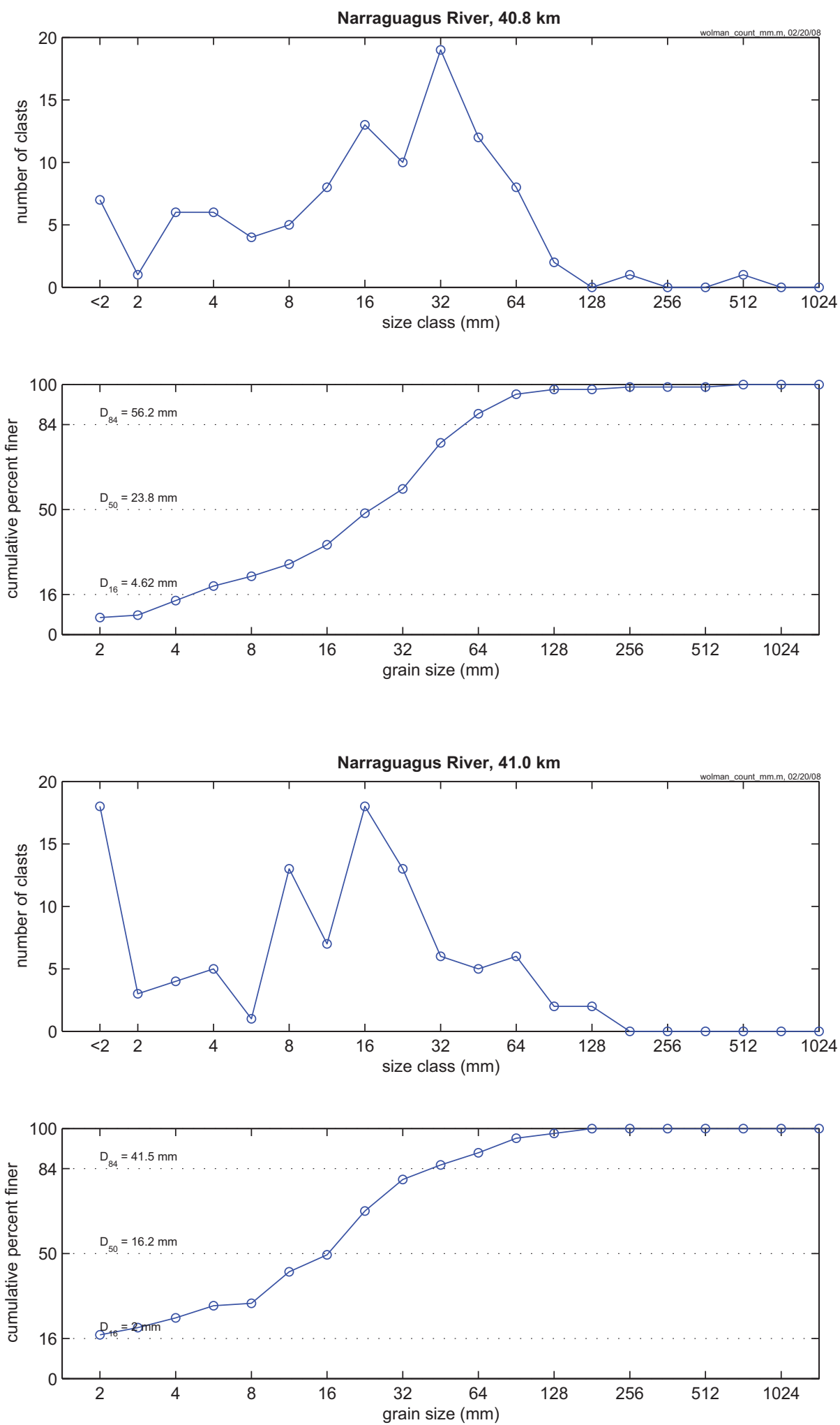

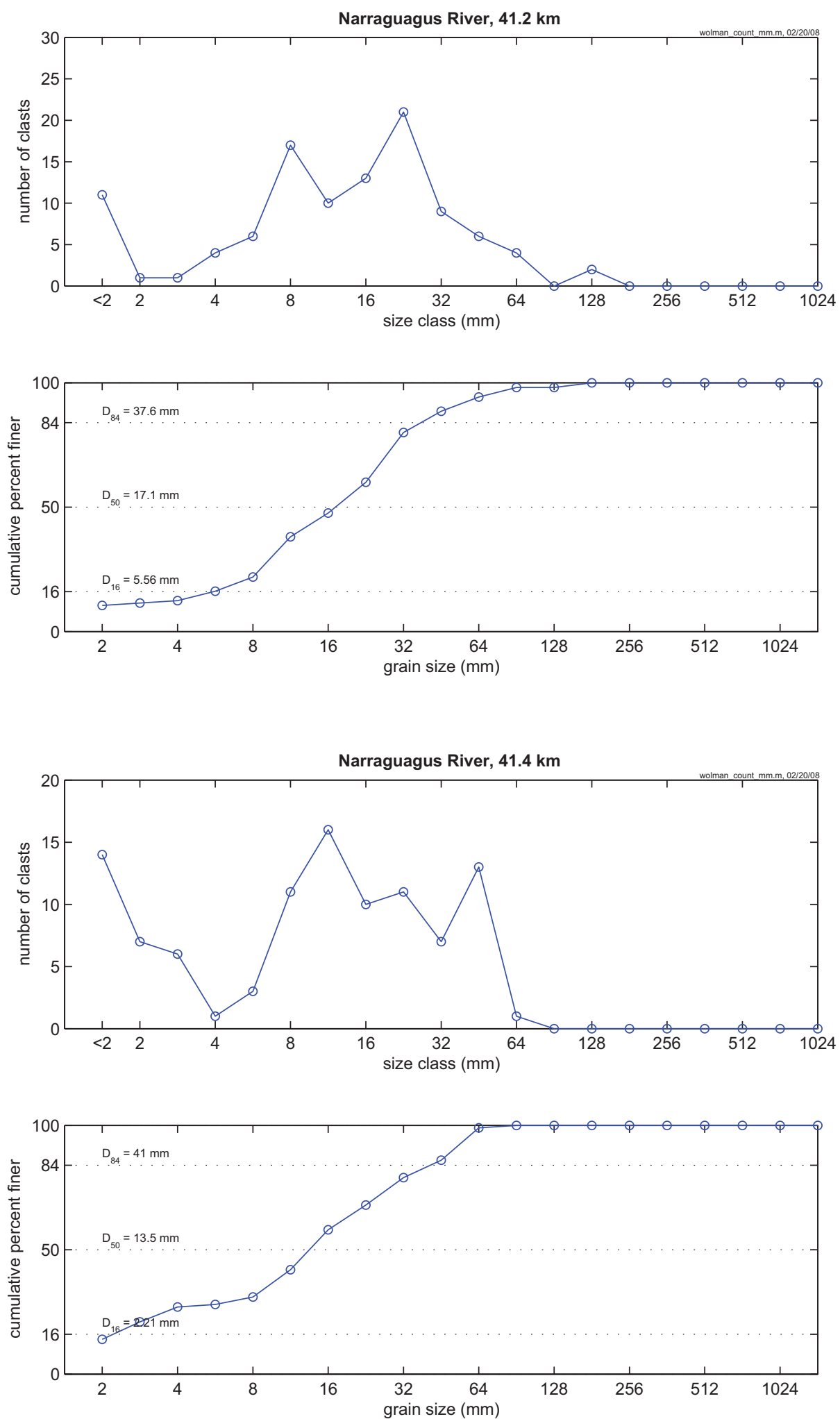

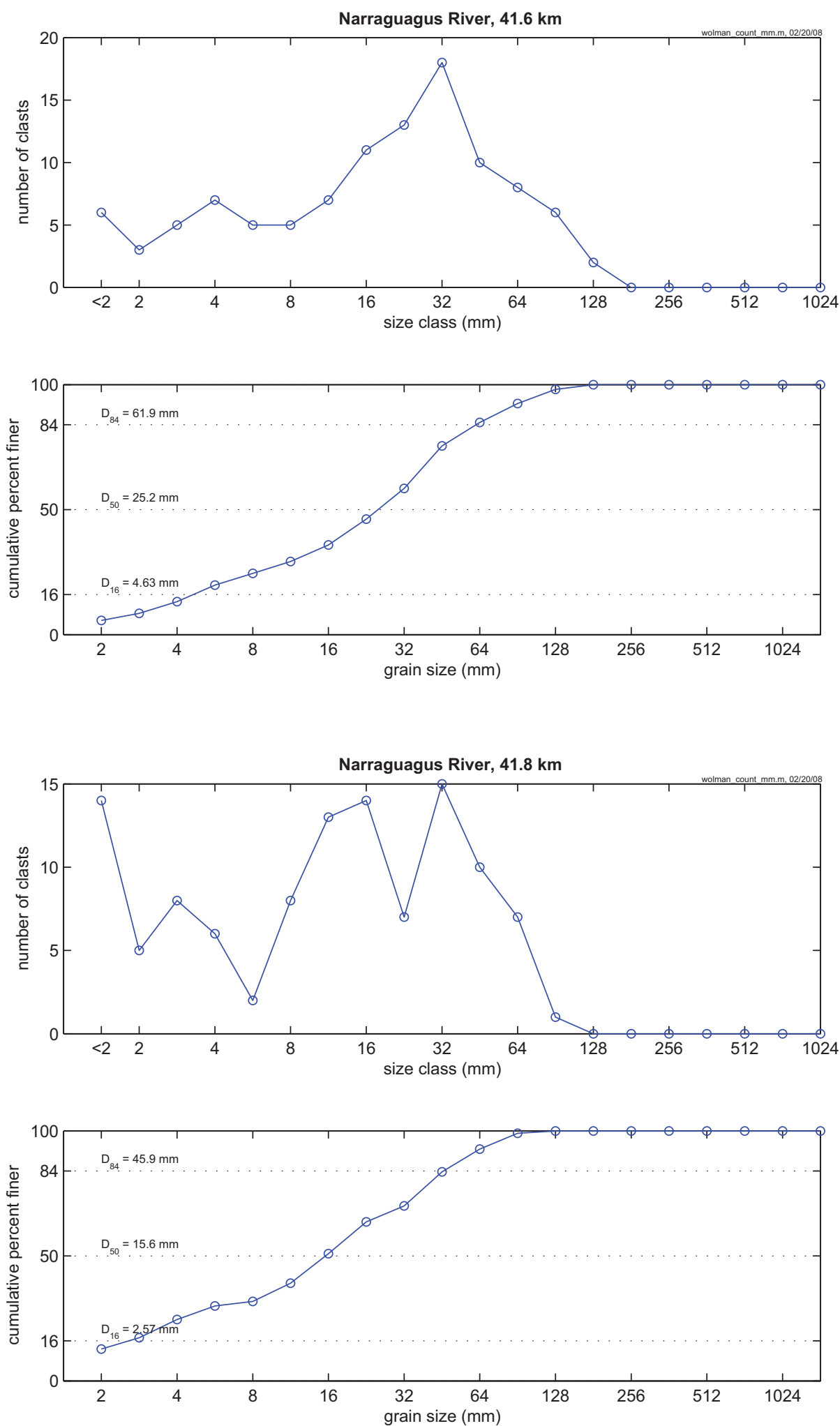

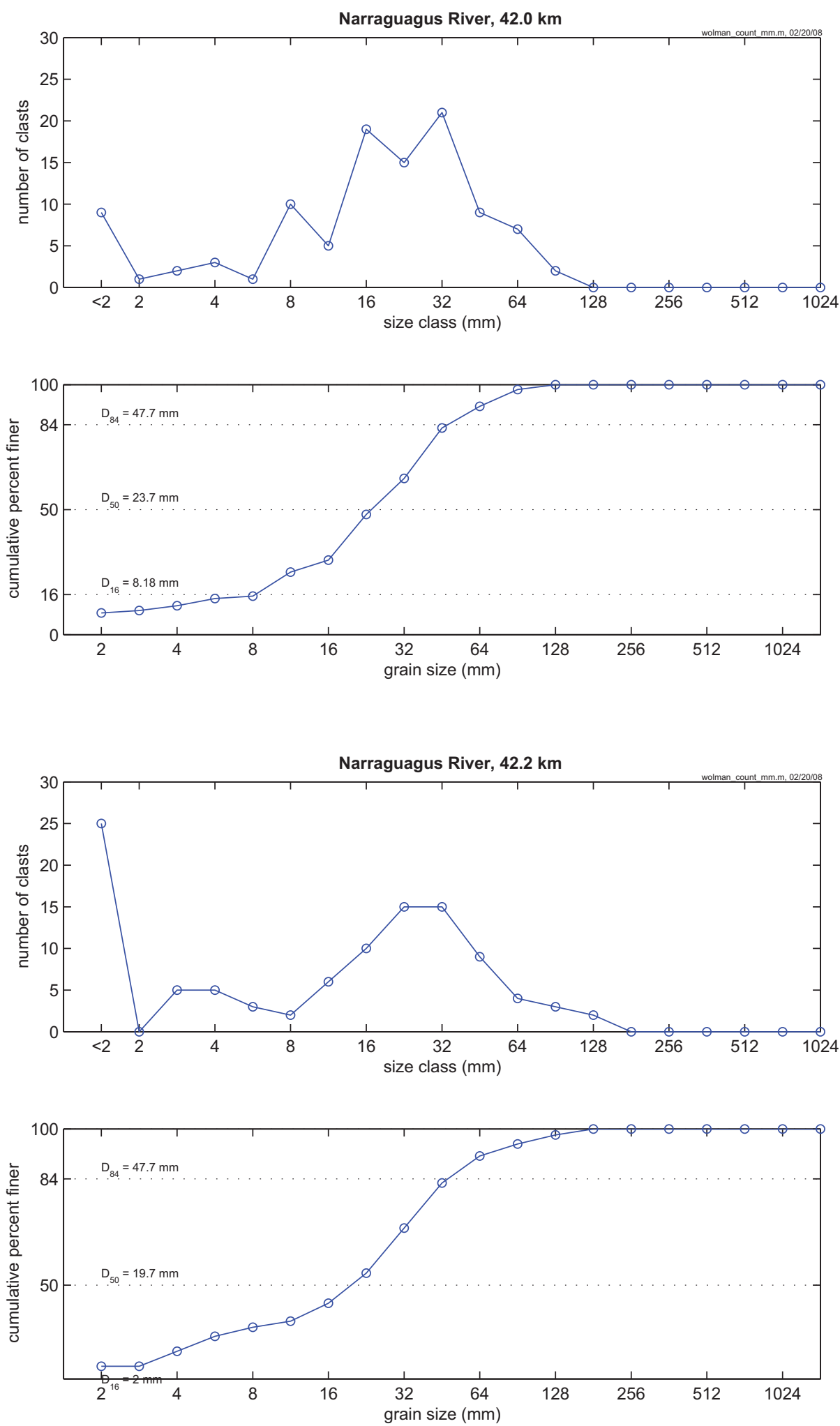

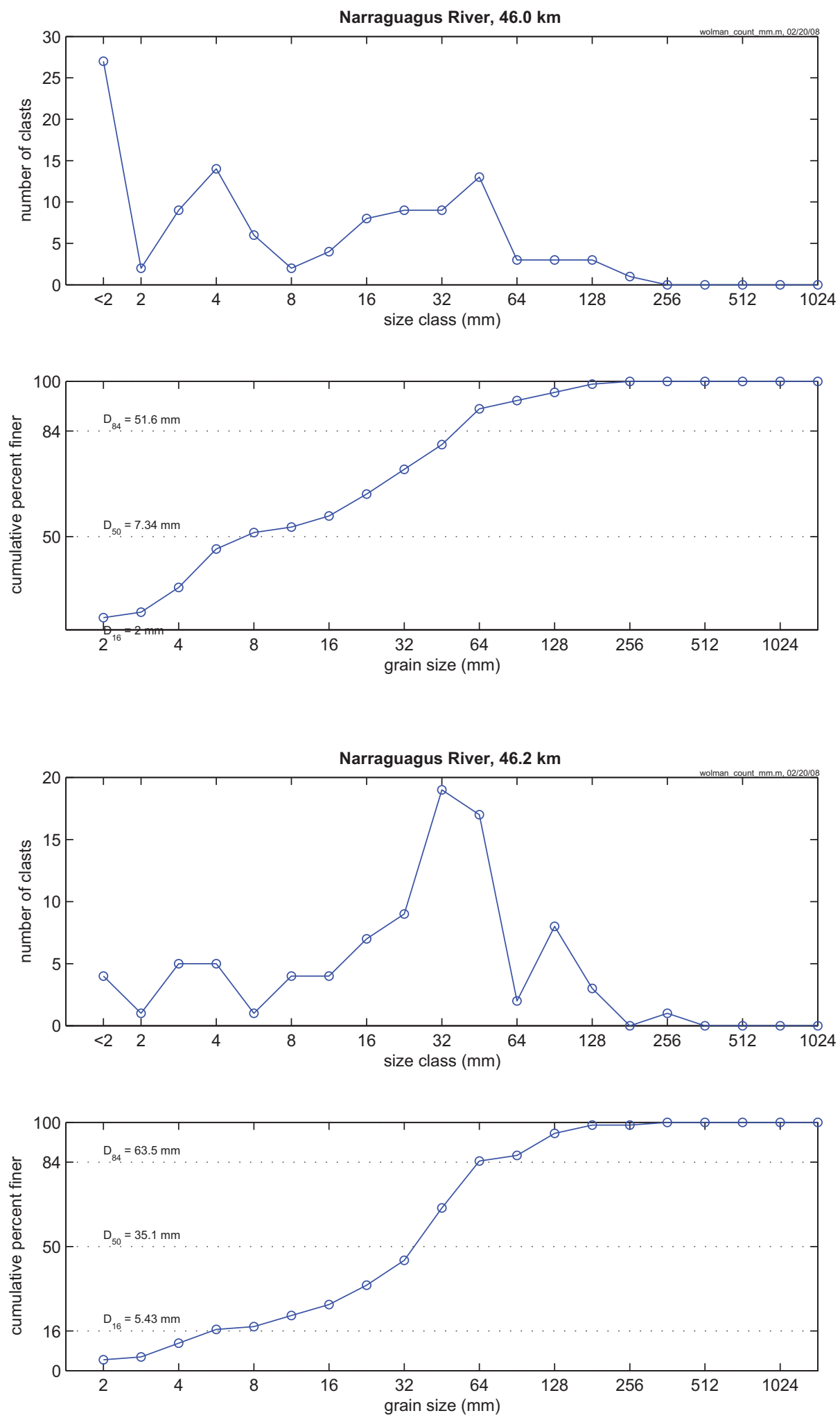

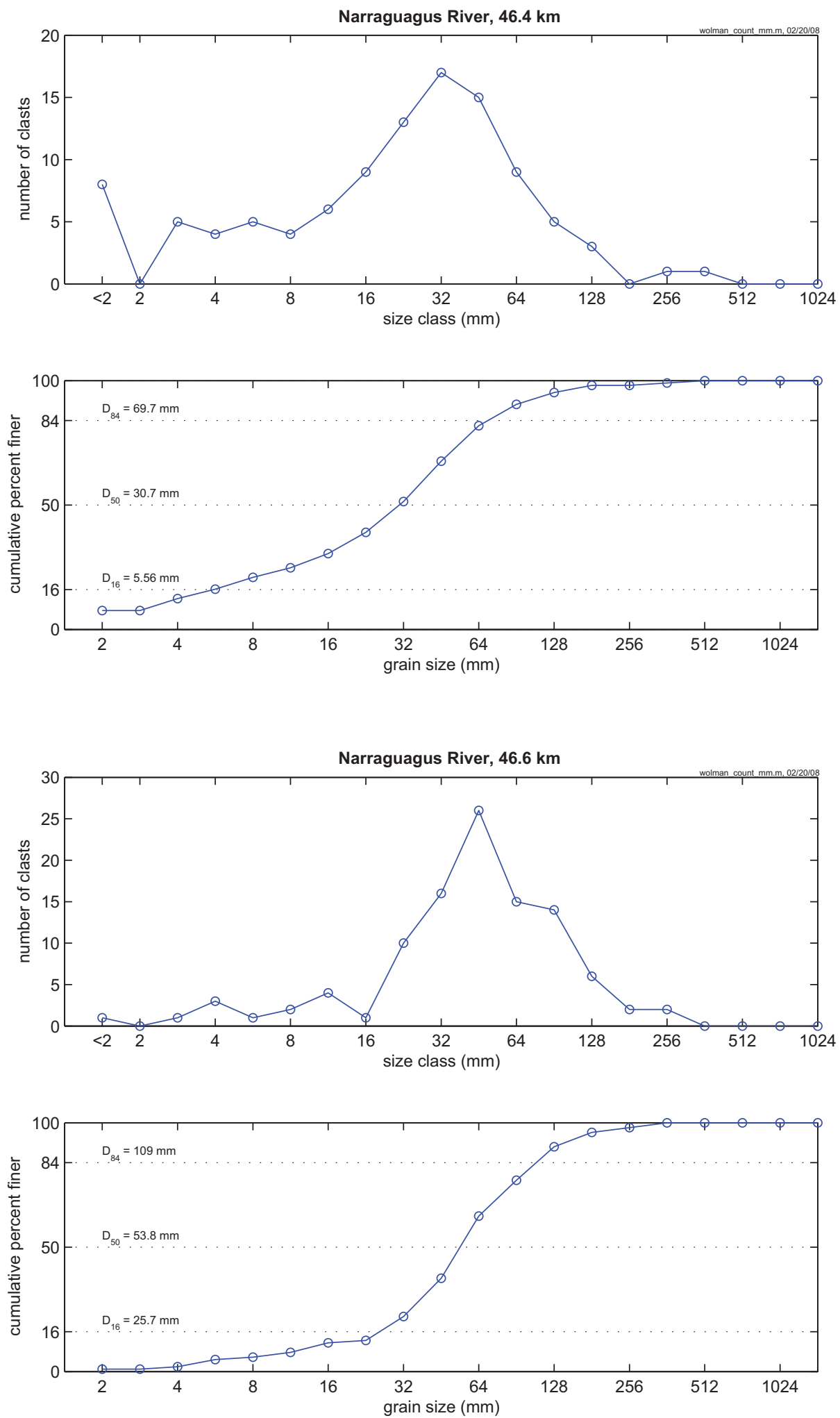

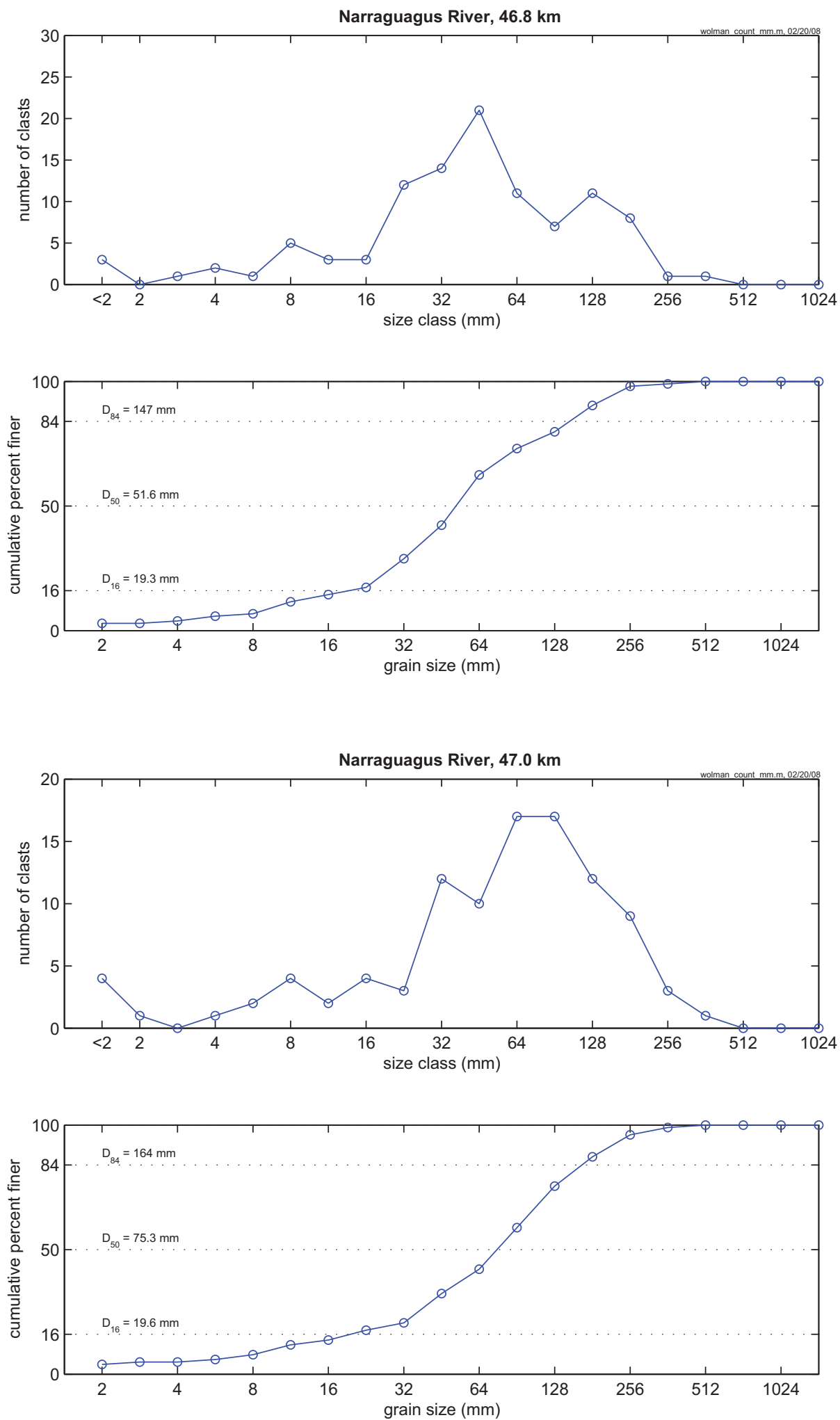

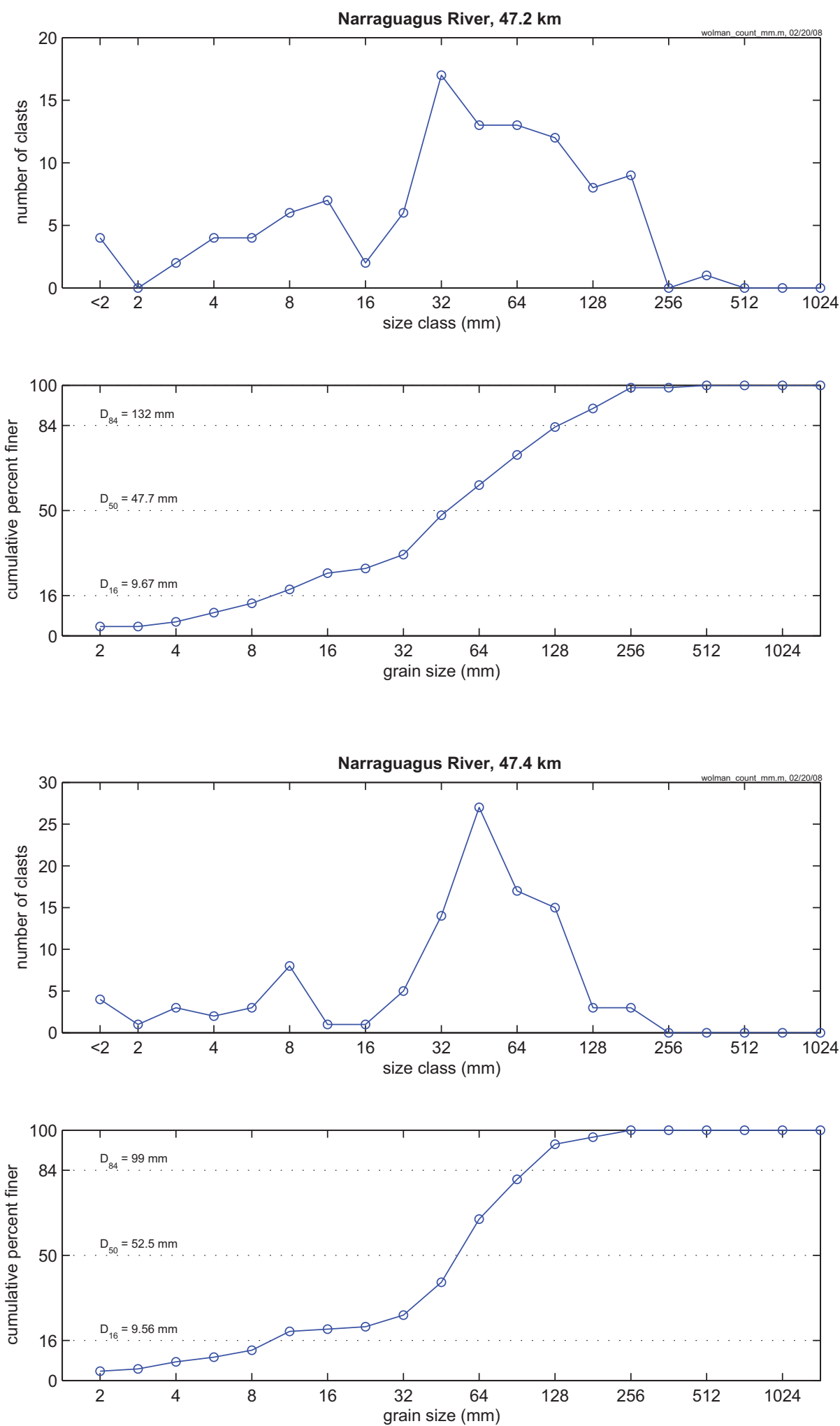

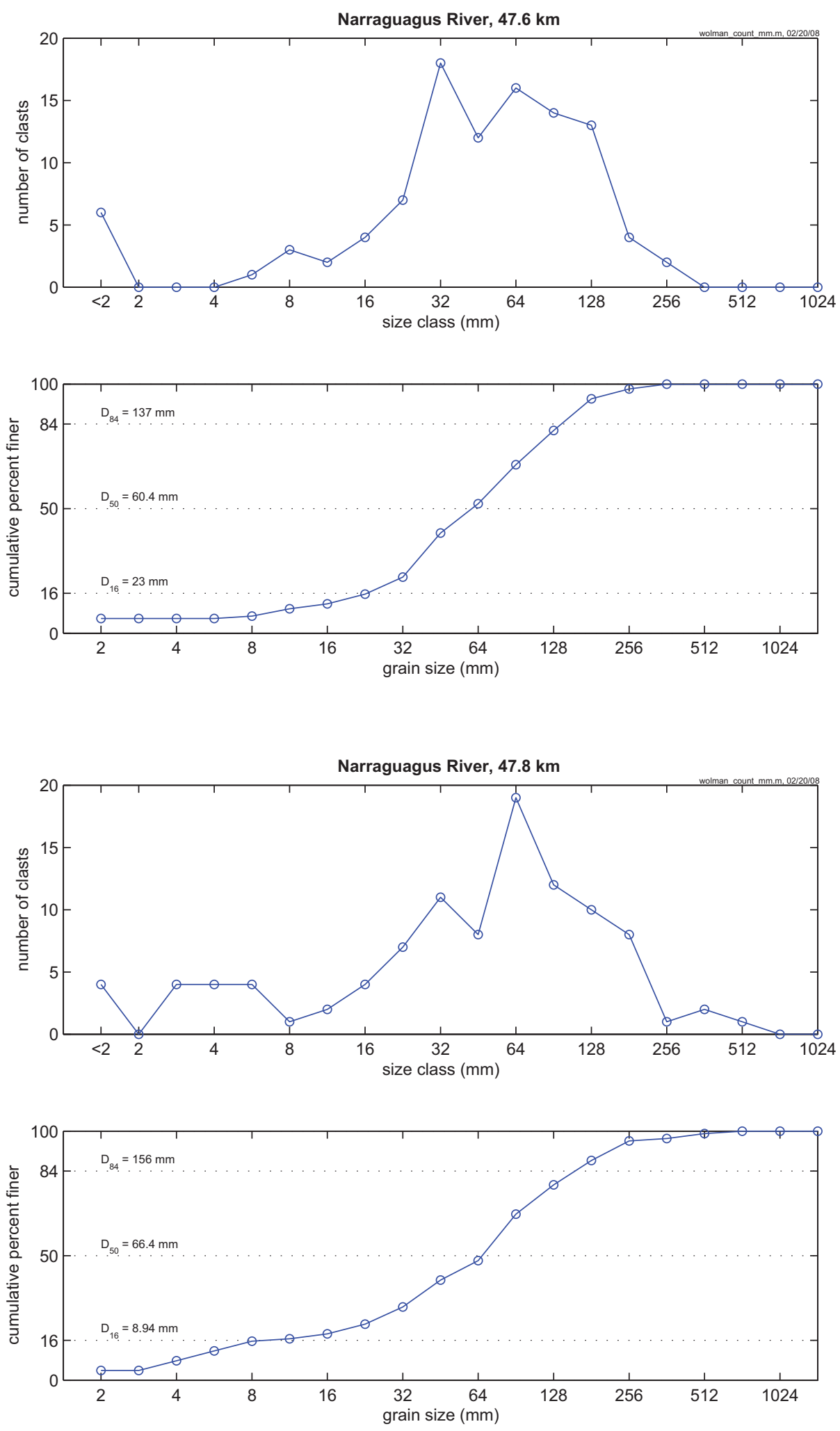

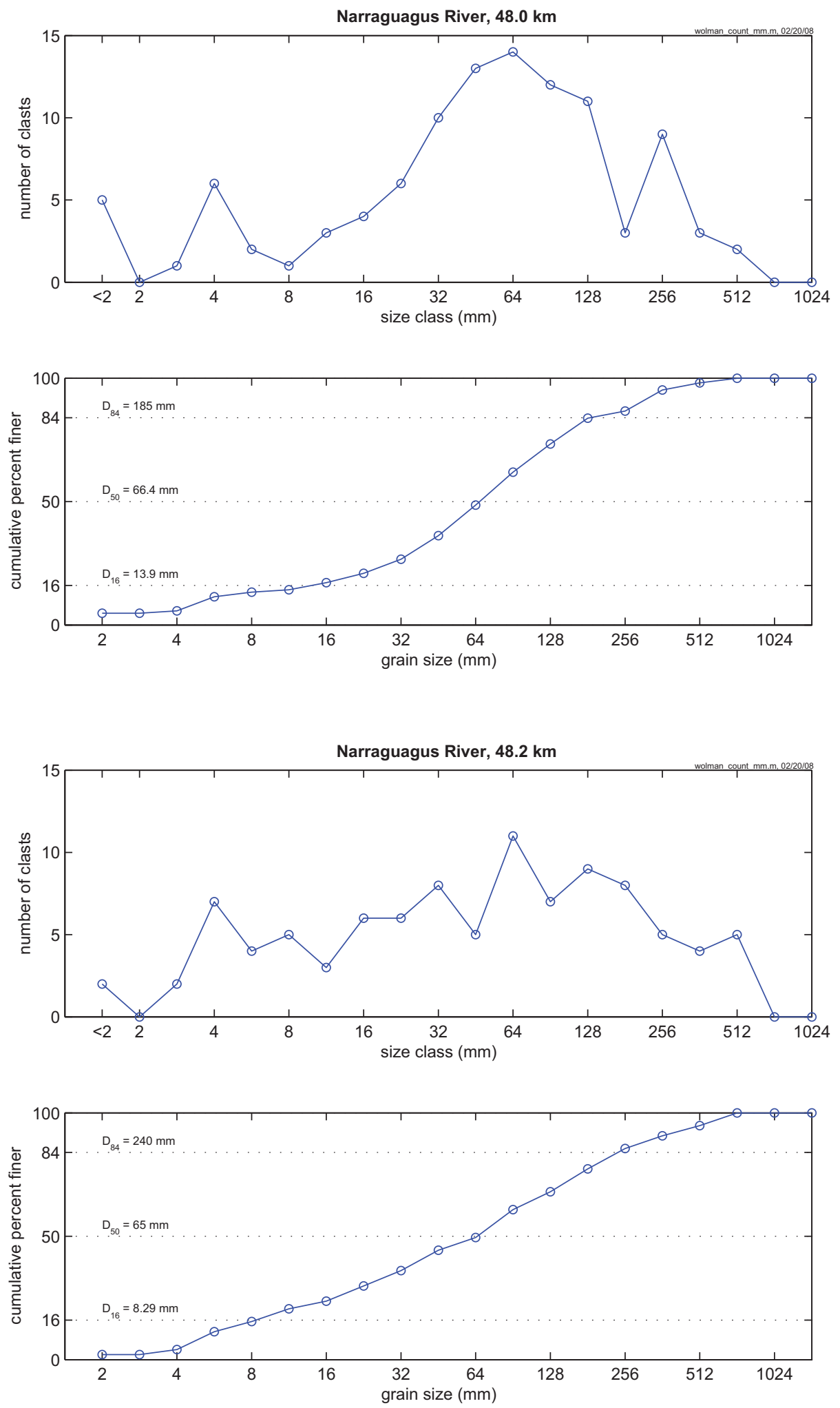

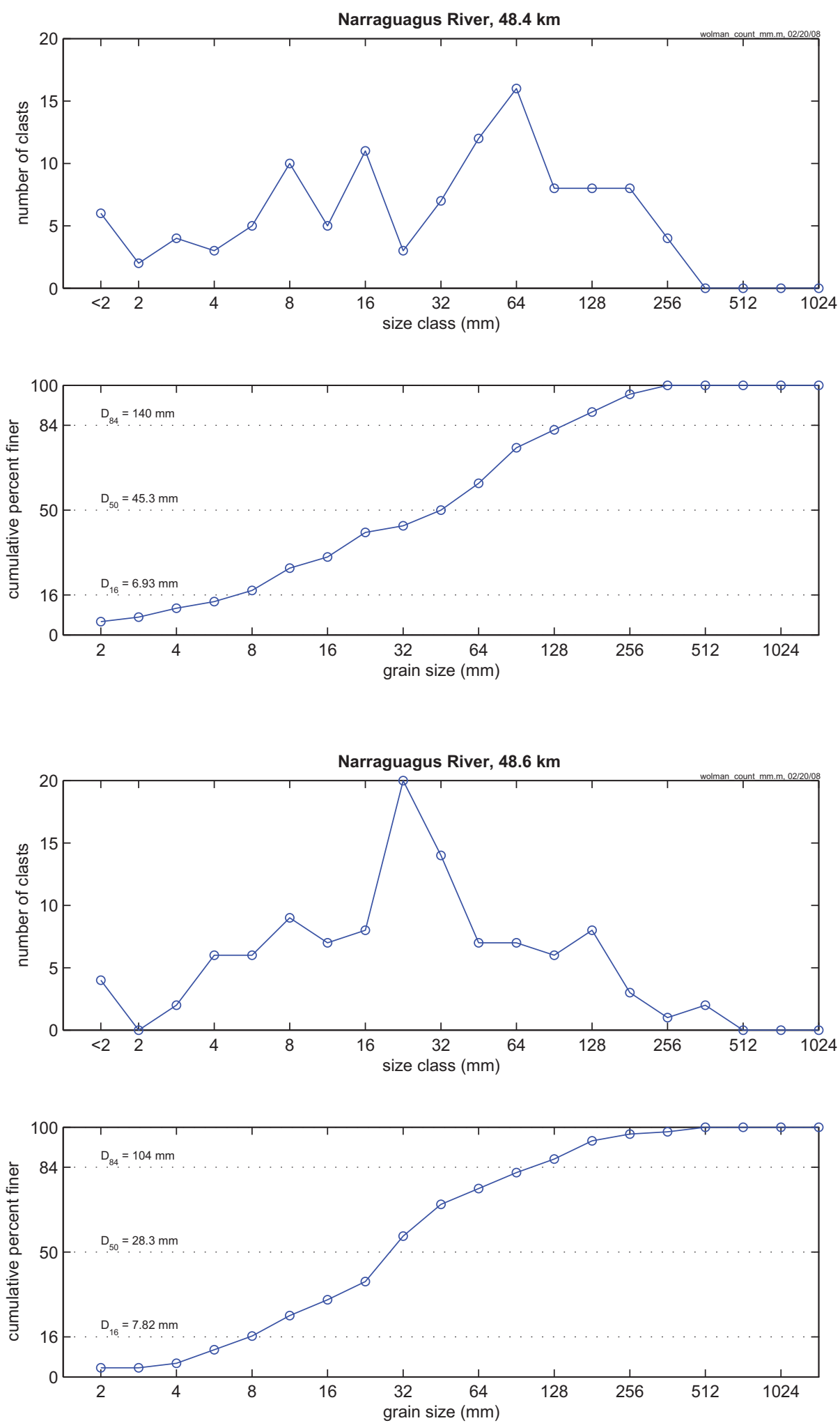

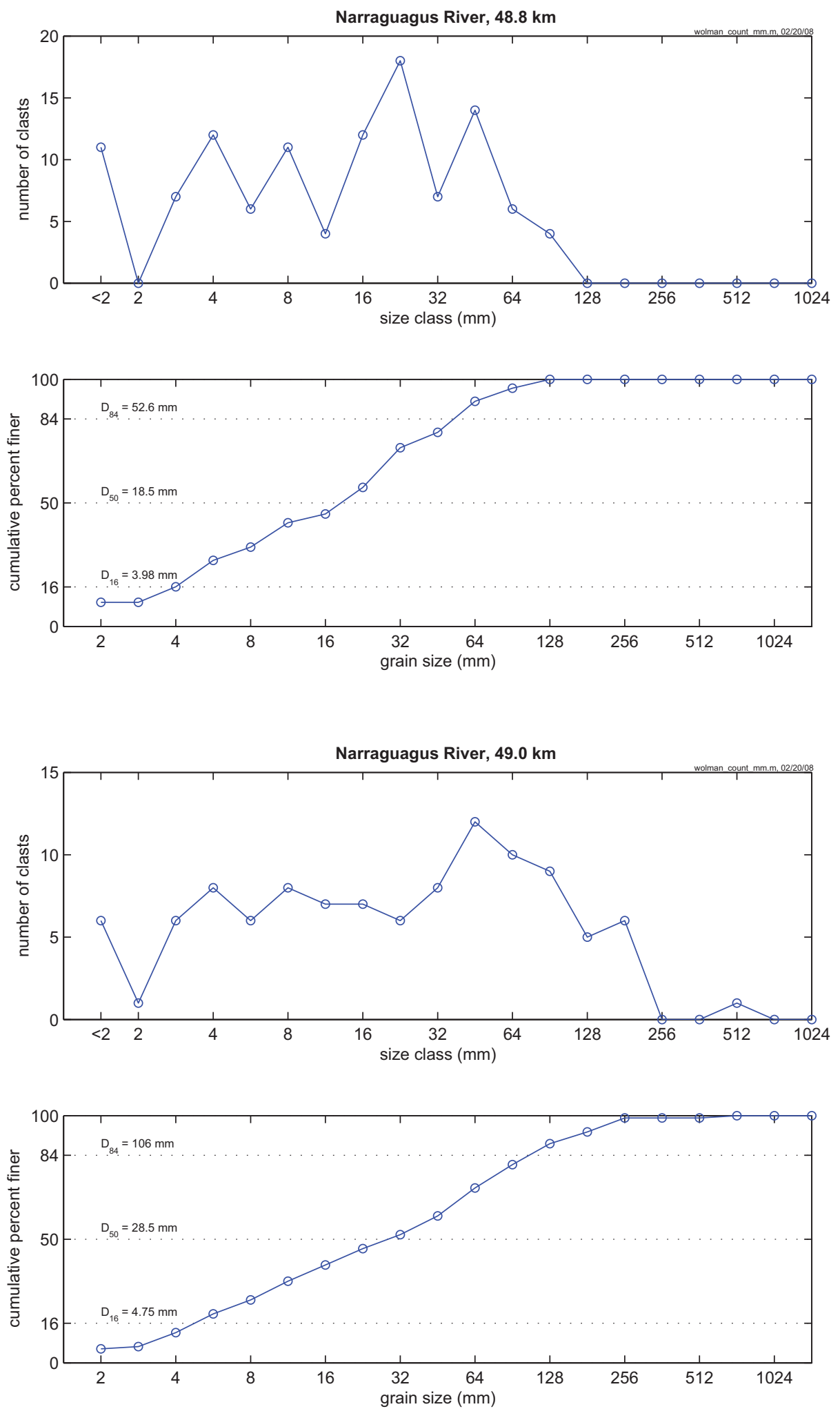

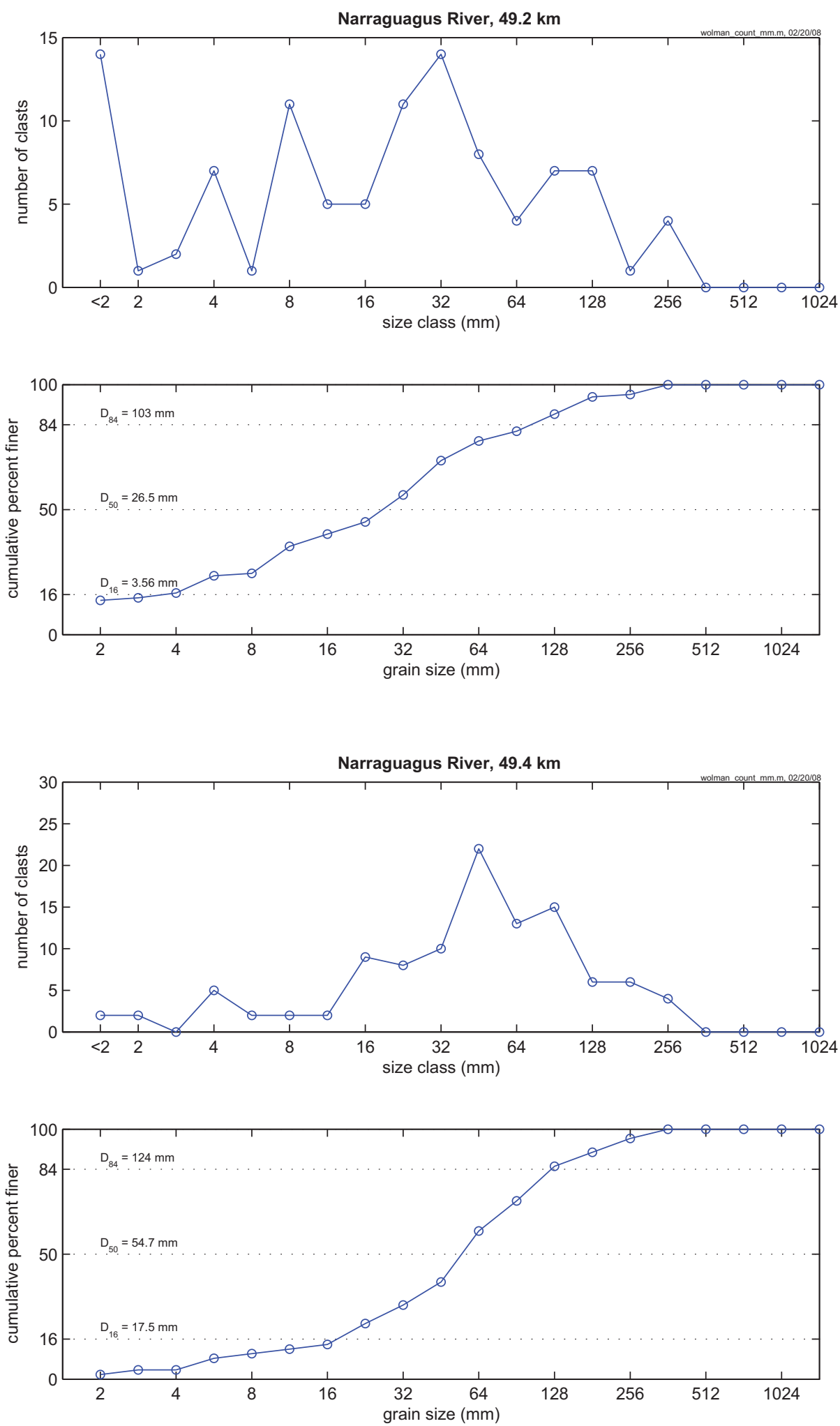

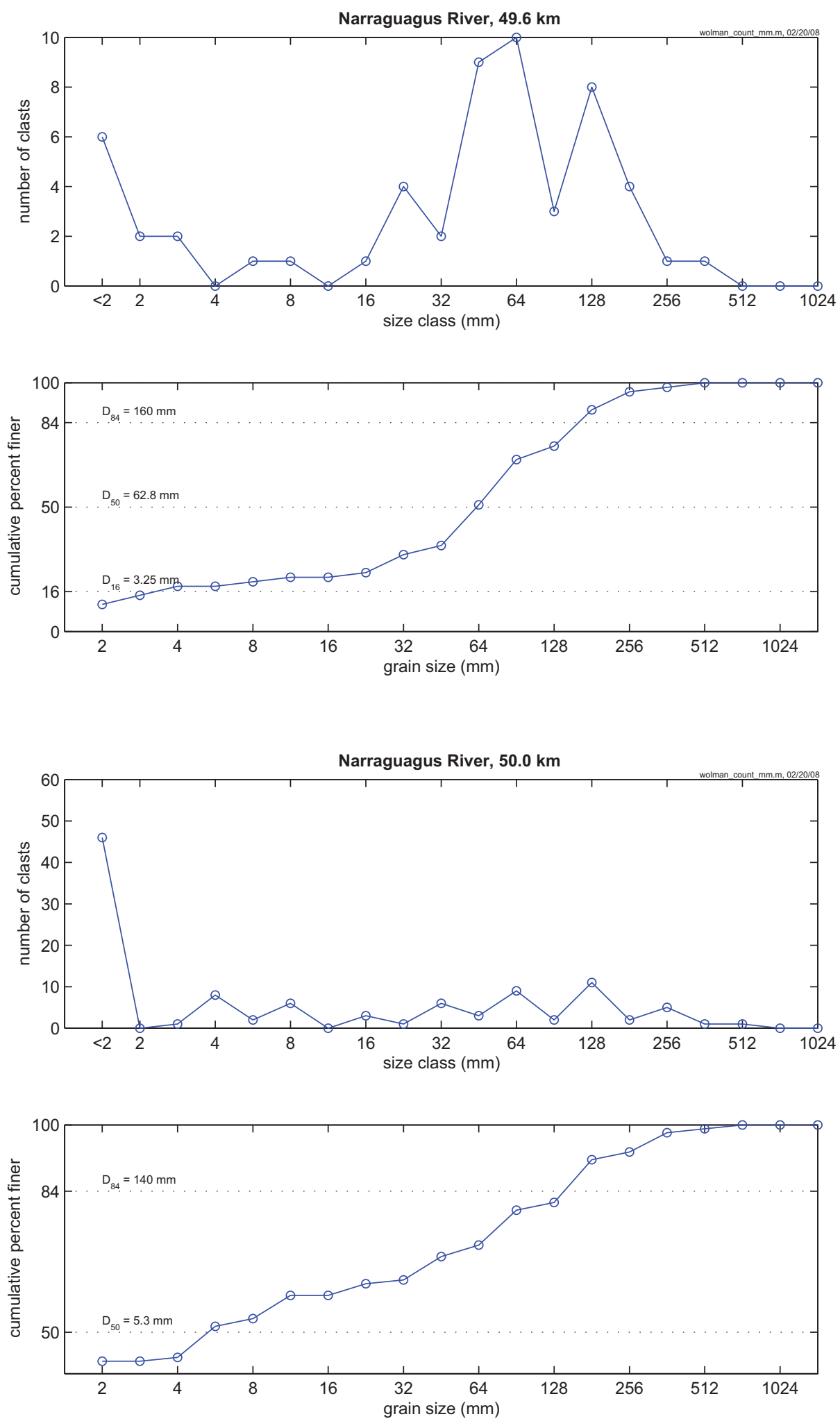

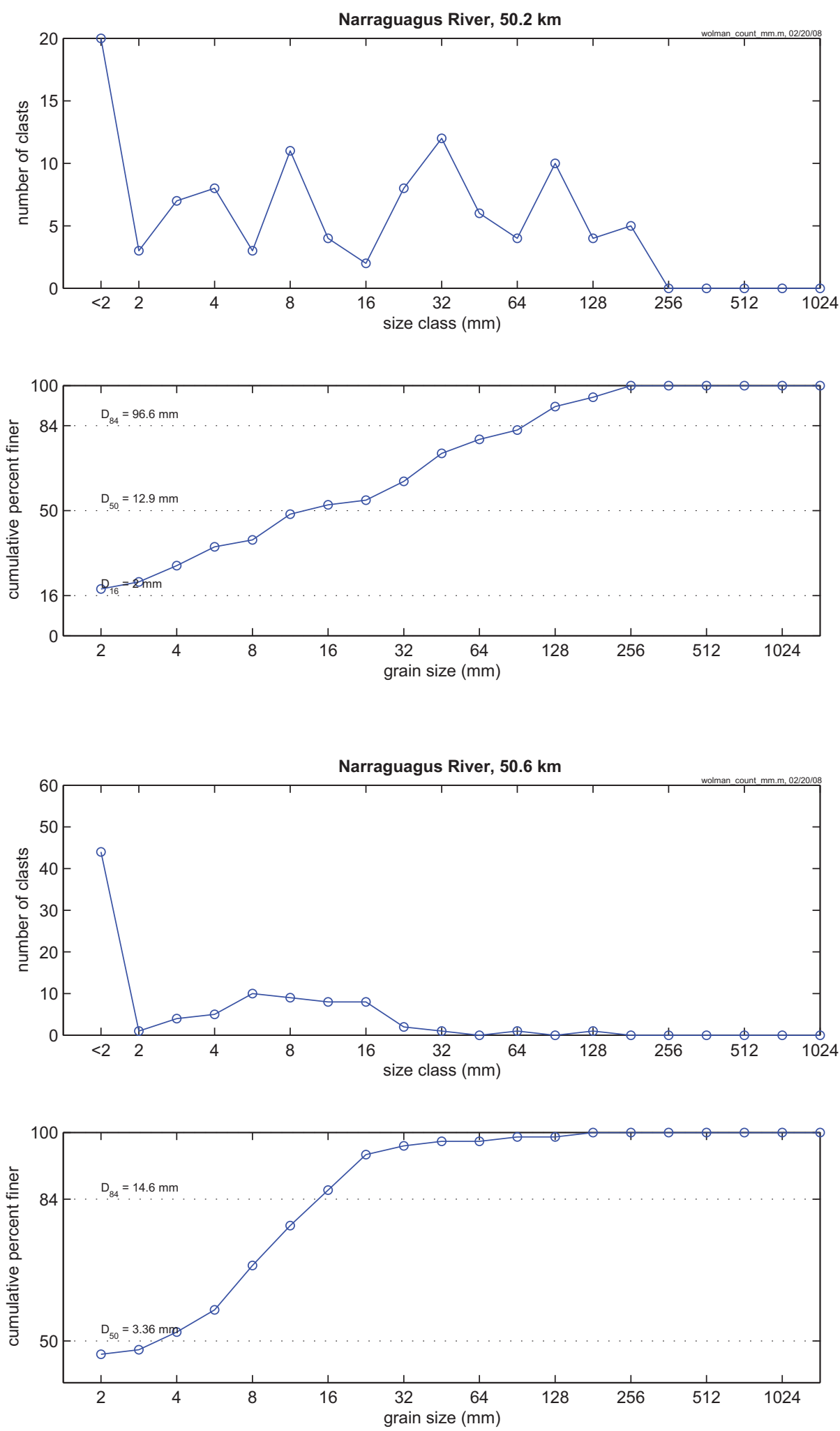

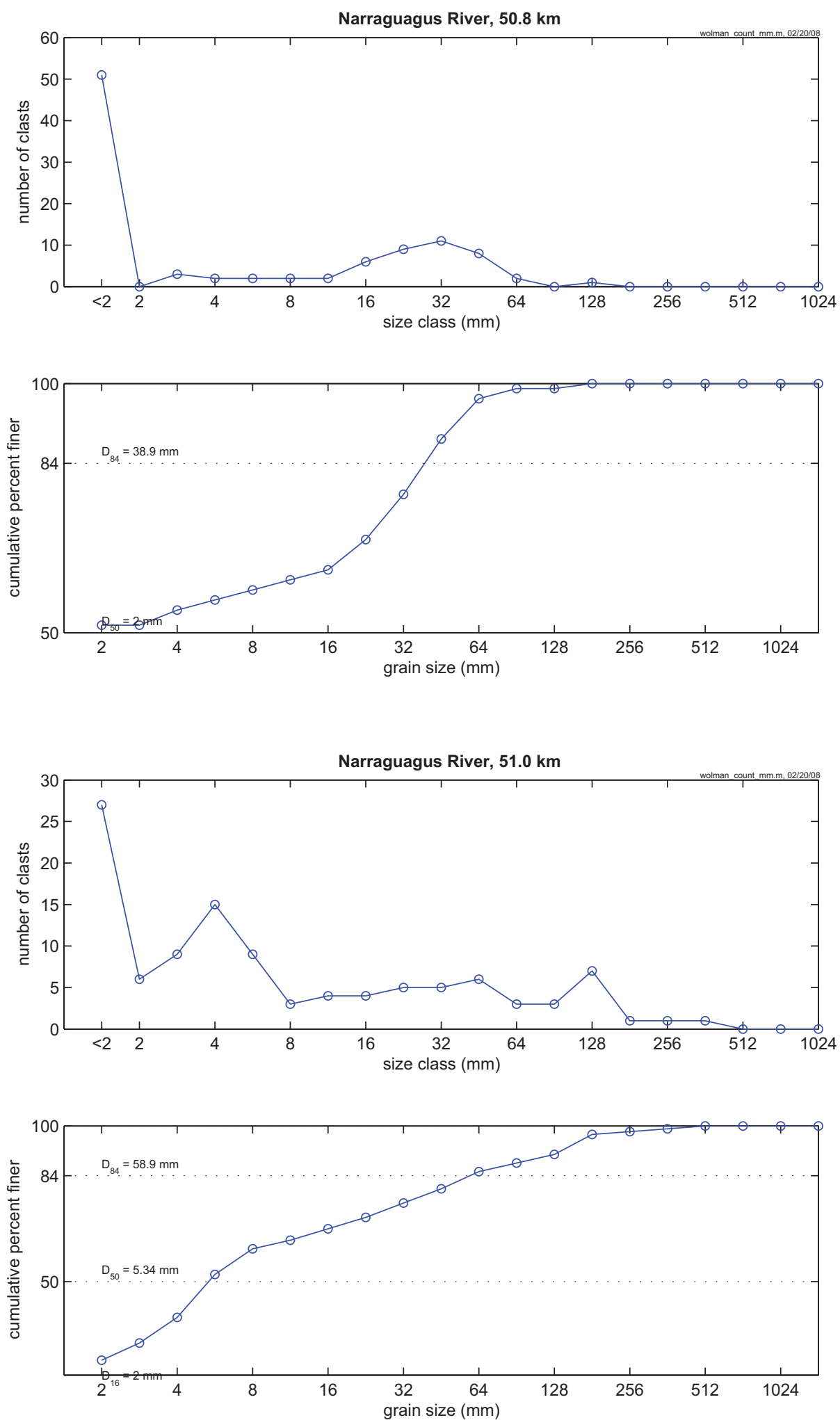

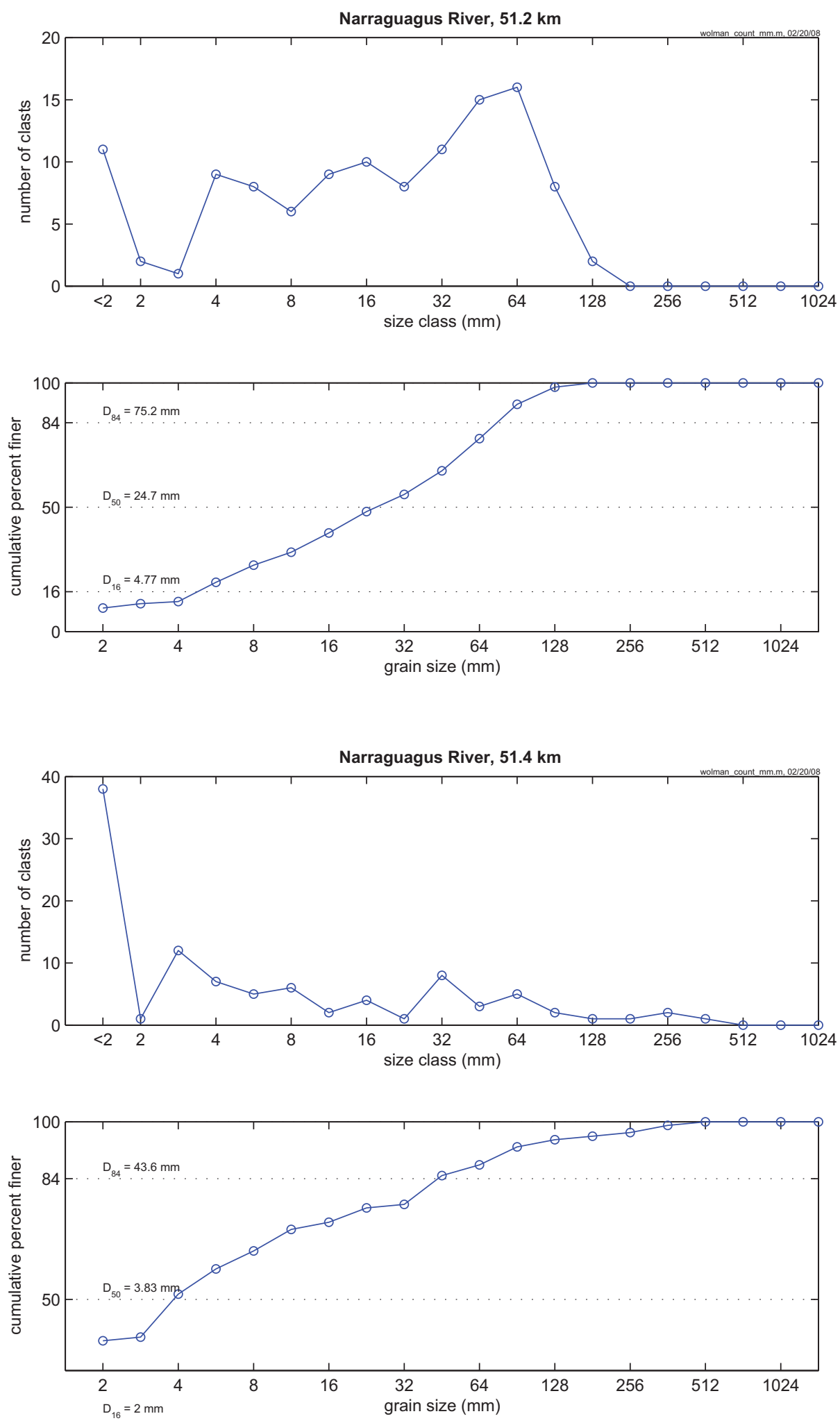

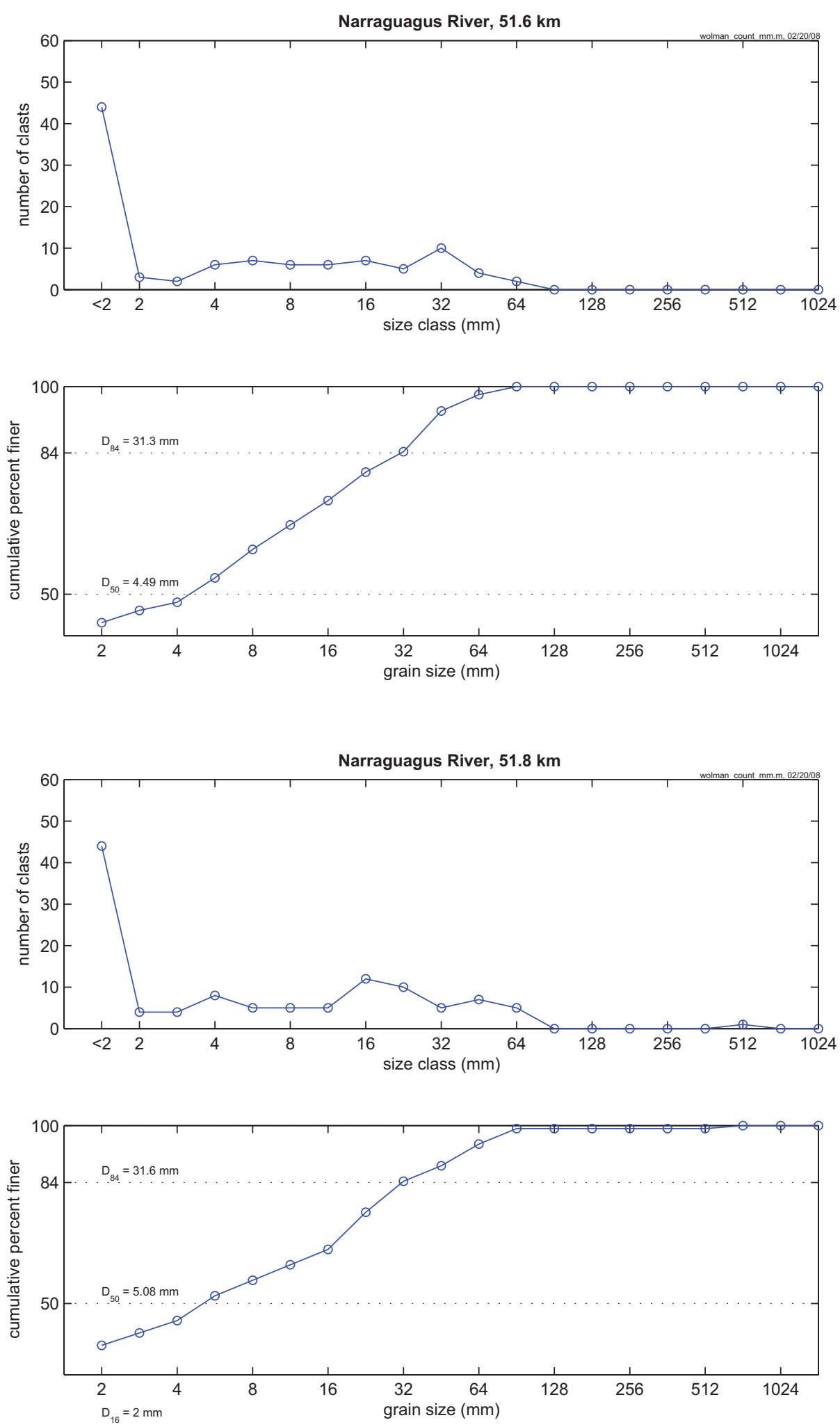

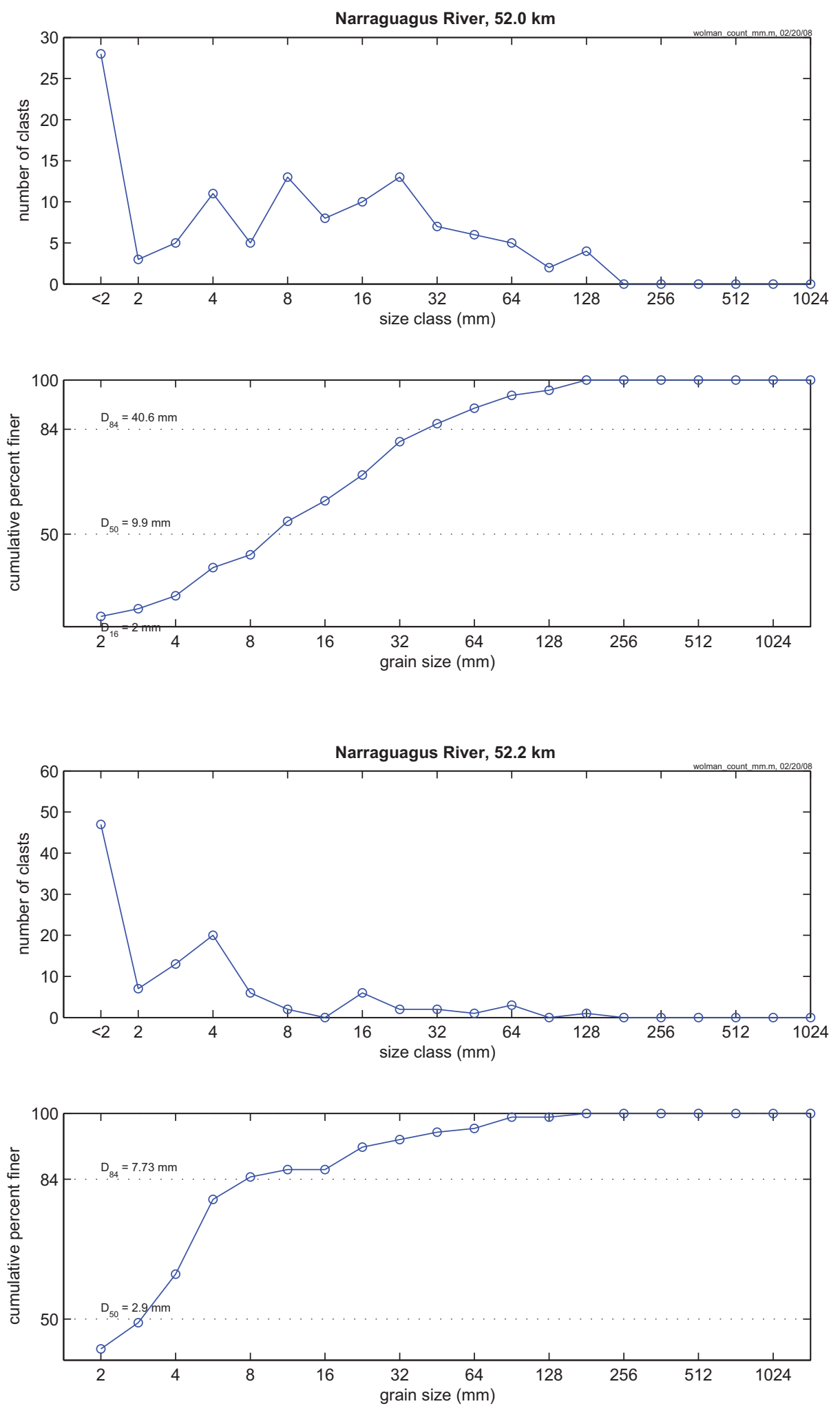

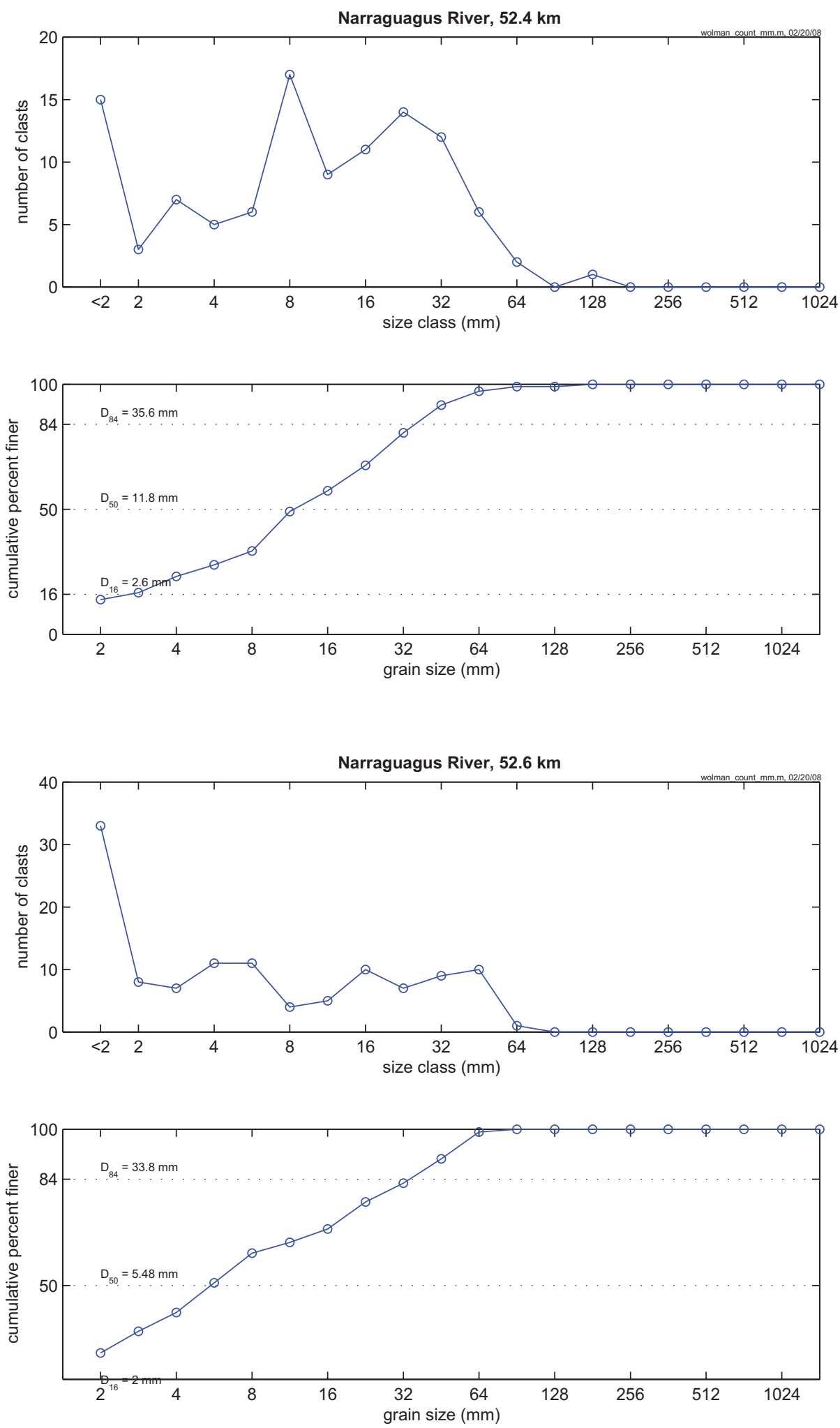

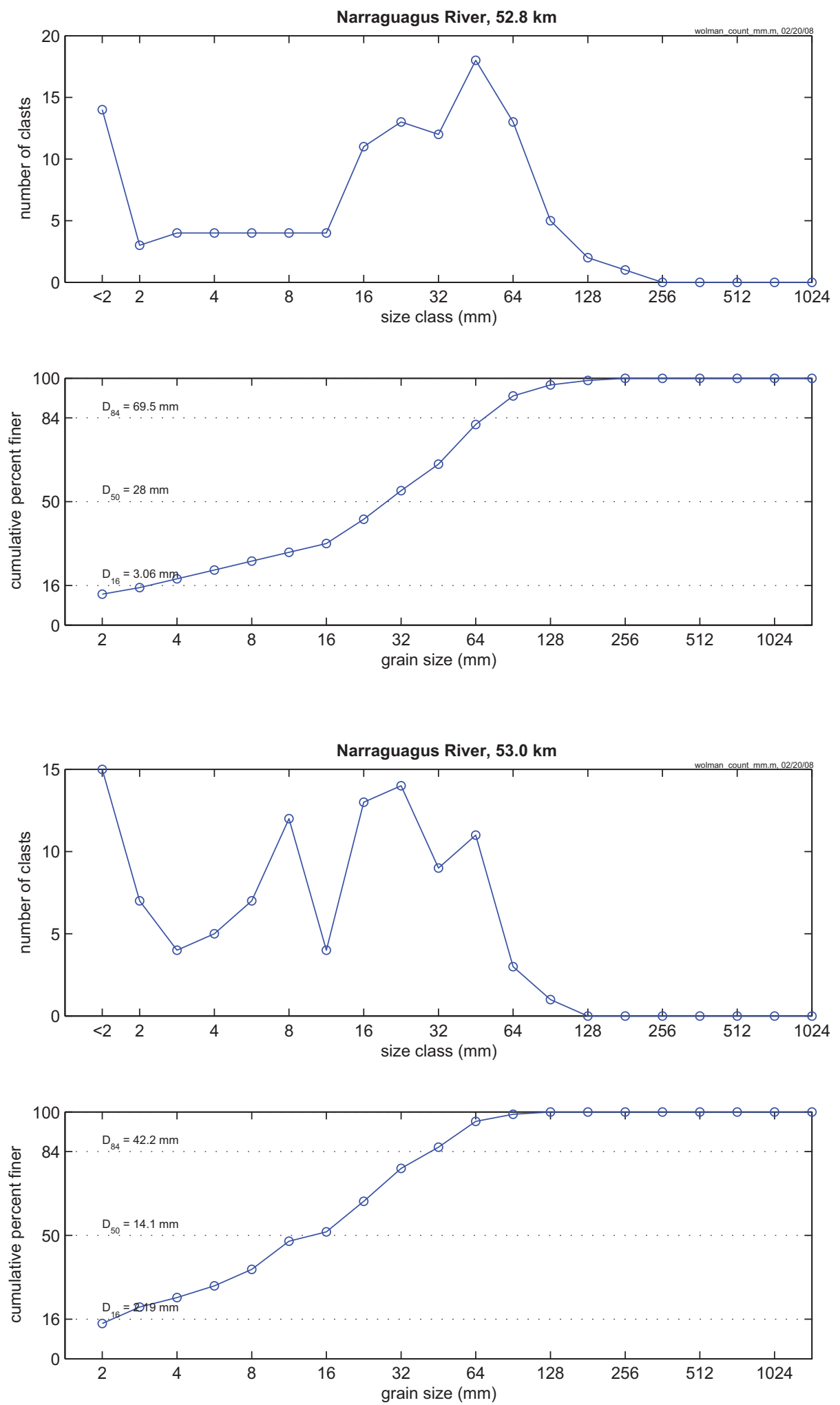

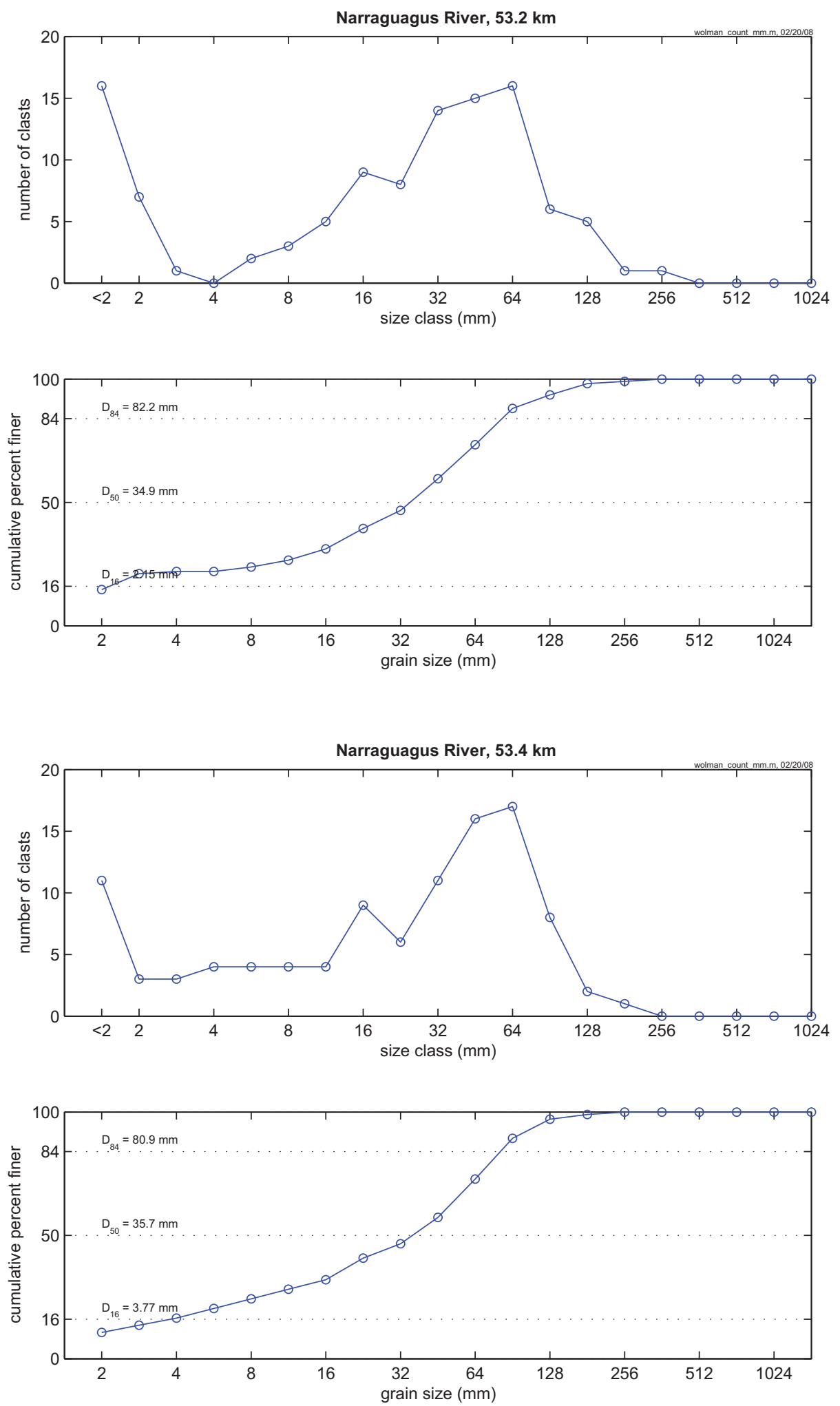

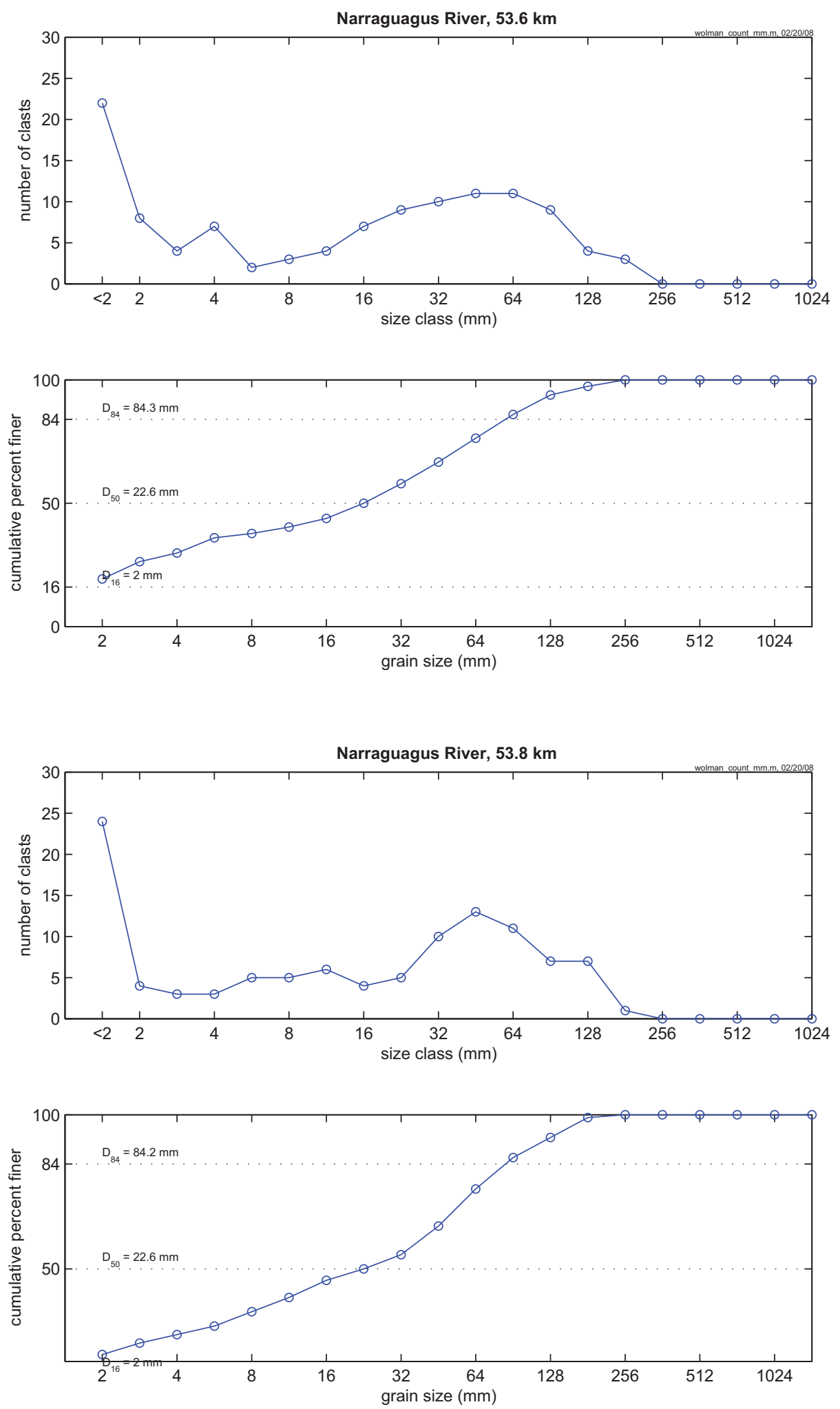

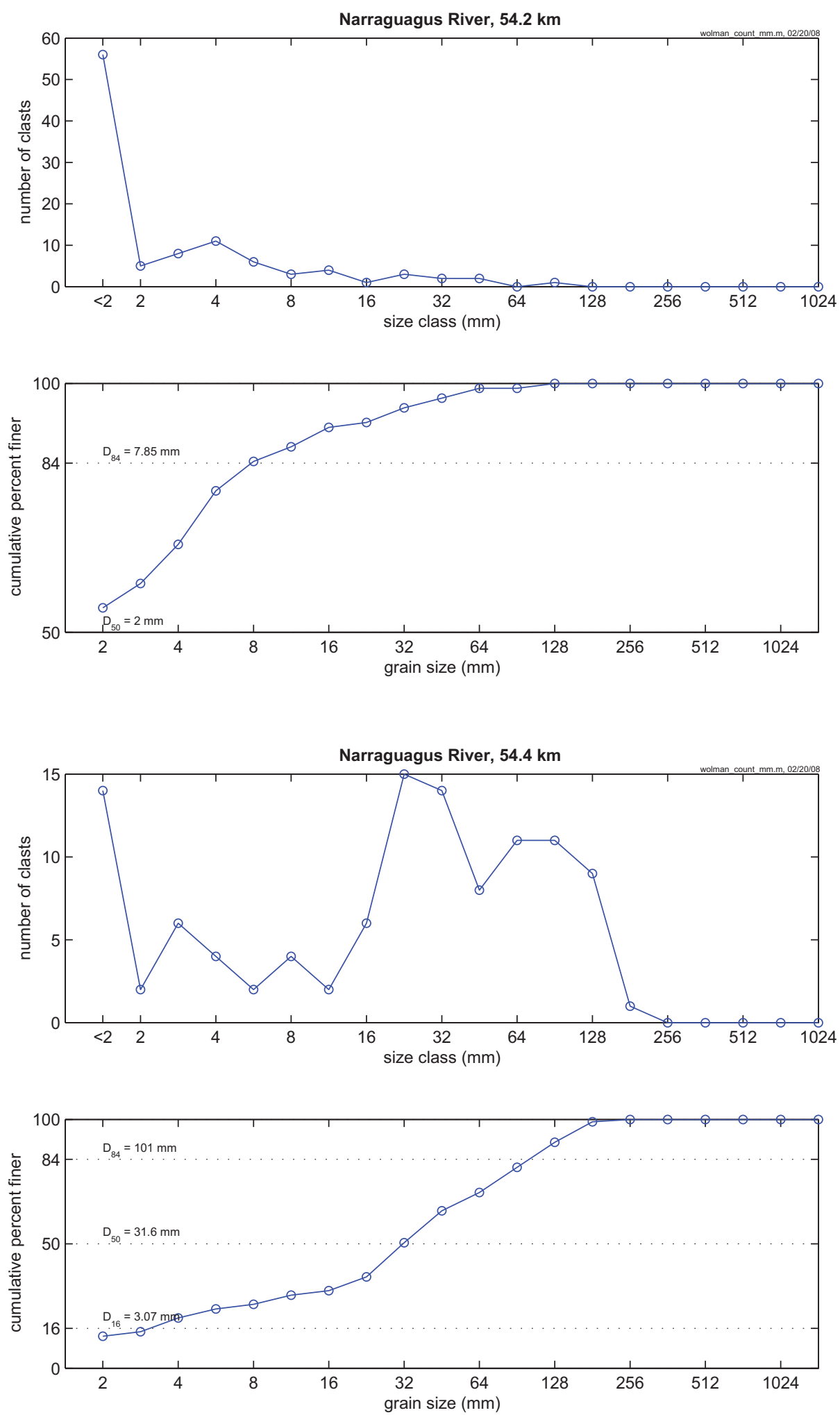

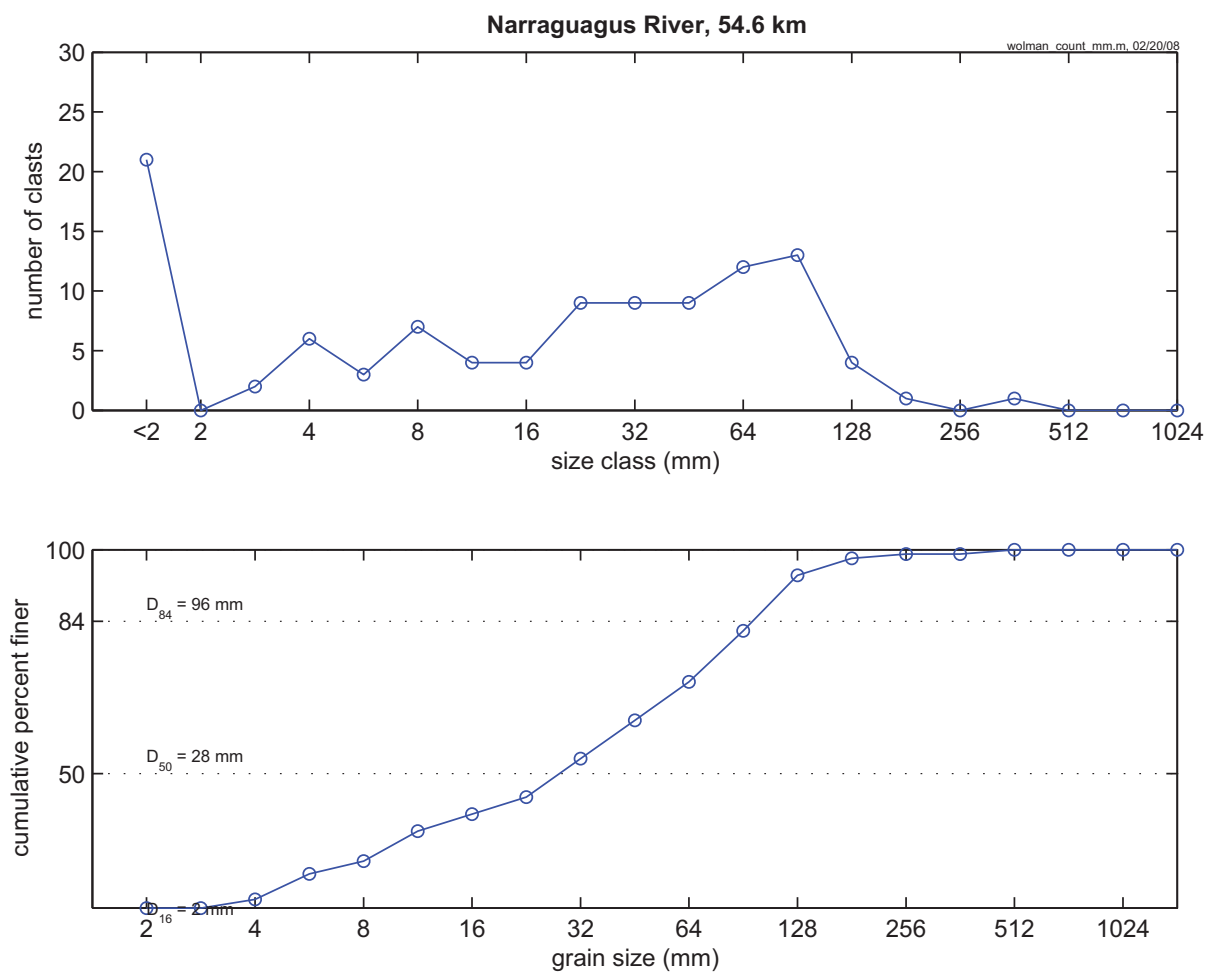

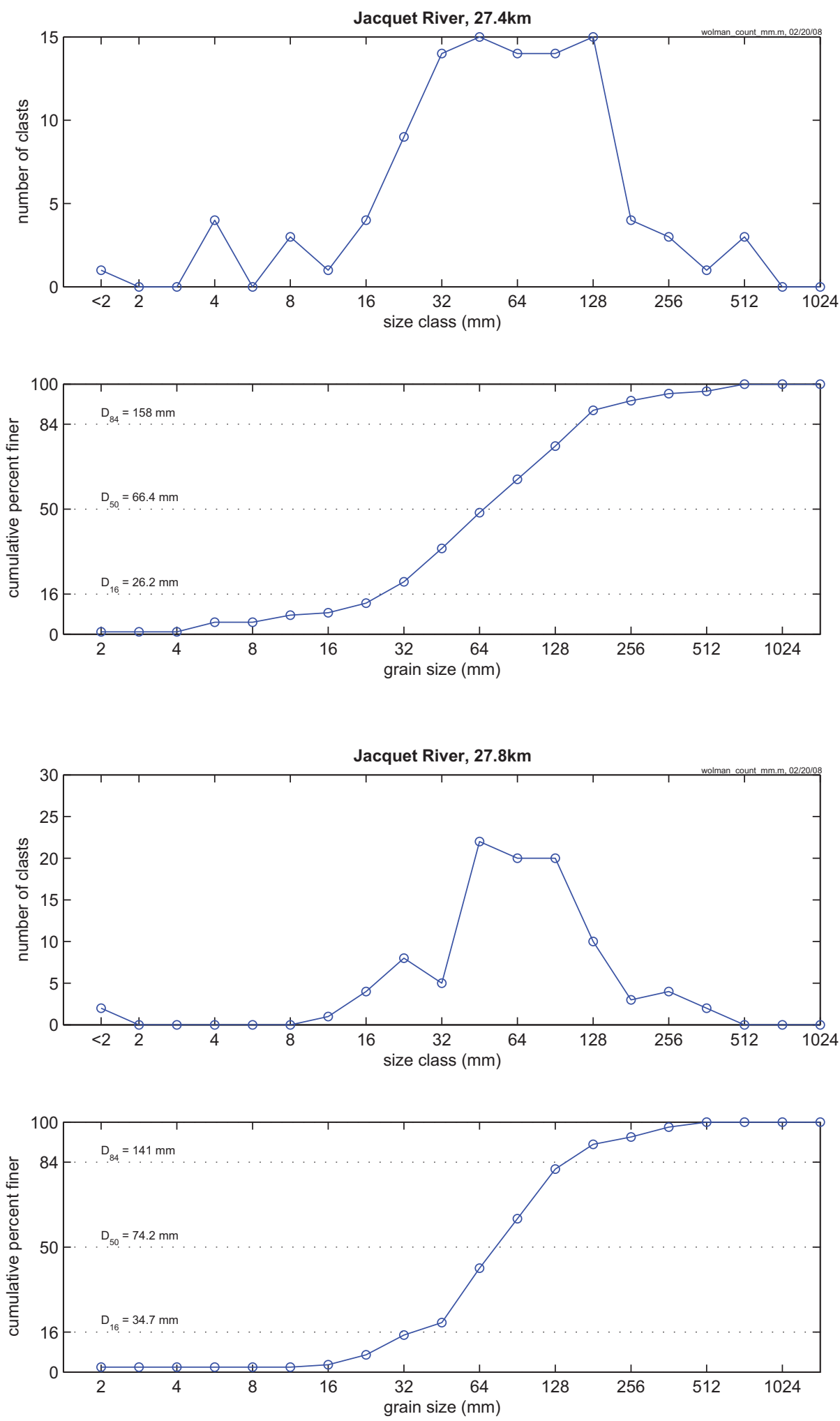

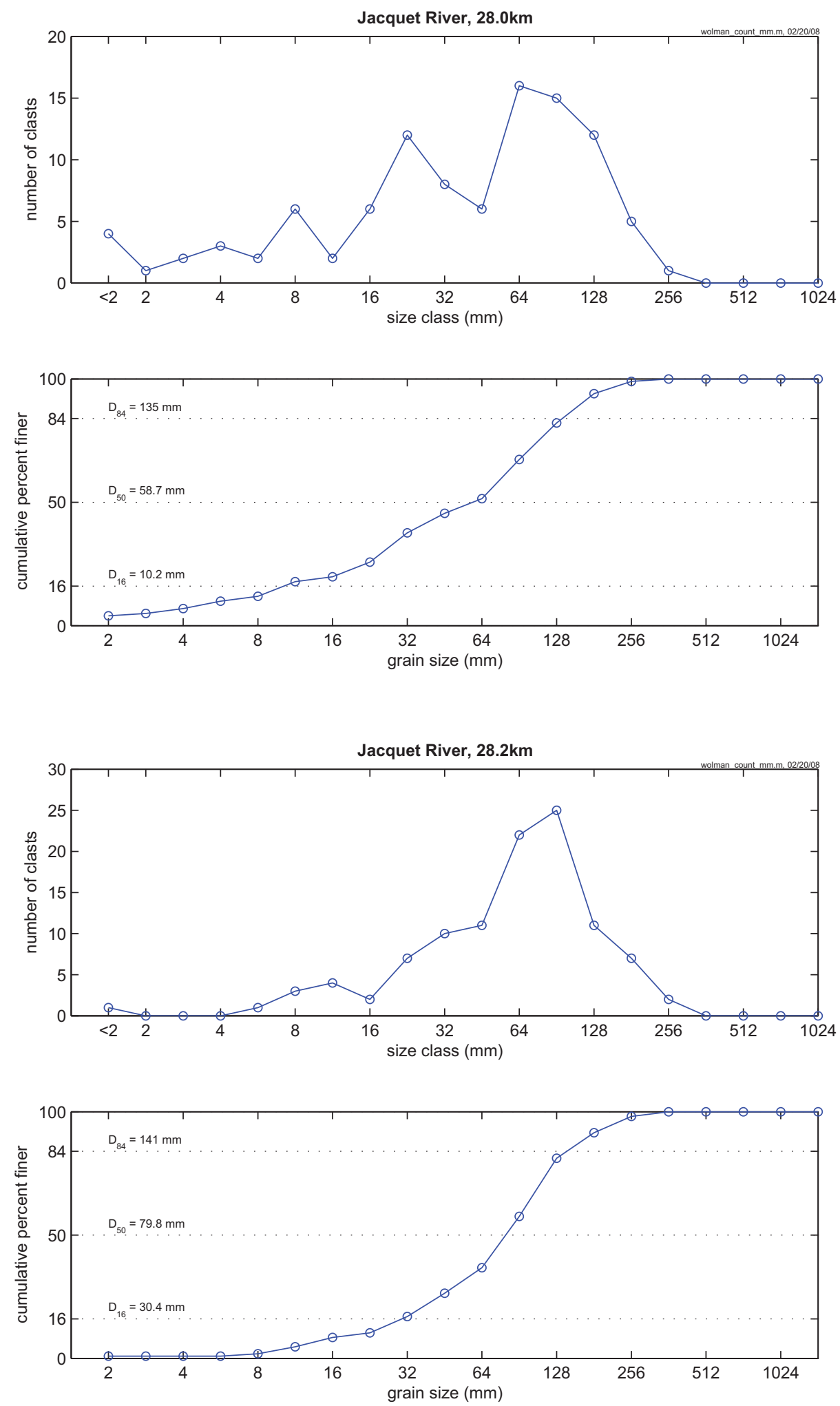

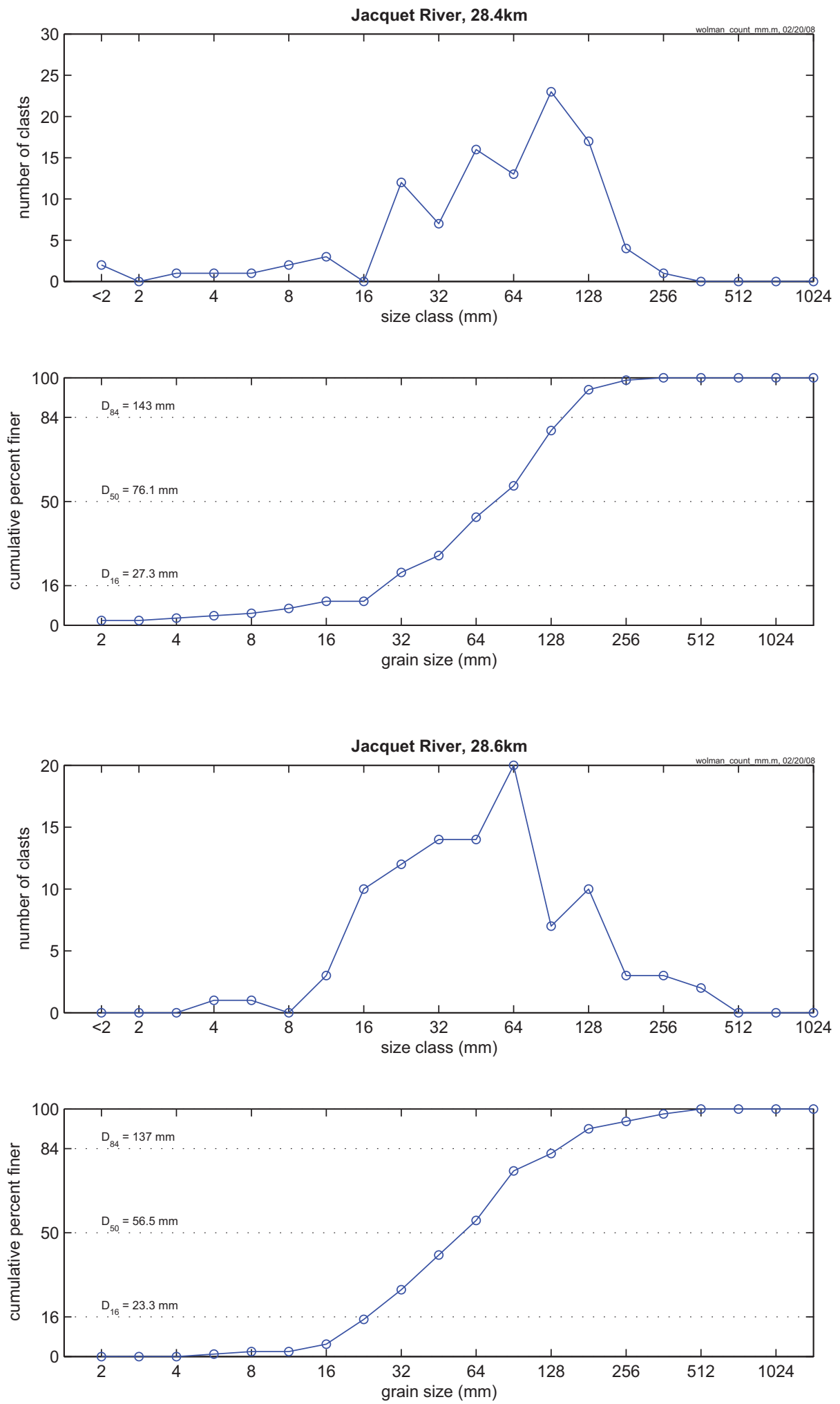

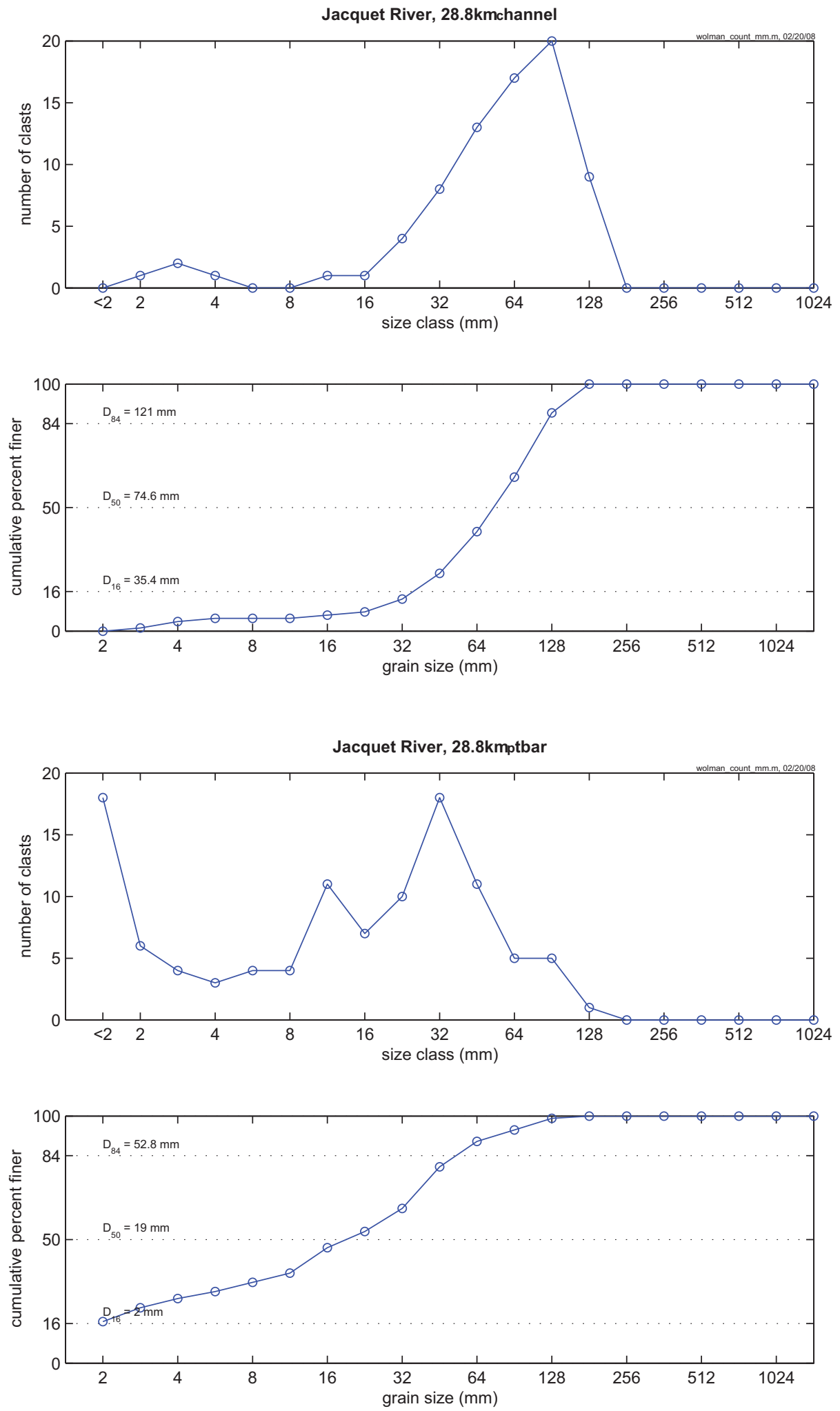

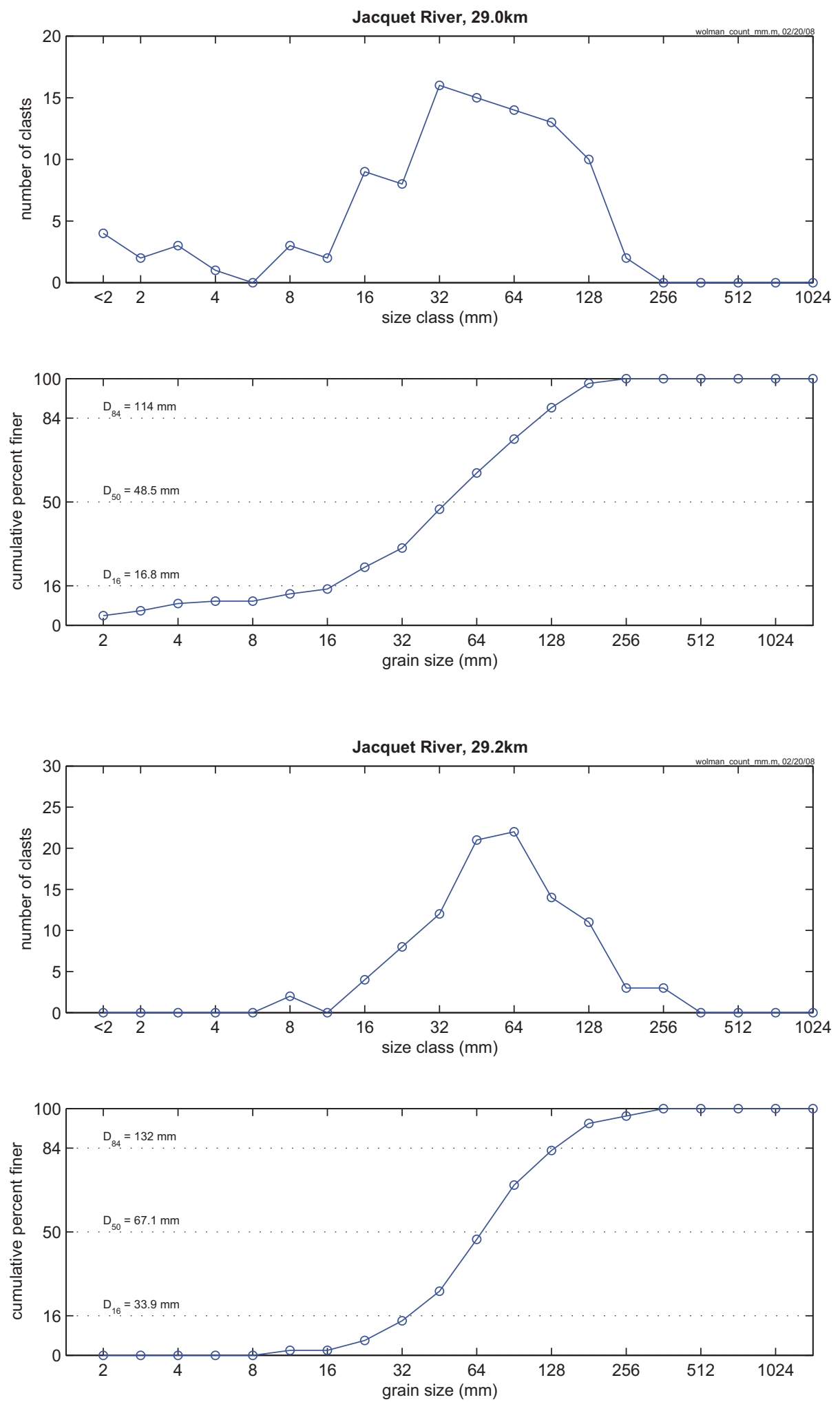

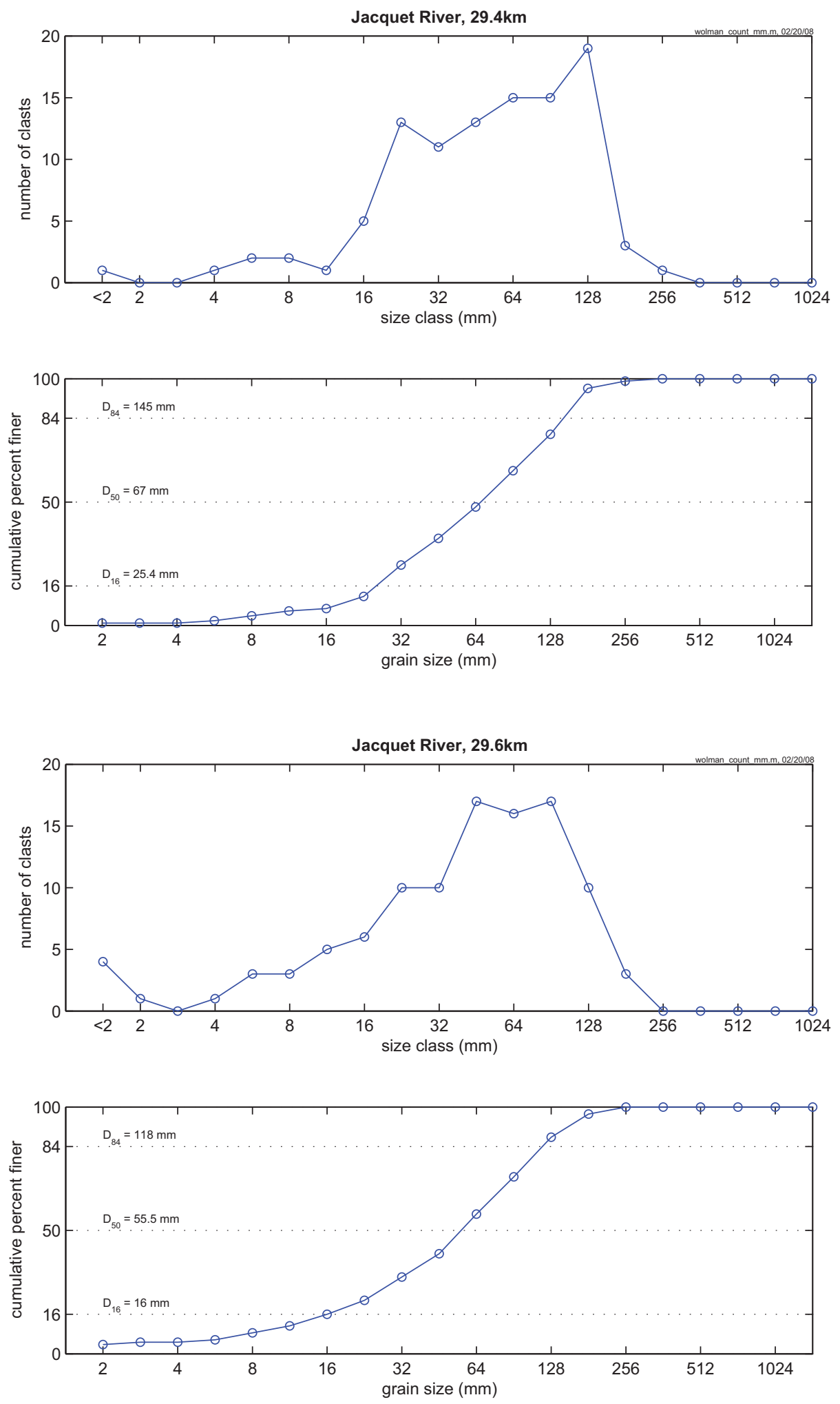

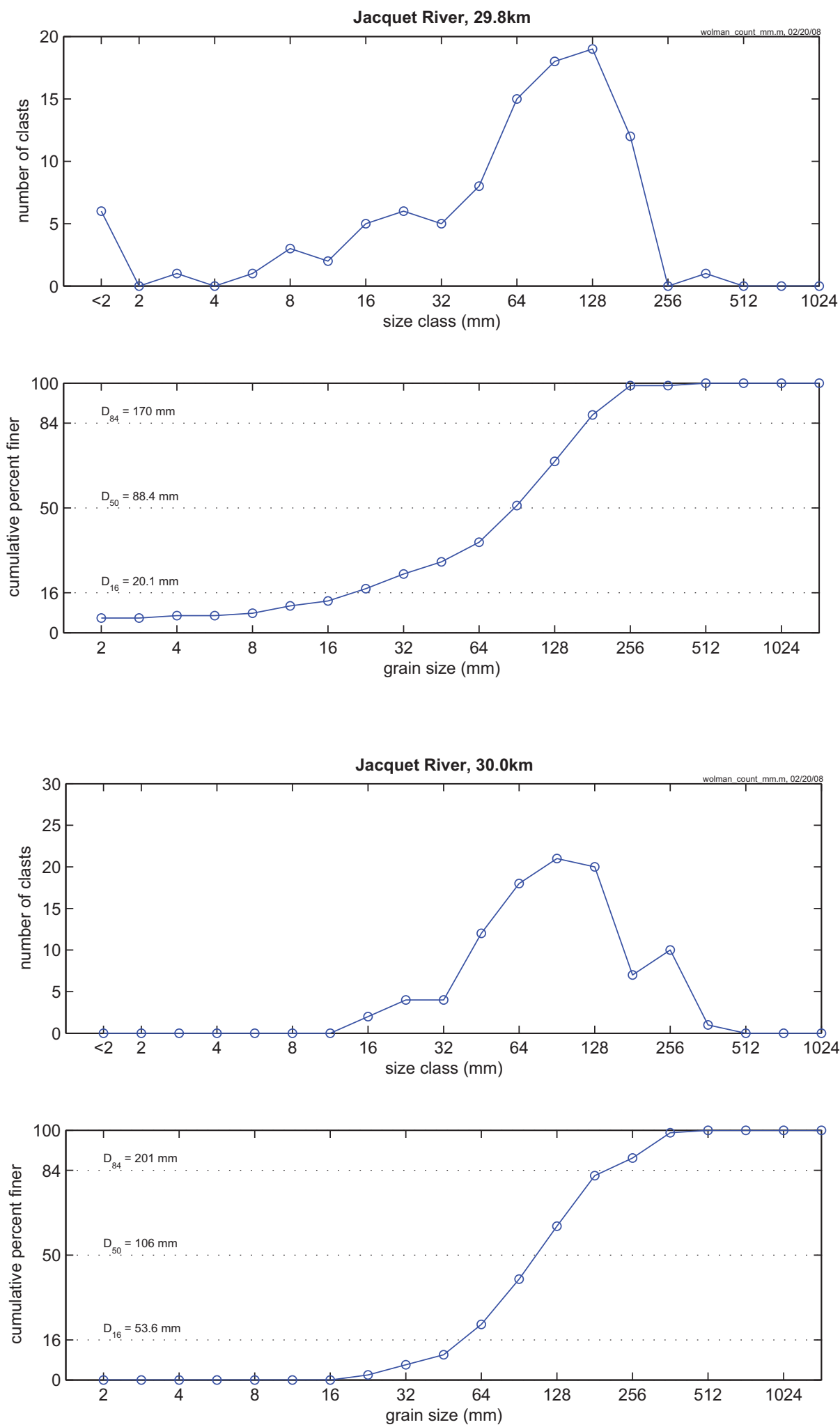

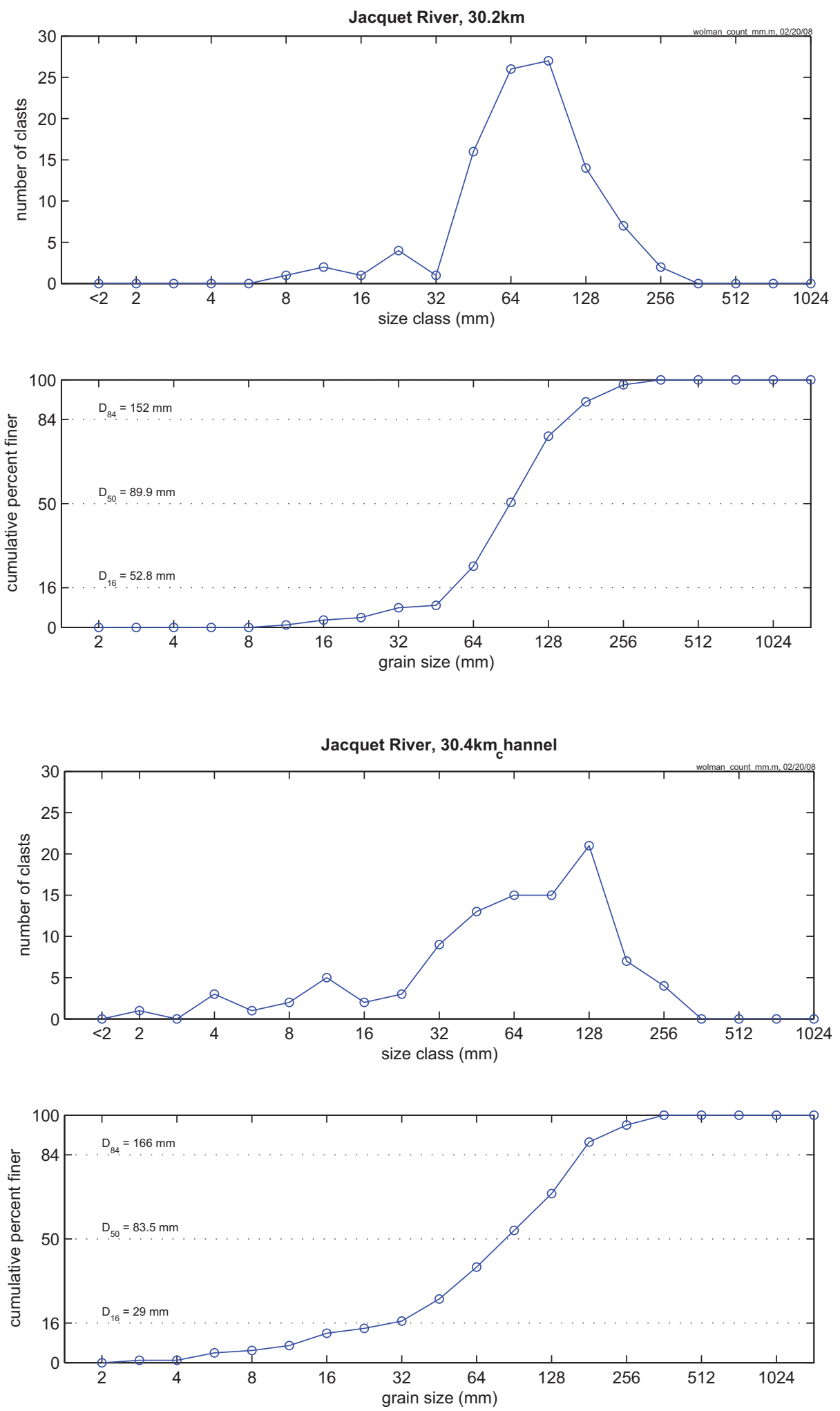

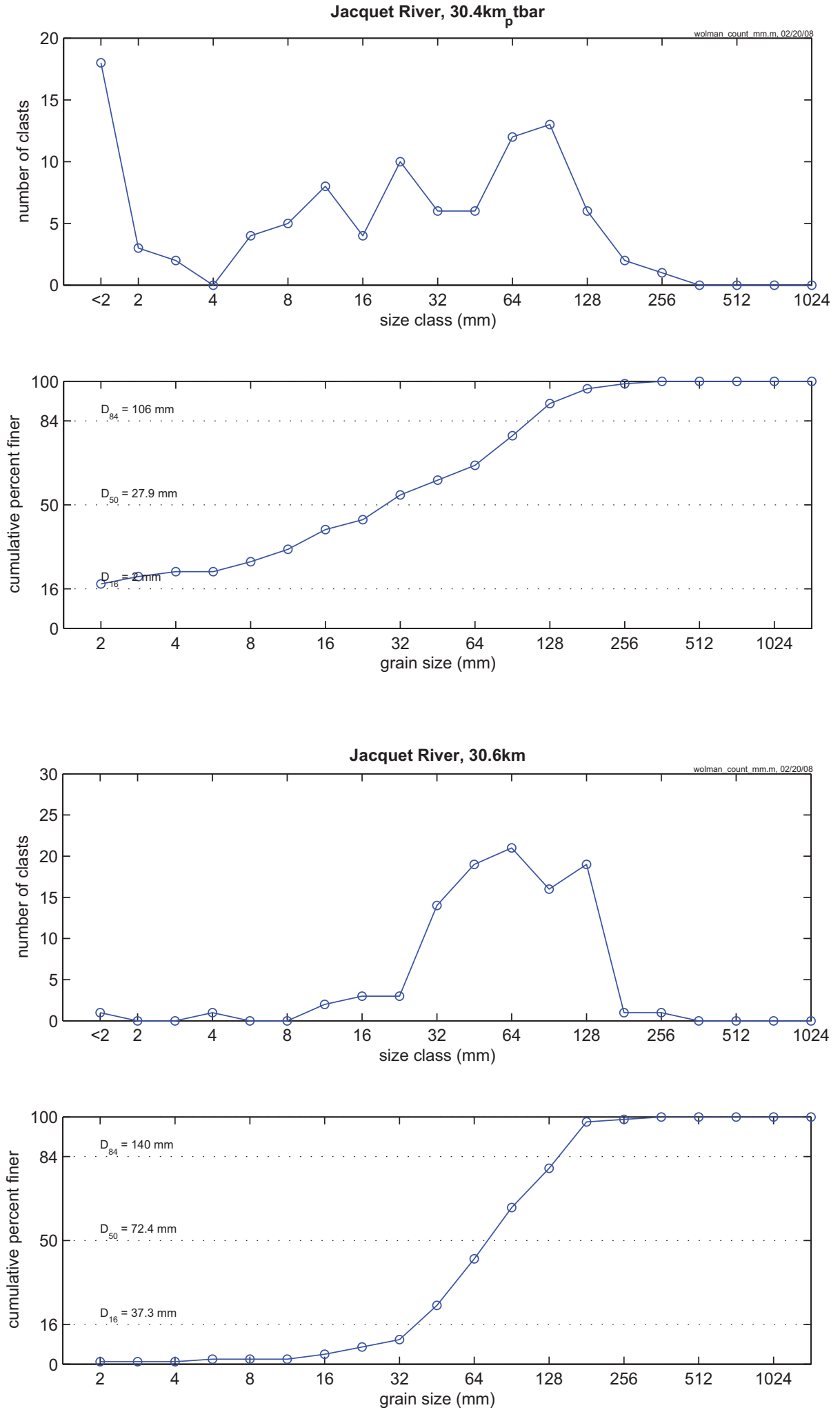

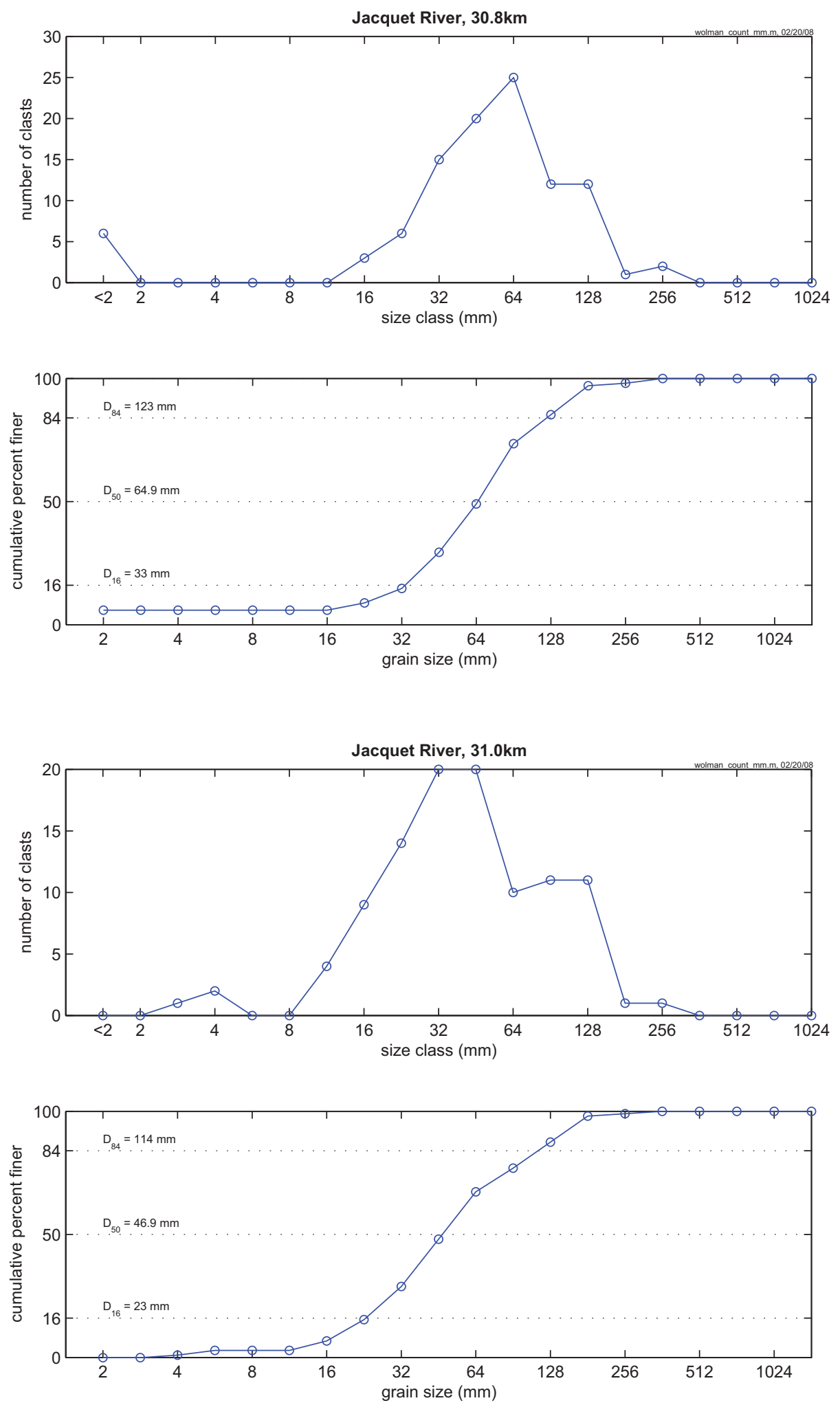

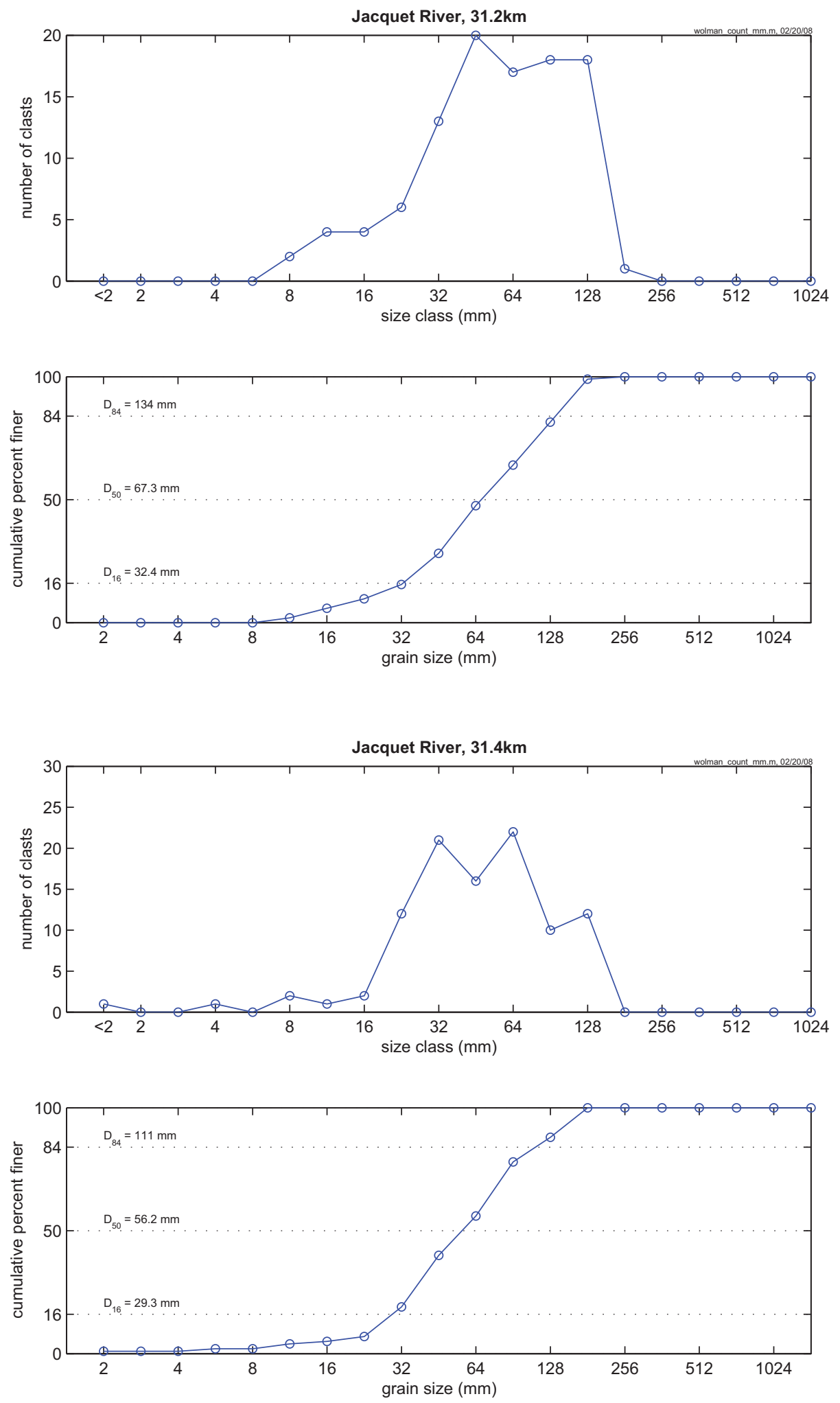

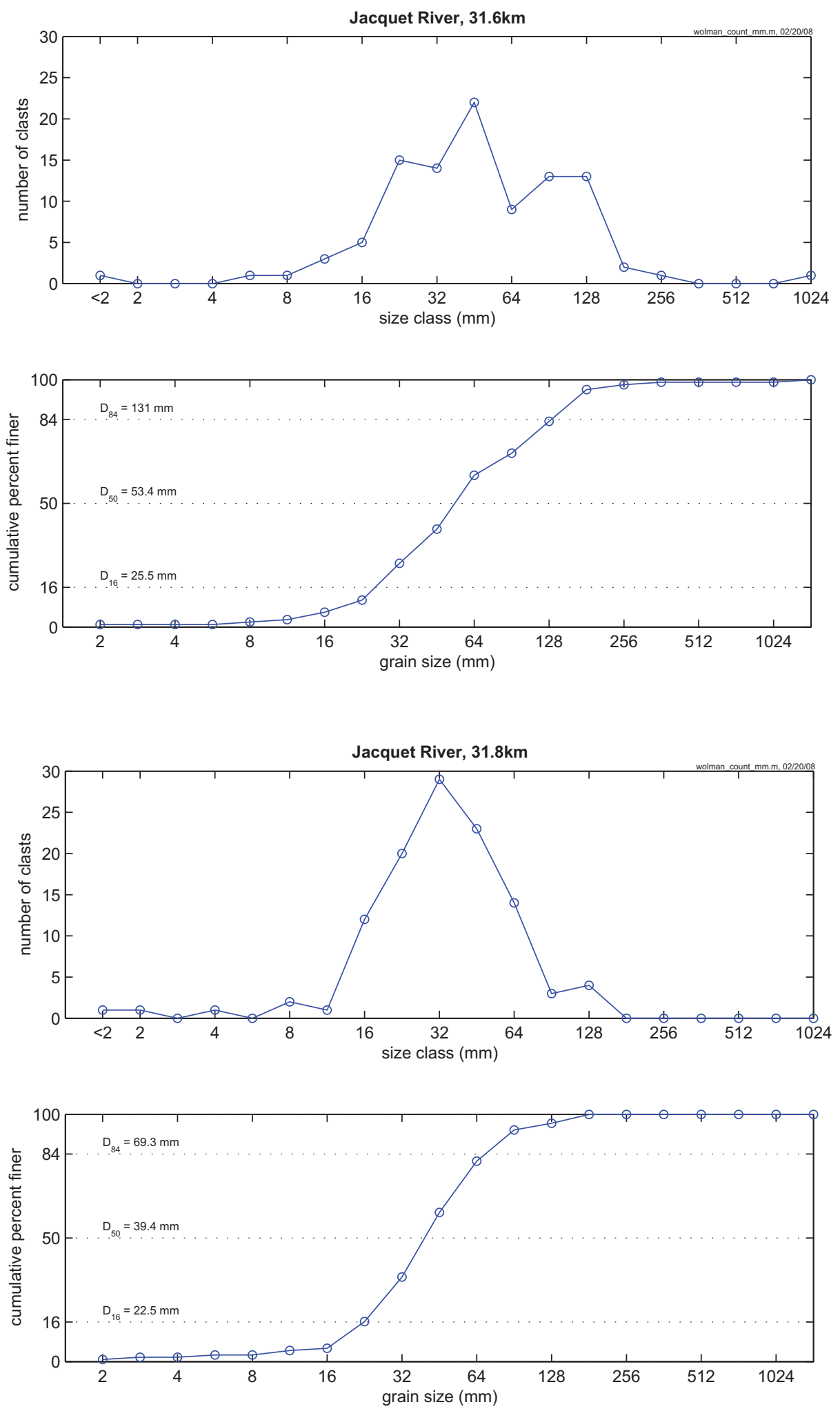

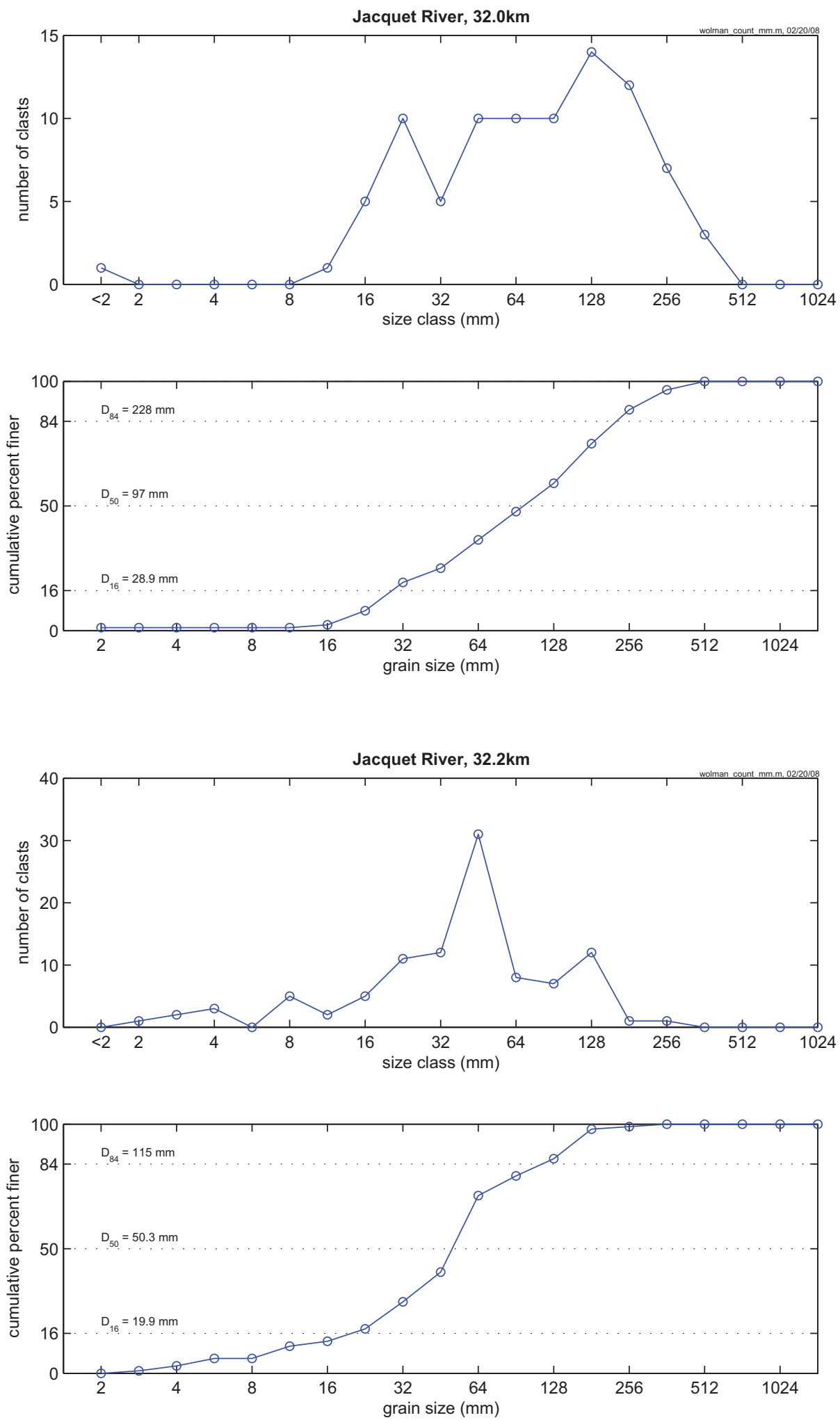

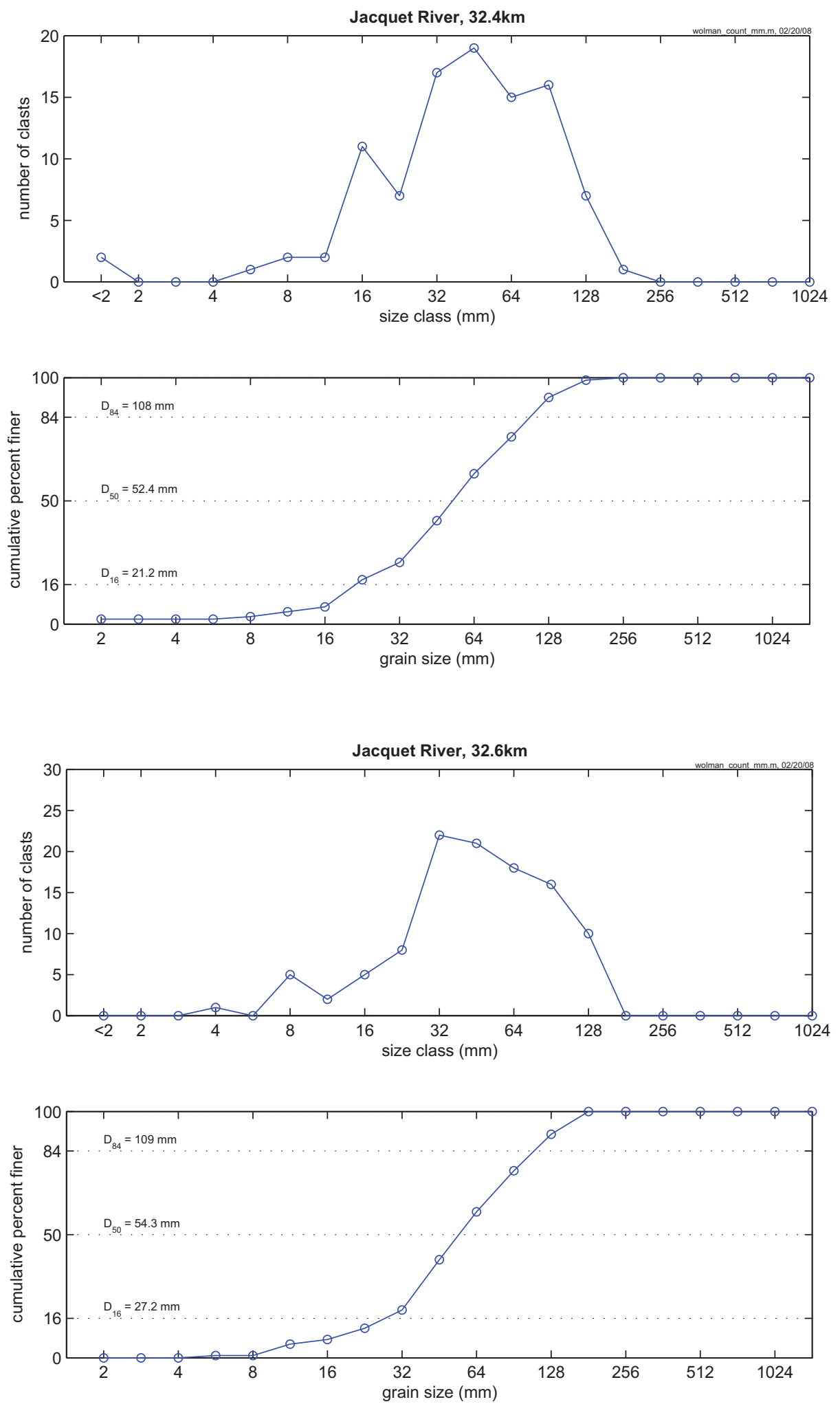

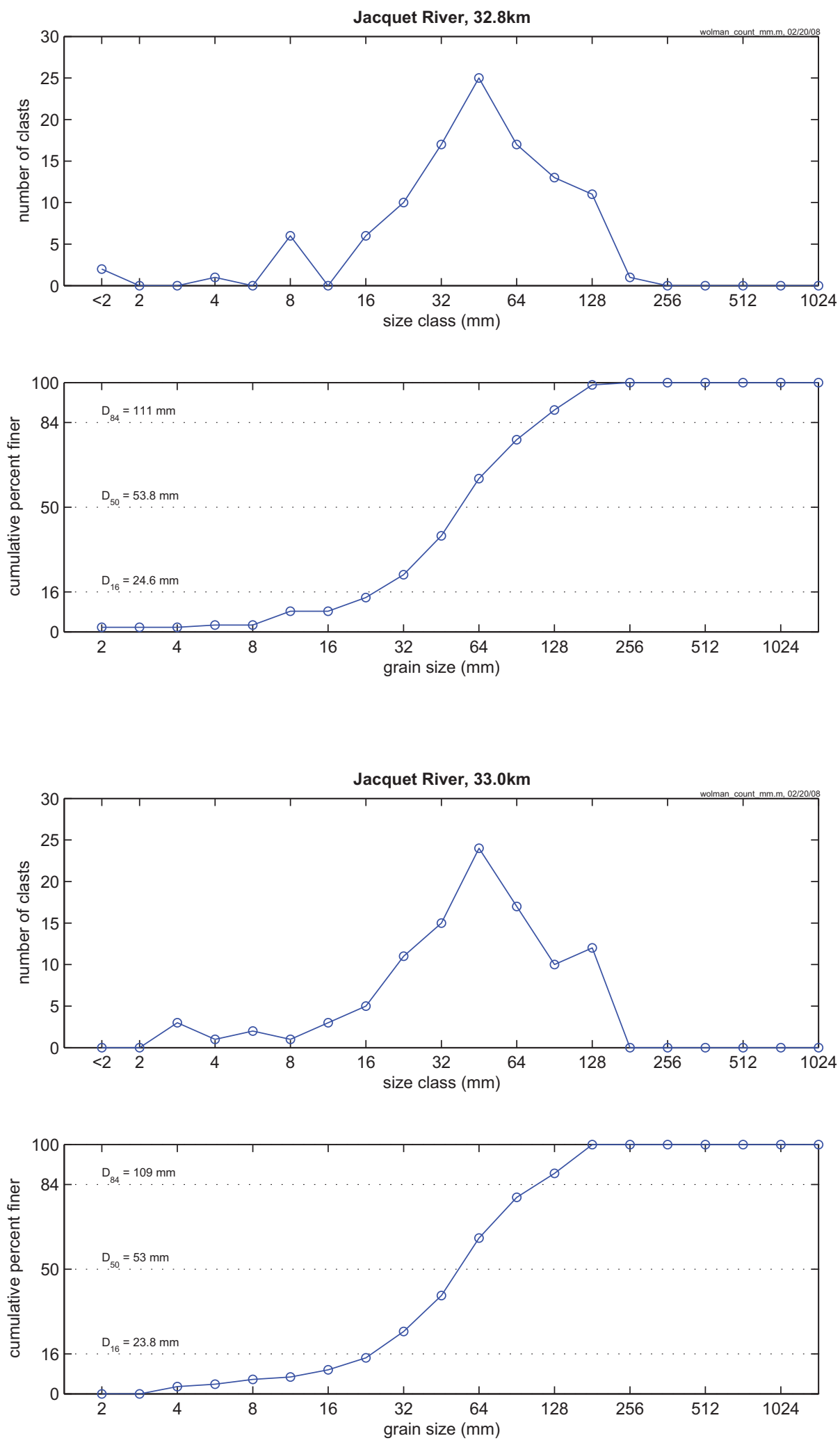

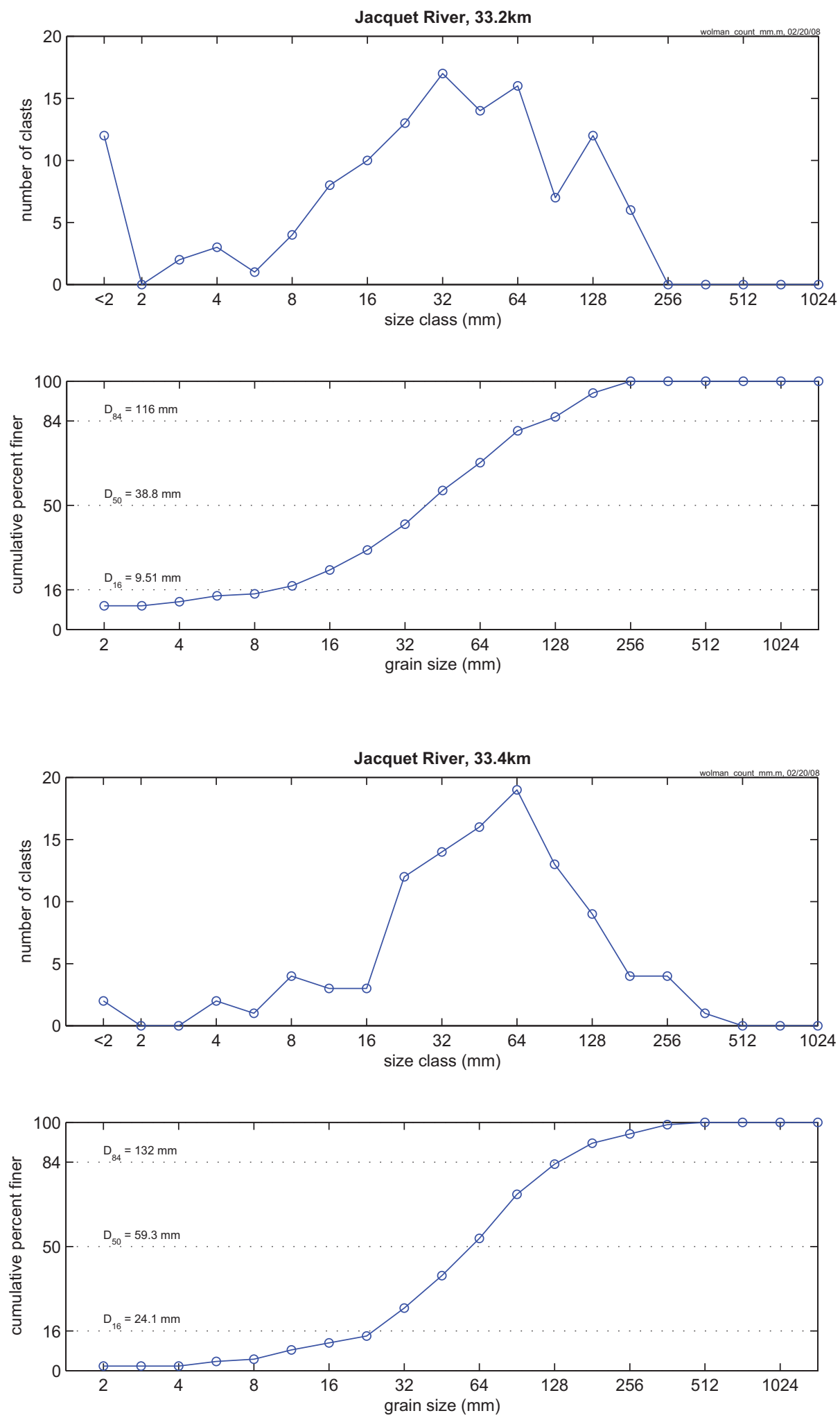

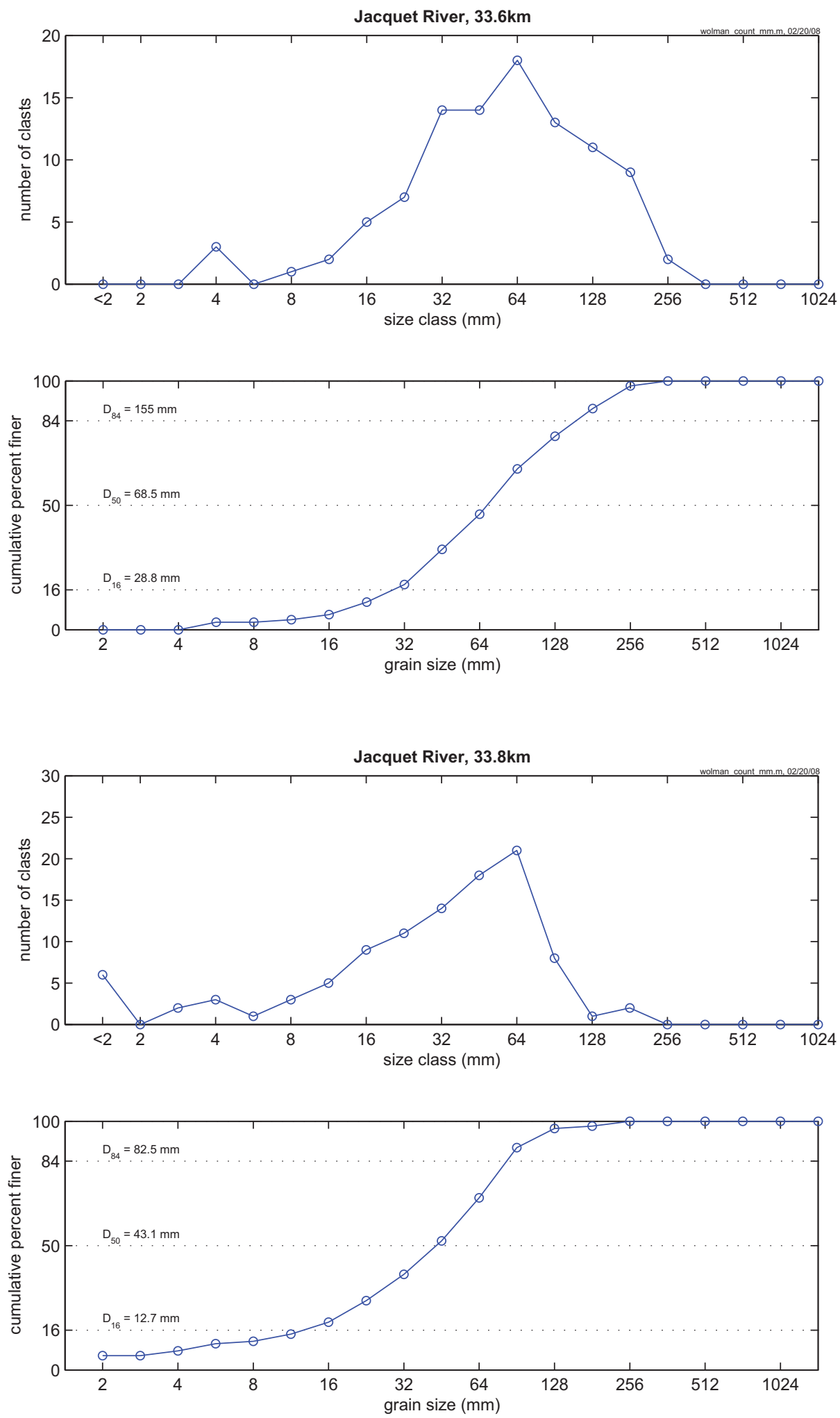

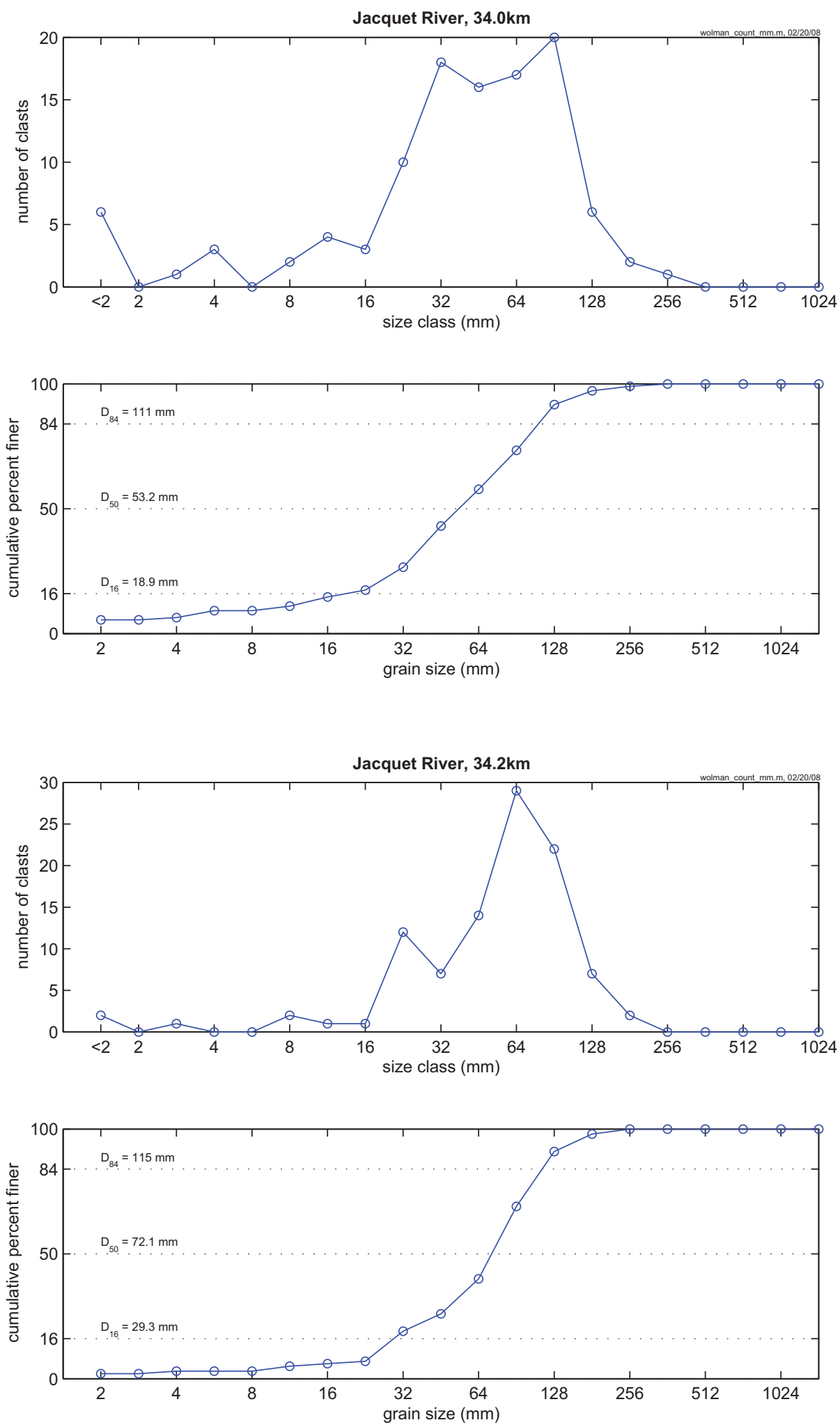

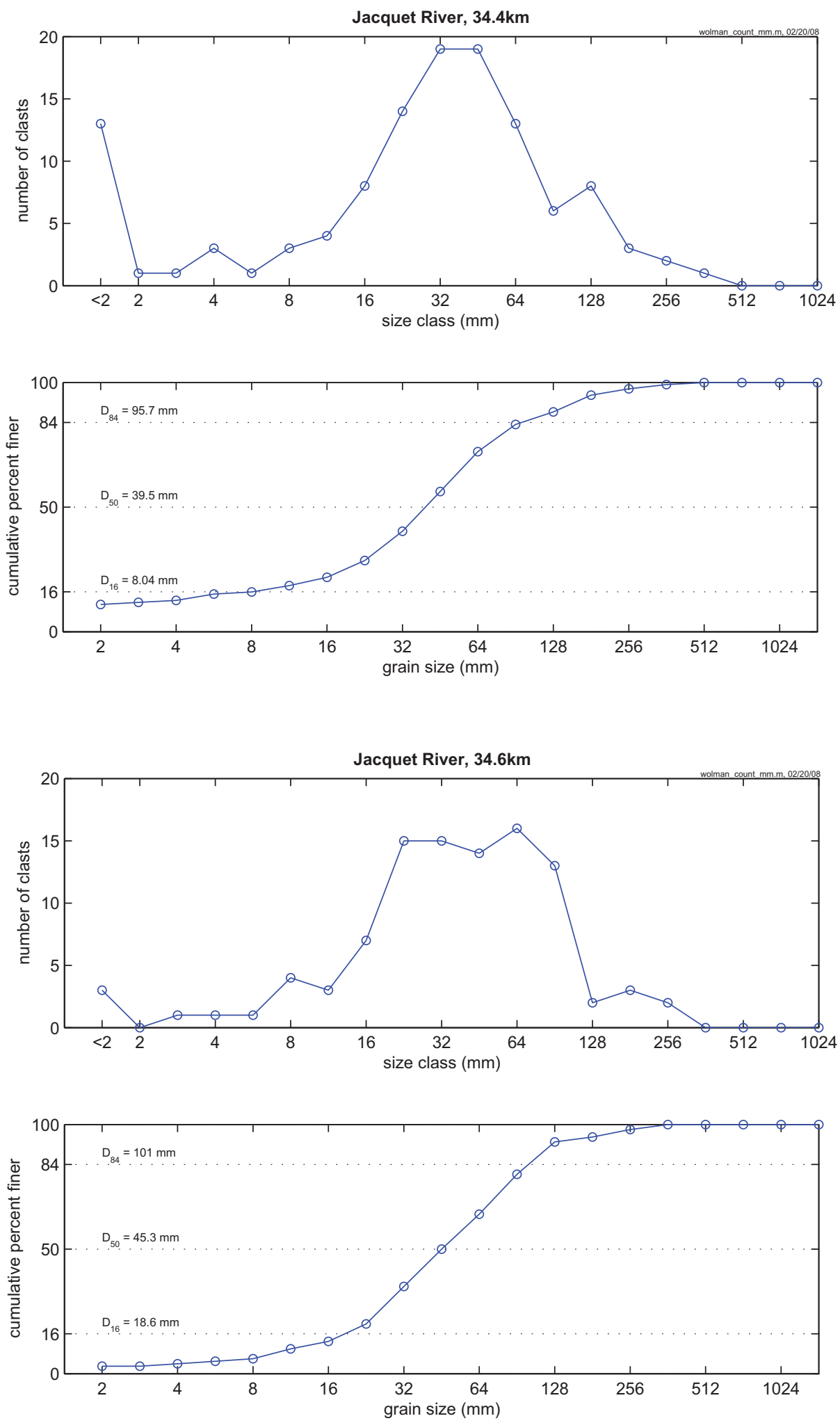

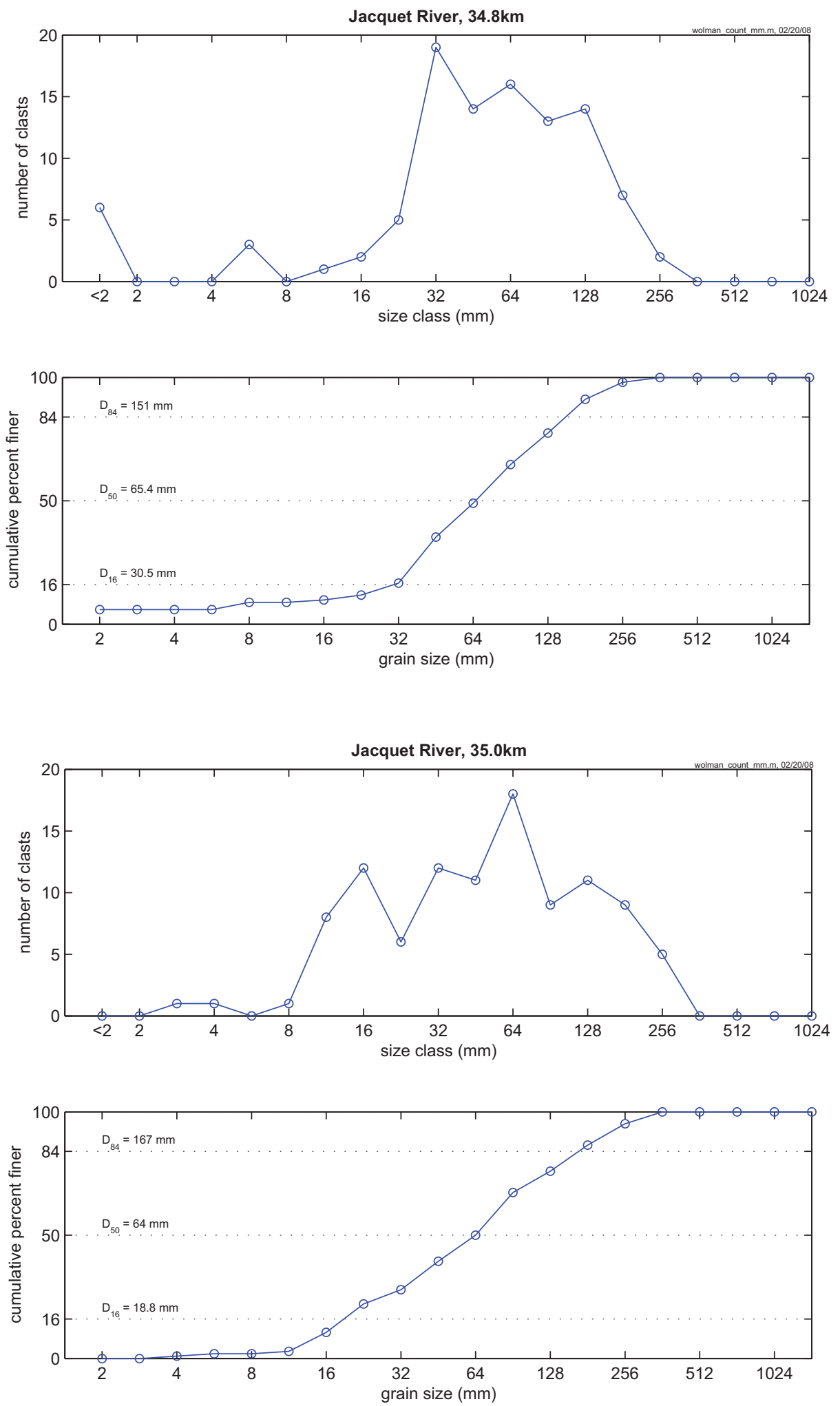

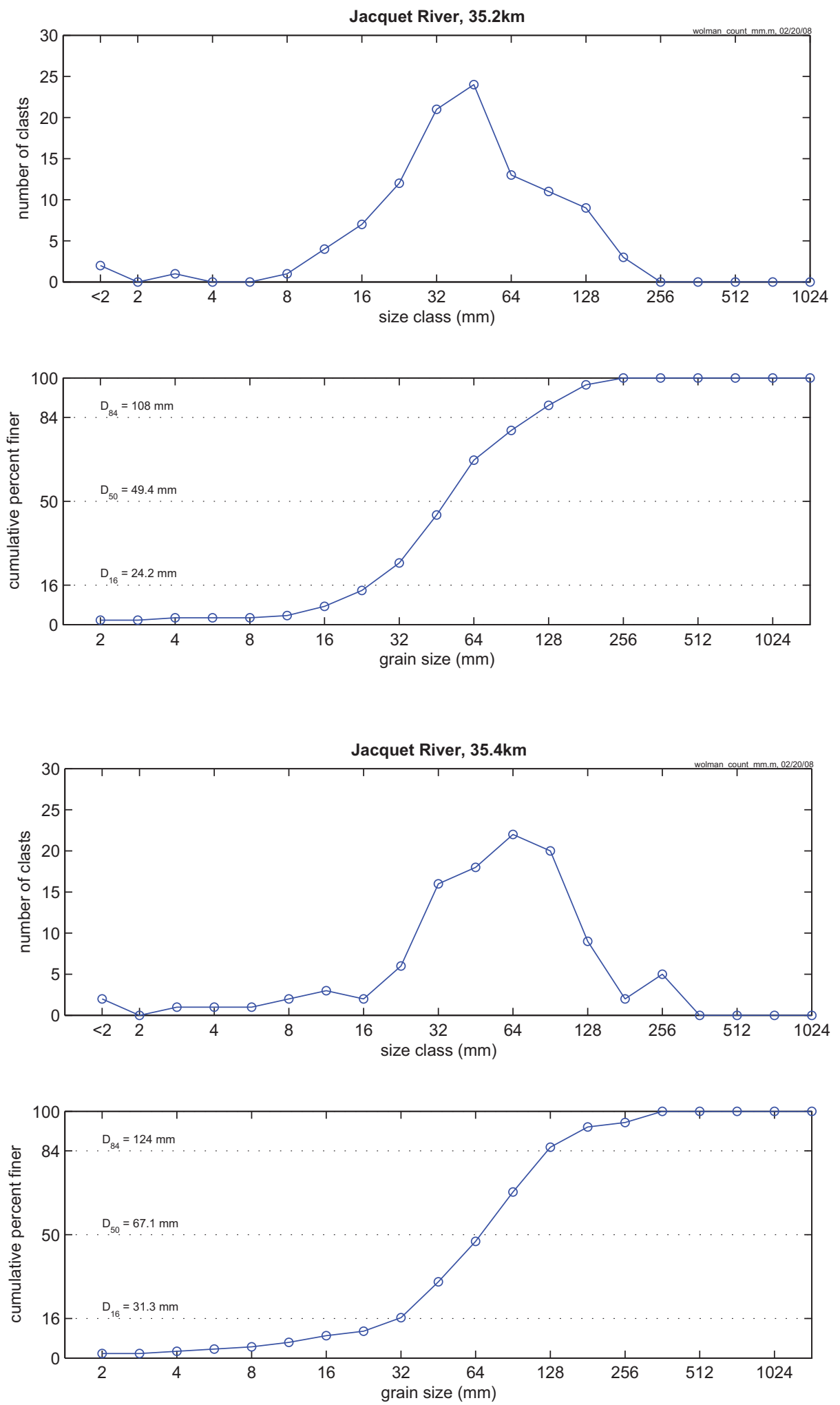

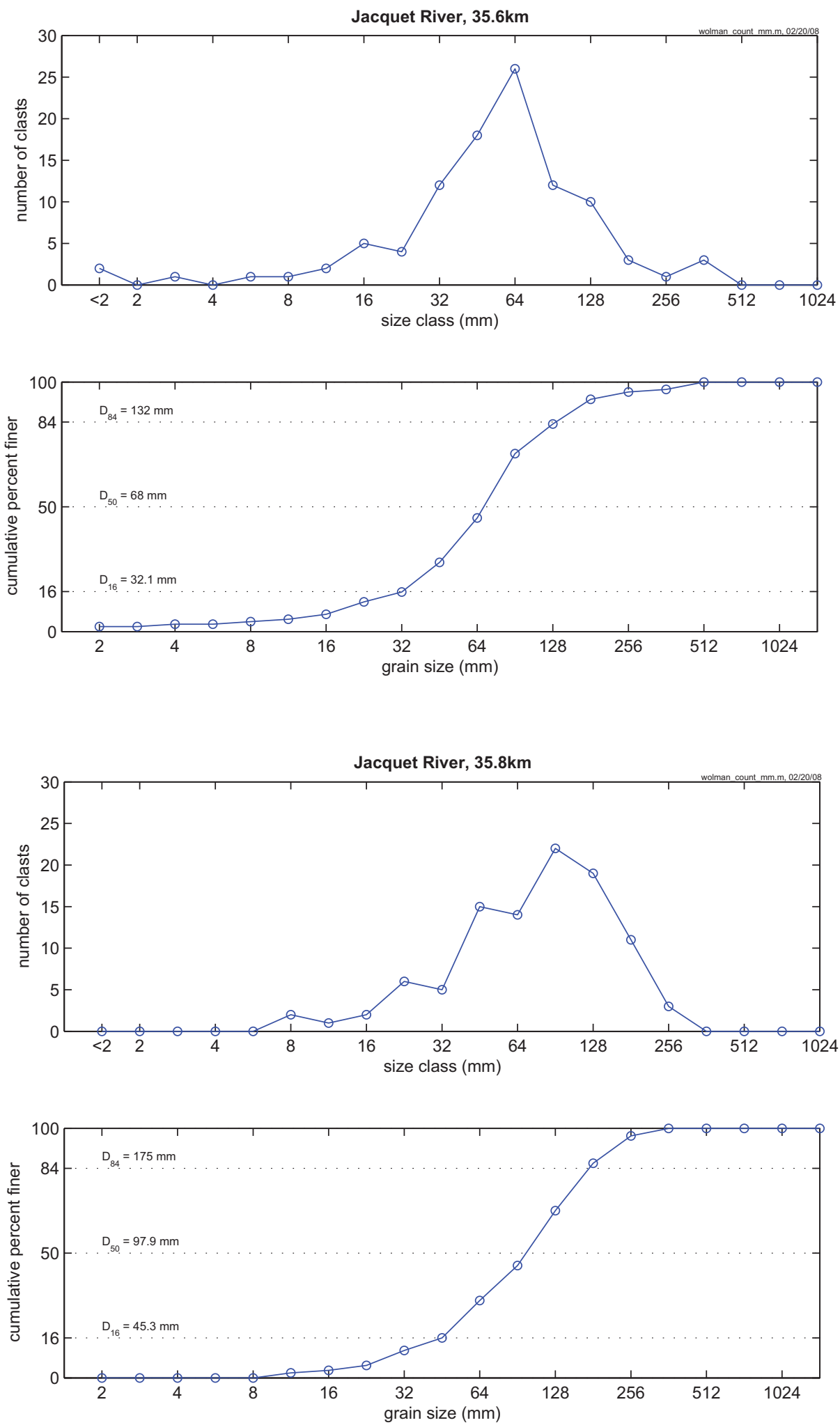

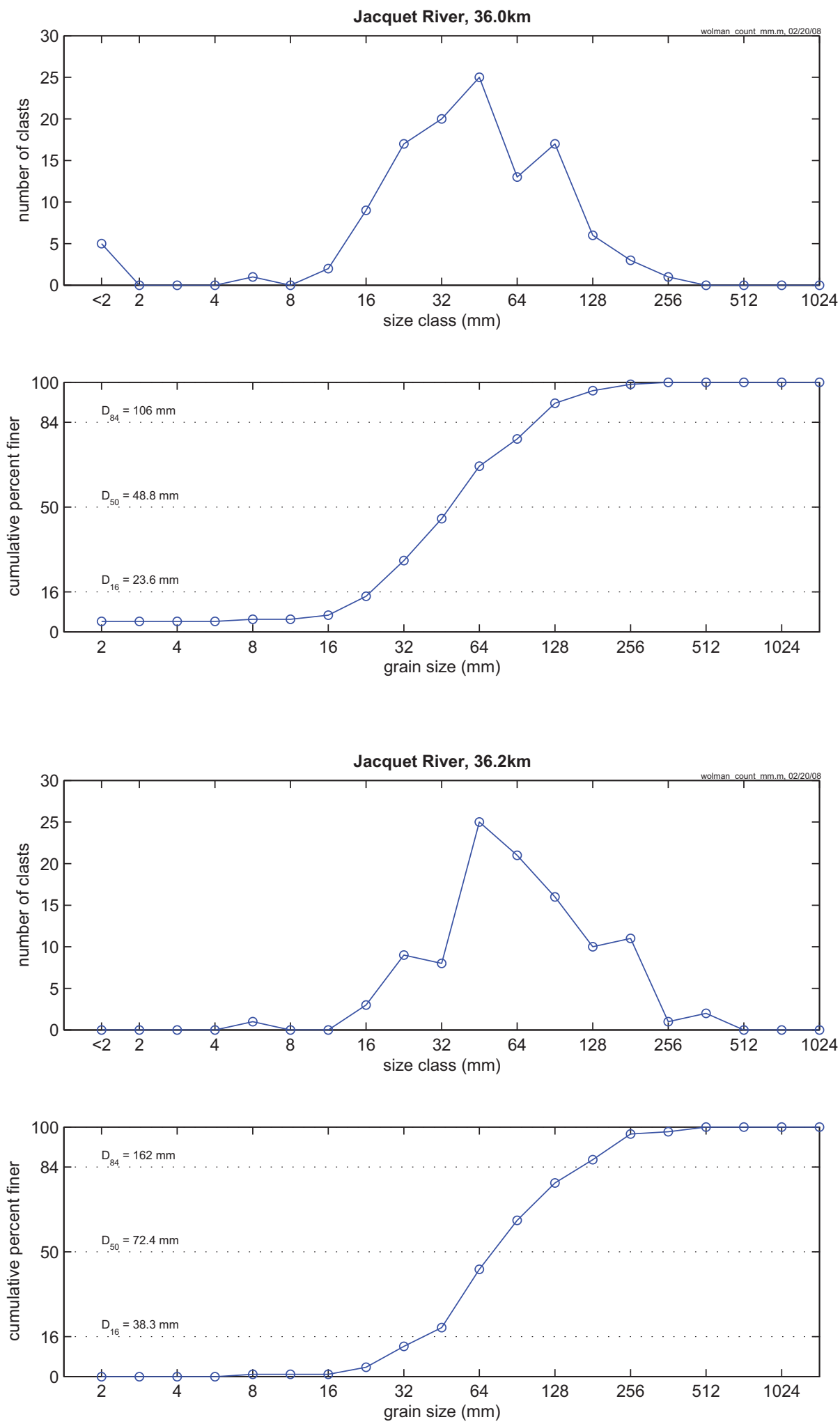

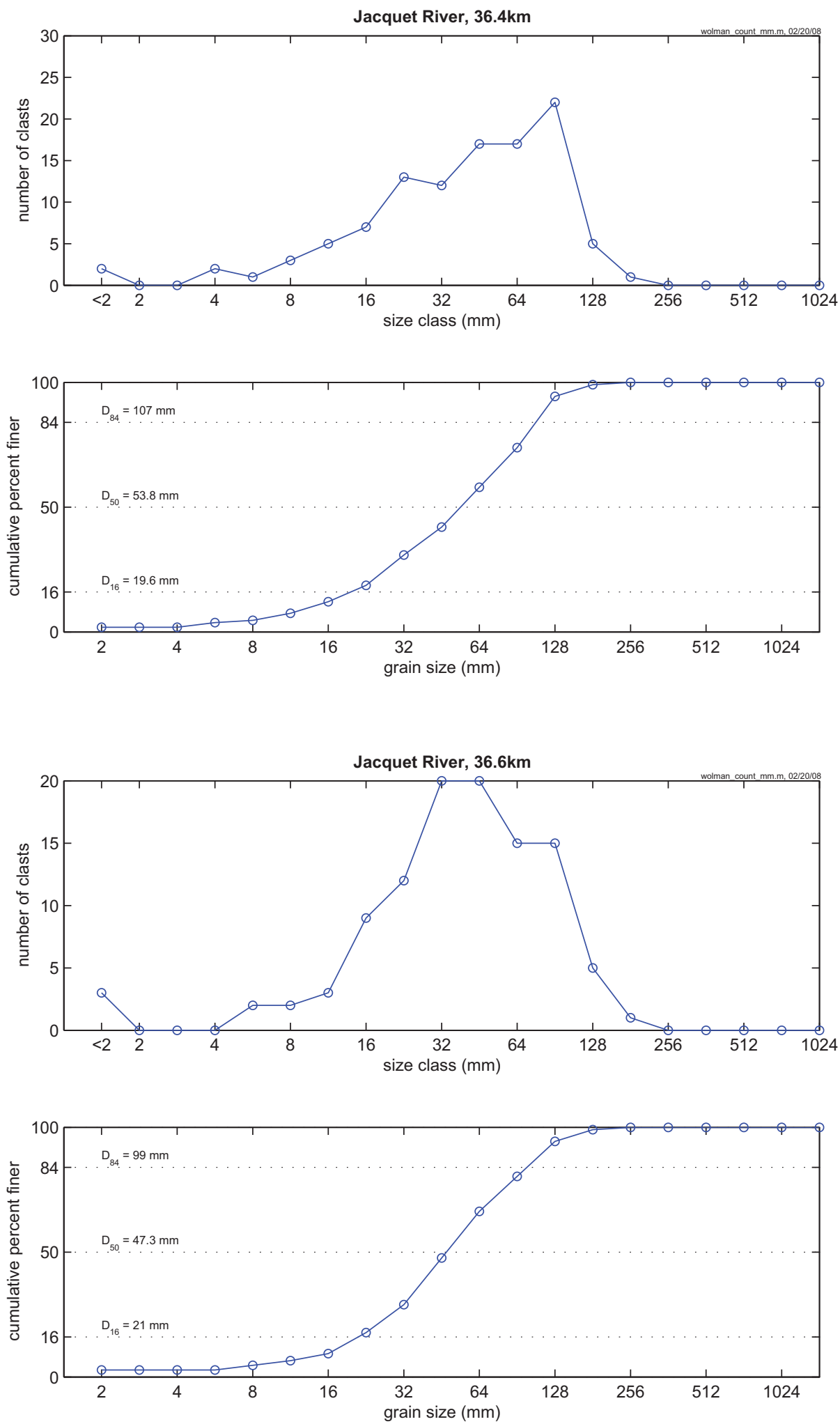

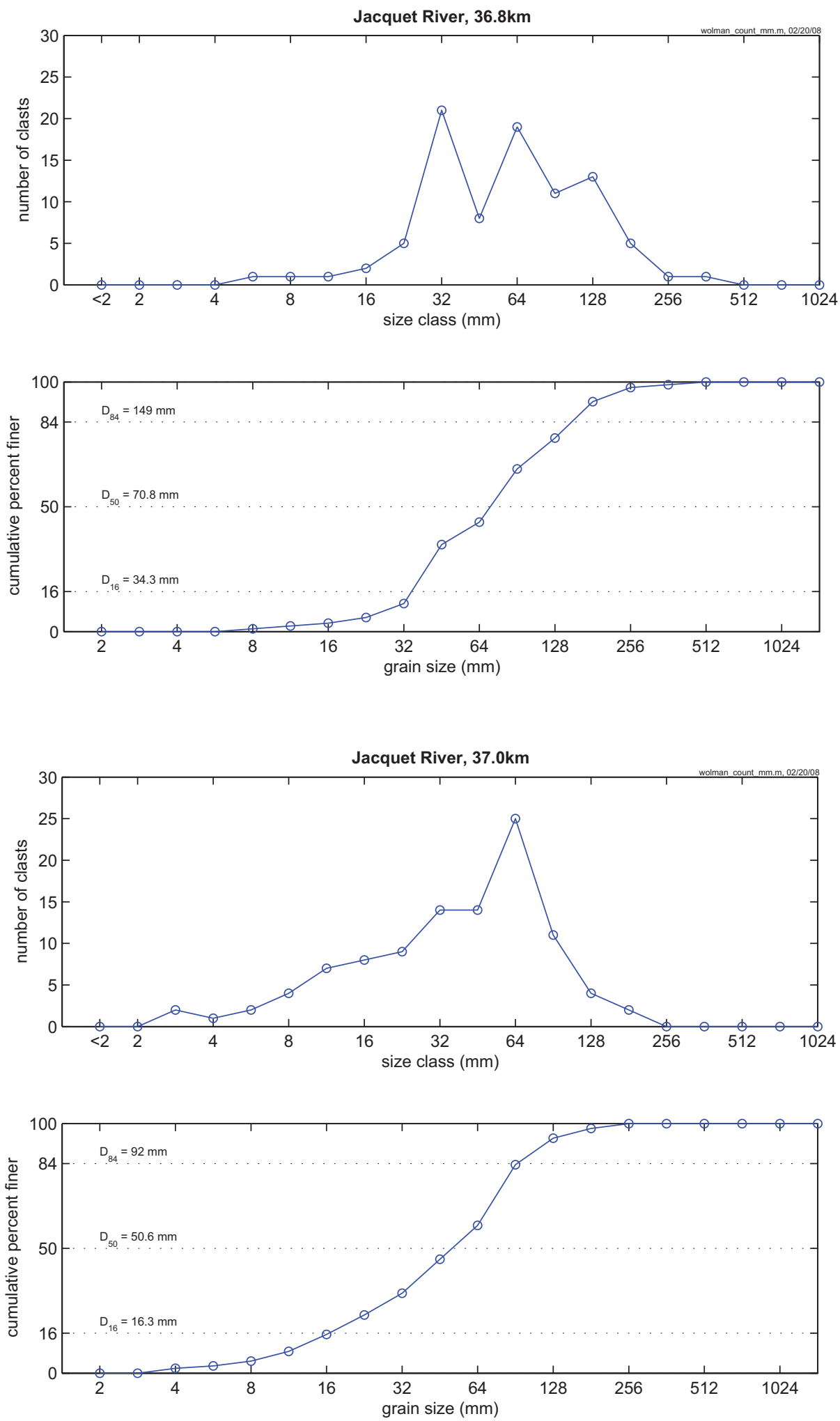

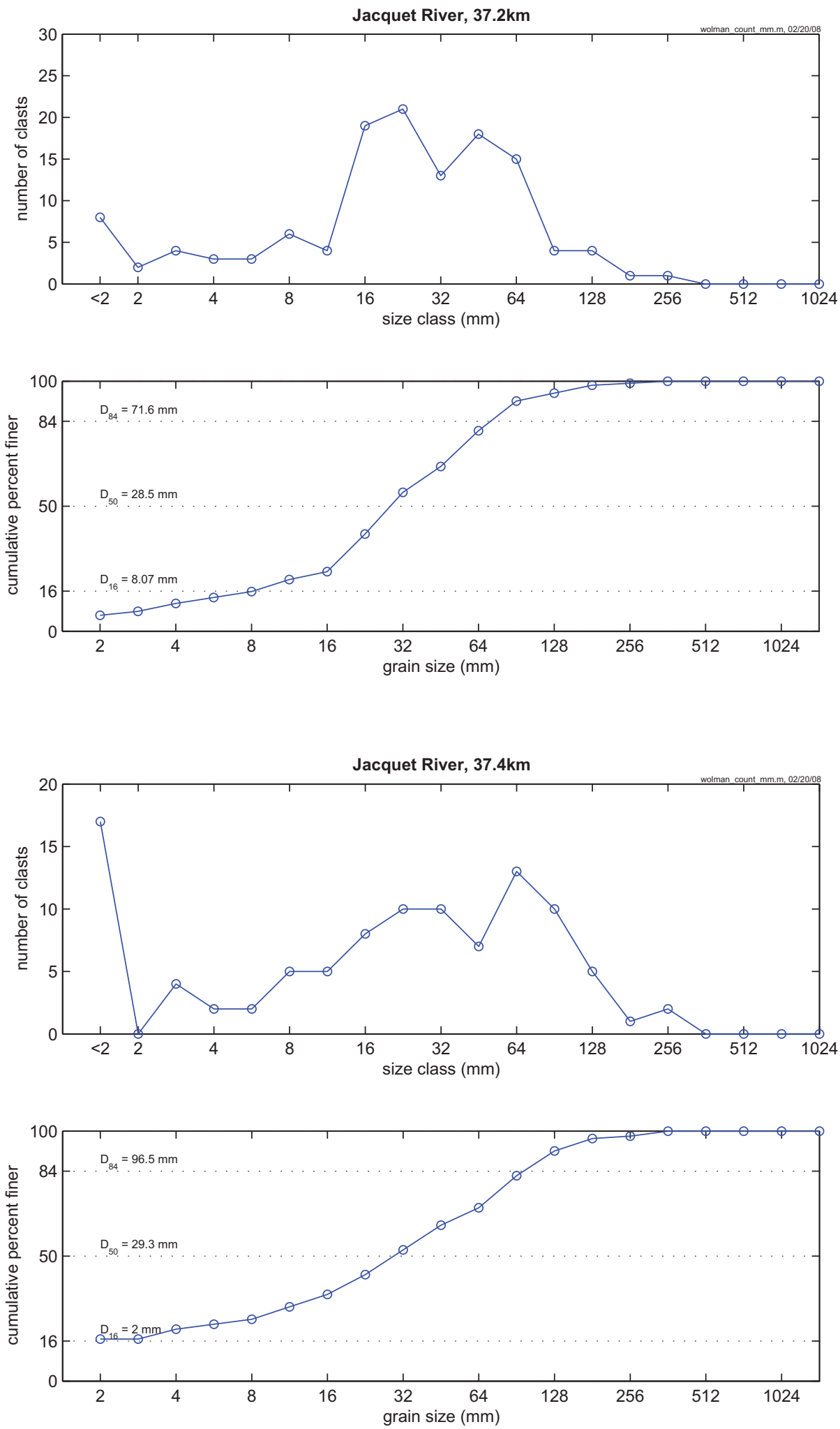


\section{Appendix 2.}

Field measurements of active and high-flow width and depth, as well as observed grain sizes $\left(D_{16}, D_{50}\right.$ and $\left.D_{84}\right)$ for the study rivers. 


\begin{tabular}{|c|c|c|c|c|c|c|c|c|}
\hline \multicolumn{9}{|c|}{ Narraguagus River } \\
\hline \multirow{2}{*}{$\begin{array}{c}\text { River } \\
\text { km } \\
\text { survey } \\
\text { point }\end{array}$} & \multirow{2}{*}{$\begin{array}{l}\text { Active } \\
\text { width } \\
\text { (m) }\end{array}$} & \multirow{2}{*}{$\begin{array}{l}\text { Active } \\
\text { depth } \\
\text { (m) }\end{array}$} & \multirow{2}{*}{$\begin{array}{l}\text { High- } \\
\text { flow } \\
\text { width } \\
\text { (m) }\end{array}$} & \multirow{2}{*}{$\begin{array}{l}\text { High- } \\
\text { flow } \\
\text { depth } \\
\text { (m) }\end{array}$} & \multirow{2}{*}{$\begin{array}{l}\text { High- } \\
\text { flow } \\
\text { w/d } \\
\text { ratio }\end{array}$} & \multicolumn{3}{|c|}{$\begin{array}{c}\text { Observed } \\
\text { grain size } \\
(\mathrm{mm})\end{array}$} \\
\hline & & & & & & $D_{16}$ & $D_{50}$ & $D_{84}$ \\
\hline 37.3 & 24.77 & 0.43 & 28.49 & 0.88 & 32.38 & & & \\
\hline 37.4 & 25.47 & 0.50 & 27.99 & 1.06 & 26.53 & 23 & 76 & 192 \\
\hline 37.5 & 37.80 & 0.26 & 42.23 & 0.96 & 44.22 & & & \\
\hline 37.6 & 24.29 & 0.52 & 27.09 & 0.99 & 27.50 & 8 & 77 & 242 \\
\hline 37.7 & 28.40 & 1.81 & 31.62 & 2.45 & 12.93 & & & \\
\hline 37.8 & 23.33 & 0.86 & 28.09 & 1.71 & 16.48 & 10 & 76 & 188 \\
\hline 37.9 & 19.52 & 0.61 & 25.73 & 0.99 & 25.99 & & & \\
\hline 38.0 & 13.81 & 0.83 & 18.70 & 1.59 & 11.80 & $\mathrm{n} / \mathrm{a}$ & $\mathrm{n} / \mathrm{a}$ & $\mathrm{n} / \mathrm{a}$ \\
\hline 38.1 & 10.22 & 1.08 & 17.78 & 1.62 & 11.01 & & & \\
\hline 38.2 & 12.78 & 0.54 & 19.53 & 1.37 & 14.31 & 79 & 141 & 389 \\
\hline 38.3 & 27.64 & 0.63 & 33.04 & 1.19 & 27.88 & & & \\
\hline 38.4 & 19.94 & 0.51 & 25.66 & 1.11 & 23.12 & 20 & 62 & 134 \\
\hline 38.5 & 19.15 & 0.35 & 23.25 & 1.14 & 20.39 & & & \\
\hline 38.6 & 22.01 & 0.46 & 26.34 & 0.94 & 28.17 & 16 & 30 & 78 \\
\hline 38.7 & 19.12 & 0.34 & 25.52 & 0.68 & 37.81 & & & \\
\hline 38.8 & 31.03 & 0.58 & 33.66 & 1.23 & 27.48 & 15 & 37 & 84 \\
\hline 38.9 & 32.86 & $\mathrm{n} / \mathrm{a}$ & 34.34 & $\mathrm{n} / \mathrm{a}$ & n/a & & & \\
\hline 39.0 & 18.05 & 0.56 & 21.05 & 0.95 & 22.28 & 39 & 89 & 181 \\
\hline 39.1 & 25.33 & 0.46 & 26.16 & 0.90 & 29.23 & & & \\
\hline 39.2 & 32.53 & 0.12 & 37.87 & 0.66 & 57.38 & 13 & 39 & 83 \\
\hline 39.3 & 36.74 & 0.12 & 41.96 & 0.66 & 63.58 & & & \\
\hline 39.4 & 38.35 & 0.90 & 41.85 & 1.35 & 31.00 & 2 & 3 & 53 \\
\hline 39.5 & 30.57 & $\mathrm{n} / \mathrm{a}$ & 42.55 & $\mathrm{n} / \mathrm{a}$ & $\mathrm{n} / \mathrm{a}$ & & & \\
\hline 39.6 & $\mathrm{n} / \mathrm{a}$ & $\mathrm{n} / \mathrm{a}$ & 52.00 & $\mathrm{n} / \mathrm{a}$ & $\mathrm{n} / \mathrm{a}$ & $\mathrm{n} / \mathrm{a}$ & $\mathrm{n} / \mathrm{a}$ & $\mathrm{n} / \mathrm{a}$ \\
\hline 39.7 & $\mathrm{n} / \mathrm{a}$ & $\mathrm{n} / \mathrm{a}$ & 80.00 & $\mathrm{n} / \mathrm{a}$ & $\mathrm{n} / \mathrm{a}$ & & & \\
\hline 39.8 & $\mathrm{n} / \mathrm{a}$ & $\mathrm{n} / \mathrm{a}$ & 83.00 & $\mathrm{n} / \mathrm{a}$ & $\mathrm{n} / \mathrm{a}$ & $\mathrm{n} / \mathrm{a}$ & $\mathrm{n} / \mathrm{a}$ & $\mathrm{n} / \mathrm{a}$ \\
\hline 39.9 & 35.87 & 1.33 & 49.18 & 1.64 & 29.99 & & & \\
\hline 40.0 & 20.86 & 0.44 & 58.99 & 0.95 & 61.85 & 2 & 6 & 13 \\
\hline 40.1 & 17.99 & 0.56 & 51.82 & 1.20 & 43.09 & & & \\
\hline 40.2 & 64.10 & 0.70 & 67.17 & 0.95 & 71.08 & 2 & 6 & 17 \\
\hline 40.3 & 43.68 & 0.36 & 48.11 & 0.88 & 54.98 & & & \\
\hline 40.4 & 33.84 & 0.73 & 37.42 & 1.23 & 30.55 & 3 & 20 & 48 \\
\hline 40.5 & 38.13 & 0.57 & 44.00 & 0.95 & 46.32 & & & \\
\hline 40.6 & 24.43 & 0.64 & 27.42 & 1.20 & 22.95 & 2 & 14 & 38 \\
\hline 40.7 & 24.77 & 1.45 & 28.43 & 2.02 & 14.07 & & & \\
\hline 40.8 & 31.17 & 0.61 & 32.66 & 0.97 & 33.84 & 5 & 24 & 56 \\
\hline 40.9 & 32.78 & 0.35 & 35.20 & 0.86 & 40.93 & & & \\
\hline 41.0 & 20.71 & 0.56 & 25.38 & 1.12 & 22.66 & 2 & 16 & 42 \\
\hline 41.1 & 27.91 & 0.49 & 42.19 & 1.04 & 40.57 & & & \\
\hline 41.2 & 23.91 & 0.30 & 58.56 & 1.03 & 56.85 & 6 & 17 & 38 \\
\hline 41.3 & 23.86 & 0.33 & 38.69 & 1.03 & 37.56 & & & \\
\hline
\end{tabular}




\begin{tabular}{|c|c|c|c|c|c|c|c|c|}
\hline \multicolumn{9}{|c|}{ Narraguagus River } \\
\hline \multirow{2}{*}{$\begin{array}{l}\text { River } \\
\text { km } \\
\text { survey } \\
\text { point }\end{array}$} & \multirow{2}{*}{$\begin{array}{l}\text { Active } \\
\text { width } \\
\text { (m) }\end{array}$} & \multirow{2}{*}{$\begin{array}{l}\text { Active } \\
\text { depth } \\
\text { (m) }\end{array}$} & \multirow{2}{*}{$\begin{array}{l}\text { High- } \\
\text { flow } \\
\text { width } \\
\text { (m) }\end{array}$} & \multirow{2}{*}{$\begin{array}{l}\text { High- } \\
\text { flow } \\
\text { depth } \\
\text { (m) }\end{array}$} & \multirow{2}{*}{$\begin{array}{l}\text { High- } \\
\text { flow } \\
\text { w/d } \\
\text { ratio }\end{array}$} & \multicolumn{3}{|c|}{$\begin{array}{l}\text { Observed } \\
\text { grain size } \\
(\mathrm{mm})\end{array}$} \\
\hline & & & & & & $D_{16}$ & $\mathrm{D}_{50}$ & $D_{84}$ \\
\hline 41.4 & 10.93 & 0.26 & 21.40 & 0.87 & 24.53 & 2 & 13 & 41 \\
\hline 41.5 & 33.52 & 0.66 & 38.51 & 1.13 & 34.23 & & & \\
\hline 41.6 & 22.60 & 0.66 & 24.53 & 1.07 & 22.93 & 5 & 25 & 62 \\
\hline 41.7 & 19.74 & 0.21 & 24.24 & 0.59 & 41.44 & & & \\
\hline 41.8 & 12.57 & 0.43 & 30.73 & 0.79 & 39.15 & 3 & 16 & 46 \\
\hline 41.9 & 67.62 & $\mathrm{n} / \mathrm{a}$ & $\mathrm{n} / \mathrm{a}$ & $\mathrm{n} / \mathrm{a}$ & $\mathrm{n} / \mathrm{a}$ & & & \\
\hline 42.0 & 37.25 & 0.22 & 43.53 & 0.63 & 69.65 & 8 & 24 & 48 \\
\hline 42.1 & 41.01 & 0.67 & 44.99 & 1.12 & 40.35 & & & \\
\hline 42.2 & 55.38 & 0.92 & 60.57 & 1.23 & 49.44 & 2 & 20 & 48 \\
\hline \multicolumn{9}{|c|}{ Beddington Lake } \\
\hline 46.0 & 22.51 & 0.35 & 38.59 & 1.00 & 38.59 & 2 & 7 & 52 \\
\hline 46.1 & 31.95 & 0.25 & 34.65 & 1.06 & 32.69 & & & \\
\hline 46.2 & 31.45 & 0.31 & 37.22 & 1.03 & 36.31 & 5 & 35 & 63 \\
\hline 46.3 & 18.84 & 0.38 & 23.46 & 0.97 & 24.19 & & & \\
\hline 46.4 & 15.48 & 0.35 & 35.50 & 0.82 & 43.29 & 6 & 31 & 70 \\
\hline 46.5 & $\mathrm{n} / \mathrm{a}$ & $\mathrm{n} / \mathrm{a}$ & $\mathrm{n} / \mathrm{a}$ & $\mathrm{n} / \mathrm{a}$ & $\mathrm{n} / \mathrm{a}$ & & & \\
\hline 46.6 & $\mathrm{n} / \mathrm{a}$ & $\mathrm{n} / \mathrm{a}$ & $\mathrm{n} / \mathrm{a}$ & $\mathrm{n} / \mathrm{a}$ & $\mathrm{n} / \mathrm{a}$ & 26 & 54 & 109 \\
\hline 46.7 & $\mathrm{n} / \mathrm{a}$ & $\mathrm{n} / \mathrm{a}$ & $\mathrm{n} / \mathrm{a}$ & $\mathrm{n} / \mathrm{a}$ & $\mathrm{n} / \mathrm{a}$ & & & \\
\hline 46.8 & $\mathrm{n} / \mathrm{a}$ & $\mathrm{n} / \mathrm{a}$ & $\mathrm{n} / \mathrm{a}$ & $\mathrm{n} / \mathrm{a}$ & $\mathrm{n} / \mathrm{a}$ & 19 & 52 & 147 \\
\hline 46.9 & $\mathrm{n} / \mathrm{a}$ & $\mathrm{n} / \mathrm{a}$ & $\mathrm{n} / \mathrm{a}$ & $\mathrm{n} / \mathrm{a}$ & $\mathrm{n} / \mathrm{a}$ & & & \\
\hline 47.0 & 14.27 & 0.53 & 25.62 & 1.27 & 20.17 & 20 & 75 & 164 \\
\hline 47.1 & 23.50 & 0.36 & 33.39 & 1.06 & 31.50 & & & \\
\hline 47.2 & 26.43 & 0.35 & 33.15 & 0.96 & 34.53 & 10 & 48 & 132 \\
\hline 47.3 & 21.94 & 0.29 & 31.19 & 1.11 & 28.10 & & & \\
\hline 47.4 & 26.63 & 0.39 & 31.81 & 1.18 & 27.07 & 10 & 52 & 99 \\
\hline 47.5 & 30.85 & 0.38 & 38.65 & 1.33 & 29.17 & & & \\
\hline 47.6 & 17.58 & 0.28 & 27.59 & 1.13 & 24.52 & 23 & 60 & 137 \\
\hline 47.7 & 13.56 & 0.66 & 18.63 & 1.41 & 13.26 & & & \\
\hline 47.8 & 21.83 & 0.36 & 28.63 & 1.15 & 25.00 & 9 & 66 & 156 \\
\hline 47.9 & 20.56 & 0.31 & 25.93 & 1.05 & 24.70 & & & \\
\hline 48.0 & 20.63 & 0.35 & 26.76 & 0.87 & 30.76 & 14 & 66 & 185 \\
\hline 48.1 & 20.03 & 0.38 & 24.27 & 1.15 & 21.10 & & & \\
\hline 48.2 & 17.06 & 0.39 & 22.80 & 1.08 & 21.11 & 8 & 65 & 240 \\
\hline 48.3 & 21.33 & 0.30 & 24.32 & 1.01 & 24.08 & & & \\
\hline 48.4 & 18.01 & 0.38 & 21.98 & 0.88 & 24.98 & 7 & 45 & 140 \\
\hline 48.5 & 20.28 & 0.29 & 23.66 & 0.84 & 28.34 & & & \\
\hline 48.6 & 33.98 & 0.28 & 37.53 & 0.90 & 41.70 & 8 & 28 & 104 \\
\hline 48.7 & 21.90 & 0.53 & 27.52 & 1.48 & 18.66 & & & \\
\hline 48.8 & $\mathrm{n} / \mathrm{a}$ & $\mathrm{n} / \mathrm{a}$ & $\mathrm{n} / \mathrm{a}$ & $\mathrm{n} / \mathrm{a}$ & $\mathrm{n} / \mathrm{a}$ & 4 & 18 & 53 \\
\hline 48.9 & 21.30 & 0.46 & 56.47 & 1.15 & 49.10 & & & \\
\hline 49.0 & 24.66 & 0.38 & 30.27 & 1.15 & 26.44 & 5 & 29 & 106 \\
\hline 49.1 & 16.59 & 0.43 & 23.87 & 0.96 & 24.99 & & & \\
\hline
\end{tabular}




\begin{tabular}{|c|c|c|c|c|c|c|c|c|}
\hline \multicolumn{9}{|c|}{ Narraguagus River } \\
\hline \multirow{2}{*}{$\begin{array}{c}\text { River } \\
\text { km } \\
\text { survey } \\
\text { point }\end{array}$} & \multirow{2}{*}{$\begin{array}{l}\text { Active } \\
\text { width } \\
\text { (m) }\end{array}$} & \multirow{2}{*}{$\begin{array}{l}\text { Active } \\
\text { depth } \\
\text { (m) }\end{array}$} & \multirow{2}{*}{$\begin{array}{l}\text { High- } \\
\text { flow } \\
\text { width } \\
\text { (m) }\end{array}$} & \multirow[t]{2}{*}{$\begin{array}{l}\text { High- } \\
\text { flow } \\
\text { depth } \\
\text { (m) }\end{array}$} & \multirow{2}{*}{$\begin{array}{l}\text { High- } \\
\text { flow } \\
\text { w/d } \\
\text { ratio }\end{array}$} & \multicolumn{3}{|c|}{$\begin{array}{l}\text { Observed } \\
\text { grain size } \\
(\mathrm{mm})\end{array}$} \\
\hline & & & & & & $D_{16}$ & $D_{50}$ & $D_{84}$ \\
\hline 49.2 & 23.22 & 0.41 & 28.53 & 0.84 & 33.96 & 4 & 26 & 103 \\
\hline 49.3 & 21.93 & 0.49 & 28.80 & 1.59 & 18.17 & & & \\
\hline 49.4 & 18.05 & 0.31 & 21.10 & 0.91 & 23.19 & 17 & 55 & 124 \\
\hline 49.5 & $\mathrm{n} / \mathrm{a}$ & $\mathrm{n} / \mathrm{a}$ & n/a & $\mathrm{n} / \mathrm{a}$ & n/a & & & \\
\hline 49.6 & 13.96 & 0.78 & 19.97 & 1.49 & 13.45 & 3 & 63 & 160 \\
\hline 49.7 & 17.51 & 0.46 & 21.57 & 0.79 & 27.30 & & & \\
\hline 49.8 & 51.92 & 0.96 & 55.44 & 1.28 & 43.31 & $n / a$ & $\mathrm{n} / \mathrm{a}$ & $\mathrm{n} / \mathrm{a}$ \\
\hline 49.9 & 18.66 & 1.11 & 26.24 & 1.41 & 18.68 & & & \\
\hline 50.0 & 34.04 & 0.85 & 44.58 & 1.67 & 26.77 & 2 & 5 & 140 \\
\hline 50.1 & $\mathrm{n} / \mathrm{a}$ & $\mathrm{n} / \mathrm{a}$ & $\mathrm{n} / \mathrm{a}$ & $\mathrm{n} / \mathrm{a}$ & n/a & & & \\
\hline 50.2 & 31.35 & 0.61 & 33.44 & 1.26 & 26.54 & 2 & 13 & 97 \\
\hline 50.3 & 29.64 & 0.77 & 37.16 & 1.48 & 25.11 & & & \\
\hline 50.4 & 24.92 & 1.15 & 30.71 & 1.84 & 16.74 & $\mathrm{n} / \mathrm{a}$ & $\mathrm{n} / \mathrm{a}$ & $\mathrm{n} / \mathrm{a}$ \\
\hline 50.5 & 29.81 & 0.71 & 44.59 & 1.61 & 27.78 & & & \\
\hline 50.6 & 26.71 & 0.83 & 32.03 & 1.37 & 23.38 & 2 & 3 & 15 \\
\hline 50.7 & 20.62 & 0.93 & 23.74 & 1.60 & 14.88 & & & \\
\hline 50.8 & 38.98 & 0.76 & $\mathrm{n} / \mathrm{a}$ & $\mathrm{n} / \mathrm{a}$ & $\mathrm{n} / \mathrm{a}$ & 2 & 2 & 39 \\
\hline 50.9 & 83.00 & 0.85 & 98.70 & $\mathrm{n} / \mathrm{a}$ & $\mathrm{n} / \mathrm{a}$ & & & \\
\hline 51.0 & 20.62 & 0.48 & 21.77 & 1.00 & 21.88 & 2 & 5 & 59 \\
\hline 51.1 & 19.08 & 0.41 & 22.09 & 1.05 & 21.04 & & & \\
\hline 51.2 & 24.59 & 1.12 & 29.15 & 1.63 & 17.94 & 5 & 25 & 75 \\
\hline 51.3 & 13.22 & 0.27 & 20.81 & 0.72 & 28.90 & & & \\
\hline 51.4 & 19.47 & 0.36 & 21.48 & 0.89 & 24.13 & 2 & 4 & 44 \\
\hline 51.5 & 24.66 & 0.39 & 26.95 & 1.17 & 23.13 & & & \\
\hline 51.6 & 15.51 & 0.53 & 18.00 & 1.28 & 14.12 & 2 & 4 & 31 \\
\hline 51.7 & 20.89 & 0.54 & 27.55 & $\mathrm{n} / \mathrm{a}$ & n/a & & & \\
\hline 51.8 & 30.01 & 0.53 & 33.39 & 1.11 & 30.08 & 2 & 5 & 32 \\
\hline 51.9 & 32.50 & 0.69 & 37.05 & 1.11 & 33.53 & & & \\
\hline 52.0 & 24.64 & 0.43 & 32.72 & 1.13 & 28.96 & 2 & 10 & 41 \\
\hline 52.1 & 10.52 & 0.39 & 18.85 & 1.17 & 16.18 & & & \\
\hline 52.2 & 18.42 & 0.33 & 29.38 & 0.85 & 34.56 & 2 & 3 & 8 \\
\hline 52.3 & 13.02 & 0.57 & 35.42 & 1.03 & 34.39 & & & \\
\hline 52.4 & 14.89 & 0.40 & 22.67 & 0.98 & 23.13 & 3 & 12 & 36 \\
\hline 52.5 & 11.32 & 0.37 & 37.50 & 0.93 & 40.32 & & & \\
\hline 52.6 & 21.28 & 0.60 & 50.70 & 0.97 & 52.27 & 2 & 5 & 34 \\
\hline 52.7 & 30.37 & 0.49 & 34.09 & 1.16 & 29.52 & & & \\
\hline 52.8 & 15.29 & 0.58 & 19.73 & 1.22 & 16.17 & 3 & 28 & 69 \\
\hline 52.9 & 18.52 & 0.74 & 21.20 & 1.40 & 15.14 & & & \\
\hline 53.0 & 34.14 & 0.22 & 44.78 & 0.70 & 63.97 & 2 & 14 & 42 \\
\hline 53.1 & 21.49 & 0.36 & 27.22 & 0.88 & 30.93 & & & \\
\hline 53.2 & 20.03 & 0.68 & 28.80 & 1.03 & 27.96 & 2 & 35 & 82 \\
\hline 53.3 & 21.49 & 0.76 & 23.72 & 1.23 & 19.28 & & & \\
\hline
\end{tabular}




\begin{tabular}{|c|cccccccc|}
\hline \multicolumn{10}{|c|}{ Narraguagus River } \\
\hline $\begin{array}{c}\text { River } \\
\text { km } \\
\text { survey } \\
\text { point }\end{array}$ & $\begin{array}{c}\text { Active } \\
\text { width } \\
(\mathbf{m})\end{array}$ & $\begin{array}{c}\text { Active } \\
\text { depth } \\
(\mathbf{m})\end{array}$ & $\begin{array}{c}\text { High- } \\
\text { flow } \\
\text { width } \\
(\mathbf{m})\end{array}$ & $\begin{array}{c}\text { High- } \\
\text { flow } \\
\text { depth } \\
(\mathbf{m})\end{array}$ & $\begin{array}{c}\text { High- } \\
\text { flow } \\
\text { w/d } \\
\text { ratio }\end{array}$ & $\begin{array}{c}\text { Observed } \\
\text { grain size } \\
(\mathbf{m m})\end{array}$ \\
\hline $\mathbf{5 3 . 4}$ & 15.70 & 0.68 & 19.44 & 1.29 & 15.13 & 4 & 36 & 81 \\
$\mathbf{\mathbf { D } _ { \mathbf { 5 0 } }}$ & $\mathbf{D}_{\mathbf{8 4}}$ \\
$\mathbf{5 3 . 5}$ & 16.72 & 0.67 & 20.96 & 1.21 & 17.32 & & & \\
$\mathbf{5 3 . 6}$ & 15.27 & 0.43 & 20.60 & 1.13 & 18.23 & 2 & 23 & 84 \\
$\mathbf{5 3 . 7}$ & 18.11 & 0.40 & 20.98 & 0.96 & 21.97 & & & \\
$\mathbf{5 3 . 8}$ & 18.75 & 0.55 & 22.19 & 1.18 & 18.89 & 2 & 23 & 84 \\
$\mathbf{5 3 . 9}$ & 23.03 & 0.31 & 28.17 & 0.84 & 33.54 & & & \\
$\mathbf{5 4 . 0}$ & $\mathrm{n} / \mathrm{a}$ & $\mathrm{n} / \mathrm{a}$ & $\mathrm{n} / \mathrm{a}$ & $\mathrm{n} / \mathrm{a}$ & $\mathrm{n} / \mathrm{a}$ & $\mathrm{n} / \mathrm{a}$ & $\mathrm{n} / \mathrm{a}$ & $\mathrm{n} / \mathrm{a}$ \\
$\mathbf{5 4 . 1}$ & 23.61 & 1.15 & 28.61 & 1.70 & 16.88 & & & \\
$\mathbf{5 4 . 2}$ & 35.01 & 0.55 & 38.19 & 1.20 & 31.96 & 2 & 2 & 8 \\
$\mathbf{5 4 . 3}$ & 36.29 & 1.04 & 42.52 & 1.47 & 29.02 & & & \\
$\mathbf{5 4 . 4}$ & 18.45 & 0.18 & 23.48 & 0.75 & 31.52 & 3 & 32 & 101 \\
$\mathbf{5 4 . 5}$ & 17.67 & 0.26 & 24.21 & 0.94 & 25.76 & & & \\
$\mathbf{5 4 . 6}$ & 22.24 & 0.39 & 25.15 & 1.00 & 25.28 & 2 & 28 & 96 \\
$\mathbf{5 4 . 7}$ & 21.01 & 0.92 & 26.63 & 1.26 & 21.13 & & & \\
\hline
\end{tabular}




\begin{tabular}{|c|c|c|c|c|c|c|c|c|}
\hline \multicolumn{9}{|c|}{ Jacquet River } \\
\hline \multirow{2}{*}{$\begin{array}{l}\text { River } \\
\text { km } \\
\text { survey } \\
\text { point }\end{array}$} & \multirow{2}{*}{$\begin{array}{c}\text { Active } \\
\text { width } \\
\text { (m) }\end{array}$} & \multirow{2}{*}{$\begin{array}{c}\text { Active } \\
\text { depth } \\
\text { (m) }\end{array}$} & \multirow{2}{*}{$\begin{array}{l}\text { High- } \\
\text { flow } \\
\text { width } \\
\text { (m) }\end{array}$} & \multirow{2}{*}{$\begin{array}{l}\text { High- } \\
\text { flow } \\
\text { depth } \\
(\mathrm{m})\end{array}$} & \multirow{2}{*}{$\begin{array}{c}\text { High- } \\
\text { flow } \\
\text { w/d } \\
\text { ratio }\end{array}$} & \multicolumn{3}{|c|}{$\begin{array}{l}\text { Observed } \\
\text { grain size } \\
(\mathrm{mm})\end{array}$} \\
\hline & & & & & & $\mathbf{D}_{16}$ & $D_{50}$ & $\mathrm{D}_{84}$ \\
\hline 27.4 & 18.82 & 0.61 & 22.82 & 0.91 & 25.08 & 26 & 66 & 158 \\
\hline 27.5 & 18.13 & 0.62 & 20.17 & 1.00 & 20.27 & & & \\
\hline 27.6 & 19.23 & 0.69 & 24.54 & 1.41 & 17.47 & $\mathrm{n} / \mathrm{a}$ & $\mathrm{n} / \mathrm{a}$ & $\mathrm{n} / \mathrm{a}$ \\
\hline 27.7 & 17.81 & 0.70 & 22.10 & 1.42 & 15.62 & & & \\
\hline 27.8 & 16.86 & 0.46 & 19.63 & 0.83 & 23.79 & 35 & 74 & 141 \\
\hline 27.9 & 22.07 & 0.46 & 25.17 & 0.96 & 26.36 & & & \\
\hline 28.0 & 14.34 & 0.81 & 16.98 & 1.02 & 16.73 & 10 & 59 & 135 \\
\hline 28.1 & 26.64 & 0.38 & 32.15 & 0.93 & 34.48 & & & \\
\hline 28.2 & 25.75 & 0.55 & 28.29 & 1.09 & 25.95 & 30 & 80 & 141 \\
\hline 28.3 & 20.74 & 0.61 & 24.15 & 1.36 & 17.76 & & & \\
\hline 28.4 & 21.42 & 0.93 & 25.46 & 0.94 & 27.09 & 27 & 76 & 143 \\
\hline 28.5 & 33.78 & 0.57 & 38.70 & 1.39 & 27.94 & & & \\
\hline 28.6 & 22.08 & 0.80 & 24.92 & 1.26 & 19.78 & 23 & 57 & 137 \\
\hline 28.7 & 17.17 & 0.59 & 20.87 & 1.37 & 15.29 & & & \\
\hline 28.8 & 12.81 & 0.74 & 65.54 & 1.86 & 35.24 & 35 & 75 & 121 \\
\hline 28.9 & 21.98 & 0.47 & 24.46 & 1.04 & 23.52 & & & \\
\hline 29.0 & 17.92 & 0.85 & 19.89 & 1.27 & 15.66 & 17 & 49 & 114 \\
\hline 29.1 & 17.10 & 1.47 & 20.78 & 1.43 & 14.58 & & & \\
\hline 29.2 & 18.27 & 0.79 & 22.64 & 1.69 & 13.44 & 34 & 67 & 132 \\
\hline 29.3 & 20.64 & 0.49 & 22.36 & 0.73 & 30.63 & & & \\
\hline 29.4 & 19.44 & 0.35 & 22.19 & 0.74 & 30.19 & 25 & 67 & 145 \\
\hline 29.5 & 21.14 & 0.38 & 22.43 & 0.68 & 33.23 & & & \\
\hline 29.6 & 21.32 & 0.51 & 22.64 & 0.97 & 23.46 & 16 & 55 & 118 \\
\hline 29.7 & 19.03 & 0.35 & 21.44 & 1.14 & 18.81 & & & \\
\hline 29.8 & 22.78 & 0.45 & 25.90 & 1.02 & 25.39 & 20 & 88 & 170 \\
\hline 29.9 & 18.43 & 0.53 & 21.54 & 1.05 & 20.51 & & & \\
\hline 30.0 & 15.23 & 0.40 & 17.63 & 0.92 & 19.16 & 54 & 106 & 201 \\
\hline 30.1 & 18.32 & 0.46 & 19.32 & 1.07 & 18.06 & & & \\
\hline 30.2 & 13.14 & 0.52 & 19.90 & 0.96 & 20.84 & 53 & 90 & 152 \\
\hline 30.3 & 32.99 & 0.83 & 35.27 & 1.08 & 32.81 & & & \\
\hline 30.4 & 15.48 & 0.72 & 27.92 & 1.32 & 21.23 & 29 & 83 & 166 \\
\hline 30.5 & 13.47 & 0.80 & 24.18 & 1.21 & 20.07 & & & \\
\hline 30.6 & 19.24 & 0.63 & 21.77 & 0.85 & 25.61 & 37 & 72 & 140 \\
\hline 30.7 & 18.74 & 0.55 & 24.79 & 1.09 & 22.85 & & & \\
\hline 30.8 & 20.03 & 0.48 & $\mathrm{n} / \mathrm{a}$ & $\mathrm{n} / \mathrm{a}$ & $\mathrm{n} / \mathrm{a}$ & 33 & 65 & 123 \\
\hline 30.9 & 19.47 & 0.47 & 21.02 & 1.02 & 20.61 & & & \\
\hline 31.0 & 12.34 & 0.39 & 28.75 & 0.89 & 32.30 & 23 & 47 & 114 \\
\hline 31.1 & 15.99 & 0.67 & 21.14 & 1.00 & 21.25 & & & \\
\hline 31.2 & 14.88 & 0.53 & 21.23 & 0.90 & 23.72 & 32 & 67 & 134 \\
\hline 31.3 & 6.74 & 0.66 & 18.59 & 1.46 & 12.78 & & & \\
\hline 31.4 & 12.34 & 0.56 & 27.60 & 0.95 & 29.21 & 29 & 56 & 111 \\
\hline
\end{tabular}




\begin{tabular}{|c|c|c|c|c|c|c|c|c|}
\hline \multicolumn{9}{|c|}{ Jacquet River } \\
\hline \multirow{2}{*}{$\begin{array}{l}\text { River } \\
\text { km } \\
\text { survey } \\
\text { point }\end{array}$} & \multirow{2}{*}{$\begin{array}{l}\text { Active } \\
\text { width } \\
\text { (m) }\end{array}$} & \multirow{2}{*}{$\begin{array}{c}\text { Active } \\
\text { depth } \\
\text { (m) }\end{array}$} & \multirow{2}{*}{$\begin{array}{l}\text { High- } \\
\text { flow } \\
\text { width } \\
\text { (m) }\end{array}$} & \multirow{2}{*}{$\begin{array}{l}\text { High- } \\
\text { flow } \\
\text { depth } \\
\text { (m) }\end{array}$} & \multirow{2}{*}{$\begin{array}{l}\text { High- } \\
\text { flow } \\
\text { w/d } \\
\text { ratio }\end{array}$} & \multicolumn{3}{|c|}{$\begin{array}{l}\text { Observed } \\
\text { grain size }\end{array}$} \\
\hline & & & & & & $D_{16}$ & $D_{50}$ & $D_{84}$ \\
\hline 31.5 & 11.18 & 0.77 & 19.88 & 1.25 & 15.97 & & & \\
\hline 31.6 & 13.49 & 0.41 & 20.38 & 0.84 & 24.41 & 25 & 53 & 131 \\
\hline 31.7 & 21.45 & 0.55 & $\mathrm{n} / \mathrm{a}$ & $\mathrm{n} / \mathrm{a}$ & $\mathrm{n} / \mathrm{a}$ & & & \\
\hline 31.8 & 25.29 & 0.31 & 26.86 & 0.81 & 33.16 & 22 & 39 & 69 \\
\hline 31.9 & 18.79 & 0.51 & 23.75 & 1.04 & 22.84 & & & \\
\hline 32.0 & 24.42 & 0.31 & 29.05 & 0.84 & 34.58 & 29 & 97 & 228 \\
\hline 32.1 & 17.77 & 0.35 & 22.29 & 1.04 & 21.54 & & & \\
\hline 32.2 & 21.64 & 0.40 & $\mathrm{n} / \mathrm{a}$ & $\mathrm{n} / \mathrm{a}$ & $\mathrm{n} / \mathrm{a}$ & 20 & 50 & 115 \\
\hline 32.3 & 31.95 & 0.53 & 35.24 & 1.09 & 32.33 & & & \\
\hline 32.4 & 17.31 & 0.69 & 22.11 & 1.09 & 20.28 & 21 & 52 & 108 \\
\hline 32.5 & 23.16 & 0.47 & 25.04 & 0.75 & 33.61 & & & \\
\hline 32.6 & 18.88 & 0.33 & 20.03 & 0.68 & 29.67 & 27 & 54 & 109 \\
\hline 32.7 & 20.00 & 0.61 & 21.87 & 0.99 & 22.20 & & & \\
\hline 32.8 & 17.96 & 0.45 & 19.65 & 0.67 & 29.33 & 25 & 54 & 111 \\
\hline 32.9 & 16.80 & 0.77 & 19.36 & 1.24 & 15.68 & & & \\
\hline 33.0 & 27.51 & 0.25 & 28.55 & 0.55 & 51.91 & 24 & 53 & 109 \\
\hline 33.1 & 22.13 & 0.58 & 23.50 & 0.84 & 27.98 & & & \\
\hline 33.2 & 19.51 & 0.49 & 21.02 & 0.77 & 27.30 & 10 & 39 & 116 \\
\hline 33.3 & 20.61 & 0.57 & 21.80 & 0.79 & 27.59 & & & \\
\hline 33.4 & 15.72 & 0.52 & 18.99 & 0.69 & 27.72 & 24 & 59 & 132 \\
\hline 33.5 & 16.96 & 0.50 & 18.68 & 1.02 & 18.40 & & & \\
\hline 33.6 & 11.70 & 0.33 & 20.78 & 0.82 & 25.50 & 29 & 68 & 155 \\
\hline 33.7 & 19.69 & 0.85 & 21.03 & 1.13 & 18.61 & & & \\
\hline 33.8 & 17.28 & 0.66 & 19.55 & 1.17 & 16.78 & 13 & 43 & 82 \\
\hline 33.9 & 23.22 & 0.40 & 25.63 & 0.79 & 32.65 & & & \\
\hline 34.0 & 21.06 & 0.27 & 21.81 & 0.69 & 31.61 & 19 & 53 & 111 \\
\hline 34.1 & 16.90 & 0.38 & 19.00 & 0.80 & 23.90 & & & \\
\hline 34.2 & 20.29 & 0.47 & 22.90 & 0.88 & 26.02 & 29 & 72 & 115 \\
\hline 34.3 & 17.69 & 0.38 & 20.31 & 0.69 & 29.43 & & & \\
\hline 34.4 & 20.79 & 0.42 & 23.03 & 0.90 & 25.59 & 8 & 39 & 96 \\
\hline 34.5 & 16.43 & 0.52 & 19.35 & 1.05 & 18.52 & & & \\
\hline 34.6 & 10.19 & 1.56 & 11.60 & 1.09 & 10.69 & 19 & 45 & 101 \\
\hline 34.7 & 15.37 & 0.41 & 17.49 & 0.82 & 21.33 & & & \\
\hline 34.8 & 19.40 & 0.33 & 21.55 & 0.71 & 30.57 & 31 & 65 & 151 \\
\hline 34.9 & 18.57 & 0.47 & 21.69 & 0.85 & 25.67 & & & \\
\hline 35.0 & 15.35 & 0.37 & 17.49 & 0.90 & 19.54 & 19 & 64 & 167 \\
\hline 35.1 & 17.29 & 0.34 & 22.17 & 0.69 & 32.13 & & & \\
\hline 35.2 & 16.27 & 0.62 & 18.44 & 0.97 & 19.01 & 24 & 49 & 108 \\
\hline 35.3 & 14.90 & 0.53 & 16.32 & 0.85 & 19.31 & & & \\
\hline 35.4 & 15.66 & 0.31 & 19.24 & 0.64 & 30.30 & 31 & 67 & 124 \\
\hline 35.5 & 17.09 & 0.40 & 18.73 & 0.68 & 27.54 & & & \\
\hline 35.6 & 11.54 & 0.62 & 12.24 & 0.88 & 13.91 & 32 & 68 & 132 \\
\hline
\end{tabular}




\begin{tabular}{|c|c|c|c|c|c|c|c|c|}
\hline \multicolumn{9}{|c|}{ Jacquet River } \\
\hline \multirow{2}{*}{$\begin{array}{l}\text { River } \\
\text { km } \\
\text { survey } \\
\text { point }\end{array}$} & \multirow{2}{*}{$\begin{array}{l}\text { Active } \\
\text { width } \\
\text { (m) }\end{array}$} & \multirow{2}{*}{$\begin{array}{l}\text { Active } \\
\text { depth } \\
(\mathrm{m})\end{array}$} & \multirow{2}{*}{$\begin{array}{l}\text { High- } \\
\text { flow } \\
\text { width } \\
\text { (m) }\end{array}$} & \multirow{2}{*}{$\begin{array}{l}\text { High- } \\
\text { flow } \\
\text { depth } \\
\text { (m) }\end{array}$} & \multirow{2}{*}{$\begin{array}{c}\text { High- } \\
\text { flow } \\
\text { w/d } \\
\text { ratio }\end{array}$} & \multicolumn{3}{|c|}{$\begin{array}{c}\text { Observed } \\
\text { grain size } \\
(\mathrm{mm})\end{array}$} \\
\hline & & & & & & $D_{16}$ & $D_{50}$ & $D_{84}$ \\
\hline 35.7 & 18.01 & 0.38 & 19.54 & 0.63 & 31.02 & & & \\
\hline 35.8 & 9.39 & 0.50 & 10.60 & 0.79 & 13.42 & 45 & 98 & 175 \\
\hline 35.9 & 23.34 & 0.24 & 24.26 & 0.69 & 35.42 & & & \\
\hline 36.0 & 19.25 & 0.46 & 19.82 & 0.78 & 25.57 & 24 & 49 & 106 \\
\hline 36.1 & 18.04 & 0.25 & 21.46 & 0.74 & 29.00 & & & \\
\hline 36.2 & 14.07 & 0.56 & 19.98 & 0.83 & 24.07 & 38 & 72 & 162 \\
\hline 36.3 & 15.21 & 0.45 & $\mathrm{n} / \mathrm{a}$ & $\mathrm{n} / \mathrm{a}$ & $\mathrm{n} / \mathrm{a}$ & & & \\
\hline 36.4 & 17.64 & 0.34 & 19.10 & 0.64 & 30.08 & 20 & 54 & 107 \\
\hline 36.5 & 15.12 & 0.41 & 17.48 & 0.60 & 29.13 & & & \\
\hline 36.6 & 19.55 & 0.30 & 24.47 & 0.49 & 50.45 & 21 & 47 & 99 \\
\hline 36.7 & 16.31 & 0.30 & 20.02 & 0.62 & 32.29 & & & \\
\hline 36.8 & 10.55 & 0.33 & 13.16 & 0.65 & 20.25 & 34 & 71 & 149 \\
\hline 36.9 & 7.86 & 0.56 & 14.06 & 0.82 & 17.15 & & & \\
\hline 37.0 & 7.35 & 0.46 & 12.56 & 0.81 & 15.51 & 16 & 51 & 92 \\
\hline 37.1 & 10.97 & 0.52 & 12.25 & 0.86 & 14.33 & & & \\
\hline 37.2 & 17.36 & 0.34 & 18.43 & 0.52 & 35.44 & 8 & 29 & 72 \\
\hline 37.3 & 9.87 & 0.58 & 12.68 & 1.15 & 11.03 & & & \\
\hline 37.4 & 9.72 & 0.37 & 12.52 & 0.82 & 15.27 & 2 & 29 & 96 \\
\hline 37.5 & 7.66 & 0.34 & 13.12 & 0.95 & 13.88 & & & \\
\hline 37.6 & 11.53 & 0.36 & 14.11 & 0.69 & 20.45 & 17 & 50 & 97 \\
\hline 37.7 & 20.64 & 0.18 & 21.57 & 0.43 & 50.75 & & & \\
\hline 37.8 & 9.28 & 0.31 & 11.16 & 0.70 & 16.06 & 11 & 38 & 71 \\
\hline
\end{tabular}




\section{Appendix 3.}

Predicted grain sizes for the study rivers. 


\begin{tabular}{|c|ccc|cc|}
\hline & \multicolumn{3}{|c|}{ Narraguagus } & \multicolumn{2}{c|}{ Jacquet } \\
River km & $\boldsymbol{D}_{50 \text { emp }}$ & $\boldsymbol{D}_{50 \text { gis }}$ & $\boldsymbol{D}_{50}$ lidar & $\boldsymbol{D}_{50 \text { emp }}$ & $\boldsymbol{D}_{50 \text { gis }}$ \\
$(\mathrm{mm})$ & $(\mathrm{mm})$ & $(\mathrm{mm})$ & $(\mathrm{mm})$ \\
\hline $\mathbf{0 . 0}$ & 200 & 237 & 152 & $\mathrm{n} / \mathrm{a}$ & $\mathrm{n} / \mathrm{a}$ \\
$\mathbf{0 . 1}$ & 136 & 161 & 91 & $\mathrm{n} / \mathrm{a}$ & $\mathrm{n} / \mathrm{a}$ \\
$\mathbf{0 . 2}$ & 95 & 111 & 94 & $\mathrm{n} / \mathrm{a}$ & $\mathrm{n} / \mathrm{a}$ \\
$\mathbf{0 . 3}$ & 96 & 113 & 100 & $\mathrm{n} / \mathrm{a}$ & $\mathrm{n} / \mathrm{a}$ \\
$\mathbf{0 . 4}$ & 96 & 113 & 109 & $\mathrm{n} / \mathrm{a}$ & $\mathrm{n} / \mathrm{a}$ \\
$\mathbf{0 . 5}$ & 104 & 122 & 150 & $\mathrm{n} / \mathrm{a}$ & $\mathrm{n} / \mathrm{a}$ \\
$\mathbf{0 . 6}$ & 117 & 137 & 197 & $\mathrm{n} / \mathrm{a}$ & $\mathrm{n} / \mathrm{a}$ \\
$\mathbf{0 . 7}$ & 162 & 191 & 127 & $\mathrm{n} / \mathrm{a}$ & $\mathrm{n} / \mathrm{a}$ \\
$\mathbf{0 . 8}$ & 78 & 91 & 84 & $\mathrm{n} / \mathrm{a}$ & $\mathrm{n} / \mathrm{a}$ \\
$\mathbf{0 . 9}$ & 86 & 100 & 88 & $\mathrm{n} / \mathrm{a}$ & $\mathrm{n} / \mathrm{a}$ \\
$\mathbf{1 . 0}$ & 25 & 28 & 174 & $\mathrm{n} / \mathrm{a}$ & $\mathrm{n} / \mathrm{a}$ \\
$\mathbf{1 . 1}$ & 25 & 28 & 214 & $\mathrm{n} / \mathrm{a}$ & $\mathrm{n} / \mathrm{a}$ \\
$\mathbf{1 . 2}$ & 31 & 36 & 226 & $\mathrm{n} / \mathrm{a}$ & $\mathrm{n} / \mathrm{a}$ \\
$\mathbf{1 . 3}$ & 29 & 34 & 164 & 57 & 34 \\
$\mathbf{1 . 4}$ & 33 & 38 & 126 & 56 & 29 \\
$\mathbf{1 . 5}$ & 28 & 32 & 58 & 58 & 51 \\
$\mathbf{1 . 6}$ & 27 & 31 & 55 & 58 & 56 \\
$\mathbf{1 . 7}$ & 25 & 28 & 45 & 60 & 73 \\
$\mathbf{1 . 8}$ & 24 & 28 & 82 & 59 & 61 \\
$\mathbf{1 . 9}$ & 24 & 27 & 66 & 62 & 100 \\
$\mathbf{2 . 0}$ & 25 & 28 & 7 & 59 & 68 \\
$\mathbf{2 . 1}$ & 24 & 28 & 7 & 62 & 100 \\
$\mathbf{2 . 2}$ & 24 & 27 & 7 & 61 & 88 \\
$\mathbf{2 . 3}$ & 25 & 28 & 7 & 64 & 126 \\
$\mathbf{2 . 4}$ & 26 & 29 & 7 & 61 & 87 \\
$\mathbf{2 . 5}$ & 26 & 29 & 7 & 58 & 50 \\
$\mathbf{2 . 6}$ & 23 & 26 & 7 & 59 & 60 \\
$\mathbf{2 . 7}$ & 17 & 19 & 5 & 59 & 59 \\
$\mathbf{2 . 8}$ & 26 & 29 & 7 & 59 & 59 \\
$\mathbf{2 . 9}$ & 28 & 32 & 7 & 58 & 53 \\
$\mathbf{4 . 0}$ & 21 & 23 & 6 & 58 & 48 \\
$\mathbf{4 . 1}$ & 19 & 21 & 10 & 58 & 49 \\
$\mathbf{3 . 2}$ & 26 & 29 & 8 & 59 & 68 \\
$\mathbf{3 . 3}$ & 33 & 38 & 9 & 58 & 57 \\
$\mathbf{3 . 4}$ & 23 & 25 & 6 & 59 & 62 \\
$\mathbf{3 . 5}$ & 29 & 33 & 9 & 59 & 59 \\
$\mathbf{3 . 6}$ & 21 & 23 & 6 & 57 & 44 \\
$\mathbf{3 . 7}$ & 30 & 35 & 10 & 58 & 52 \\
$\mathbf{3 . 8}$ & 33 & 38 & 10 & 58 & 50 \\
$\mathbf{4 . 0}$ & 31 & 36 & 9 & 59 & 58 \\
$\mathbf{4 . 1}$ & 28 & 32 & 8 & 58 & 57 \\
$\mathrm{n} / \mathrm{a}$ & $\mathrm{n} / \mathrm{a}$ & 3 & 58 & 55 \\
& 30 & 35 & 9 & 58 & 47 \\
& 30 & 34 & 9 & 59 & 58 \\
& & 34 & 8 & 61 & 88 \\
& & & & 92
\end{tabular}




\begin{tabular}{|c|c|c|c|c|c|}
\hline \multirow[b]{2}{*}{ River km } & \multicolumn{3}{|c|}{ Narraguagus } & \multicolumn{2}{|c|}{ Jacquet } \\
\hline & $\begin{array}{c}\boldsymbol{D}_{50 \text { emp }} \\
(\mathrm{mm})\end{array}$ & $\begin{array}{c}\boldsymbol{D}_{50 \text { gis }} \\
(\mathrm{mm})\end{array}$ & $\begin{array}{c}\boldsymbol{D}_{50} \text { lidar } \\
(\mathrm{mm})\end{array}$ & $\begin{array}{c}\boldsymbol{D}_{50 \text { emp }} \\
(\mathrm{mm})\end{array}$ & $\begin{array}{c}\boldsymbol{D}_{50 \text { gis }} \\
(\mathrm{mm})\end{array}$ \\
\hline 4.6 & 31 & 36 & 9 & 60 & 75 \\
\hline 4.7 & 30 & 34 & 8 & 59 & 70 \\
\hline 4.8 & 27 & 30 & 8 & 59 & 70 \\
\hline 4.9 & 30 & 34 & 9 & 59 & 64 \\
\hline 5.0 & 19 & 21 & 8 & 59 & 68 \\
\hline 5.1 & 26 & 29 & 7 & 60 & 73 \\
\hline 5.2 & 26 & 30 & 8 & 60 & 82 \\
\hline 5.3 & 27 & 31 & 8 & 58 & 54 \\
\hline 5.4 & 30 & 34 & 9 & 62 & 103 \\
\hline 5.5 & 28 & 31 & 8 & 61 & 95 \\
\hline 5.6 & 28 & 32 & 10 & 62 & 97 \\
\hline 5.7 & 26 & 30 & 11 & 61 & 88 \\
\hline 5.8 & 28 & 32 & 12 & 60 & 82 \\
\hline 5.9 & 26 & 30 & 12 & 61 & 91 \\
\hline 6.0 & 29 & 33 & 13 & 61 & 88 \\
\hline 6.1 & 31 & 35 & 12 & 60 & 82 \\
\hline 6.2 & 29 & 33 & 12 & 61 & 92 \\
\hline 6.3 & 28 & 32 & 13 & 60 & 79 \\
\hline 6.4 & 29 & 34 & 13 & 60 & 80 \\
\hline 6.5 & 30 & 34 & 13 & 60 & 75 \\
\hline 6.6 & 29 & 32 & 12 & 61 & 90 \\
\hline 6.7 & 29 & 33 & 10 & 59 & 67 \\
\hline 6.8 & 23 & 26 & 10 & 59 & 61 \\
\hline 6.9 & 27 & 31 & 13 & 58 & 56 \\
\hline 7.0 & 25 & 28 & 12 & 58 & 52 \\
\hline 7.1 & 42 & 48 & 12 & 58 & 54 \\
\hline 7.2 & 39 & 45 & 13 & 60 & 70 \\
\hline 7.3 & 36 & 42 & 13 & 60 & 73 \\
\hline 7.4 & 36 & 42 & 12 & 59 & 66 \\
\hline 7.5 & 34 & 39 & 12 & 59 & 62 \\
\hline 7.6 & 31 & 36 & 10 & 59 & 59 \\
\hline 7.7 & 35 & 40 & 29 & 59 & 62 \\
\hline 7.8 & 33 & 38 & 38 & 58 & 56 \\
\hline 7.9 & 33 & 38 & 48 & 58 & 57 \\
\hline 8.0 & 37 & 42 & 48 & 60 & 73 \\
\hline 8.1 & 51 & 59 & 69 & 60 & 80 \\
\hline 8.2 & 34 & 39 & 52 & 59 & 60 \\
\hline 8.3 & 34 & 38 & 30 & 58 & 51 \\
\hline 8.4 & 31 & 36 & 22 & 59 & 61 \\
\hline 8.5 & 33 & 37 & 20 & 59 & 60 \\
\hline 8.6 & 33 & 38 & 22 & 59 & 70 \\
\hline 8.7 & 33 & 38 & 24 & 59 & 59 \\
\hline 8.8 & 31 & 35 & 21 & 59 & 60 \\
\hline 8.9 & 27 & 31 & 21 & 60 & 80 \\
\hline 9.0 & 24 & 27 & 54 & 59 & 64 \\
\hline 9.1 & 20 & 23 & 64 & 59 & 64 \\
\hline
\end{tabular}




\begin{tabular}{|c|c|c|c|c|c|}
\hline \multirow[b]{2}{*}{ River km } & \multicolumn{3}{|c|}{ Narraguagus } & \multicolumn{2}{|c|}{ Jacquet } \\
\hline & $\begin{array}{c}\boldsymbol{D}_{50 \text { emp }} \\
(\mathrm{mm})\end{array}$ & $\begin{array}{c}\boldsymbol{D}_{50 \text { gis }} \\
(\mathrm{mm})\end{array}$ & $\begin{array}{c}\boldsymbol{D}_{50} \text { lidar } \\
(\mathrm{mm})\end{array}$ & $\begin{array}{c}\boldsymbol{D}_{50 \text { emp }} \\
(\mathrm{mm})\end{array}$ & $\begin{array}{c}\boldsymbol{D}_{50} \text { gis } \\
(\mathrm{mm})\end{array}$ \\
\hline 9.2 & 22 & 25 & 16 & 58 & 52 \\
\hline 9.3 & 21 & 24 & 16 & 58 & 52 \\
\hline 9.4 & 21 & 24 & 16 & 58 & 54 \\
\hline 9.5 & 22 & 24 & 16 & 59 & 64 \\
\hline 9.6 & 22 & 25 & 18 & 59 & 59 \\
\hline 9.7 & 21 & 24 & 15 & 58 & 56 \\
\hline 9.8 & 21 & 24 & 16 & 59 & 60 \\
\hline 9.9 & 20 & 22 & 16 & 58 & 55 \\
\hline 10.0 & 21 & 23 & 17 & 59 & 62 \\
\hline 10.1 & 20 & 22 & 18 & 59 & 68 \\
\hline 10.2 & 25 & 28 & 19 & 60 & 73 \\
\hline 10.3 & 20 & 23 & 21 & 59 & 60 \\
\hline 10.4 & 18 & 19 & 17 & 59 & 66 \\
\hline 10.5 & 21 & 24 & 26 & 59 & 62 \\
\hline 10.6 & 21 & 24 & 24 & 59 & 67 \\
\hline 10.7 & 21 & 24 & 25 & 59 & 67 \\
\hline 10.8 & 23 & 26 & 32 & 60 & 73 \\
\hline 10.9 & 13 & 14 & 15 & 59 & 63 \\
\hline 11.0 & 33 & 37 & 76 & 59 & 67 \\
\hline 11.1 & 28 & 32 & 143 & 58 & 56 \\
\hline 11.2 & 25 & 28 & 94 & 59 & 68 \\
\hline 11.3 & 18 & 19 & 45 & 59 & 64 \\
\hline 11.4 & 18 & 20 & 34 & 59 & 62 \\
\hline 11.5 & 20 & 23 & 29 & 59 & 67 \\
\hline 11.6 & 23 & 26 & 16 & 60 & 75 \\
\hline 11.7 & 22 & 25 & 12 & 60 & 78 \\
\hline 11.8 & 23 & 26 & 13 & 60 & 72 \\
\hline 11.9 & 21 & 24 & 12 & 60 & 71 \\
\hline 12.0 & 23 & 26 & 12 & 60 & 72 \\
\hline 12.1 & 24 & 27 & 11 & 59 & 69 \\
\hline 12.2 & 25 & 28 & 13 & 60 & 71 \\
\hline 12.3 & 24 & 27 & 12 & 60 & 77 \\
\hline 12.4 & 24 & 28 & 14 & 60 & 71 \\
\hline 12.5 & 22 & 25 & 11 & 60 & 72 \\
\hline 12.6 & 23 & 26 & 11 & 60 & 74 \\
\hline 12.7 & 29 & 33 & 15 & 59 & 70 \\
\hline 12.8 & 27 & 31 & 16 & 60 & 78 \\
\hline 12.9 & 21 & 23 & 10 & 59 & 67 \\
\hline 13.0 & 16 & 18 & 12 & 60 & 74 \\
\hline 13.1 & 17 & 18 & 15 & 60 & 80 \\
\hline 13.2 & 16 & 18 & 13 & 60 & 77 \\
\hline 13.3 & 17 & 18 & 13 & 60 & 81 \\
\hline 13.4 & 16 & 17 & 10 & 60 & 71 \\
\hline 13.5 & 16 & 17 & 16 & 60 & 81 \\
\hline 13.6 & 15 & 16 & 13 & 60 & 70 \\
\hline 13.7 & 18 & 19 & 16 & 60 & 75 \\
\hline
\end{tabular}




\begin{tabular}{|c|c|c|c|c|c|}
\hline \multirow[b]{2}{*}{ River km } & \multicolumn{3}{|c|}{ Narraguagus } & \multicolumn{2}{|c|}{ Jacquet } \\
\hline & $\begin{array}{c}\boldsymbol{D}_{50 \text { emp }} \\
(\mathrm{mm})\end{array}$ & $\begin{array}{c}\boldsymbol{D}_{50 \text { gis }} \\
(\mathrm{mm})\end{array}$ & $\begin{array}{c}\boldsymbol{D}_{50} \text { lidar } \\
(\mathrm{mm})\end{array}$ & $\begin{array}{c}\boldsymbol{D}_{50 \text { emp }} \\
(\mathrm{mm})\end{array}$ & $\begin{array}{c}\boldsymbol{D}_{50} \text { gis } \\
(\mathrm{mm})\end{array}$ \\
\hline 13.8 & 15 & 17 & 22 & 61 & 83 \\
\hline 13.9 & 16 & 17 & 28 & 61 & 87 \\
\hline 14.0 & 18 & 20 & 34 & 60 & 76 \\
\hline 14.1 & 16 & 18 & 28 & 58 & 55 \\
\hline 14.2 & 17 & 19 & 34 & 60 & 71 \\
\hline 14.3 & 19 & 21 & 29 & 59 & 68 \\
\hline 14.4 & 16 & 18 & 27 & 61 & 85 \\
\hline 14.5 & 17 & 19 & 29 & 62 & 96 \\
\hline 14.6 & 18 & 20 & 18 & 59 & 61 \\
\hline 14.7 & 13 & 14 & 16 & 59 & 59 \\
\hline 14.8 & 17 & 19 & 16 & 59 & 68 \\
\hline 14.9 & 18 & 20 & 14 & 59 & 70 \\
\hline 15.0 & 17 & 19 & 18 & 59 & 69 \\
\hline 15.1 & 17 & 18 & 13 & 60 & 76 \\
\hline 15.2 & 16 & 17 & 13 & 61 & 89 \\
\hline 15.3 & 18 & 20 & 15 & 60 & 74 \\
\hline 15.4 & 17 & 19 & 17 & 60 & 78 \\
\hline 15.5 & 13 & 14 & 14 & 60 & 81 \\
\hline 15.6 & 20 & 23 & 13 & 62 & 101 \\
\hline 15.7 & 14 & 15 & 16 & 61 & 83 \\
\hline 15.8 & 18 & 19 & 16 & 59 & 68 \\
\hline 15.9 & 15 & 17 & 16 & 60 & 72 \\
\hline 16.0 & 15 & 16 & 13 & 59 & 65 \\
\hline 16.1 & 16 & 18 & 14 & 61 & 87 \\
\hline 16.2 & 17 & 18 & 15 & 61 & 88 \\
\hline 16.3 & 16 & 18 & 18 & 60 & 72 \\
\hline 16.4 & 11 & 12 & 12 & 62 & 97 \\
\hline 16.5 & 17 & 19 & 23 & 60 & 71 \\
\hline 16.6 & 17 & 18 & 21 & 59 & 65 \\
\hline 16.7 & 17 & 19 & 23 & 60 & 77 \\
\hline 16.8 & 16 & 18 & 23 & 60 & 82 \\
\hline 16.9 & 19 & 21 & 20 & 60 & 75 \\
\hline 17.0 & 18 & 20 & 20 & 59 & 70 \\
\hline 17.1 & 17 & 19 & 20 & 59 & 66 \\
\hline 17.2 & 17 & 19 & 21 & 59 & 69 \\
\hline 17.3 & 19 & 21 & 20 & 60 & 80 \\
\hline 17.4 & 17 & 18 & 21 & 60 & 76 \\
\hline 17.5 & 15 & 17 & 21 & 61 & 87 \\
\hline 17.6 & 20 & 22 & 26 & 59 & 62 \\
\hline 17.7 & 17 & 18 & 33 & 61 & 90 \\
\hline 17.8 & 19 & 21 & 34 & 62 & 105 \\
\hline 17.9 & 18 & 20 & 30 & 61 & 86 \\
\hline 18.0 & 17 & 19 & 31 & 61 & 95 \\
\hline 18.1 & 18 & 19 & 33 & 61 & 85 \\
\hline 18.2 & 19 & 21 & 34 & 60 & 83 \\
\hline 18.3 & 18 & 20 & 33 & 62 & 97 \\
\hline
\end{tabular}




\begin{tabular}{|c|c|c|c|c|c|}
\hline \multirow[b]{2}{*}{ River km } & \multicolumn{3}{|c|}{ Narraguagus } & \multicolumn{2}{|c|}{ Jacquet } \\
\hline & $\begin{array}{c}\boldsymbol{D}_{50 \text { emp }} \\
(\mathrm{mm})\end{array}$ & $\begin{array}{c}\boldsymbol{D}_{50 \text { gis }} \\
(\mathrm{mm})\end{array}$ & $\begin{array}{c}\boldsymbol{D}_{50} \text { lidar } \\
(\mathrm{mm})\end{array}$ & $\begin{array}{c}\boldsymbol{D}_{50 \text { emp }} \\
(\mathrm{mm})\end{array}$ & $\begin{array}{c}\boldsymbol{D}_{50} \text { gis } \\
(\mathrm{mm})\end{array}$ \\
\hline 18.4 & 18 & 20 & 27 & 62 & 96 \\
\hline 18.5 & 16 & 18 & 25 & 61 & 87 \\
\hline 18.6 & 15 & 17 & 20 & 61 & 94 \\
\hline 18.7 & 16 & 17 & 22 & 62 & 107 \\
\hline 18.8 & 19 & 22 & 23 & 60 & 73 \\
\hline 18.9 & 17 & 19 & 25 & 60 & 83 \\
\hline 19.0 & 17 & 19 & 23 & 61 & 88 \\
\hline 19.1 & 18 & 20 & 29 & 61 & 87 \\
\hline 19.2 & 16 & 17 & 36 & 61 & 88 \\
\hline 19.3 & 20 & 22 & 49 & 61 & 84 \\
\hline 19.4 & 16 & 18 & 42 & 61 & 87 \\
\hline 19.5 & 18 & 21 & 39 & 60 & 74 \\
\hline 19.6 & 18 & 20 & 38 & 61 & 83 \\
\hline 19.7 & 16 & 18 & 24 & 61 & 94 \\
\hline 19.8 & 18 & 19 & 28 & 61 & 88 \\
\hline 19.9 & 16 & 18 & 27 & 60 & 76 \\
\hline 20.0 & 15 & 16 & 26 & 62 & 99 \\
\hline 20.1 & 15 & 17 & 29 & 61 & 88 \\
\hline 20.2 & 15 & 16 & 26 & 60 & 75 \\
\hline 20.3 & 20 & 22 & 28 & 62 & 96 \\
\hline 20.4 & 27 & 31 & 25 & 60 & 73 \\
\hline 20.5 & 29 & 33 & 24 & 61 & 84 \\
\hline 20.6 & 29 & 33 & 31 & 60 & 73 \\
\hline 20.7 & 28 & 31 & 25 & 61 & 91 \\
\hline 20.8 & 32 & 36 & 25 & 62 & 95 \\
\hline 20.9 & 29 & 33 & 28 & 62 & 107 \\
\hline 21.0 & 27 & 31 & 28 & 64 & 131 \\
\hline 21.1 & 28 & 32 & 23 & 61 & 95 \\
\hline 21.2 & 22 & 25 & 22 & 63 & 112 \\
\hline 21.3 & 29 & 33 & 24 & 64 & 125 \\
\hline 21.4 & 19 & 21 & 17 & 62 & 99 \\
\hline 21.5 & 24 & 27 & 27 & 64 & 121 \\
\hline 21.6 & 24 & 27 & 33 & 62 & 107 \\
\hline 21.7 & 27 & 31 & 30 & 63 & 115 \\
\hline 21.8 & 28 & 32 & 25 & 67 & 168 \\
\hline 21.9 & 26 & 30 & 27 & 66 & 152 \\
\hline 22.0 & 25 & 28 & 31 & 64 & 123 \\
\hline 22.1 & 23 & 26 & 25 & 63 & 113 \\
\hline 22.2 & 31 & 35 & 27 & 65 & 140 \\
\hline 22.3 & 29 & 33 & 31 & 63 & 118 \\
\hline 22.4 & 29 & 33 & 25 & 64 & 123 \\
\hline 22.5 & 25 & 28 & 26 & 62 & 100 \\
\hline 22.6 & 25 & 29 & 23 & 62 & 102 \\
\hline 22.7 & 31 & 36 & 22 & 66 & 151 \\
\hline 22.8 & 24 & 27 & 23 & 62 & 104 \\
\hline 22.9 & 26 & 29 & 32 & 62 & 102 \\
\hline
\end{tabular}




\begin{tabular}{|c|ccc|cc|}
\hline & \multicolumn{3}{|c|}{ Narraguagus } & \multicolumn{2}{c|}{ Jacquet } \\
River km & $\boldsymbol{D}_{\mathbf{5 0} \text { emp }}$ & $\boldsymbol{D}_{\mathbf{5 0} \text { gis }}$ & $\boldsymbol{D}_{\mathbf{5 0} \text { lidar }}$ & $\boldsymbol{D}_{\mathbf{5 0} \text { emp }}$ & $\begin{array}{c}\boldsymbol{D}_{\mathbf{5 0} \text { gis }} \\
(\mathrm{mm})\end{array}$ \\
$(\mathrm{mm})$ & $(\mathrm{mm})$ & $(\mathrm{mm})$ \\
\hline $\mathbf{2 3 . 0}$ & 24 & 27 & 31 & 61 & 86 \\
$\mathbf{2 3 . 1}$ & 31 & 36 & 31 & 60 & 78 \\
$\mathbf{2 3 . 2}$ & 30 & 35 & 42 & 60 & 77 \\
$\mathbf{2 3 . 3}$ & 37 & 43 & 27 & 62 & 106 \\
$\mathbf{2 3 . 4}$ & 34 & 40 & 35 & 64 & 130 \\
$\mathbf{2 3 . 5}$ & 19 & 21 & 29 & 62 & 105 \\
$\mathbf{2 3 . 6}$ & 21 & 23 & 32 & 63 & 114 \\
$\mathbf{2 3 . 7}$ & 34 & 39 & 43 & 63 & 111 \\
$\mathbf{2 3 . 8}$ & 29 & 33 & 34 & 64 & 123 \\
$\mathbf{2 3 . 9}$ & 34 & 39 & 36 & 62 & 104 \\
$\mathbf{2 4 . 0}$ & 33 & 37 & 40 & 59 & 69 \\
$\mathbf{2 4 . 1}$ & 29 & 33 & 29 & 62 & 98 \\
$\mathbf{2 4 . 2}$ & 31 & 35 & 34 & 60 & 81 \\
$\mathbf{2 4 . 3}$ & 33 & 38 & 32 & 61 & 95 \\
$\mathbf{2 4 . 4}$ & 27 & 30 & 26 & 63 & 115 \\
$\mathbf{2 4 . 5}$ & 29 & 33 & 29 & 63 & 113 \\
$\mathbf{2 4 . 6}$ & 28 & 32 & 24 & 63 & 117 \\
$\mathbf{2 4 . 7}$ & 30 & 34 & 27 & 62 & 102 \\
$\mathbf{2 4 . 8}$ & 28 & 32 & 29 & 62 & 99 \\
$\mathbf{2 4 . 9}$ & 39 & 44 & 37 & 61 & 94 \\
$\mathbf{2 5 . 0}$ & 24 & 27 & 27 & 62 & 101 \\
$\mathbf{2 5 . 1}$ & 28 & 32 & 32 & 62 & 106 \\
$\mathbf{2 5 . 2}$ & 27 & 30 & 44 & 63 & 120 \\
$\mathbf{2 5 . 3}$ & 19 & 22 & 36 & 61 & 93 \\
$\mathbf{2 5 . 4}$ & 32 & 37 & 30 & 62 & 104 \\
$\mathbf{2 5 . 5}$ & 17 & 19 & 16 & 62 & 96 \\
$\mathbf{2 5 . 6}$ & 27 & 31 & 26 & 61 & 93 \\
$\mathbf{2 5 . 7}$ & 31 & 35 & 24 & 61 & 92 \\
$\mathbf{2 5 . 8}$ & 31 & 35 & 20 & 61 & 93 \\
$\mathbf{2 5 . 9}$ & 31 & 36 & 22 & 61 & 92 \\
$\mathbf{2 6 . 0}$ & 27 & 31 & 23 & 61 & 93 \\
$\mathbf{2 6 . 1}$ & 26 & 30 & 19 & 61 & 83 \\
$\mathbf{2 6 . 2}$ & 25 & 29 & 22 & 61 & 89 \\
$\mathbf{2 6 . 3}$ & 24 & 27 & 20 & 61 & 86 \\
$\mathbf{2 6 . 4}$ & 30 & 34 & 25 & 60 & 72 \\
$\mathbf{2 6 . 5}$ & 30 & 34 & 24 & 61 & 94 \\
$\mathbf{2 6 . 6}$ & 29 & 32 & 25 & 62 & 105 \\
$\mathbf{2 6 . 7}$ & 28 & 32 & 22 & 60 & 83 \\
$\mathbf{2 6 . 8}$ & 30 & 34 & 27 & 61 & 88 \\
$\mathbf{2 6 . 9}$ & 21 & 23 & 23 & 62 & 107 \\
$\mathbf{2 7 . 0}$ & 21 & 23 & 28 & 63 & 117 \\
$\mathbf{2 7 . 1}$ & 25 & 28 & 21 & 63 & 109 \\
$\mathbf{2 7 . 2}$ & 36 & 42 & 27 & 64 & 125 \\
$\mathbf{2 7 . 3}$ & 27 & 30 & 23 & 61 & 88 \\
& 23 & 26 & 23 & 62 & 103 \\
& 30 & 35 & 33 & 61 & 94
\end{tabular}




\begin{tabular}{|c|c|c|c|c|c|}
\hline \multirow[b]{2}{*}{ River km } & \multicolumn{3}{|c|}{ Narraguagus } & \multicolumn{2}{|c|}{ Jacquet } \\
\hline & $\begin{array}{c}\boldsymbol{D}_{50 \mathrm{emp}} \\
(\mathrm{mm})\end{array}$ & $\begin{array}{c}\boldsymbol{D}_{50 \text { gis }} \\
(\mathrm{mm})\end{array}$ & $\begin{array}{c}\boldsymbol{D}_{50} \text { lidar } \\
(\mathrm{mm})\end{array}$ & $\begin{array}{c}\boldsymbol{D}_{50 \text { emp }} \\
(\mathrm{mm})\end{array}$ & $\begin{array}{c}\boldsymbol{D}_{50} \text { gis } \\
(\mathrm{mm})\end{array}$ \\
\hline 27.6 & 39 & 45 & 40 & 62 & 101 \\
\hline 27.7 & 25 & 28 & 33 & 60 & 83 \\
\hline 27.8 & 25 & 29 & 37 & 62 & 106 \\
\hline 27.9 & 20 & 23 & 33 & 62 & 98 \\
\hline 28.0 & 29 & 33 & 29 & 61 & 85 \\
\hline 28.1 & 29 & 33 & 31 & 60 & 77 \\
\hline 28.2 & 31 & 35 & 27 & 60 & 78 \\
\hline 28.3 & 26 & 29 & 30 & 61 & 85 \\
\hline 28.4 & 21 & 23 & 21 & 64 & 128 \\
\hline 28.5 & 20 & 22 & 27 & 63 & 108 \\
\hline 28.6 & 21 & 23 & 27 & 66 & 146 \\
\hline 28.7 & 27 & 30 & 27 & 65 & 143 \\
\hline 28.8 & 23 & 26 & 29 & 60 & 81 \\
\hline 28.9 & 23 & 26 & 29 & 63 & 108 \\
\hline 29.0 & 29 & 33 & 28 & 64 & 122 \\
\hline 29.1 & 20 & 22 & 27 & 66 & 149 \\
\hline 29.2 & 24 & 27 & 35 & 68 & 170 \\
\hline 29.3 & 26 & 30 & 28 & 64 & 128 \\
\hline 29.4 & 25 & 28 & 30 & 65 & 145 \\
\hline 29.5 & 23 & 26 & 28 & 65 & 141 \\
\hline 29.6 & 28 & 32 & 33 & 64 & 127 \\
\hline 29.7 & 27 & 31 & 34 & 63 & 118 \\
\hline 29.8 & 29 & 33 & 28 & 63 & 118 \\
\hline 29.9 & 27 & 31 & 39 & 65 & 138 \\
\hline 30.0 & 26 & 29 & 39 & 60 & 73 \\
\hline 30.1 & 27 & 31 & 42 & 61 & 89 \\
\hline 30.2 & 27 & 30 & 44 & 57 & 40 \\
\hline 30.3 & 20 & 23 & 46 & 58 & 56 \\
\hline 30.4 & 27 & 30 & 54 & 57 & 43 \\
\hline 30.5 & 28 & 31 & 58 & 58 & 54 \\
\hline 30.6 & 31 & 35 & 48 & 59 & 66 \\
\hline 30.7 & 21 & 24 & 31 & 59 & 68 \\
\hline 30.8 & 116 & 136 & 73 & 59 & 64 \\
\hline 30.9 & 117 & 138 & 199 & 58 & 57 \\
\hline 31.0 & 129 & 152 & 270 & 58 & 55 \\
\hline 31.1 & 203 & 240 & 67 & 59 & 70 \\
\hline 31.2 & 90 & 105 & 59 & 60 & 71 \\
\hline 31.3 & 200 & 237 & 131 & 60 & 73 \\
\hline 31.4 & 245 & 290 & 294 & 61 & 83 \\
\hline 31.5 & 189 & 224 & 284 & 60 & 79 \\
\hline 31.6 & 23 & 25 & 143 & 59 & 68 \\
\hline 31.7 & 27 & 31 & 84 & 58 & 54 \\
\hline 31.8 & 30 & 34 & 38 & 59 & 59 \\
\hline 31.9 & 24 & 26 & 57 & 59 & 63 \\
\hline 32.0 & 37 & 42 & 62 & 59 & 67 \\
\hline 32.1 & 25 & 28 & 17 & 58 & 57 \\
\hline
\end{tabular}




\begin{tabular}{|c|c|c|c|c|c|}
\hline \multirow[b]{2}{*}{ River km } & \multicolumn{3}{|c|}{ Narraguagus } & \multicolumn{2}{|c|}{ Jacquet } \\
\hline & $\begin{array}{c}\boldsymbol{D}_{50 \text { emp }} \\
(\mathrm{mm})\end{array}$ & $\begin{array}{c}\boldsymbol{D}_{50 \text { gis }} \\
(\mathrm{mm})\end{array}$ & $\begin{array}{c}\boldsymbol{D}_{50} \text { lidar } \\
(\mathrm{mm})\end{array}$ & $\begin{array}{c}\boldsymbol{D}_{50 \text { emp }} \\
(\mathrm{mm})\end{array}$ & $\begin{array}{c}\boldsymbol{D}_{50} \text { gis } \\
(\mathrm{mm})\end{array}$ \\
\hline 32.2 & 29 & 33 & 17 & 58 & 49 \\
\hline 32.3 & 32 & 37 & 16 & 58 & 54 \\
\hline 32.4 & 31 & 36 & 21 & 59 & 59 \\
\hline 32.5 & 32 & 37 & 25 & 58 & 54 \\
\hline 32.6 & 26 & 30 & 16 & 60 & 75 \\
\hline 32.7 & 25 & 28 & 21 & 59 & 60 \\
\hline 32.8 & 36 & 41 & 23 & 60 & 77 \\
\hline 32.9 & 23 & 26 & 15 & 59 & 70 \\
\hline 33.0 & 27 & 30 & 29 & 58 & 56 \\
\hline 33.1 & 30 & 34 & 43 & 60 & 71 \\
\hline 33.2 & 41 & 48 & 44 & 60 & 82 \\
\hline 33.3 & 26 & 30 & 30 & 58 & 53 \\
\hline 33.4 & 33 & 38 & 55 & 60 & 75 \\
\hline 33.5 & 26 & 30 & 31 & 59 & 70 \\
\hline 33.6 & 47 & 54 & 40 & 60 & 73 \\
\hline 33.7 & 33 & 37 & 39 & 59 & 68 \\
\hline 33.8 & 40 & 47 & 41 & 60 & 79 \\
\hline 33.9 & 30 & 34 & 34 & 59 & 70 \\
\hline 34.0 & 35 & 41 & 49 & 66 & 147 \\
\hline 34.1 & 31 & 36 & 35 & 65 & 142 \\
\hline 34.2 & 38 & 44 & 42 & 61 & 94 \\
\hline 34.3 & 33 & 38 & 48 & 62 & 105 \\
\hline 34.4 & 25 & 29 & 32 & 62 & 103 \\
\hline 34.5 & 33 & 38 & 26 & 63 & 114 \\
\hline 34.6 & 21 & 24 & 26 & 64 & 121 \\
\hline 34.7 & 29 & 32 & 24 & 63 & 115 \\
\hline 34.8 & 26 & 29 & 25 & 63 & 108 \\
\hline 34.9 & 29 & 33 & 45 & 62 & 104 \\
\hline 35.0 & 37 & 43 & 74 & 65 & 133 \\
\hline 35.1 & 31 & 36 & 53 & 63 & 109 \\
\hline 35.2 & 27 & 30 & 42 & 64 & 126 \\
\hline 35.3 & 28 & 32 & 50 & 64 & 126 \\
\hline 35.4 & 33 & 38 & 40 & 64 & 128 \\
\hline 35.5 & 25 & 28 & 34 & 63 & 108 \\
\hline 35.6 & 29 & 33 & 35 & 65 & 136 \\
\hline 35.7 & 20 & 22 & 43 & 63 & 119 \\
\hline 35.8 & 22 & 25 & 59 & 65 & 135 \\
\hline 35.9 & 38 & 44 & 106 & 59 & 67 \\
\hline 36.0 & 26 & 29 & 72 & 62 & 96 \\
\hline 36.1 & 23 & 25 & 67 & 61 & 83 \\
\hline 36.2 & 96 & 113 & 111 & 61 & 92 \\
\hline 36.3 & 71 & 83 & 76 & 60 & 73 \\
\hline 36.4 & 78 & 92 & 94 & 61 & 84 \\
\hline 36.5 & 97 & 114 & 118 & 60 & 78 \\
\hline 36.6 & 110 & 130 & 105 & 59 & 62 \\
\hline 36.7 & 75 & 87 & 92 & 59 & 68 \\
\hline
\end{tabular}




\begin{tabular}{|c|ccc|cc|}
\hline & \multicolumn{3}{|c|}{ Narraguagus } & \multicolumn{2}{c|}{ Jacquet } \\
River km & $\boldsymbol{D}_{50 \text { emp }}$ & $\boldsymbol{D}_{\mathbf{5 0} \text { gis }}$ & $\boldsymbol{D}_{\mathbf{5 0} \text { lidar }}$ & $\boldsymbol{D}_{50 \text { emp }}$ & $\boldsymbol{D}_{50 \text { gis }}$ \\
$(\mathrm{mm})$ & $(\mathrm{mm})$ & $(\mathrm{mm})$ & $(\mathrm{mm})$ \\
\hline $\mathbf{3 6 . 8}$ & 89 & 104 & 122 & 60 & 80 \\
$\mathbf{3 6 . 9}$ & 73 & 86 & 119 & 60 & 74 \\
$\mathbf{3 7 . 0}$ & 87 & 102 & 103 & 59 & 59 \\
$\mathbf{3 7 . 1}$ & 70 & 82 & 94 & 58 & 57 \\
$\mathbf{3 7 . 2}$ & 71 & 83 & 134 & 58 & 55 \\
$\mathbf{3 7 . 3}$ & 77 & 91 & 102 & 60 & 72 \\
$\mathbf{3 7 . 4}$ & 75 & 88 & 59 & 58 & 50 \\
$\mathbf{3 7 . 5}$ & 64 & 74 & 40 & 58 & 54 \\
$\mathbf{3 7 . 6}$ & 69 & 80 & 37 & 58 & 56 \\
$\mathbf{3 7 . 7}$ & 63 & 73 & 39 & 58 & 53 \\
$\mathbf{3 7 . 8}$ & 65 & 76 & 81 & 59 & 69 \\
$\mathbf{3 7 . 9}$ & 74 & 87 & 117 & 60 & 83 \\
$\mathbf{3 8 . 0}$ & 85 & 100 & 170 & 58 & 48 \\
$\mathbf{3 8 . 1}$ & 88 & 104 & 157 & 58 & 57 \\
$\mathbf{3 8 . 2}$ & 114 & 134 & 112 & 59 & 70 \\
$\mathbf{3 8 . 3}$ & 89 & 104 & 69 & 59 & 63 \\
$\mathbf{3 8 . 4}$ & 100 & 118 & 86 & 58 & 53 \\
$\mathbf{3 8 . 5}$ & 134 & 158 & 100 & 59 & 58 \\
$\mathbf{3 8 . 6}$ & 21 & 23 & 67 & 58 & 51 \\
$\mathbf{3 8 . 7}$ & 22 & 24 & 49 & 59 & 67 \\
$\mathbf{3 8 . 8}$ & 21 & 23 & 50 & 62 & 97 \\
$\mathbf{3 8 . 9}$ & 19 & 21 & 35 & 59 & 61 \\
$\mathbf{3 9 . 0}$ & 23 & 26 & 68 & 62 & 96 \\
$\mathbf{3 9 . 1}$ & 22 & 24 & 85 & 62 & 104 \\
$\mathbf{3 9 . 2}$ & 19 & 21 & 42 & 64 & 129 \\
$\mathbf{3 9 . 3}$ & 17 & 18 & 20 & 64 & 125 \\
$\mathbf{3 9 . 4}$ & 15 & 17 & 11 & 59 & 66 \\
$\mathbf{3 9 . 5}$ & 17 & 19 & 12 & 62 & 103 \\
$\mathbf{3 9 . 6}$ & 14 & 16 & 7 & 63 & 113 \\
$\mathbf{3 9 . 7}$ & 10 & 11 & 9 & 63 & 110 \\
$\mathbf{3 9 . 8}$ & 16 & 17 & 13 & 62 & 102 \\
$\mathbf{3 9 . 9}$ & 15 & 16 & 11 & 61 & 88 \\
$\mathbf{4 0 . 0}$ & 16 & 18 & 10 & 62 & 100 \\
$\mathbf{4 0 . 1}$ & 15 & 16 & 8 & 62 & 103 \\
$\mathbf{4 0 . 2}$ & 15 & 17 & 8 & 62 & 104 \\
$\mathbf{4 0 . 3}$ & 15 & 16 & 9 & 61 & 93 \\
$\mathbf{4 0 . 4}$ & 19 & 21 & 14 & 63 & 108 \\
$\mathbf{4 0 . 5}$ & 16 & 18 & 11 & 63 & 117 \\
$\mathbf{4 0 . 6}$ & 31 & 36 & 13 & 61 & 94 \\
$\mathbf{4 0 . 7}$ & 21 & 23 & 13 & 61 & 90 \\
$\mathbf{4 0 . 8}$ & 17 & 18 & 11 & 62 & 98 \\
$\mathbf{4 0 . 9}$ & 19 & 21 & 13 & 61 & 84 \\
$\mathbf{4 1 . 0}$ & 23 & 26 & 18 & 61 & 90 \\
& 21 & 24 & 19 & 60 & 80 \\
$\mathbf{4 1}$ & 19 & 21 & 17 & 62 & 104 \\
& & 21 & 13 & 59 & 60
\end{tabular}




\begin{tabular}{|c|ccc|cc|}
\hline & \multicolumn{3}{|c|}{ Narraguagus } & \multicolumn{2}{c|}{ Jacquet } \\
River km & $\boldsymbol{D}_{50 \text { emp }}$ & $\boldsymbol{D}_{50 \text { gis }}$ & $\boldsymbol{D}_{50}$ lidar & $\boldsymbol{D}_{50 \text { emp }}$ & $\boldsymbol{D}_{50 \text { gis }}$ \\
$(\mathrm{mm})$ & $(\mathrm{mm})$ & $(\mathrm{mm})$ & $(\mathrm{mm})$ \\
\hline $\mathbf{4 1 . 4}$ & 27 & 31 & 21 & 60 & 74 \\
$\mathbf{4 1 . 5}$ & 18 & 20 & 29 & 62 & 97 \\
$\mathbf{4 1 . 6}$ & 23 & 26 & 47 & 60 & 78 \\
$\mathbf{4 1 . 7}$ & 26 & 30 & 41 & 61 & 89 \\
$\mathbf{4 1 . 8}$ & 19 & 21 & 30 & 60 & 78 \\
$\mathbf{4 1 . 9}$ & 10 & 11 & 3 & 61 & 84 \\
$\mathbf{4 2 . 0}$ & 11 & 12 & 4 & 60 & 78 \\
$\mathbf{4 2 . 1}$ & 12 & 13 & 4 & 65 & 137 \\
$\mathbf{4 2 . 2}$ & 9 & 9 & 3 & 64 & 125 \\
$\mathbf{4 2 . 3}$ & 8 & 8 & 3 & 63 & 115 \\
$\mathbf{4 2 . 4}$ & 7 & 7 & 2 & 61 & 91 \\
$\mathbf{4 2 . 5}$ & 7 & 6 & 2 & 64 & 123 \\
$\mathbf{4 2 . 6}$ & 5 & 5 & 1 & 62 & 106 \\
$\mathbf{4 2 . 7}$ & 5 & 4 & 1 & 64 & 123 \\
$\mathbf{4 2 . 8}$ & 4 & 4 & 1 & 63 & 116 \\
$\mathbf{4 2 . 9}$ & 6 & 5 & 2 & 63 & 114 \\
$\mathbf{4 3 . 0}$ & 7 & 6 & 2 & 61 & 94 \\
$\mathbf{4 3 . 1}$ & 6 & 6 & 2 & 65 & 134 \\
$\mathbf{4 3 . 2}$ & 3 & 3 & 1 & 72 & 231 \\
$\mathbf{4 3 . 3}$ & 3 & 2 & 1 & 70 & 207 \\
$\mathbf{4 3 . 4}$ & 3 & 2 & 1 & 72 & 231 \\
$\mathbf{4 3 . 5}$ & 3 & 3 & 1 & 72 & 225 \\
$\mathbf{4 3 . 6}$ & 3 & 3 & 1 & 73 & 238 \\
$\mathbf{4 3 . 7}$ & 4 & 3 & 1 & 65 & 133 \\
$\mathbf{4 3 . 8}$ & 4 & 3 & 1 & 65 & 133 \\
$\mathbf{4 3 . 9}$ & 4 & 3 & 1 & 64 & 127 \\
$\mathbf{4 4 . 0}$ & 4 & 3 & 1 & 63 & 115 \\
$\mathbf{4 4 . 1}$ & 3 & 3 & 1 & 64 & 124 \\
$\mathbf{4 4 . 2}$ & 3 & 2 & 1 & 64 & 128 \\
$\mathbf{4 4 . 3}$ & 3 & 2 & 1 & 62 & 104 \\
$\mathbf{4 4 . 4}$ & 3 & 2 & 1 & 64 & 122 \\
$\mathbf{4 4 . 5}$ & 3 & 3 & 1 & 65 & 133 \\
$\mathbf{4 4 . 6}$ & 4 & 3 & 1 & 62 & 103 \\
$\mathbf{4 4 . 7}$ & 4 & 4 & 1 & 61 & 87 \\
$\mathbf{4 4 . 8}$ & 5 & 5 & 2 & 62 & 96 \\
$\mathbf{4 4 . 9}$ & 6 & 6 & 2 & 62 & 101 \\
$\mathbf{4 5 . 0}$ & 11 & 12 & 2 & 62 & 97 \\
$\mathbf{4 5 . 1}$ & 10 & 10 & 3 & 63 & 117 \\
$\mathbf{4 5 . 2}$ & 10 & 10 & 3 & 63 & 117 \\
$\mathbf{4 5 . 3}$ & 11 & 12 & 3 & 62 & 103 \\
$\mathbf{4 5 . 4}$ & 10 & 11 & 3 & 62 & 103 \\
$\mathbf{4 5 . 5}$ & 11 & 11 & 4 & 63 & 112 \\
$\mathbf{4 5 . 6}$ & 10 & 11 & 3 & 59 & 59 \\
$\mathbf{4 5 . 7}$ & 12 & 12 & 4 & 59 & 64 \\
& 9 & 9 & 5 & 59 & 67 \\
& 7 & 6 & 6 & 59 & 62
\end{tabular}




\begin{tabular}{|c|ccc|cc|}
\hline & \multicolumn{3}{|c|}{ Narraguagus } & \multicolumn{2}{c|}{ Jacquet } \\
River km & $\boldsymbol{D}_{50 \text { emp }}$ & $\boldsymbol{D}_{50 \text { gis }}$ & $\boldsymbol{D}_{50}$ lidar & $\boldsymbol{D}_{50 \text { emp }}$ & $\boldsymbol{D}_{50 \text { gis }}$ \\
$(\mathrm{mm})$ & $(\mathrm{mm})$ & $(\mathrm{mm})$ & $(\mathrm{mm})$ \\
\hline $\mathbf{4 6 . 0}$ & 16 & 18 & 28 & 59 & 60 \\
$\mathbf{4 6 . 1}$ & 11 & 12 & 47 & 62 & 103 \\
$\mathbf{4 6 . 2}$ & 10 & 11 & 52 & 62 & 106 \\
$\mathbf{4 6 . 3}$ & 14 & 15 & 64 & 63 & 117 \\
$\mathbf{4 6 . 4}$ & 34 & 39 & 75 & 64 & 124 \\
$\mathbf{4 6 . 5}$ & 39 & 45 & 56 & 62 & 107 \\
$\mathbf{4 6 . 6}$ & 48 & 55 & 56 & 63 & 109 \\
$\mathbf{4 6 . 7}$ & 36 & 41 & 49 & 57 & 45 \\
$\mathbf{4 6 . 8}$ & 37 & 42 & 45 & 59 & 61 \\
$\mathbf{4 6 . 9}$ & 51 & 59 & 56 & 57 & 41 \\
$\mathbf{4 7 . 0}$ & 56 & 65 & 95 & 57 & 43 \\
$\mathbf{4 7 . 1}$ & 57 & 66 & 68 & 56 & 30 \\
$\mathbf{4 7 . 2}$ & 50 & 58 & 53 & 57 & 40 \\
$\mathbf{4 7 . 3}$ & 54 & 63 & 53 & 58 & 54 \\
$\mathbf{4 7 . 4}$ & 54 & 63 & 63 & 56 & 31 \\
$\mathbf{4 7 . 5}$ & 47 & 54 & 53 & 57 & 35 \\
$\mathbf{4 7 . 6}$ & 42 & 48 & 59 & 56 & 31 \\
$\mathbf{4 7 . 7}$ & 49 & 57 & 86 & 56 & 33 \\
$\mathbf{4 7 . 8}$ & 43 & 50 & 76 & 59 & 63 \\
$\mathbf{4 7 . 9}$ & 47 & 54 & 76 & 66 & 152 \\
$\mathbf{4 8 . 0}$ & 45 & 52 & 74 & 67 & 167 \\
$\mathbf{4 8 . 1}$ & 54 & 63 & 72 & 66 & 151 \\
$\mathbf{4 8 . 2}$ & 55 & 64 & 96 & 67 & 168 \\
$\mathbf{4 8 . 3}$ & 49 & 57 & 88 & 70 & 204 \\
$\mathbf{4 8 . 4}$ & 53 & 62 & 82 & 58 & 52 \\
$\mathbf{4 8 . 5}$ & 52 & 61 & 81 & 58 & 48 \\
$\mathbf{4 8 . 6}$ & 38 & 44 & 37 & 58 & 50 \\
$\mathbf{4 8 . 7}$ & 43 & 50 & 28 & 59 & 59 \\
$\mathbf{4 8 . 8}$ & 38 & 44 & 19 & 57 & 35 \\
$\mathbf{4 8 . 9}$ & 40 & 46 & 49 & 57 & 40 \\
$\mathbf{4 9 . 0}$ & 51 & 60 & 55 & 56 & 33 \\
$\mathbf{4 9 . 1}$ & 73 & 85 & 60 & 58 & 55 \\
$\mathbf{4 9 . 2}$ & 53 & 61 & 45 & 56 & 31 \\
$\mathbf{4 9 . 3}$ & 60 & 70 & 67 & 55 & 19 \\
$\mathbf{4 9 . 4}$ & 61 & 71 & 80 & 55 & 18 \\
$\mathbf{4 9 . 5}$ & 65 & 75 & 55 & 56 & 28 \\
$\mathbf{4 9 . 6}$ & 32 & 36 & 123 & 57 & 40 \\
$\mathbf{4 9 . 7}$ & 30 & 35 & 138 & 57 & 39 \\
$\mathbf{4 9 . 8}$ & 18 & 20 & 42 & 57 & 38 \\
$\mathbf{4 9 . 9}$ & 23 & 26 & 26 & 58 & 53 \\
$\mathbf{5 0 . 0}$ & 21 & 23 & 18 & 57 & 37 \\
$\mathbf{5 0 . 1}$ & 24 & 27 & 30 & 56 & 29 \\
$\mathbf{5 0 . 2}$ & 25 & 29 & 19 & 57 & 41 \\
$\mathbf{5 0 . 3}$ & 19 & 21 & 14 & 57 & 44 \\
$\mathbf{5 0 . 4}$ & 19 & 21 & 14 & 56 & 31 \\
& 20 & 22 & 12 & 57 & 40
\end{tabular}




\begin{tabular}{|c|c|c|c|c|c|}
\hline \multirow[b]{2}{*}{ River km } & \multicolumn{3}{|c|}{ Narraguagus } & \multicolumn{2}{|c|}{ Jacquet } \\
\hline & $\begin{array}{c}\boldsymbol{D}_{50 \mathrm{emp}} \\
(\mathrm{mm})\end{array}$ & $\begin{array}{c}\boldsymbol{D}_{50 \text { gis }} \\
(\mathrm{mm})\end{array}$ & $\begin{array}{c}\boldsymbol{D}_{50} \text { lidar } \\
(\mathrm{mm})\end{array}$ & $\begin{array}{c}\boldsymbol{D}_{50 \text { emp }} \\
(\mathrm{mm})\end{array}$ & $\begin{array}{c}\boldsymbol{D}_{50} \text { gis } \\
(\mathrm{mm})\end{array}$ \\
\hline 50.6 & 21 & 23 & 15 & 57 & 39 \\
\hline 50.7 & 29 & 33 & 15 & 57 & 39 \\
\hline 50.8 & 30 & 34 & 18 & 56 & 32 \\
\hline 50.9 & 24 & 28 & 24 & 56 & 30 \\
\hline 51.0 & 25 & 29 & 50 & 58 & 50 \\
\hline 51.1 & 32 & 36 & 53 & 58 & 48 \\
\hline 51.2 & 25 & 28 & 26 & 56 & 31 \\
\hline 51.3 & 28 & 32 & 24 & 56 & 27 \\
\hline 51.4 & 22 & 24 & 39 & 57 & 40 \\
\hline 51.5 & 24 & 28 & 16 & 57 & 40 \\
\hline 51.6 & 19 & 21 & 23 & 58 & 49 \\
\hline 51.7 & 26 & 30 & 18 & 59 & 66 \\
\hline 51.8 & 16 & 18 & 17 & 60 & 74 \\
\hline 51.9 & 14 & 16 & 20 & 61 & 90 \\
\hline 52.0 & 18 & 20 & 17 & 60 & 77 \\
\hline 52.1 & 22 & 25 & 22 & 59 & 63 \\
\hline 52.2 & 18 & 20 & 22 & 58 & 57 \\
\hline 52.3 & 16 & 18 & 32 & 58 & 55 \\
\hline 52.4 & 23 & 26 & 27 & 59 & 63 \\
\hline 52.5 & 15 & 16 & 27 & 58 & 56 \\
\hline 52.6 & 27 & 31 & 24 & 58 & 52 \\
\hline 52.7 & 15 & 16 & 16 & 59 & 61 \\
\hline 52.8 & 18 & 20 & 30 & 58 & 57 \\
\hline 52.9 & 24 & 27 & 25 & 60 & 78 \\
\hline 53.0 & 18 & 20 & 14 & 58 & 51 \\
\hline 53.1 & 19 & 22 & 20 & 59 & 61 \\
\hline 53.2 & 18 & 20 & 20 & 59 & 58 \\
\hline 53.3 & 15 & 17 & 23 & 59 & 61 \\
\hline 53.4 & 18 & 20 & 23 & 55 & 14 \\
\hline 53.5 & 15 & 16 & 24 & 54 & 4 \\
\hline 53.6 & 19 & 22 & 20 & 54 & 4 \\
\hline 53.7 & 15 & 17 & 21 & 54 & 6 \\
\hline 53.8 & 20 & 22 & 17 & 55 & 10 \\
\hline 53.9 & 15 & 16 & 14 & 54 & 3 \\
\hline 54.0 & 13 & 14 & 9 & 54 & 4 \\
\hline 54.1 & 13 & 14 & 14 & 54 & 5 \\
\hline 54.2 & 14 & 15 & 13 & 54 & 3 \\
\hline 54.3 & 10 & 10 & 11 & 54 & 4 \\
\hline 54.4 & 18 & 20 & 27 & 54 & 4 \\
\hline 54.5 & 18 & 20 & 34 & 54 & 4 \\
\hline 54.6 & 22 & 25 & 30 & 54 & 4 \\
\hline 54.7 & 16 & 17 & 17 & 54 & 5 \\
\hline 54.8 & 18 & 20 & 21 & 55 & 11 \\
\hline 54.9 & 14 & 15 & 15 & 55 & 10 \\
\hline 55.0 & 9 & 9 & 14 & 55 & 10 \\
\hline 55.1 & 7 & 7 & 11 & 55 & 9 \\
\hline
\end{tabular}




\begin{tabular}{|c|c|c|c|c|c|}
\hline \multirow[b]{2}{*}{ River km } & \multicolumn{3}{|c|}{ Narraguagus } & \multicolumn{2}{|c|}{ Jacquet } \\
\hline & $\begin{array}{c}\boldsymbol{D}_{50 \text { emp }} \\
(\mathrm{mm})\end{array}$ & $\begin{array}{c}\boldsymbol{D}_{50 \text { gis }} \\
(\mathrm{mm})\end{array}$ & $\begin{array}{c}\boldsymbol{D}_{50} \text { lidar } \\
(\mathrm{mm})\end{array}$ & $\begin{array}{c}\boldsymbol{D}_{50 \mathrm{emp}} \\
(\mathrm{mm})\end{array}$ & $\begin{array}{c}\boldsymbol{D}_{50 \text { gis }} \\
(\mathrm{mm})\end{array}$ \\
\hline 55.2 & 12 & 12 & 24 & 54 & 5 \\
\hline 55.3 & 17 & 19 & 24 & 54 & 7 \\
\hline 55.4 & 11 & 11 & 25 & 55 & 10 \\
\hline 55.5 & 5 & 5 & 12 & 55 & 10 \\
\hline 55.6 & 10 & 11 & 34 & 54 & 7 \\
\hline 55.7 & 11 & 12 & 23 & 54 & 7 \\
\hline 55.8 & 9 & 9 & 7 & 54 & 6 \\
\hline 55.9 & 7 & 6 & 4 & 55 & 9 \\
\hline 56.0 & 8 & 8 & 5 & 54 & 7 \\
\hline 56.1 & 4 & 4 & 3 & 54 & 8 \\
\hline 56.2 & 5 & 5 & 4 & 55 & 8 \\
\hline 56.3 & 7 & 6 & 5 & 54 & 7 \\
\hline 56.4 & 7 & 7 & 8 & & \\
\hline 56.5 & 10 & 10 & 8 & & \\
\hline 56.6 & 9 & 9 & 8 & & \\
\hline 56.7 & 10 & 11 & 10 & & \\
\hline 56.8 & 10 & 11 & 10 & & \\
\hline 56.9 & 11 & 11 & 11 & & \\
\hline 57.0 & 13 & 14 & 10 & & \\
\hline 57.1 & 13 & 14 & 8 & & \\
\hline 57.2 & 8 & 8 & 47 & & \\
\hline 57.3 & 11 & 11 & 43 & & \\
\hline 57.4 & 11 & 12 & 16 & & \\
\hline 57.5 & 18 & 19 & 18 & & \\
\hline 57.6 & 10 & 10 & 18 & & \\
\hline 57.7 & 10 & 11 & 21 & & \\
\hline 57.8 & 14 & 15 & 19 & & \\
\hline 57.9 & 11 & 11 & 19 & & \\
\hline 58.0 & 12 & 12 & 20 & & \\
\hline 58.1 & 11 & 11 & 21 & & \\
\hline 58.2 & 16 & 17 & 25 & & \\
\hline 58.3 & 14 & 15 & 25 & & \\
\hline 58.4 & 16 & 18 & 15 & & \\
\hline 58.5 & 8 & 8 & 9 & & \\
\hline 58.6 & 10 & 10 & 7 & & \\
\hline 58.7 & 8 & 8 & 6 & & \\
\hline 58.8 & 7 & 6 & 7 & & \\
\hline 58.9 & 8 & 8 & 6 & & \\
\hline 59.0 & 7 & 7 & 6 & & \\
\hline 59.1 & 4 & 3 & 2 & & \\
\hline 59.2 & 3 & 2 & 2 & & \\
\hline 59.3 & 4 & 3 & 2 & & \\
\hline 59.4 & 7 & 6 & 6 & & \\
\hline 59.5 & 11 & 12 & 11 & & \\
\hline 59.6 & 15 & 17 & 11 & & \\
\hline 59.7 & 12 & 13 & 13 & & \\
\hline
\end{tabular}




\begin{tabular}{|c|ccc|}
\hline & \multicolumn{3}{|c|}{ Narraguagus } \\
& $\boldsymbol{D}_{50 \text { emp }}$ & $\boldsymbol{D}_{50 \text { gis }}$ & $\boldsymbol{D}_{50}$ lidar \\
River km & $(\mathrm{mm})$ & $(\mathrm{mm})$ & $(\mathrm{mm})$ \\
\hline $\mathbf{5 9 . 8}$ & 10 & 10 & 14 \\
$\mathbf{5 9 . 9}$ & 7 & 7 & 16 \\
$\mathbf{6 0 . 0}$ & 9 & 9 & 16 \\
$\mathbf{6 0 . 1}$ & 9 & 9 & 20 \\
$\mathbf{6 0 . 2}$ & 10 & 11 & 18 \\
$\mathbf{6 0 . 3}$ & 11 & 11 & 18 \\
$\mathbf{6 0 . 4}$ & 11 & 11 & 17 \\
$\mathbf{6 0 . 5}$ & 13 & 14 & 24 \\
$\mathbf{6 0 . 6}$ & 10 & 11 & 17 \\
$\mathbf{6 0 . 7}$ & 8 & 8 & 18 \\
$\mathbf{6 0 . 8}$ & 10 & 10 & 20 \\
$\mathbf{6 0 . 9}$ & 10 & 10 & 21 \\
$\mathbf{6 1 . 0}$ & 14 & 15 & 23 \\
$\mathbf{6 1 . 1}$ & 10 & 11 & 23 \\
$\mathbf{6 1 . 2}$ & 15 & 16 & 21 \\
$\mathbf{6 1 . 3}$ & 39 & 45 & 18 \\
$\mathbf{6 1 . 4}$ & 26 & 29 & 25 \\
$\mathbf{6 1 . 5}$ & 38 & 43 & 29 \\
$\mathbf{6 1 . 6}$ & 35 & 40 & 29 \\
$\mathbf{6 1 . 7}$ & 37 & 43 & 46 \\
$\mathbf{6 1 . 8}$ & 39 & 45 & 46 \\
$\mathbf{6 1 . 9}$ & 26 & 29 & 29 \\
$\mathbf{6 2 . 0}$ & 29 & 33 & 26 \\
$\mathbf{6 2 . 1}$ & 27 & 30 & 29 \\
$\mathbf{6 2 . 2}$ & 69 & 81 & 32 \\
$\mathbf{6 2 . 3}$ & 34 & 39 & 33 \\
$\mathbf{6 2 . 4}$ & 52 & 60 & 36 \\
$\mathbf{6 2 . 5}$ & 61 & 71 & 62 \\
$\mathbf{6 2 . 6}$ & 43 & 50 & 51 \\
$\mathbf{6 2 . 7}$ & 39 & 45 & 49 \\
$\mathbf{6 2 . 8}$ & 46 & 53 & 60 \\
$\mathbf{6 2 . 9}$ & 40 & 46 & 42 \\
$\mathbf{6 3 . 0}$ & 45 & 52 & 37 \\
$\mathbf{6 3 . 1}$ & 49 & 57 & 33 \\
$\mathbf{6 3 . 2}$ & 33 & 38 & 73 \\
$\mathbf{6 3 . 3}$ & 45 & 53 & 77 \\
$\mathbf{6 3 . 4}$ & 40 & 46 & 58 \\
$\mathbf{6 3 . 5}$ & 56 & 65 & 60 \\
$\mathbf{6 3 . 6}$ & 38 & 43 & 81 \\
$\mathbf{6 3 . 7}$ & 29 & 33 & 61 \\
$\mathbf{6 3 . 8}$ & 28 & 32 & 22 \\
$\mathbf{6 3 . 9}$ & 20 & 22 & 8 \\
$\mathbf{6 4 . 0}$ & 15 & 16 & 6 \\
$\mathbf{6 4 . 1}$ & 14 & 15 & 5 \\
$\mathbf{6 4 . 2}$ & 14 & 16 & 7 \\
$\mathbf{6 4 . 3}$ & 17 & 19 & 8
\end{tabular}




\begin{tabular}{|c|c|c|c|}
\hline \multirow[b]{2}{*}{ River km } & \multicolumn{3}{|c|}{ Narraguagus } \\
\hline & $\begin{array}{c}D_{50 \text { emp }} \\
(\mathrm{mm})\end{array}$ & $\begin{array}{c}\boldsymbol{D}_{50 \text { gis }} \\
(\mathrm{mm})\end{array}$ & $\begin{array}{c}\boldsymbol{D}_{50 \text { lidar }} \\
(\mathrm{mm})\end{array}$ \\
\hline 64.4 & 15 & 16 & 5 \\
\hline 64.5 & 16 & 18 & 8 \\
\hline 64.6 & 17 & 18 & 8 \\
\hline 64.7 & 16 & 17 & 6 \\
\hline 64.8 & 13 & 14 & 15 \\
\hline 64.9 & 17 & 18 & 21 \\
\hline 65.0 & 5 & 4 & 17 \\
\hline 65.1 & 5 & 5 & 5 \\
\hline 65.2 & 7 & 7 & 7 \\
\hline 65.3 & 6 & 5 & 5 \\
\hline 65.4 & 6 & 6 & 6 \\
\hline 65.5 & 6 & 6 & 7 \\
\hline 65.6 & 5 & 4 & 4 \\
\hline 65.7 & 5 & 5 & 5 \\
\hline 65.8 & 6 & 5 & 5 \\
\hline 65.9 & 5 & 5 & 5 \\
\hline 66.0 & 5 & 5 & 6 \\
\hline 66.1 & 5 & 4 & 6 \\
\hline 66.2 & 6 & 5 & 5 \\
\hline 66.3 & 6 & 5 & 5 \\
\hline 66.4 & 6 & 6 & 7 \\
\hline 66.5 & 6 & 5 & 8 \\
\hline 66.6 & 5 & 4 & 9 \\
\hline 66.7 & 5 & 4 & 9 \\
\hline 66.8 & 5 & 5 & 11 \\
\hline 66.9 & 5 & 4 & 9 \\
\hline 67.0 & 4 & 3 & 4 \\
\hline 67.1 & 6 & 5 & 6 \\
\hline 67.2 & 5 & 5 & 6 \\
\hline 67.3 & 5 & 5 & 5 \\
\hline 67.4 & 6 & 5 & 6 \\
\hline 67.5 & 5 & 5 & 5 \\
\hline 67.6 & 6 & 5 & 6 \\
\hline 67.7 & 6 & 6 & 7 \\
\hline 67.8 & 6 & 6 & 6 \\
\hline 67.9 & 7 & 7 & 6 \\
\hline 68.0 & 6 & 5 & 6 \\
\hline 68.1 & 4 & 4 & 5 \\
\hline 68.2 & 5 & 4 & 5 \\
\hline 68.3 & 6 & 5 & 5 \\
\hline 68.4 & 6 & 6 & 3 \\
\hline 68.5 & 7 & 6 & 3 \\
\hline 68.6 & 6 & 6 & 3 \\
\hline 68.7 & 5 & 5 & 2 \\
\hline 68.8 & 4 & 4 & 2 \\
\hline 68.9 & 5 & 4 & 2 \\
\hline
\end{tabular}




\begin{tabular}{|c|c|c|c|}
\hline \multirow[b]{2}{*}{ River km } & \multicolumn{3}{|c|}{ Narraguagus } \\
\hline & $\begin{array}{c}D_{50 \text { emp }} \\
(\mathrm{mm})\end{array}$ & $\begin{array}{c}\boldsymbol{D}_{50 \text { gis }} \\
(\mathrm{mm})\end{array}$ & $\begin{array}{c}\boldsymbol{D}_{50} \text { lidar } \\
(\mathrm{mm})\end{array}$ \\
\hline 69.0 & 4 & 4 & 2 \\
\hline 69.1 & 4 & 4 & 2 \\
\hline 69.2 & 4 & 4 & 2 \\
\hline 69.3 & 5 & 4 & 2 \\
\hline 69.4 & 5 & 5 & 2 \\
\hline 69.5 & 4 & 3 & 2 \\
\hline 69.6 & 4 & 4 & 2 \\
\hline 69.7 & 4 & 3 & 2 \\
\hline 69.8 & 5 & 4 & 2 \\
\hline 69.9 & 5 & 4 & 2 \\
\hline 70.0 & 4 & 4 & 2 \\
\hline 70.1 & 4 & 3 & 2 \\
\hline 70.2 & 5 & 5 & 2 \\
\hline 70.3 & 4 & 3 & 1 \\
\hline 70.4 & 4 & 4 & 2 \\
\hline 70.5 & 5 & 4 & 2 \\
\hline 70.6 & 5 & 4 & 2 \\
\hline 70.7 & 5 & 5 & 3 \\
\hline 70.8 & 5 & 5 & 2 \\
\hline 70.9 & 5 & 4 & 2 \\
\hline 71.0 & 5 & 5 & 3 \\
\hline 71.1 & 5 & 5 & 2 \\
\hline 71.2 & 5 & 5 & 2 \\
\hline 71.3 & 6 & 5 & 1 \\
\hline 71.4 & 6 & 5 & 2 \\
\hline 71.5 & 6 & 5 & 2 \\
\hline 71.6 & 5 & 4 & 2 \\
\hline 71.7 & 5 & 4 & 2 \\
\hline 71.8 & 6 & 5 & 3 \\
\hline 71.9 & 6 & 5 & 3 \\
\hline 72.0 & 5 & 5 & 2 \\
\hline 72.1 & 6 & 5 & 2 \\
\hline 72.2 & 6 & 6 & 3 \\
\hline 72.3 & 6 & 5 & 2 \\
\hline 72.4 & 5 & 5 & 3 \\
\hline 72.5 & 5 & 5 & 3 \\
\hline 72.6 & 7 & 7 & 7 \\
\hline 72.7 & 7 & 7 & 13 \\
\hline 72.8 & 6 & 6 & 12 \\
\hline 72.9 & 7 & 7 & 16 \\
\hline 73.0 & 6 & 5 & 14 \\
\hline 73.1 & 6 & 5 & 13 \\
\hline 73.2 & 6 & 6 & 9 \\
\hline 73.3 & 7 & 7 & 11 \\
\hline 73.4 & 5 & 5 & 10 \\
\hline 73.5 & 6 & 5 & 10 \\
\hline
\end{tabular}




\begin{tabular}{|c|c|c|c|}
\hline \multirow[b]{2}{*}{ River km } & \multicolumn{3}{|c|}{ Narraguagus } \\
\hline & $\begin{array}{c}\boldsymbol{D}_{50 \mathrm{emp}} \\
(\mathrm{mm})\end{array}$ & $\begin{array}{c}D_{50 \text { gis }} \\
(\mathrm{mm})\end{array}$ & $\begin{array}{c}\boldsymbol{D}_{50} \text { lidar } \\
(\mathrm{mm})\end{array}$ \\
\hline 73.6 & 7 & 7 & 11 \\
\hline 73.7 & 4 & 4 & 15 \\
\hline 73.8 & 9 & 10 & 32 \\
\hline 73.9 & 4 & 4 & 11 \\
\hline 74.0 & 5 & 5 & 5 \\
\hline 74.1 & 6 & 5 & 6 \\
\hline 74.2 & 7 & 7 & 9 \\
\hline 74.3 & 5 & 5 & 5 \\
\hline 74.4 & 5 & 5 & 2 \\
\hline 74.5 & 5 & 4 & 2 \\
\hline 74.6 & 4 & 3 & 1 \\
\hline 74.7 & 2 & 1 & 1 \\
\hline 74.8 & 2 & 1 & 0 \\
\hline 74.9 & 2 & 1 & 0 \\
\hline 75.0 & 2 & 1 & 0 \\
\hline 75.1 & 5 & 5 & 2 \\
\hline 75.2 & 6 & 5 & 2 \\
\hline 75.3 & 6 & 6 & 3 \\
\hline 75.4 & 6 & 6 & 2 \\
\hline 75.5 & 6 & 5 & 2 \\
\hline 75.6 & 6 & 5 & 2 \\
\hline 75.7 & 7 & 7 & 2 \\
\hline 75.8 & 6 & 6 & 2 \\
\hline 75.9 & 6 & 6 & 2 \\
\hline 76.0 & 7 & 7 & 2 \\
\hline 76.1 & 6 & 5 & 2 \\
\hline 76.2 & 6 & 5 & 2 \\
\hline 76.3 & 7 & 7 & 2 \\
\hline 76.4 & 7 & 6 & 3 \\
\hline 76.5 & 7 & 7 & 3 \\
\hline 76.6 & 8 & 8 & 3 \\
\hline 76.7 & 11 & 11 & 7 \\
\hline 76.8 & 12 & 13 & 15 \\
\hline 76.9 & 6 & 6 & 15 \\
\hline 77.0 & 12 & 12 & 25 \\
\hline 77.1 & 9 & 9 & 19 \\
\hline 77.2 & 17 & 18 & 12 \\
\hline 77.3 & 17 & 19 & 10 \\
\hline 77.4 & 16 & 17 & 13 \\
\hline 77.5 & 13 & 14 & 24 \\
\hline 77.6 & 14 & 15 & 17 \\
\hline 77.7 & 15 & 16 & 8 \\
\hline 77.8 & 18 & 20 & 10 \\
\hline 77.9 & 20 & 22 & 27 \\
\hline 78.0 & 19 & 21 & 22 \\
\hline
\end{tabular}




\section{Appendix 4.}

Calculated basal shear stress $\left(\tau_{b}\right)$ and Shields parameter $\left(\tau^{*}\right)$ values for the study rivers. 


\begin{tabular}{|c|c|c|c|c|c|c|}
\hline \multirow[b]{2}{*}{ River km } & \multicolumn{6}{|c|}{ Narraguagus } \\
\hline & $\tau_{b \text { field }}$ & $\tau_{\mathrm{b} \text { gis }}$ & $\tau_{\mathrm{b} \text { lidar }}$ & $\tau_{\text {field }}^{*}$ & $\tau_{\text {gis }}^{*}$ & $\tau^{*}{ }_{\text {lidar }}$ \\
\hline 0.0 & - & 153.26 & 98.48 & - & - & - \\
\hline 0.1 & - & 104.11 & 58.83 & - & - & - \\
\hline 0.2 & - & 72.03 & 60.67 & - & - & - \\
\hline 0.3 & - & 72.80 & 64.70 & - & - & - \\
\hline 0.4 & - & 72.87 & 70.19 & - & - & - \\
\hline 0.5 & - & 79.04 & 97.26 & - & - & - \\
\hline 0.6 & - & 88.77 & 127.61 & - & - & - \\
\hline 0.7 & - & 123.51 & 82.41 & - & - & - \\
\hline 0.8 & - & 58.82 & 54.34 & - & - & - \\
\hline 0.9 & - & 64.97 & 57.07 & - & - & - \\
\hline 1.0 & - & 18.04 & 112.51 & - & - & - \\
\hline 1.1 & - & 17.94 & 138.12 & - & - & - \\
\hline 1.2 & - & 23.26 & 146.37 & - & - & - \\
\hline 1.3 & - & 21.70 & 106.34 & - & - & - \\
\hline 1.4 & - & 24.57 & 81.31 & - & - & - \\
\hline 1.5 & - & 20.51 & 37.75 & - & - & - \\
\hline 1.6 & - & 19.85 & 35.83 & - & - & - \\
\hline 1.7 & - & 18.28 & 29.37 & - & - & - \\
\hline 1.8 & - & 17.80 & 52.79 & - & - & - \\
\hline 1.9 & - & 17.77 & 42.40 & - & - & - \\
\hline 2.0 & - & 18.19 & 4.44 & - & - & - \\
\hline 2.1 & - & 17.81 & 4.35 & - & - & - \\
\hline 2.2 & - & 17.74 & 4.54 & - & - & - \\
\hline 2.3 & - & 18.27 & 4.67 & - & - & - \\
\hline 2.4 & - & 18.87 & 4.47 & - & - & - \\
\hline 2.5 & - & 18.89 & 4.52 & - & - & - \\
\hline 2.6 & - & 17.05 & 4.47 & - & - & - \\
\hline 2.7 & - & 12.38 & 3.10 & - & - & - \\
\hline 2.8 & - & 18.87 & 4.62 & - & - & - \\
\hline 2.9 & - & 20.85 & 4.82 & - & - & - \\
\hline 3.0 & - & 15.13 & 3.73 & - & - & - \\
\hline 3.1 & - & 13.60 & 6.39 & - & - & - \\
\hline 3.2 & - & 18.83 & 4.94 & - & - & - \\
\hline 3.3 & - & 24.26 & 5.87 & - & - & - \\
\hline 3.4 & - & 16.40 & 4.09 & - & - & - \\
\hline 3.5 & - & 21.45 & 6.02 & - & - & - \\
\hline 3.6 & - & 14.84 & 3.62 & - & - & - \\
\hline 3.7 & - & 22.33 & 6.32 & - & - & - \\
\hline 3.8 & - & 24.35 & 6.18 & - & - & - \\
\hline 3.9 & - & 23.25 & 6.04 & - & - & - \\
\hline 4.0 & - & 20.94 & 4.94 & - & - & - \\
\hline 4.1 & - & - & 1.62 & - & - & - \\
\hline 4.2 & - & 22.36 & 5.58 & - & - & - \\
\hline 4.3 & - & 21.31 & 5.58 & - & - & - \\
\hline 4.4 & - & 21.86 & 5.63 & - & - & - \\
\hline 4.5 & - & 21.85 & 5.28 & - & - & - \\
\hline 4.6 & - & 23.06 & 5.61 & - & - & - \\
\hline
\end{tabular}




\begin{tabular}{|c|c|c|c|c|c|c|}
\hline \multirow[b]{2}{*}{ River km } & \multicolumn{6}{|c|}{ Narraguagus } \\
\hline & $\tau_{b \text { field }}$ & $\tau_{\mathrm{b} \text { gis }}$ & $\tau_{b \text { lidar }}$ & $\tau_{\text {field }}^{*}$ & $\tau_{\text {gis }}^{*}$ & $\tau^{*}{ }_{\text {lidar }}$ \\
\hline 4.7 & - & 22.22 & 5.41 & - & - & - \\
\hline 4.8 & - & 19.53 & 5.03 & - & - & - \\
\hline 4.9 & - & 22.03 & 5.73 & - & - & - \\
\hline 5.0 & - & 13.69 & 5.47 & - & - & - \\
\hline 5.1 & - & 18.86 & 4.61 & - & - & - \\
\hline 5.2 & - & 19.26 & 5.25 & - & - & - \\
\hline 5.3 & - & 19.98 & 5.08 & - & - & - \\
\hline 5.4 & - & 22.15 & 5.58 & - & - & - \\
\hline 5.5 & - & 20.25 & 5.18 & - & - & - \\
\hline 5.6 & - & 20.63 & 6.28 & - & - & - \\
\hline 5.7 & - & 19.29 & 6.89 & - & - & - \\
\hline 5.8 & - & 20.78 & 7.81 & - & - & - \\
\hline 5.9 & - & 19.27 & 8.06 & - & - & - \\
\hline 6.0 & - & 21.10 & 8.13 & - & - & - \\
\hline 6.1 & - & 22.61 & 7.97 & - & - & - \\
\hline 6.2 & - & 21.28 & 7.95 & - & - & - \\
\hline 6.3 & - & 20.60 & 8.11 & - & - & - \\
\hline 6.4 & - & 21.71 & 8.33 & - & - & - \\
\hline 6.5 & - & 21.93 & 8.59 & - & - & - \\
\hline 6.6 & - & 20.98 & 8.08 & - & - & - \\
\hline 6.7 & - & 21.09 & 6.42 & - & - & - \\
\hline 6.8 & - & 17.11 & 6.41 & - & - & - \\
\hline 6.9 & - & 20.08 & 8.11 & - & - & - \\
\hline 7.0 & - & 18.12 & 7.72 & - & - & - \\
\hline 7.1 & - & 31.29 & 7.97 & - & - & - \\
\hline 7.2 & - & 29.09 & 8.23 & - & - & - \\
\hline 7.3 & - & 26.91 & 8.18 & - & - & - \\
\hline 7.4 & - & 27.10 & 7.84 & - & - & - \\
\hline 7.5 & - & 25.14 & 7.79 & - & - & - \\
\hline 7.6 & - & 23.24 & 6.74 & - & - & - \\
\hline 7.7 & - & 26.11 & 18.52 & - & - & - \\
\hline 7.8 & - & 24.48 & 24.41 & - & - & - \\
\hline 7.9 & - & 24.55 & 31.13 & - & - & - \\
\hline 8.0 & - & 27.31 & 31.27 & - & - & - \\
\hline 8.1 & - & 37.95 & 44.75 & - & - & - \\
\hline 8.2 & - & 25.25 & 33.34 & - & - & - \\
\hline 8.3 & - & 24.84 & 19.63 & - & - & - \\
\hline 8.4 & - & 23.15 & 14.21 & - & - & - \\
\hline 8.5 & - & 24.21 & 13.26 & - & - & - \\
\hline 8.6 & - & 24.71 & 14.19 & - & - & - \\
\hline 8.7 & - & 24.31 & 15.75 & - & - & - \\
\hline 8.8 & - & 22.74 & 13.50 & - & - & - \\
\hline 8.9 & - & 20.12 & 13.55 & - & - & - \\
\hline 9.0 & - & 17.40 & 34.93 & - & - & - \\
\hline 9.1 & - & 14.70 & 41.20 & - & - & - \\
\hline 9.2 & - & 16.15 & 10.28 & - & - & - \\
\hline 9.3 & - & 15.33 & 10.25 & - & - & - \\
\hline
\end{tabular}




\begin{tabular}{|c|c|c|c|c|c|c|}
\hline \multirow[b]{2}{*}{ River km } & \multicolumn{6}{|c|}{ Narraguagus } \\
\hline & $\tau_{b \text { field }}$ & $\tau_{b \text { gis }}$ & $\tau_{\mathrm{b} \text { lidar }}$ & $\tau_{\text {field }}^{*}$ & $\tau_{\text {gis }}^{*}$ & $\tau_{\text {lidar }}^{*}$ \\
\hline 9.4 & - & 15.49 & 10.45 & - & - & - \\
\hline 9.5 & - & 15.68 & 10.15 & - & - & - \\
\hline 9.6 & - & 16.20 & 11.34 & - & - & - \\
\hline 9.7 & - & 15.23 & 9.67 & - & - & - \\
\hline 9.8 & - & 15.26 & 10.07 & - & - & - \\
\hline 9.9 & - & 14.08 & 10.43 & - & - & - \\
\hline 10.0 & - & 15.11 & 11.18 & - & - & - \\
\hline 10.1 & - & 14.28 & 11.54 & - & - & - \\
\hline 10.2 & - & 18.18 & 12.25 & - & - & - \\
\hline 10.3 & - & 14.67 & 13.74 & - & - & - \\
\hline 10.4 & - & 12.53 & 11.14 & - & - & - \\
\hline 10.5 & - & 15.41 & 16.91 & - & - & - \\
\hline 10.6 & - & 15.28 & 15.65 & - & - & - \\
\hline 10.7 & - & 15.29 & 16.00 & - & - & - \\
\hline 10.8 & - & 16.67 & 20.38 & - & - & - \\
\hline 10.9 & - & 9.35 & 9.95 & - & - & - \\
\hline 11.0 & - & 24.25 & 49.07 & - & - & - \\
\hline 11.1 & - & 20.57 & 92.23 & - & - & - \\
\hline 11.2 & - & 18.04 & 60.79 & - & - & - \\
\hline 11.3 & - & 12.61 & 29.14 & - & - & - \\
\hline 11.4 & - & 12.73 & 22.26 & - & - & - \\
\hline 11.5 & - & 14.73 & 18.67 & - & - & - \\
\hline 11.6 & - & 16.83 & 10.04 & - & - & - \\
\hline 11.7 & - & 15.94 & 7.44 & - & - & - \\
\hline 11.8 & - & 16.65 & 8.21 & - & - & - \\
\hline 11.9 & - & 15.52 & 7.49 & - & - & - \\
\hline 12.0 & - & 16.58 & 7.69 & - & - & - \\
\hline 12.1 & - & 17.42 & 7.37 & - & - & - \\
\hline 12.2 & - & 17.93 & 8.55 & - & - & - \\
\hline 12.3 & - & 17.20 & 8.08 & - & - & - \\
\hline 12.4 & - & 17.81 & 8.77 & - & - & - \\
\hline 12.5 & - & 16.02 & 7.26 & - & - & - \\
\hline 12.6 & - & 16.62 & 7.21 & - & - & - \\
\hline 12.7 & - & 21.32 & 9.51 & - & - & - \\
\hline 12.8 & - & 20.04 & 10.44 & - & - & - \\
\hline 12.9 & - & 15.00 & 6.79 & - & - & - \\
\hline 13.0 & - & 11.63 & 7.81 & - & - & - \\
\hline 13.1 & - & 11.87 & 9.79 & - & - & - \\
\hline 13.2 & - & 11.34 & 8.10 & - & - & - \\
\hline 13.3 & - & 11.91 & 8.45 & - & - & - \\
\hline 13.4 & - & 10.98 & 6.39 & - & - & - \\
\hline 13.5 & - & 11.16 & 10.28 & - & - & - \\
\hline 13.6 & - & 10.40 & 8.41 & - & - & - \\
\hline 13.7 & - & 12.51 & 10.14 & - & - & - \\
\hline 13.8 & - & 10.73 & 14.48 & - & - & - \\
\hline 13.9 & - & 11.01 & 18.10 & - & - & - \\
\hline 14.0 & - & 12.67 & 21.68 & - & - & - \\
\hline
\end{tabular}




\begin{tabular}{|c|c|c|c|c|c|c|}
\hline \multirow[b]{2}{*}{ River km } & \multicolumn{6}{|c|}{ Narraguagus } \\
\hline & $\tau_{b \text { field }}$ & $\tau_{\mathrm{b} \text { gis }}$ & $\tau_{b \text { lidar }}$ & $\tau_{\text {field }}^{*}$ & $\tau_{\text {gis }}^{*}$ & $\tau_{\text {lidar }}^{*}$ \\
\hline 14.1 & - & 11.53 & 18.40 & - & - & - \\
\hline 14.2 & - & 12.23 & 21.68 & - & - & - \\
\hline 14.3 & - & 13.30 & 18.47 & - & - & - \\
\hline 14.4 & - & 11.63 & 17.30 & - & - & - \\
\hline 14.5 & - & 12.06 & 18.64 & - & - & - \\
\hline 14.6 & - & 12.96 & 11.37 & - & - & - \\
\hline 14.7 & - & 9.27 & 10.55 & - & - & - \\
\hline 14.8 & - & 12.18 & 10.65 & - & - & - \\
\hline 14.9 & - & 13.03 & 9.20 & - & - & - \\
\hline 15.0 & - & 12.45 & 11.74 & - & - & - \\
\hline 15.1 & - & 11.88 & 8.55 & - & - & - \\
\hline 15.2 & - & 11.19 & 8.55 & - & - & - \\
\hline 15.3 & - & 12.81 & 9.79 & - & - & - \\
\hline 15.4 & - & 12.41 & 10.88 & - & - & - \\
\hline 15.5 & - & 9.00 & 8.86 & - & - & - \\
\hline 15.6 & - & 14.63 & 8.21 & - & - & - \\
\hline 15.7 & - & 9.78 & 10.36 & - & - & - \\
\hline 15.8 & - & 12.59 & 10.22 & - & - & - \\
\hline 15.9 & - & 10.85 & 10.17 & - & - & - \\
\hline 16.0 & - & 10.49 & 8.38 & - & - & - \\
\hline 16.1 & - & 11.48 & 8.96 & - & - & - \\
\hline 16.2 & - & 11.76 & 9.84 & - & - & - \\
\hline 16.3 & - & 11.34 & 11.35 & - & - & - \\
\hline 16.4 & - & 7.69 & 7.70 & - & - & - \\
\hline 16.5 & - & 12.41 & 15.12 & - & - & - \\
\hline 16.6 & - & 11.76 & 13.36 & - & - & - \\
\hline 16.7 & - & 12.09 & 14.91 & - & - & - \\
\hline 16.8 & - & 11.65 & 14.93 & - & - & - \\
\hline 16.9 & - & 13.86 & 13.24 & - & - & - \\
\hline 17.0 & - & 12.91 & 12.82 & - & - & - \\
\hline 17.1 & - & 12.47 & 13.18 & - & - & - \\
\hline 17.2 & - & 12.25 & 13.81 & - & - & - \\
\hline 17.3 & - & 13.51 & 12.71 & - & - & - \\
\hline 17.4 & - & 11.75 & 13.73 & - & - & - \\
\hline 17.5 & - & 10.69 & 13.49 & - & - & - \\
\hline 17.6 & - & 14.07 & 17.14 & - & - & - \\
\hline 17.7 & - & 11.86 & 21.57 & - & - & - \\
\hline 17.8 & - & 13.56 & 22.09 & - & - & - \\
\hline 17.9 & - & 12.65 & 19.71 & - & - & - \\
\hline 18.0 & - & 12.05 & 20.07 & - & - & - \\
\hline 18.1 & - & 12.57 & 21.63 & - & - & - \\
\hline 18.2 & - & 13.40 & 21.83 & - & - & - \\
\hline 18.3 & - & 13.11 & 21.66 & - & - & - \\
\hline 18.4 & - & 13.02 & 17.22 & - & - & - \\
\hline 18.5 & - & 11.61 & 16.16 & - & - & - \\
\hline 18.6 & - & 10.70 & 12.62 & - & - & - \\
\hline 18.7 & - & 11.32 & 14.15 & - & - & - \\
\hline
\end{tabular}




\begin{tabular}{|c|c|c|c|c|c|c|}
\hline \multirow[b]{2}{*}{ River km } & \multicolumn{6}{|c|}{ Narraguagus } \\
\hline & $\tau_{b \text { field }}$ & $\tau_{\mathrm{b} \text { gis }}$ & $\tau_{\mathrm{b} \text { lidar }}$ & $\tau_{\text {field }}^{*}$ & $\tau_{\text {gis }}^{*}$ & $\tau_{\text {lidar }}^{*}$ \\
\hline 18.8 & - & 13.96 & 14.86 & - & - & - \\
\hline 18.9 & - & 12.23 & 16.14 & - & - & - \\
\hline 19.0 & - & 12.07 & 14.69 & - & - & - \\
\hline 19.1 & - & 12.89 & 18.55 & - & - & - \\
\hline 19.2 & - & 11.15 & 23.51 & - & - & - \\
\hline 19.3 & - & 14.55 & 31.77 & - & - & - \\
\hline 19.4 & - & 11.50 & 27.45 & - & - & - \\
\hline 19.5 & - & 13.26 & 25.09 & - & - & - \\
\hline 19.6 & - & 12.97 & 24.67 & - & - & - \\
\hline 19.7 & - & 11.32 & 15.70 & - & - & - \\
\hline 19.8 & - & 12.50 & 18.32 & - & - & - \\
\hline 19.9 & - & 11.36 & 17.34 & - & - & - \\
\hline 20.0 & - & 10.66 & 16.87 & - & - & - \\
\hline 20.1 & - & 10.91 & 18.63 & - & - & - \\
\hline 20.2 & - & 10.25 & 16.90 & - & - & - \\
\hline 20.3 & - & 14.23 & 18.35 & - & - & - \\
\hline 20.4 & - & 19.92 & 16.31 & - & - & - \\
\hline 20.5 & - & 21.50 & 15.32 & - & - & - \\
\hline 20.6 & - & 21.60 & 19.74 & - & - & - \\
\hline 20.7 & - & 20.25 & 16.10 & - & - & - \\
\hline 20.8 & - & 23.54 & 15.93 & - & - & - \\
\hline 20.9 & - & 21.51 & 17.92 & - & - & - \\
\hline 21.0 & - & 19.99 & 17.88 & - & - & - \\
\hline 21.1 & - & 20.87 & 14.80 & - & - & - \\
\hline 21.2 & - & 15.94 & 13.96 & - & - & - \\
\hline 21.3 & - & 21.42 & 15.48 & - & - & - \\
\hline 21.4 & - & 13.27 & 10.90 & - & - & - \\
\hline 21.5 & - & 17.65 & 17.78 & - & - & - \\
\hline 21.6 & - & 17.15 & 21.35 & - & - & - \\
\hline 21.7 & - & 20.03 & 19.58 & - & - & - \\
\hline 21.8 & - & 20.89 & 16.34 & - & - & - \\
\hline 21.9 & - & 19.33 & 17.46 & - & - & - \\
\hline 22.0 & - & 18.02 & 20.23 & - & - & - \\
\hline 22.1 & - & 16.64 & 16.31 & - & - & - \\
\hline 22.2 & - & 22.61 & 17.56 & - & - & - \\
\hline 22.3 & - & 21.65 & 20.27 & - & - & - \\
\hline 22.4 & - & 21.63 & 16.26 & - & - & - \\
\hline 22.5 & - & 18.21 & 16.59 & - & - & - \\
\hline 22.6 & - & 18.49 & 14.79 & - & - & - \\
\hline 22.7 & - & 23.19 & 14.47 & - & - & - \\
\hline 22.8 & - & 17.52 & 14.63 & - & - & - \\
\hline 22.9 & - & 18.74 & 20.43 & - & - & - \\
\hline 23.0 & - & 17.69 & 19.98 & - & - & - \\
\hline 23.1 & - & 22.99 & 19.87 & - & - & - \\
\hline 23.2 & - & 22.33 & 26.99 & - & - & - \\
\hline 23.3 & - & 27.67 & 17.49 & - & - & - \\
\hline 23.4 & - & 25.56 & 22.35 & - & - & - \\
\hline
\end{tabular}




\begin{tabular}{|c|c|c|c|c|c|c|}
\hline \multirow[b]{2}{*}{ River km } & \multicolumn{6}{|c|}{ Narraguagus } \\
\hline & $\tau_{b \text { field }}$ & $\tau_{\mathrm{b} \text { gis }}$ & $\tau_{\mathrm{b} \text { lidar }}$ & $\tau^{*}$ field & $\tau_{\text {gis }}^{*}$ & $\tau^{*}{ }_{\text {lidar }}$ \\
\hline 23.5 & - & 13.65 & 18.56 & - & - & - \\
\hline 23.6 & - & 15.15 & 20.54 & - & - & - \\
\hline 23.7 & - & 25.25 & 27.49 & - & - & - \\
\hline 23.8 & - & 21.23 & 22.21 & - & - & - \\
\hline 23.9 & - & 25.05 & 22.98 & - & - & - \\
\hline 24.0 & - & 24.07 & 25.87 & - & - & - \\
\hline 24.1 & - & 21.43 & 18.94 & - & - & - \\
\hline 24.2 & - & 22.89 & 21.80 & - & - & - \\
\hline 24.3 & - & 24.60 & 20.43 & - & - & - \\
\hline 24.4 & - & 19.65 & 16.83 & - & - & - \\
\hline 24.5 & - & 21.56 & 19.03 & - & - & - \\
\hline 24.6 & - & 20.68 & 15.82 & - & - & - \\
\hline 24.7 & - & 21.92 & 17.64 & - & - & - \\
\hline 24.8 & - & 20.68 & 18.56 & - & - & - \\
\hline 24.9 & - & 28.78 & 23.88 & - & - & - \\
\hline 25.0 & - & 17.33 & 17.33 & - & - & - \\
\hline 25.1 & - & 20.90 & 20.64 & - & - & - \\
\hline 25.2 & - & 19.51 & 28.32 & - & - & - \\
\hline 25.3 & - & 14.02 & 23.01 & - & - & - \\
\hline 25.4 & - & 23.87 & 19.20 & - & - & - \\
\hline 25.5 & - & 12.14 & 10.30 & - & - & - \\
\hline 25.6 & - & 19.82 & 16.71 & - & - & - \\
\hline 25.7 & - & 22.57 & 15.73 & - & - & - \\
\hline 25.8 & - & 22.54 & 13.10 & - & - & - \\
\hline 25.9 & - & 23.21 & 14.13 & - & - & - \\
\hline 26.0 & - & 20.07 & 15.14 & - & - & - \\
\hline 26.1 & - & 19.11 & 12.18 & - & - & - \\
\hline 26.2 & - & 18.60 & 14.28 & - & - & - \\
\hline 26.3 & - & 17.37 & 12.77 & - & - & - \\
\hline 26.4 & - & 22.19 & 16.00 & - & - & - \\
\hline 26.5 & - & 21.97 & 15.26 & - & - & - \\
\hline 26.6 & - & 20.97 & 16.22 & - & - & - \\
\hline 26.7 & - & 20.56 & 14.05 & - & - & - \\
\hline 26.8 & - & 22.19 & 17.72 & - & - & - \\
\hline 26.9 & - & 15.16 & 14.58 & - & - & - \\
\hline 27.0 & - & 14.89 & 18.33 & - & - & - \\
\hline 27.1 & - & 17.98 & 13.68 & - & - & - \\
\hline 27.2 & - & 26.97 & 17.37 & - & - & - \\
\hline 27.3 & - & 19.57 & 14.87 & - & - & - \\
\hline 27.4 & - & 17.00 & 15.03 & - & - & - \\
\hline 27.5 & - & 22.35 & 21.39 & - & - & - \\
\hline 27.6 & - & 29.37 & 26.01 & - & - & - \\
\hline 27.7 & - & 18.38 & 21.30 & - & - & - \\
\hline 27.8 & - & 18.53 & 23.86 & - & - & - \\
\hline 27.9 & - & 14.70 & 21.36 & - & - & - \\
\hline 28.0 & - & 21.07 & 19.04 & - & - & - \\
\hline 28.1 & - & 21.07 & 20.36 & - & - & - \\
\hline
\end{tabular}




\begin{tabular}{|c|c|c|c|c|c|c|}
\hline \multirow[b]{2}{*}{ River km } & \multicolumn{6}{|c|}{ Narraguagus } \\
\hline & $\tau_{b \text { field }}$ & $\tau_{\mathrm{b} \text { gis }}$ & $\tau_{\mathrm{b} \text { lidar }}$ & $\tau_{\text {field }}^{*}$ & $\tau_{\text {gis }}^{*}$ & $\tau_{\text {lidar }}^{*}$ \\
\hline 28.2 & - & 22.82 & 17.31 & - & - & - \\
\hline 28.3 & - & 18.74 & 19.53 & - & - & - \\
\hline 28.4 & - & 15.18 & 13.31 & - & - & - \\
\hline 28.5 & - & 14.15 & 17.36 & - & - & - \\
\hline 28.6 & - & 14.85 & 17.40 & - & - & - \\
\hline 28.7 & - & 19.72 & 17.46 & - & - & - \\
\hline 28.8 & - & 16.71 & 18.95 & - & - & - \\
\hline 28.9 & - & 16.71 & 18.92 & - & - & - \\
\hline 29.0 & - & 21.10 & 18.34 & - & - & - \\
\hline 29.1 & - & 14.21 & 17.40 & - & - & - \\
\hline 29.2 & - & 17.66 & 22.45 & - & - & - \\
\hline 29.3 & - & 19.37 & 18.19 & - & - & - \\
\hline 29.4 & - & 17.98 & 19.25 & - & - & - \\
\hline 29.5 & - & 16.83 & 18.01 & - & - & - \\
\hline 29.6 & - & 20.53 & 21.64 & - & - & - \\
\hline 29.7 & - & 20.03 & 22.13 & - & - & - \\
\hline 29.8 & - & 21.42 & 17.85 & - & - & - \\
\hline 29.9 & - & 19.85 & 25.41 & - & - & - \\
\hline 30.0 & - & 18.84 & 25.09 & - & - & - \\
\hline 30.1 & - & 19.88 & 27.32 & - & - & - \\
\hline 30.2 & - & 19.52 & 28.19 & - & - & - \\
\hline 30.3 & - & 14.72 & 29.58 & - & - & - \\
\hline 30.4 & - & 19.66 & 34.76 & - & - & - \\
\hline 30.5 & - & 20.31 & 37.72 & - & - & - \\
\hline 30.6 & - & 22.63 & 31.09 & - & - & - \\
\hline 30.7 & - & 15.52 & 19.86 & - & - & - \\
\hline 30.8 & - & 88.25 & 47.07 & - & - & - \\
\hline 30.9 & - & 89.30 & 128.83 & - & - & - \\
\hline 31.0 & - & 98.15 & 174.56 & - & - & - \\
\hline 31.1 & - & 155.39 & 43.09 & - & - & - \\
\hline 31.2 & - & 68.02 & 38.15 & - & - & - \\
\hline 31.3 & - & 153.39 & 85.03 & - & - & - \\
\hline 31.4 & - & 187.82 & 190.04 & - & - & - \\
\hline 31.5 & - & 144.77 & 183.92 & - & - & - \\
\hline 31.6 & - & 16.43 & 92.78 & - & - & - \\
\hline 31.7 & - & 20.10 & 54.26 & - & - & - \\
\hline 31.8 & - & 21.93 & 24.35 & - & - & - \\
\hline 31.9 & - & 17.12 & 36.63 & - & - & - \\
\hline 32.0 & - & 27.38 & 40.30 & - & - & - \\
\hline 32.1 & - & 18.28 & 10.68 & - & - & - \\
\hline 32.2 & - & 21.51 & 10.94 & - & - & - \\
\hline 32.3 & - & 24.00 & 10.42 & - & - & - \\
\hline 32.4 & - & 23.15 & 13.45 & - & - & - \\
\hline 32.5 & - & 23.78 & 16.22 & - & - & - \\
\hline 32.6 & - & 19.39 & 10.47 & - & - & - \\
\hline 32.7 & - & 18.08 & 13.72 & - & - & - \\
\hline 32.8 & - & 26.82 & 15.16 & - & - & - \\
\hline
\end{tabular}




\begin{tabular}{|c|c|c|c|c|c|c|}
\hline \multirow[b]{2}{*}{ River km } & \multicolumn{6}{|c|}{ Narraguagus } \\
\hline & $\tau_{b \text { field }}$ & $\tau_{\mathrm{b} \text { gis }}$ & $\tau_{\mathrm{b} \text { lidar }}$ & $\tau_{\text {field }}^{*}$ & $\tau_{\text {gis }}^{*}$ & $\tau^{*}$ lidar \\
\hline 32.9 & - & 16.84 & 9.40 & - & - & - \\
\hline 33.0 & - & 19.44 & 19.05 & - & - & - \\
\hline 33.1 & - & 21.81 & 27.91 & - & - & - \\
\hline 33.2 & - & 30.97 & 28.31 & - & - & - \\
\hline 33.3 & - & 19.18 & 19.14 & - & - & - \\
\hline 33.4 & - & 24.70 & 35.42 & - & - & - \\
\hline 33.5 & - & 19.22 & 20.02 & - & - & - \\
\hline 33.6 & - & 35.25 & 26.05 & - & - & - \\
\hline 33.7 & - & 24.20 & 25.46 & - & - & - \\
\hline 33.8 & - & 30.16 & 26.31 & - & - & - \\
\hline 33.9 & - & 22.26 & 21.73 & - & - & - \\
\hline 34.0 & - & 26.35 & 31.80 & - & - & - \\
\hline 34.1 & - & 22.98 & 22.70 & - & - & - \\
\hline 34.2 & - & 28.44 & 26.94 & - & - & - \\
\hline 34.3 & - & 24.76 & 31.35 & - & - & - \\
\hline 34.4 & - & 18.45 & 20.96 & - & - & - \\
\hline 34.5 & - & 24.42 & 17.02 & - & - & - \\
\hline 34.6 & - & 15.24 & 16.77 & - & - & - \\
\hline 34.7 & - & 20.98 & 15.65 & - & - & - \\
\hline 34.8 & - & 19.02 & 16.48 & - & - & - \\
\hline 34.9 & - & 21.16 & 28.83 & - & - & - \\
\hline 35.0 & - & 27.85 & 47.68 & - & - & - \\
\hline 35.1 & - & 23.00 & 34.08 & - & - & - \\
\hline 35.2 & - & 19.44 & 26.97 & - & - & - \\
\hline 35.3 & - & 20.82 & 32.62 & - & - & - \\
\hline 35.4 & - & 24.71 & 26.08 & - & - & - \\
\hline 35.5 & - & 18.37 & 22.09 & - & - & - \\
\hline 35.6 & - & 21.54 & 22.64 & - & - & - \\
\hline 35.7 & - & 14.53 & 27.65 & - & - & - \\
\hline 35.8 & - & 16.09 & 38.24 & - & - & - \\
\hline 35.9 & - & 28.54 & 68.78 & - & - & - \\
\hline 36.0 & - & 19.04 & 46.45 & - & - & - \\
\hline 36.1 & - & 16.43 & 43.39 & - & - & - \\
\hline 36.2 & - & 72.98 & 71.76 & - & - & - \\
\hline 36.3 & - & 53.46 & 48.84 & - & - & - \\
\hline 36.4 & - & 59.27 & 60.95 & - & - & - \\
\hline 36.5 & - & 73.87 & 76.38 & - & - & - \\
\hline 36.6 & - & 84.05 & 67.99 & - & - & - \\
\hline 36.7 & - & 56.47 & 59.75 & - & - & - \\
\hline 36.8 & - & 67.19 & 79.03 & - & - & - \\
\hline 36.9 & - & 55.38 & 77.06 & - & - & - \\
\hline 37.0 & - & 66.05 & 66.85 & - & - & - \\
\hline 37.1 & - & 53.06 & 60.64 & - & - & - \\
\hline 37.2 & - & 53.42 & 86.81 & - & - & - \\
\hline 37.3 & 43.81 & 58.56 & 66.21 & - & - & - \\
\hline 37.4 & 52.52 & 56.86 & 38.48 & 0.0427 & 0.0462 & 0.0313 \\
\hline 37.5 & 47.54 & 48.11 & 25.89 & - & - & - \\
\hline
\end{tabular}




\begin{tabular}{|c|c|c|c|c|c|c|}
\hline \multirow[b]{2}{*}{ River km } & \multicolumn{6}{|c|}{ Narraguagus } \\
\hline & $\tau_{b \text { field }}$ & $\tau_{b \text { gis }}$ & $\tau_{\mathrm{b} \text { lidar }}$ & $\tau_{\text {field }}^{*}$ & $\tau_{\text {gis }}^{*}$ & $\tau^{*}{ }_{\text {lidar }}$ \\
\hline 37.6 & 49.04 & 51.80 & 23.77 & 0.0392 & 0.0414 & 0.0190 \\
\hline 37.7 & 146.07 & 47.46 & 25.01 & - & - & - \\
\hline 37.8 & 101.86 & 49.18 & 52.08 & 0.0828 & 0.0400 & 0.0423 \\
\hline 37.9 & 59.14 & 56.27 & 75.45 & - & - & - \\
\hline 38.0 & 94.69 & 64.78 & 110.24 & - & - & - \\
\hline 38.1 & 96.48 & 66.97 & 101.27 & - & - & - \\
\hline 38.2 & 101.93 & 86.45 & 72.30 & 0.0448 & 0.0380 & 0.0318 \\
\hline 38.3 & 88.49 & 67.48 & 44.72 & - & - & - \\
\hline 38.4 & 82.89 & 76.09 & 55.56 & 0.0824 & 0.0757 & 0.0553 \\
\hline 38.5 & 85.13 & 102.47 & 64.84 & - & - & - \\
\hline 38.6 & 8.21 & 14.84 & 43.09 & 0.0172 & 0.0310 & 0.0901 \\
\hline 38.7 & 5.93 & 15.58 & 31.64 & - & - & - \\
\hline 38.8 & 10.76 & 15.11 & 32.08 & 0.0180 & 0.0253 & 0.0537 \\
\hline 38.9 & - & 13.80 & 22.50 & - & - & - \\
\hline 39.0 & 8.30 & 17.09 & 44.16 & 0.0058 & 0.0119 & 0.0308 \\
\hline 39.1 & 7.86 & 15.60 & 54.98 & - & - & - \\
\hline 39.2 & 5.80 & 13.81 & 27.08 & 0.0092 & 0.0220 & 0.0432 \\
\hline 39.3 & 5.80 & 11.92 & 13.13 & - & - & - \\
\hline 39.4 & 11.86 & 10.79 & 6.94 & 0.2525 & 0.2298 & 0.1477 \\
\hline 39.5 & - & 12.10 & 7.53 & - & - & - \\
\hline 39.6 & - & 10.06 & 4.78 & - & - & - \\
\hline 39.7 & - & 6.97 & 5.54 & - & - & - \\
\hline 39.8 & - & 11.18 & 8.24 & - & - & - \\
\hline 39.9 & 14.41 & 10.49 & 7.41 & - & - & - \\
\hline 40.0 & 9.29 & 11.57 & 6.72 & 0.0886 & 0.1104 & 0.0642 \\
\hline 40.1 & 11.78 & 10.36 & 5.41 & - & - & - \\
\hline 40.2 & 8.30 & 10.85 & 5.49 & 0.0797 & 0.1042 & 0.0527 \\
\hline 40.3 & 7.69 & 10.33 & 5.81 & - & - & - \\
\hline 40.4 & 10.76 & 13.75 & 8.84 & 0.0333 & 0.0425 & 0.0274 \\
\hline 40.5 & 8.35 & 11.59 & 7.35 & - & - & - \\
\hline 40.6 & 10.50 & 22.99 & 8.40 & 0.0475 & 0.1040 & 0.0380 \\
\hline 40.7 & 17.75 & 14.82 & 8.31 & - & - & - \\
\hline 40.8 & 8.48 & 11.86 & 7.13 & 0.0220 & 0.0308 & 0.0185 \\
\hline 40.9 & 7.56 & 13.55 & 8.44 & - & - & - \\
\hline 41.0 & 9.84 & 16.88 & 11.85 & 0.0377 & 0.0646 & 0.0454 \\
\hline 41.1 & 9.14 & 15.34 & 12.15 & - & - & - \\
\hline 41.2 & 9.05 & 13.46 & 11.10 & 0.0327 & 0.0487 & 0.0401 \\
\hline 41.3 & 9.05 & 13.45 & 8.44 & - & - & - \\
\hline 41.4 & 8.27 & 20.07 & 13.33 & 0.0380 & 0.0923 & 0.0613 \\
\hline 41.5 & 9.88 & 13.23 & 18.74 & - & - & - \\
\hline 41.6 & 9.40 & 16.55 & 30.16 & 0.0231 & 0.0407 & 0.0741 \\
\hline 41.7 & 5.14 & 19.10 & 26.62 & - & - & - \\
\hline 41.8 & 6.52 & 13.50 & 19.32 & 0.0259 & 0.0536 & 0.0767 \\
\hline 41.9 & - & 7.06 & 1.64 & - & - & - \\
\hline 42.0 & 4.24 & 7.79 & 2.71 & 0.0111 & 0.0203 & 0.0071 \\
\hline 42.1 & 7.57 & 8.09 & 2.31 & - & - & - \\
\hline 42.2 & 8.32 & 6.02 & 2.12 & 0.0261 & 0.0189 & 0.0067 \\
\hline
\end{tabular}




\begin{tabular}{|c|c|c|c|c|c|c|}
\hline \multirow[b]{2}{*}{ River km } & \multicolumn{6}{|c|}{ Narraguagus } \\
\hline & $\tau_{b \text { field }}$ & $\tau_{b \text { gis }}$ & $\tau_{b \text { lidar }}$ & $\tau_{\text {field }}^{*}$ & $\tau_{\text {gis }}^{*}$ & $\tau^{*}{ }_{\text {lidar }}$ \\
\hline 42.3 & - & 5.30 & 1.84 & - & - & - \\
\hline 42.4 & - & 4.37 & 1.35 & - & - & - \\
\hline 42.5 & - & 4.14 & 1.19 & - & - & - \\
\hline 42.6 & - & 3.06 & 0.90 & - & - & - \\
\hline 42.7 & - & 2.67 & 0.73 & - & - & - \\
\hline 42.8 & - & 2.30 & 0.68 & - & - & - \\
\hline 42.9 & - & 3.41 & 0.99 & - & - & - \\
\hline 43.0 & - & 4.09 & 1.17 & - & - & - \\
\hline 43.1 & - & 3.63 & 1.08 & - & - & - \\
\hline 43.2 & - & 1.70 & 0.81 & - & - & - \\
\hline 43.3 & - & 1.51 & 0.69 & - & - & - \\
\hline 43.4 & - & 1.59 & 0.48 & - & - & - \\
\hline 43.5 & - & 1.64 & 0.47 & - & - & - \\
\hline 43.6 & - & 1.62 & 0.50 & - & - & - \\
\hline 43.7 & - & 1.93 & 0.59 & - & - & - \\
\hline 43.8 & - & 1.80 & 0.52 & - & - & - \\
\hline 43.9 & - & 1.78 & 0.54 & - & - & - \\
\hline 44.0 & - & 1.72 & 0.49 & - & - & - \\
\hline 44.1 & - & 1.64 & 0.46 & - & - & - \\
\hline 44.2 & - & 1.34 & 0.41 & - & - & - \\
\hline 44.3 & - & 1.45 & 0.40 & - & - & - \\
\hline 44.4 & - & 1.35 & 0.39 & - & - & - \\
\hline 44.5 & - & 1.64 & 0.47 & - & - & - \\
\hline 44.6 & - & 1.76 & 0.50 & - & - & - \\
\hline 44.7 & - & 2.42 & 0.70 & - & - & - \\
\hline 44.8 & - & 3.02 & 1.06 & - & - & - \\
\hline 44.9 & - & 3.63 & 1.06 & - & - & - \\
\hline 45.0 & - & 7.80 & 1.31 & - & - & - \\
\hline 45.1 & - & 6.66 & 2.11 & - & - & - \\
\hline 45.2 & - & 6.45 & 1.93 & - & - & - \\
\hline 45.3 & - & 7.57 & 2.18 & - & - & - \\
\hline 45.4 & - & 7.08 & 2.22 & - & - & - \\
\hline 45.5 & - & 7.30 & 2.42 & - & - & - \\
\hline 45.6 & - & 6.88 & 2.02 & - & - & - \\
\hline 45.7 & - & 7.97 & 2.47 & - & - & - \\
\hline 45.8 & - & 5.70 & 3.16 & - & - & - \\
\hline 45.9 & - & 4.13 & 3.79 & - & - & - \\
\hline 46.0 & - & 11.54 & 17.83 & 0.0572 & 0.0972 & 0.1503 \\
\hline 46.1 & - & 7.77 & 30.35 & - & - & - \\
\hline 46.2 & - & 7.07 & 33.40 & 0.0123 & 0.0125 & 0.0589 \\
\hline 46.3 & - & 9.67 & 41.24 & - & - & - \\
\hline 46.4 & - & 25.40 & 48.28 & 0.0704 & 0.0511 & 0.0971 \\
\hline 46.5 & - & 29.40 & 36.53 & - & - & - \\
\hline 46.6 & - & 35.65 & 36.47 & - & - & - \\
\hline 46.7 & - & 26.84 & 31.49 & - & - & - \\
\hline 46.8 & - & 27.41 & 28.96 & - & - & - \\
\hline 46.9 & - & 38.39 & 36.22 & - & - & - \\
\hline
\end{tabular}




\begin{tabular}{|c|cccccc|}
\hline & & \multicolumn{5}{c}{ Narraguagus } \\
River km & $\boldsymbol{\tau}_{\mathbf{b} \text { field }}$ & $\boldsymbol{\tau}_{\text {b gis }}$ & $\boldsymbol{\tau}_{\text {b lidar }}$ & $\boldsymbol{\tau}_{\text {field }}^{*}$ & $\boldsymbol{\tau}_{\text {gis }}^{*}$ & $\boldsymbol{\tau}^{*}$ lidar \\
\hline $\mathbf{4 7 . 0}$ & - & 41.86 & 61.74 & 0.0445 & 0.0344 & 0.0507 \\
$\mathbf{4 7 . 1}$ & - & 42.64 & 44.11 & - & - & - \\
$\mathbf{4 7 . 2}$ & - & 37.35 & 34.37 & 0.0743 & 0.0484 & 0.0445 \\
$\mathbf{4 7 . 3}$ & - & 40.81 & 34.44 & - & - & - \\
$\mathbf{4 7 . 4}$ & - & 40.46 & 40.76 & 0.0828 & 0.0477 & 0.0481 \\
$\mathbf{4 7 . 5}$ & - & 34.98 & 34.37 & - & - & - \\
$\mathbf{4 7 . 6}$ & - & 31.33 & 37.88 & 0.0430 & 0.0321 & 0.0388 \\
$\mathbf{4 7 . 7}$ & - & 36.94 & 55.70 & - & - & - \\
$\mathbf{4 7 . 8}$ & - & 32.02 & 48.85 & 0.0398 & 0.0298 & 0.0455 \\
$\mathbf{4 7 . 9}$ & - & 35.04 & 48.90 & - & - & - \\
$\mathbf{4 8 . 0}$ & - & 33.53 & 48.13 & 0.0302 & 0.0312 & 0.0448 \\
$\mathbf{4 8 . 1}$ & - & 40.88 & 46.64 & - & - & - \\
$\mathbf{4 8 . 2}$ & - & 41.17 & 62.27 & 0.0384 & 0.0392 & 0.0592 \\
$\mathbf{4 8 . 3}$ & - & 36.58 & 56.76 & - & - & - \\
$\mathbf{4 8 . 4}$ & - & 40.09 & 53.20 & 0.0513 & 0.0548 & 0.0727 \\
$\mathbf{4 8 . 5}$ & - & 39.37 & 52.59 & - & - & - \\
$\mathbf{4 8 . 6}$ & - & 28.42 & 23.89 & 0.0838 & 0.0620 & 0.0521 \\
$\mathbf{4 8 . 7}$ & - & 32.14 & 17.99 & - & - & - \\
$\mathbf{4 8 . 8}$ & - & 28.58 & 12.35 & - & - & - \\
$\mathbf{4 8 . 9}$ & - & 29.95 & 31.46 & - & - & - \\
$\mathbf{4 9 . 0}$ & - & 38.53 & 35.61 & 0.1060 & 0.0836 & 0.0772 \\
$\mathbf{4 9 . 1}$ & - & 55.22 & 39.03 & - & - & - \\
$\mathbf{4 9 . 2}$ & - & 39.60 & 29.28 & 0.1172 & 0.0925 & 0.0684 \\
$\mathbf{4 9 . 3}$ & - & 45.57 & 43.32 & - & - & - \\
$\mathbf{4 9 . 4}$ & - & 45.95 & 51.88 & 0.0615 & 0.0520 & 0.0587 \\
$\mathbf{4 9 . 5}$ & - & 48.82 & 35.56 & - & - & - \\
$\mathbf{4 9 . 6}$ & - & 23.51 & 79.78 & 0.0218 & 0.0232 & 0.0786 \\
$\mathbf{4 9 . 7}$ & - & 22.44 & 89.13 & - & - & - \\
$\mathbf{4 9 . 8}$ & - & 12.93 & 27.18 & - & - & - \\
$\mathbf{4 9 . 9}$ & - & 16.56 & 16.64 & - & - & - \\
$\mathbf{5 0 . 0}$ & - & 14.90 & 11.51 & 0.2901 & 0.1739 & 0.1342 \\
$\mathbf{5 0 . 1}$ & - & 17.52 & 19.16 & - & - & - \\
$\mathbf{5 0 . 2}$ & - & 18.64 & 12.03 & 0.0903 & 0.0895 & 0.0577 \\
$\mathbf{5 0 . 3}$ & - & 13.44 & 8.94 & - & - & - \\
$\mathbf{5 0 . 4}$ & - & 13.51 & 9.35 & - & - & - \\
$\mathbf{5 0 . 5}$ & - & 14.05 & 8.01 & - & - & - \\
$\mathbf{5 0 . 6}$ & - & 14.97 & 9.86 & 0.3762 & 0.2753 & 0.1812 \\
$\mathbf{5 0 . 7}$ & - & 21.60 & 10.00 & - & - & - \\
$\mathbf{5 0 . 8}$ & - & 22.23 & 11.73 & - & - & - \\
$\mathbf{5 0 . 9}$ & - & 17.81 & 15.56 & - & - & - \\
$\mathbf{5 1 . 0}$ & - & 18.61 & 32.25 & 0.1721 & 0.2155 & 0.3735 \\
$\mathbf{5 1 . 1}$ & - & 23.54 & 34.27 & - & - & - \\
$\mathbf{5 1 . 2}$ & - & 18.03 & 16.68 & 0.0608 & 0.0452 & 0.0418 \\
$\mathbf{5 1 . 3}$ & - & 20.72 & 15.78 & - & - & - \\
$\mathbf{5 1 . 4}$ & - & 15.65 & 25.04 & 0.2146 & 0.2526 & 0.4042 \\
$\mathbf{5 1 . 6}$ & - & 17.86 & 10.57 & - & - & - \\
& - & 13.36 & 14.88 & 0.1543 & 0.1841 & 0.2050
\end{tabular}




\begin{tabular}{|c|c|c|c|c|c|c|}
\hline \multirow[b]{2}{*}{ River km } & \multicolumn{6}{|c|}{ Narraguagus } \\
\hline & $\tau_{b \text { field }}$ & $\tau_{\mathrm{b} \text { gis }}$ & $\tau_{b \text { lidar }}$ & $\tau_{\text {field }}^{*}$ & $\tau_{\text {gis }}^{*}$ & $\tau^{*}{ }_{\text {lidar }}$ \\
\hline 51.7 & - & 19.27 & 11.34 & - & - & - \\
\hline 51.8 & - & 11.63 & 11.23 & 0.1188 & 0.1416 & 0.1368 \\
\hline 51.9 & - & 10.06 & 12.62 & - & - & - \\
\hline 52.0 & - & 12.74 & 11.31 & 0.0620 & 0.0796 & 0.0707 \\
\hline 52.1 & - & 15.93 & 14.53 & - & - & - \\
\hline 52.2 & - & 13.18 & 13.95 & 0.1590 & 0.2805 & 0.2971 \\
\hline 52.3 & - & 11.39 & 20.44 & - & - & - \\
\hline 52.4 & - & 16.98 & 17.24 & 0.0453 & 0.0893 & 0.0907 \\
\hline 52.5 & - & 10.36 & 17.52 & - & - & - \\
\hline 52.6 & - & 19.95 & 15.75 & 0.0961 & 0.2250 & 0.1776 \\
\hline 52.7 & - & 10.47 & 10.54 & - & - & - \\
\hline 52.8 & - & 12.65 & 19.36 & 0.0237 & 0.0279 & 0.0428 \\
\hline 52.9 & - & 17.18 & 16.02 & - & - & - \\
\hline 53.0 & - & 12.95 & 9.04 & 0.0271 & 0.0570 & 0.0398 \\
\hline 53.1 & - & 13.93 & 12.82 & - & - & - \\
\hline 53.2 & - & 12.84 & 13.21 & 0.0160 & 0.0228 & 0.0234 \\
\hline 53.3 & - & 10.91 & 14.61 & - & - & - \\
\hline 53.4 & - & 13.05 & 14.72 & 0.0195 & 0.0226 & 0.0255 \\
\hline 53.5 & - & 10.21 & 15.62 & - & - & - \\
\hline 53.6 & - & 14.00 & 12.73 & 0.0271 & 0.0383 & 0.0348 \\
\hline 53.7 & - & 10.95 & 13.43 & - & - & - \\
\hline 53.8 & - & 14.42 & 10.70 & 0.0282 & 0.0394 & 0.0293 \\
\hline 53.9 & - & 10.40 & 9.10 & - & - & - \\
\hline 54.0 & - & 9.36 & 5.97 & - & - & - \\
\hline 54.1 & - & 8.82 & 8.90 & - & - & - \\
\hline 54.2 & - & 9.75 & 8.59 & 0.3246 & 0.3016 & 0.2657 \\
\hline 54.3 & - & 6.41 & 6.83 & - & - & - \\
\hline 54.4 & - & 13.18 & 17.51 & 0.0128 & 0.0258 & 0.0342 \\
\hline 54.5 & - & 13.05 & 22.28 & - & - & - \\
\hline 54.6 & - & 16.25 & 19.28 & 0.0193 & 0.0359 & 0.0426 \\
\hline 54.7 & - & 11.17 & 11.23 & - & - & - \\
\hline 54.8 & - & 13.20 & 13.79 & - & - & - \\
\hline 54.9 & - & 9.74 & 9.70 & - & - & - \\
\hline 55.0 & - & 5.72 & 9.12 & - & - & - \\
\hline 55.1 & - & 4.39 & 6.80 & - & - & - \\
\hline 55.2 & - & 8.07 & 15.50 & - & - & - \\
\hline 55.3 & - & 12.03 & 15.52 & - & - & - \\
\hline 55.4 & - & 7.31 & 15.91 & - & - & - \\
\hline 55.5 & - & 3.17 & 7.74 & - & - & - \\
\hline 55.6 & - & 7.05 & 21.85 & - & - & - \\
\hline 55.7 & - & 7.83 & 14.90 & - & - & - \\
\hline 55.8 & - & 5.74 & 4.76 & - & - & - \\
\hline 55.9 & - & 4.08 & 2.40 & - & - & - \\
\hline 56.0 & - & 4.85 & 3.28 & - & - & - \\
\hline 56.1 & - & 2.39 & 1.79 & - & - & - \\
\hline 56.2 & - & 3.01 & 2.28 & - & - & - \\
\hline 56.3 & - & 4.18 & 3.01 & - & - & - \\
\hline
\end{tabular}




\begin{tabular}{|c|c|c|c|c|c|c|}
\hline \multirow[b]{2}{*}{ River km } & \multicolumn{6}{|c|}{ Narraguagus } \\
\hline & $\tau_{b \text { field }}$ & $\tau_{\mathrm{b} \text { gis }}$ & $\tau_{b \text { lidar }}$ & $\tau^{*}$ field & $\tau_{\text {gis }}^{*}$ & $\tau^{*}{ }_{\text {lidar }}$ \\
\hline 56.4 & - & 4.39 & 4.89 & - & - & - \\
\hline 56.5 & - & 6.49 & 5.12 & - & - & - \\
\hline 56.6 & - & 5.57 & 4.95 & - & - & - \\
\hline 56.7 & - & 7.05 & 6.67 & - & - & - \\
\hline 56.8 & - & 7.08 & 6.66 & - & - & - \\
\hline 56.9 & - & 7.16 & 6.80 & - & - & - \\
\hline 57.0 & - & 9.29 & 6.55 & - & - & - \\
\hline 57.1 & - & 8.86 & 5.47 & - & - & - \\
\hline 57.2 & - & 5.32 & 30.38 & - & - & - \\
\hline 57.3 & - & 7.19 & 27.54 & - & - & - \\
\hline 57.4 & - & 7.74 & 10.19 & - & - & - \\
\hline 57.5 & - & 12.51 & 11.72 & - & - & - \\
\hline 57.6 & - & 6.71 & 11.88 & - & - & - \\
\hline 57.7 & - & 6.89 & 13.59 & - & - & - \\
\hline 57.8 & - & 9.66 & 11.98 & - & - & - \\
\hline 57.9 & - & 7.42 & 12.34 & - & - & - \\
\hline 58.0 & - & 7.94 & 12.78 & - & - & - \\
\hline 58.1 & - & 7.40 & 13.51 & - & - & - \\
\hline 58.2 & - & 11.14 & 16.10 & - & - & - \\
\hline 58.3 & - & 9.74 & 16.06 & - & - & - \\
\hline 58.4 & - & 11.41 & 9.46 & - & - & - \\
\hline 58.5 & - & 5.07 & 5.77 & - & - & - \\
\hline 58.6 & - & 6.72 & 4.74 & - & - & - \\
\hline 58.7 & - & 5.25 & 3.95 & - & - & - \\
\hline 58.8 & - & 4.15 & 4.22 & - & - & - \\
\hline 58.9 & - & 5.38 & 4.07 & - & - & - \\
\hline 59.0 & - & 4.22 & 3.67 & - & - & - \\
\hline 59.1 & - & 1.82 & 1.45 & - & - & - \\
\hline 59.2 & - & 1.57 & 1.25 & - & - & - \\
\hline 59.3 & - & 1.73 & 1.50 & - & - & - \\
\hline 59.4 & - & 4.08 & 3.74 & - & - & - \\
\hline 59.5 & - & 7.83 & 6.79 & - & - & - \\
\hline 59.6 & - & 10.74 & 6.91 & - & - & - \\
\hline 59.7 & - & 8.46 & 8.19 & - & - & - \\
\hline 59.8 & - & 6.71 & 9.12 & - & - & - \\
\hline 59.9 & - & 4.67 & 10.08 & - & - & - \\
\hline 60.0 & - & 5.90 & 10.64 & - & - & - \\
\hline 60.1 & - & 5.81 & 12.98 & - & - & - \\
\hline 60.2 & - & 6.84 & 11.62 & - & - & - \\
\hline 60.3 & - & 7.40 & 11.72 & - & - & - \\
\hline 60.4 & - & 7.28 & 11.16 & - & - & - \\
\hline 60.5 & - & 8.98 & 15.20 & - & - & - \\
\hline 60.6 & - & 6.82 & 10.70 & - & - & - \\
\hline 60.7 & - & 5.32 & 11.66 & - & - & - \\
\hline 60.8 & - & 6.51 & 12.83 & - & - & - \\
\hline 60.9 & - & 6.48 & 13.90 & - & - & - \\
\hline 61.0 & - & 9.72 & 14.68 & - & - & - \\
\hline
\end{tabular}




\begin{tabular}{|c|c|c|c|c|c|c|}
\hline \multirow[b]{2}{*}{ River km } & \multicolumn{6}{|c|}{ Narraguagus } \\
\hline & $\tau_{b \text { field }}$ & $\tau_{\mathrm{b} \text { gis }}$ & $\tau_{\mathrm{b} \text { lidar }}$ & $\tau^{*}$ field & $\tau_{\text {gis }}^{*}$ & $\tau^{*}{ }_{\text {lidar }}$ \\
\hline 61.1 & - & 7.06 & 14.70 & - & - & - \\
\hline 61.2 & - & 10.57 & 13.68 & - & - & - \\
\hline 61.3 & - & 29.17 & 11.53 & - & - & - \\
\hline 61.4 & - & 18.72 & 16.26 & - & - & - \\
\hline 61.5 & - & 28.13 & 18.91 & - & - & - \\
\hline 61.6 & - & 25.97 & 18.95 & - & - & - \\
\hline 61.7 & - & 27.82 & 29.46 & - & - & - \\
\hline 61.8 & - & 29.09 & 29.44 & - & - & - \\
\hline 61.9 & - & 18.88 & 18.83 & - & - & - \\
\hline 62.0 & - & 21.04 & 16.99 & - & - & - \\
\hline 62.1 & - & 19.51 & 18.50 & - & - & - \\
\hline 62.2 & - & 52.36 & 21.01 & - & - & - \\
\hline 62.3 & - & 24.95 & 21.16 & - & - & - \\
\hline 62.4 & - & 38.96 & 23.44 & - & - & - \\
\hline 62.5 & - & 45.73 & 39.95 & - & - & - \\
\hline 62.6 & - & 32.48 & 32.82 & - & - & - \\
\hline 62.7 & - & 29.26 & 31.41 & - & - & - \\
\hline 62.8 & - & 34.10 & 38.98 & - & - & - \\
\hline 62.9 & - & 29.99 & 27.01 & - & - & - \\
\hline 63.0 & - & 33.90 & 23.82 & - & - & - \\
\hline 63.1 & - & 36.93 & 21.06 & - & - & - \\
\hline 63.2 & - & 24.28 & 47.35 & - & - & - \\
\hline 63.3 & - & 34.02 & 49.74 & - & - & - \\
\hline 63.4 & - & 30.07 & 37.23 & - & - & - \\
\hline 63.5 & - & 41.77 & 38.79 & - & - & - \\
\hline 63.6 & - & 28.03 & 52.15 & - & - & - \\
\hline 63.7 & - & 21.53 & 39.32 & - & - & - \\
\hline 63.8 & - & 20.86 & 14.15 & - & - & - \\
\hline 63.9 & - & 14.33 & 5.38 & - & - & - \\
\hline 64.0 & - & 10.31 & 3.94 & - & - & - \\
\hline 64.1 & - & 9.77 & 3.55 & - & - & - \\
\hline 64.2 & - & 10.17 & 4.84 & - & - & - \\
\hline 64.3 & - & 12.45 & 5.22 & - & - & - \\
\hline 64.4 & - & 10.50 & 3.47 & - & - & - \\
\hline 64.5 & - & 11.42 & 4.86 & - & - & - \\
\hline 64.6 & - & 11.90 & 5.13 & - & - & - \\
\hline 64.7 & - & 11.22 & 3.57 & - & - & - \\
\hline 64.8 & - & 8.96 & 9.41 & - & - & - \\
\hline 64.9 & - & 11.81 & 13.62 & - & - & - \\
\hline 65.0 & - & 2.56 & 10.81 & - & - & - \\
\hline 65.1 & - & 2.93 & 3.09 & - & - & - \\
\hline 65.2 & - & 4.49 & 4.63 & - & - & - \\
\hline 65.3 & - & 3.47 & 3.24 & - & - & - \\
\hline 65.4 & - & 3.68 & 3.65 & - & - & - \\
\hline 65.5 & - & 3.84 & 4.77 & - & - & - \\
\hline 65.6 & - & 2.86 & 2.39 & - & - & - \\
\hline 65.7 & - & 3.14 & 3.05 & - & - & - \\
\hline
\end{tabular}




\begin{tabular}{|c|c|c|c|c|c|c|}
\hline \multirow[b]{2}{*}{ River km } & \multicolumn{6}{|c|}{ Narraguagus } \\
\hline & $\tau_{b \text { field }}$ & $\tau_{\mathrm{b} \text { gis }}$ & $\tau_{b \text { lidar }}$ & $\tau^{*}$ field & $\tau_{\text {gis }}^{*}$ & $\tau^{*}{ }_{\text {lidar }}$ \\
\hline 65.8 & - & 3.45 & 3.03 & - & - & - \\
\hline 65.9 & - & 3.04 & 3.16 & - & - & - \\
\hline 66.0 & - & 3.06 & 3.67 & - & - & - \\
\hline 66.1 & - & 2.79 & 3.72 & - & - & - \\
\hline 66.2 & - & 3.43 & 3.27 & - & - & - \\
\hline 66.3 & - & 3.34 & 3.48 & - & - & - \\
\hline 66.4 & - & 3.82 & 4.37 & - & - & - \\
\hline 66.5 & - & 3.55 & 5.01 & - & - & - \\
\hline 66.6 & - & 2.66 & 5.51 & - & - & - \\
\hline 66.7 & - & 2.64 & 5.95 & - & - & - \\
\hline 66.8 & - & 3.12 & 6.95 & - & - & - \\
\hline 66.9 & - & 2.60 & 5.74 & - & - & - \\
\hline 67.0 & - & 1.85 & 2.73 & - & - & - \\
\hline 67.1 & - & 3.28 & 3.81 & - & - & - \\
\hline 67.2 & - & 3.11 & 3.61 & - & - & - \\
\hline 67.3 & - & 3.09 & 3.23 & - & - & - \\
\hline 67.4 & - & 3.54 & 3.63 & - & - & - \\
\hline 67.5 & - & 2.99 & 3.19 & - & - & - \\
\hline 67.6 & - & 3.46 & 3.75 & - & - & - \\
\hline 67.7 & - & 3.85 & 4.27 & - & - & - \\
\hline 67.8 & - & 3.81 & 3.95 & - & - & - \\
\hline 67.9 & - & 4.36 & 4.00 & - & - & - \\
\hline 68.0 & - & 3.45 & 3.62 & - & - & - \\
\hline 68.1 & - & 2.33 & 3.17 & - & - & - \\
\hline 68.2 & - & 2.75 & 2.97 & - & - & - \\
\hline 68.3 & - & 3.33 & 3.05 & - & - & - \\
\hline 68.4 & - & 3.63 & 1.90 & - & - & - \\
\hline 68.5 & - & 4.10 & 1.82 & - & - & - \\
\hline 68.6 & - & 3.60 & 2.13 & - & - & - \\
\hline 68.7 & - & 3.04 & 1.38 & - & - & - \\
\hline 68.8 & - & 2.48 & 1.20 & - & - & - \\
\hline 68.9 & - & 2.72 & 1.33 & - & - & - \\
\hline 69.0 & - & 2.33 & 1.29 & - & - & - \\
\hline 69.1 & - & 2.28 & 1.17 & - & - & - \\
\hline 69.2 & - & 2.39 & 1.12 & - & - & - \\
\hline 69.3 & - & 2.76 & 1.34 & - & - & - \\
\hline 69.4 & - & 2.91 & 1.40 & - & - & - \\
\hline 69.5 & - & 1.92 & 1.00 & - & - & - \\
\hline 69.6 & - & 2.33 & 1.07 & - & - & - \\
\hline 69.7 & - & 2.14 & 1.21 & - & - & - \\
\hline 69.8 & - & 2.63 & 1.32 & - & - & - \\
\hline 69.9 & - & 2.68 & 1.34 & - & - & - \\
\hline 70.0 & - & 2.42 & 1.32 & - & - & - \\
\hline 70.1 & - & 2.05 & 1.25 & - & - & - \\
\hline 70.2 & - & 2.99 & 1.29 & - & - & - \\
\hline 70.3 & - & 2.22 & 0.92 & - & - & - \\
\hline 70.4 & - & 2.36 & 1.11 & - & - & - \\
\hline
\end{tabular}




\begin{tabular}{|c|c|c|c|c|c|c|}
\hline \multirow[b]{2}{*}{ River km } & \multicolumn{6}{|c|}{ Narraguagus } \\
\hline & $\tau_{b \text { field }}$ & $\tau_{b \text { gis }}$ & $\tau_{\mathrm{b} \text { lidar }}$ & $\tau_{\text {field }}^{*}$ & $\tau_{\text {gis }}^{*}$ & $\tau_{\text {lidar }}^{*}$ \\
\hline 70.5 & - & 2.77 & 1.37 & - & - & - \\
\hline 70.6 & - & 2.78 & 1.37 & - & - & - \\
\hline 70.7 & - & 3.18 & 1.88 & - & - & - \\
\hline 70.8 & - & 3.25 & 1.42 & - & - & - \\
\hline 70.9 & - & 2.83 & 1.44 & - & - & - \\
\hline 71.0 & - & 3.06 & 1.72 & - & - & - \\
\hline 71.1 & - & 3.02 & 1.38 & - & - & - \\
\hline 71.2 & - & 3.06 & 1.48 & - & - & - \\
\hline 71.3 & - & 3.48 & 0.93 & - & - & - \\
\hline 71.4 & - & 3.46 & 1.59 & - & - & - \\
\hline 71.5 & - & 3.31 & 1.31 & - & - & - \\
\hline 71.6 & - & 2.68 & 1.51 & - & - & - \\
\hline 71.7 & - & 2.53 & 1.31 & - & - & - \\
\hline 71.8 & - & 3.34 & 1.87 & - & - & - \\
\hline 71.9 & - & 3.44 & 2.01 & - & - & - \\
\hline 72.0 & - & 3.14 & 1.53 & - & - & - \\
\hline 72.1 & - & 3.53 & 1.49 & - & - & - \\
\hline 72.2 & - & 3.57 & 1.63 & - & - & - \\
\hline 72.3 & - & 3.36 & 1.55 & - & - & - \\
\hline 72.4 & - & 3.03 & 1.75 & - & - & - \\
\hline 72.5 & - & 3.15 & 1.74 & - & - & - \\
\hline 72.6 & - & 4.78 & 4.82 & - & - & - \\
\hline 72.7 & - & 4.51 & 8.37 & - & - & - \\
\hline 72.8 & - & 3.74 & 7.63 & - & - & - \\
\hline 72.9 & - & 4.69 & 10.17 & - & - & - \\
\hline 73.0 & - & 3.56 & 8.93 & - & - & - \\
\hline 73.1 & - & 3.45 & 8.52 & - & - & - \\
\hline 73.2 & - & 3.65 & 6.09 & - & - & - \\
\hline 73.3 & - & 4.40 & 7.23 & - & - & - \\
\hline 73.4 & - & 3.12 & 6.54 & - & - & - \\
\hline 73.5 & - & 3.40 & 6.18 & - & - & - \\
\hline 73.6 & - & 4.39 & 7.37 & - & - & - \\
\hline 73.7 & - & 2.46 & 9.89 & - & - & - \\
\hline 73.8 & - & 6.16 & 20.61 & - & - & - \\
\hline 73.9 & - & 2.38 & 7.29 & - & - & - \\
\hline 74.0 & - & 3.14 & 3.29 & - & - & - \\
\hline 74.1 & - & 3.47 & 3.82 & - & - & - \\
\hline 74.2 & - & 4.21 & 5.53 & - & - & - \\
\hline 74.3 & - & 2.96 & 2.94 & - & - & - \\
\hline 74.4 & - & 3.05 & 1.51 & - & - & - \\
\hline 74.5 & - & 2.73 & 1.30 & - & - & - \\
\hline 74.6 & - & 2.10 & 0.78 & - & - & - \\
\hline 74.7 & - & 0.38 & 0.77 & - & - & - \\
\hline 74.8 & - & 0.38 & 0.18 & - & - & - \\
\hline 74.9 & - & 0.37 & 0.18 & - & - & - \\
\hline 75.0 & - & 0.57 & 0.20 & - & - & - \\
\hline 75.1 & - & 2.97 & 1.36 & - & - & - \\
\hline
\end{tabular}




\begin{tabular}{|c|cccccc|}
\hline & \multicolumn{7}{|c|}{ Narraguagus } \\
River $\mathbf{~ k m}$ & $\tau_{\mathrm{b} \text { field }}$ & $\tau_{\text {b } \text { gis }}$ & $\tau_{\text {b lidar }}$ & $\boldsymbol{\tau}_{\text {field }}^{*}$ & $\boldsymbol{\tau}^{*}{ }_{\text {gis }}$ & $\tau^{*}{ }_{\text {lidar }}$ \\
\hline $\mathbf{7 5 . 2}$ & - & 3.51 & 1.21 & - & - & - \\
$\mathbf{7 5 . 3}$ & - & 3.93 & 1.81 & - & - & - \\
$\mathbf{7 5 . 4}$ & - & 3.66 & 1.43 & - & - & - \\
$\mathbf{7 5 . 5}$ & - & 3.55 & 1.34 & - & - & - \\
$\mathbf{7 5 . 6}$ & - & 3.45 & 1.34 & - & - & - \\
$\mathbf{7 5 . 7}$ & - & 4.21 & 1.52 & - & - & - \\
$\mathbf{7 5 . 8}$ & - & 3.92 & 1.49 & - & - & - \\
$\mathbf{7 5 . 9}$ & - & 3.64 & 1.40 & - & - & - \\
$\mathbf{7 6 . 0}$ & - & 4.46 & 1.41 & - & - & - \\
$\mathbf{7 6 . 1}$ & - & 3.40 & 1.33 & - & - & - \\
$\mathbf{7 6 . 2}$ & - & 3.36 & 1.43 & - & - & - \\
$\mathbf{7 6 . 3}$ & - & 4.28 & 1.47 & - & - & - \\
$\mathbf{7 6 . 4}$ & - & 4.08 & 1.77 & - & - & - \\
$\mathbf{7 6 . 5}$ & - & 4.64 & 1.85 & - & - & - \\
$\mathbf{7 6 . 6}$ & - & 5.49 & 1.67 & - & - & - \\
$\mathbf{7 6 . 7}$ & - & 7.16 & 4.66 & - & - & - \\
$\mathbf{7 6 . 8}$ & - & 8.18 & 9.96 & - & - & - \\
$\mathbf{7 6 . 9}$ & - & 3.85 & 9.97 & - & - & - \\
$\mathbf{7 7 . 0}$ & - & 7.93 & 16.09 & - & - & - \\
$\mathbf{7 7 . 1}$ & - & 5.99 & 12.13 & - & - & - \\
$\mathbf{7 7 . 2}$ & - & 11.73 & 7.81 & - & - & - \\
$\mathbf{7 7 . 3}$ & - & 12.21 & 6.29 & - & - & - \\
$\mathbf{7 7 . 4}$ & - & 10.96 & 8.18 & - & - & - \\
$\mathbf{7 7 . 5}$ & - & 9.13 & 15.28 & - & - & - \\
$\mathbf{7 7 . 6}$ & - & 9.73 & 10.81 & - & - & - \\
$\mathbf{7 7 . 7}$ & - & 10.54 & 4.87 & - & - & - \\
$\mathbf{7 7 . 8}$ & - & 12.68 & 6.41 & - & - & - \\
$\mathbf{7 7 . 9}$ & - & 14.30 & 17.26 & - & - & - \\
$\mathbf{7 8 . 0}$ & - & 13.29 & 14.35 & - & - & - \\
\hline & & & & & & \\
\end{tabular}




\begin{tabular}{|c|c|c|c|c|}
\hline \multirow[b]{2}{*}{ River km } & \multicolumn{4}{|c|}{ Jacquet } \\
\hline & $\tau_{b \text { field }}$ & $\tau_{b \text { gis }}$ & $\tau_{\text {field }}^{*}$ & $\tau_{\text {gis }}^{*}$ \\
\hline 0.0 & - & - & - & - \\
\hline 0.1 & - & - & - & - \\
\hline 0.2 & - & - & - & - \\
\hline 0.3 & - & - & - & - \\
\hline 0.4 & - & - & - & - \\
\hline 0.5 & - & - & - & - \\
\hline 0.6 & - & - & - & - \\
\hline 0.7 & - & - & - & - \\
\hline 0.8 & - & - & - & - \\
\hline 0.9 & - & - & - & - \\
\hline 1.0 & - & - & - & - \\
\hline 1.1 & - & - & - & - \\
\hline 1.2 & - & - & - & - \\
\hline 1.3 & - & 21.73 & - & - \\
\hline 1.4 & - & 18.64 & - & - \\
\hline 1.5 & - & 32.98 & - & - \\
\hline 1.6 & - & 36.37 & - & - \\
\hline 1.7 & - & 47.19 & - & - \\
\hline 1.8 & - & 39.55 & - & - \\
\hline 1.9 & - & 64.77 & - & - \\
\hline 2.0 & - & 43.84 & - & - \\
\hline 2.1 & - & 64.90 & - & - \\
\hline 2.2 & - & 56.88 & - & - \\
\hline 2.3 & - & 81.66 & - & - \\
\hline 2.4 & - & 56.59 & - & - \\
\hline 2.5 & - & 32.29 & - & - \\
\hline 2.6 & - & 38.83 & - & - \\
\hline 2.7 & - & 37.98 & - & - \\
\hline 2.8 & - & 38.16 & - & - \\
\hline 2.9 & - & 34.21 & - & - \\
\hline 3.0 & - & 30.89 & - & - \\
\hline 3.1 & - & 31.51 & - & - \\
\hline 3.2 & - & 44.02 & - & - \\
\hline 3.3 & - & 36.59 & - & - \\
\hline 3.4 & - & 40.23 & - & - \\
\hline 3.5 & - & 38.36 & - & - \\
\hline 3.6 & - & 28.47 & - & - \\
\hline 3.7 & - & 33.82 & - & - \\
\hline 3.8 & - & 32.08 & - & - \\
\hline 3.9 & - & 37.69 & - & - \\
\hline 4.0 & - & 36.60 & - & - \\
\hline 4.1 & - & 35.85 & - & - \\
\hline 4.2 & - & 30.47 & - & - \\
\hline 4.3 & - & 37.69 & - & - \\
\hline 4.4 & - & 57.09 & - & - \\
\hline 4.5 & - & 59.58 & - & - \\
\hline 4.6 & - & 48.54 & - & - \\
\hline
\end{tabular}




\begin{tabular}{|c|c|c|c|c|}
\hline \multirow[b]{2}{*}{ River km } & \multicolumn{4}{|c|}{ Jacquet } \\
\hline & $\tau_{b \text { field }}$ & $\tau_{b \text { gis }}$ & $\tau_{\text {field }}^{*}$ & $\tau_{\text {gis }}^{*}$ \\
\hline 4.7 & - & 44.96 & - & - \\
\hline 4.8 & - & 45.23 & - & - \\
\hline 4.9 & - & 41.16 & - & - \\
\hline 5.0 & - & 43.79 & - & - \\
\hline 5.1 & - & 47.08 & - & - \\
\hline 5.2 & - & 53.05 & - & - \\
\hline 5.3 & - & 34.69 & - & - \\
\hline 5.4 & - & 66.54 & - & - \\
\hline 5.5 & - & 61.36 & - & - \\
\hline 5.6 & - & 62.74 & - & - \\
\hline 5.7 & - & 57.21 & - & - \\
\hline 5.8 & - & 53.10 & - & - \\
\hline 5.9 & - & 59.08 & - & - \\
\hline 6.0 & - & 57.15 & - & - \\
\hline 6.1 & - & 53.10 & - & - \\
\hline 6.2 & - & 59.30 & - & - \\
\hline 6.3 & - & 51.10 & - & - \\
\hline 6.4 & - & 51.59 & - & - \\
\hline 6.5 & - & 48.64 & - & - \\
\hline 6.6 & - & 58.45 & - & - \\
\hline 6.7 & - & 43.51 & - & - \\
\hline 6.8 & - & 39.67 & - & - \\
\hline 6.9 & - & 36.28 & - & - \\
\hline 7.0 & - & 33.31 & - & - \\
\hline 7.1 & - & 35.18 & - & - \\
\hline 7.2 & - & 45.57 & - & - \\
\hline 7.3 & - & 47.19 & - & - \\
\hline 7.4 & - & 42.49 & - & - \\
\hline 7.5 & - & 39.97 & - & - \\
\hline 7.6 & - & 38.09 & - & - \\
\hline 7.7 & - & 40.19 & - & - \\
\hline 7.8 & - & 36.49 & - & - \\
\hline 7.9 & - & 37.03 & - & - \\
\hline 8.0 & - & 46.99 & - & - \\
\hline 8.1 & - & 51.45 & - & - \\
\hline 8.2 & - & 38.67 & - & - \\
\hline 8.3 & - & 33.13 & - & - \\
\hline 8.4 & - & 39.27 & - & - \\
\hline 8.5 & - & 39.07 & - & - \\
\hline 8.6 & - & 45.42 & - & - \\
\hline 8.7 & - & 37.84 & - & - \\
\hline 8.8 & - & 38.53 & - & - \\
\hline 8.9 & - & 51.94 & - & - \\
\hline 9.0 & - & 41.28 & - & - \\
\hline 9.1 & - & 41.16 & - & - \\
\hline 9.2 & - & 33.42 & - & - \\
\hline 9.3 & - & 33.69 & - & - \\
\hline
\end{tabular}




\begin{tabular}{|c|c|c|c|c|}
\hline \multirow[b]{2}{*}{ River km } & \multicolumn{4}{|c|}{ Jacquet } \\
\hline & $\tau_{b \text { field }}$ & $\tau_{b \text { gis }}$ & $\tau^{*}$ field & $\tau_{\text {gis }}^{*}$ \\
\hline 9.4 & - & 35.17 & - & - \\
\hline 9.5 & - & 41.08 & - & - \\
\hline 9.6 & - & 38.27 & - & - \\
\hline 9.7 & - & 36.09 & - & - \\
\hline 9.8 & - & 39.09 & - & - \\
\hline 9.9 & - & 35.62 & - & - \\
\hline 10.0 & - & 40.27 & - & - \\
\hline 10.1 & - & 43.86 & - & - \\
\hline 10.2 & - & 47.48 & - & - \\
\hline 10.3 & - & 38.84 & - & - \\
\hline 10.4 & - & 42.62 & - & - \\
\hline 10.5 & - & 39.82 & - & - \\
\hline 10.6 & - & 43.60 & - & - \\
\hline 10.7 & - & 43.48 & - & - \\
\hline 10.8 & - & 47.15 & - & - \\
\hline 10.9 & - & 40.94 & - & - \\
\hline 11.0 & - & 43.49 & - & - \\
\hline 11.1 & - & 36.31 & - & - \\
\hline 11.2 & - & 44.10 & - & - \\
\hline 11.3 & - & 41.35 & - & - \\
\hline 11.4 & - & 40.13 & - & - \\
\hline 11.5 & - & 43.58 & - & - \\
\hline 11.6 & - & 48.32 & - & - \\
\hline 11.7 & - & 50.36 & - & - \\
\hline 11.8 & - & 46.47 & - & - \\
\hline 11.9 & - & 45.69 & - & - \\
\hline 12.0 & - & 46.34 & - & - \\
\hline 12.1 & - & 44.94 & - & - \\
\hline 12.2 & - & 45.86 & - & - \\
\hline 12.3 & - & 49.97 & - & - \\
\hline 12.4 & - & 45.63 & - & - \\
\hline 12.5 & - & 46.62 & - & - \\
\hline 12.6 & - & 47.76 & - & - \\
\hline 12.7 & - & 45.34 & - & - \\
\hline 12.8 & - & 50.17 & - & - \\
\hline 12.9 & - & 43.26 & - & - \\
\hline 13.0 & - & 47.76 & - & - \\
\hline 13.1 & - & 51.63 & - & - \\
\hline 13.2 & - & 49.66 & - & - \\
\hline 13.3 & - & 52.42 & - & - \\
\hline 13.4 & - & 45.88 & - & - \\
\hline 13.5 & - & 52.59 & - & - \\
\hline 13.6 & - & 45.58 & - & - \\
\hline 13.7 & - & 48.31 & - & - \\
\hline 13.8 & - & 53.81 & - & - \\
\hline 13.9 & - & 56.38 & - & - \\
\hline 14.0 & - & 49.09 & - & - \\
\hline
\end{tabular}




\begin{tabular}{|c|c|c|c|c|}
\hline \multirow[b]{2}{*}{ River km } & \multicolumn{4}{|c|}{ Jacquet } \\
\hline & $\tau_{b \text { field }}$ & $\tau_{b \text { gis }}$ & $\tau_{\text {field }}^{*}$ & $\tau_{\text {gis }}^{*}$ \\
\hline 14.1 & - & 35.42 & - & - \\
\hline 14.2 & - & 45.94 & - & - \\
\hline 14.3 & - & 44.24 & - & - \\
\hline 14.4 & - & 55.28 & - & - \\
\hline 14.5 & - & 62.22 & - & - \\
\hline 14.6 & - & 39.58 & - & - \\
\hline 14.7 & - & 38.09 & - & - \\
\hline 14.8 & - & 44.26 & - & - \\
\hline 14.9 & - & 45.51 & - & - \\
\hline 15.0 & - & 44.42 & - & - \\
\hline 15.1 & - & 49.36 & - & - \\
\hline 15.2 & - & 57.85 & - & - \\
\hline 15.3 & - & 47.58 & - & - \\
\hline 15.4 & - & 50.31 & - & - \\
\hline 15.5 & - & 52.14 & - & - \\
\hline 15.6 & - & 65.45 & - & - \\
\hline 15.7 & - & 53.94 & - & - \\
\hline 15.8 & - & 44.04 & - & - \\
\hline 15.9 & - & 46.54 & - & - \\
\hline 16.0 & - & 42.34 & - & - \\
\hline 16.1 & - & 56.44 & - & - \\
\hline 16.2 & - & 56.85 & - & - \\
\hline 16.3 & - & 46.51 & - & - \\
\hline 16.4 & - & 62.86 & - & - \\
\hline 16.5 & - & 45.67 & - & - \\
\hline 16.6 & - & 41.95 & - & - \\
\hline 16.7 & - & 49.59 & - & - \\
\hline 16.8 & - & 52.96 & - & - \\
\hline 16.9 & - & 48.61 & - & - \\
\hline 17.0 & - & 45.47 & - & - \\
\hline 17.1 & - & 42.55 & - & - \\
\hline 17.2 & - & 44.87 & - & - \\
\hline 17.3 & - & 51.59 & - & - \\
\hline 17.4 & - & 48.86 & - & - \\
\hline 17.5 & - & 56.08 & - & - \\
\hline 17.6 & - & 40.40 & - & - \\
\hline 17.7 & - & 57.94 & - & - \\
\hline 17.8 & - & 67.91 & - & - \\
\hline 17.9 & - & 55.33 & - & - \\
\hline 18.0 & - & 61.49 & - & - \\
\hline 18.1 & - & 55.08 & - & - \\
\hline 18.2 & - & 53.56 & - & - \\
\hline 18.3 & - & 62.71 & - & - \\
\hline 18.4 & - & 61.78 & - & - \\
\hline 18.5 & - & 56.37 & - & - \\
\hline 18.6 & - & 60.54 & - & - \\
\hline 18.7 & - & 69.12 & - & - \\
\hline
\end{tabular}




\begin{tabular}{|c|c|c|c|c|}
\hline \multirow[b]{2}{*}{ River km } & \multicolumn{4}{|c|}{ Jacquet } \\
\hline & $\tau_{b \text { field }}$ & $\tau_{b \text { gis }}$ & $\tau_{\text {field }}^{*}$ & $\tau_{\text {gis }}^{*}$ \\
\hline 18.8 & - & 46.95 & - & - \\
\hline 18.9 & - & 53.45 & - & - \\
\hline 19.0 & - & 56.70 & - & - \\
\hline 19.1 & - & 56.50 & - & - \\
\hline 19.2 & - & 56.64 & - & - \\
\hline 19.3 & - & 54.45 & - & - \\
\hline 19.4 & - & 56.18 & - & - \\
\hline 19.5 & - & 47.88 & - & - \\
\hline 19.6 & - & 53.80 & - & - \\
\hline 19.7 & - & 61.07 & - & - \\
\hline 19.8 & - & 57.05 & - & - \\
\hline 19.9 & - & 49.19 & - & - \\
\hline 20.0 & - & 64.03 & - & - \\
\hline 20.1 & - & 56.84 & - & - \\
\hline 20.2 & - & 48.27 & - & - \\
\hline 20.3 & - & 62.22 & - & - \\
\hline 20.4 & - & 47.05 & - & - \\
\hline 20.5 & - & 54.60 & - & - \\
\hline 20.6 & - & 47.32 & - & - \\
\hline 20.7 & - & 59.01 & - & - \\
\hline 20.8 & - & 61.69 & - & - \\
\hline 20.9 & - & 69.37 & - & - \\
\hline 21.0 & - & 84.70 & - & - \\
\hline 21.1 & - & 61.34 & - & - \\
\hline 21.2 & - & 72.59 & - & - \\
\hline 21.3 & - & 80.70 & - & - \\
\hline 21.4 & - & 63.90 & - & - \\
\hline 21.5 & - & 78.42 & - & - \\
\hline 21.6 & - & 69.31 & - & - \\
\hline 21.7 & - & 74.51 & - & - \\
\hline 21.8 & - & 108.81 & - & - \\
\hline 21.9 & - & 98.33 & - & - \\
\hline 22.0 & - & 79.43 & - & - \\
\hline 22.1 & - & 72.95 & - & - \\
\hline 22.2 & - & 90.46 & - & - \\
\hline 22.3 & - & 76.19 & - & - \\
\hline 22.4 & - & 79.76 & - & - \\
\hline 22.5 & - & 64.46 & - & - \\
\hline 22.6 & - & 65.97 & - & - \\
\hline 22.7 & - & 97.42 & - & - \\
\hline 22.8 & - & 67.49 & - & - \\
\hline 22.9 & - & 66.21 & - & - \\
\hline 23.0 & - & 55.41 & - & - \\
\hline 23.1 & - & 50.34 & - & - \\
\hline 23.2 & - & 49.74 & - & - \\
\hline 23.3 & - & 68.42 & - & - \\
\hline 23.4 & - & 84.40 & - & - \\
\hline
\end{tabular}




\begin{tabular}{|c|c|c|c|c|}
\hline \multirow[b]{2}{*}{ River km } & \multicolumn{4}{|c|}{ Jacquet } \\
\hline & $\tau_{b \text { field }}$ & $\tau_{b \text { gis }}$ & $\tau_{\text {field }}^{*}$ & $\tau_{\text {gis }}^{*}$ \\
\hline 23.5 & - & 67.62 & - & - \\
\hline 23.6 & - & 73.67 & - & - \\
\hline 23.7 & - & 72.02 & - & - \\
\hline 23.8 & - & 79.36 & - & - \\
\hline 23.9 & - & 67.14 & - & - \\
\hline 24.0 & - & 44.41 & - & - \\
\hline 24.1 & - & 63.46 & - & - \\
\hline 24.2 & - & 52.10 & - & - \\
\hline 24.3 & - & 61.53 & - & - \\
\hline 24.4 & - & 74.22 & - & - \\
\hline 24.5 & - & 73.26 & - & - \\
\hline 24.6 & - & 75.86 & - & - \\
\hline 24.7 & - & 66.16 & - & - \\
\hline 24.8 & - & 64.10 & - & - \\
\hline 24.9 & - & 60.55 & - & - \\
\hline 25.0 & - & 65.49 & - & - \\
\hline 25.1 & - & 68.50 & - & - \\
\hline 25.2 & - & 77.33 & - & - \\
\hline 25.3 & - & 60.30 & - & - \\
\hline 25.4 & - & 67.54 & - & - \\
\hline 25.5 & - & 62.02 & - & - \\
\hline 25.6 & - & 60.00 & - & - \\
\hline 25.7 & - & 59.29 & - & - \\
\hline 25.8 & - & 59.87 & - & - \\
\hline 25.9 & - & 59.50 & - & - \\
\hline 26.0 & - & 59.98 & - & - \\
\hline 26.1 & - & 53.93 & - & - \\
\hline 26.2 & - & 57.38 & - & - \\
\hline 26.3 & - & 55.79 & - & - \\
\hline 26.4 & - & 46.37 & - & - \\
\hline 26.5 & - & 60.83 & - & - \\
\hline 26.6 & - & 67.83 & - & - \\
\hline 26.7 & - & 53.37 & - & - \\
\hline 26.8 & - & 57.02 & - & - \\
\hline 26.9 & - & 69.24 & - & - \\
\hline 27.0 & - & 75.97 & - & - \\
\hline 27.1 & - & 70.52 & - & - \\
\hline 27.2 & - & 80.81 & - & - \\
\hline 27.3 & - & 56.78 & - & - \\
\hline 27.4 & 30.75 & 66.64 & 0.0286 & 0.0620 \\
\hline 27.5 & 33.62 & 60.59 & - & - \\
\hline 27.6 & 47.48 & 65.22 & - & - \\
\hline 27.7 & 47.82 & 53.46 & - & - \\
\hline 27.8 & 27.88 & 68.46 & 0.0233 & 0.0571 \\
\hline 27.9 & 32.27 & 63.46 & - & - \\
\hline 28.0 & 34.30 & 55.05 & 0.0361 & 0.0580 \\
\hline 28.1 & 31.51 & 49.48 & - & - \\
\hline
\end{tabular}




\begin{tabular}{|c|cccc|}
\hline & \multicolumn{4}{|c|}{ Jacquet } \\
River km & $\boldsymbol{\tau}_{\text {b field }}$ & $\boldsymbol{\tau}_{\text {b gis }}$ & $\boldsymbol{\tau}_{\text {field }}^{*}$ & $\boldsymbol{\tau}^{*}{ }_{\text {gis }}$ \\
\hline $\mathbf{2 8 . 2}$ & 36.83 & 50.13 & 0.0285 & 0.0389 \\
$\mathbf{2 8 . 3}$ & 45.96 & 54.82 & - & - \\
$\mathbf{2 8 . 4}$ & 57.58 & 83.09 & 0.0468 & 0.0675 \\
$\mathbf{2 8 . 5}$ & 84.83 & 69.65 & - & - \\
$\mathbf{2 8 . 6}$ & 77.18 & 94.45 & 0.0844 & 0.1033 \\
$\mathbf{2 8 . 7}$ & 83.61 & 92.63 & - & - \\
$\mathbf{2 8 . 8}$ & 113.93 & 52.54 & 0.0945 & 0.0436 \\
$\mathbf{2 8 . 9}$ & 63.70 & 70.06 & - & - \\
$\mathbf{2 9 . 0}$ & 77.79 & 78.76 & 0.0992 & 0.1004 \\
$\mathbf{2 9 . 1}$ & 87.28 & 96.51 & - & - \\
$\mathbf{2 9 . 2}$ & 103.21 & 109.93 & 0.0951 & 0.1013 \\
$\mathbf{2 9 . 3}$ & 44.71 & 83.09 & - & - \\
$\mathbf{2 9 . 4}$ & 45.02 & 93.48 & 0.0415 & 0.0863 \\
$\mathbf{2 9 . 5}$ & 41.34 & 91.11 & - & - \\
$\mathbf{2 9 . 6}$ & 59.11 & 82.34 & 0.0659 & 0.0918 \\
$\mathbf{2 9 . 7}$ & 69.83 & 76.59 & - & - \\
$\mathbf{2 9 . 8}$ & 62.48 & 76.62 & 0.0437 & 0.0536 \\
$\mathbf{2 9 . 9}$ & 64.31 & 89.38 & - & - \\
$\mathbf{3 0 . 0}$ & 22.54 & 46.98 & 0.0132 & 0.0274 \\
$\mathbf{3 0 . 1}$ & 26.22 & 57.56 & - & - \\
$\mathbf{3 0 . 2}$ & 23.40 & 25.72 & 0.0161 & 0.0177 \\
$\mathbf{3 0 . 3}$ & 26.34 & 36.01 & - & - \\
$\mathbf{3 0 . 4}$ & 32.22 & 28.05 & 0.0239 & 0.0208 \\
$\mathbf{3 0 . 5}$ & 29.52 & 34.97 & - & - \\
$\mathbf{3 0 . 6}$ & 20.83 & 42.62 & 0.0178 & 0.0364 \\
$\mathbf{3 0 . 7}$ & 26.58 & 44.28 & - & - \\
$\mathbf{3 0 . 8}$ & - & 41.38 & - & 0.0394 \\
$\mathbf{3 0 . 9}$ & 24.99 & 36.97 & - & - \\
$\mathbf{3 1 . 0}$ & 21.81 & 35.73 & 0.0288 & 0.0472 \\
$\mathbf{3 1 . 1}$ & 24.38 & 45.39 & - & - \\
$\mathbf{3 1 . 2}$ & 21.93 & 46.06 & 0.0201 & 0.0423 \\
$\mathbf{3 1 . 3}$ & 35.65 & 46.99 & - & - \\
$\mathbf{3 1 . 4}$ & 23.15 & 53.79 & 0.0255 & 0.0592 \\
$\mathbf{3 1 . 5}$ & 30.50 & 50.80 & - & - \\
$\mathbf{3 1 . 6}$ & 20.46 & 43.89 & 0.0237 & 0.0508 \\
$\mathbf{3 1 . 7}$ & - & 35.16 & - & - \\
$\mathbf{3 1 . 8}$ & 19.85 & 38.18 & 0.0311 & 0.0599 \\
$\mathbf{3 1 . 9}$ & 25.48 & 40.44 & - & - \\
$\mathbf{3 2 . 0}$ & 20.58 & 43.65 & 0.0131 & 0.0278 \\
$\mathbf{3 2 . 1}$ & 25.36 & 37.05 & - & - \\
$\mathbf{3 2 . 2}$ & - & 31.54 & - & 0.0388 \\
$\mathbf{3 2 . 3}$ & 26.71 & 34.76 & - & - \\
$\mathbf{3 2 . 4}$ & 26.71 & 38.06 & 0.0315 & 0.0449 \\
$\mathbf{3 2 . 5}$ & 18.25 & 35.01 & - & - \\
& 16.54 & 48.57 & 0.0188 & 0.0553 \\
$\mathbf{3 2 . 7}$ & 16.13 & 39.02 & - & - \\
& & 50.07 & 0.0189 & 0.0575
\end{tabular}




\begin{tabular}{|c|c|c|c|c|}
\hline \multirow[b]{2}{*}{ River km } & \multicolumn{4}{|c|}{ Jacquet } \\
\hline & $\tau_{b \text { field }}$ & $\tau_{b \text { gis }}$ & $\tau_{\text {field }}^{*}$ & $\tau_{\text {gis }}^{*}$ \\
\hline 32.9 & 30.26 & 45.12 & - & - \\
\hline 33.0 & 13.48 & 36.43 & 0.0157 & 0.0425 \\
\hline 33.1 & 20.58 & 45.75 & - & - \\
\hline 33.2 & 18.87 & 53.01 & 0.0300 & 0.0844 \\
\hline 33.3 & 19.36 & 34.44 & - & - \\
\hline 33.4 & 16.78 & 48.67 & 0.0175 & 0.0507 \\
\hline 33.5 & 24.87 & 45.03 & - & - \\
\hline 33.6 & 19.97 & 47.13 & 0.0180 & 0.0426 \\
\hline 33.7 & 27.69 & 43.76 & - & - \\
\hline 33.8 & 28.54 & 51.03 & 0.0410 & 0.0733 \\
\hline 33.9 & 19.23 & 45.45 & - & - \\
\hline 34.0 & 35.59 & 94.92 & 0.0413 & 0.1103 \\
\hline 34.1 & 41.01 & 91.63 & - & - \\
\hline 34.2 & 45.39 & 60.53 & 0.0389 & 0.0519 \\
\hline 34.3 & 35.59 & 68.03 & - & - \\
\hline 34.4 & 46.42 & 66.32 & 0.0727 & 0.1039 \\
\hline 34.5 & 53.90 & 73.94 & - & - \\
\hline 34.6 & 55.96 & 78.40 & 0.0765 & 0.1071 \\
\hline 34.7 & 42.29 & 74.30 & - & - \\
\hline 34.8 & 36.36 & 70.15 & 0.0344 & 0.0663 \\
\hline 34.9 & 43.58 & 67.20 & - & - \\
\hline 35.0 & 46.16 & 85.78 & 0.0446 & 0.0829 \\
\hline 35.1 & 35.59 & 70.64 & - & - \\
\hline 35.2 & 50.03 & 81.48 & 0.0627 & 0.1021 \\
\hline 35.3 & 43.58 & 81.46 & - & - \\
\hline 35.4 & 32.75 & 82.49 & 0.0302 & 0.0760 \\
\hline 35.5 & 35.07 & 69.91 & - & - \\
\hline 35.6 & 45.39 & 87.68 & 0.0413 & 0.0798 \\
\hline 35.7 & 32.49 & 76.83 & - & - \\
\hline 35.8 & 40.75 & 87.61 & 0.0257 & 0.0553 \\
\hline 35.9 & 23.15 & 43.24 & - & - \\
\hline 36.0 & 26.19 & 61.86 & 0.0332 & 0.0783 \\
\hline 36.1 & 25.01 & 53.87 & - & - \\
\hline 36.2 & 28.05 & 59.69 & 0.0239 & 0.0510 \\
\hline 36.3 & - & 47.38 & - & - \\
\hline 36.4 & 21.46 & 54.15 & 0.0247 & 0.0622 \\
\hline 36.5 & 20.28 & 50.72 & - & - \\
\hline 36.6 & 16.39 & 39.86 & 0.0214 & 0.0522 \\
\hline 36.7 & 20.95 & 43.81 & - & - \\
\hline 36.8 & 21.97 & 52.00 & 0.0192 & 0.0454 \\
\hline 36.9 & 27.71 & 47.77 & - & - \\
\hline 37.0 & 27.37 & 38.02 & 0.0335 & 0.0465 \\
\hline 37.1 & 28.89 & 36.93 & - & - \\
\hline 37.2 & 17.57 & 35.67 & 0.0381 & 0.0774 \\
\hline 37.3 & 38.86 & 46.73 & - & - \\
\hline 37.4 & 27.71 & 32.22 & 0.0584 & 0.0679 \\
\hline 37.5 & 31.93 & 34.90 & - & - \\
\hline
\end{tabular}




\begin{tabular}{|c|c|c|c|c|}
\hline \multirow[b]{2}{*}{ River km } & \multicolumn{4}{|c|}{ Jacquet } \\
\hline & $\tau_{b \text { field }}$ & $\tau_{b \text { gis }}$ & $\tau_{\text {field }}^{*}$ & $\tau_{\text {gis }}^{*}$ \\
\hline 37.6 & 23.32 & 36.44 & 0.0289 & 0.0451 \\
\hline 37.7 & 14.36 & 34.01 & - & - \\
\hline 37.8 & 23.49 & 44.89 & 0.0385 & 0.0735 \\
\hline 37.9 & - & 53.55 & - & - \\
\hline 38.0 & - & 30.81 & - & - \\
\hline 38.1 & - & 36.70 & - & - \\
\hline 38.2 & - & 45.39 & - & - \\
\hline 38.3 & - & 40.83 & - & - \\
\hline 38.4 & - & 34.41 & - & - \\
\hline 38.5 & - & 37.66 & - & - \\
\hline 38.6 & - & 32.76 & - & - \\
\hline 38.7 & - & 43.61 & - & - \\
\hline 38.8 & - & 62.90 & - & - \\
\hline 38.9 & - & 39.67 & - & - \\
\hline 39.0 & - & 62.27 & - & - \\
\hline 39.1 & - & 67.45 & - & - \\
\hline 39.2 & - & 83.56 & - & - \\
\hline 39.3 & - & 80.86 & - & - \\
\hline 39.4 & - & 42.40 & - & - \\
\hline 39.5 & - & 66.70 & - & - \\
\hline 39.6 & - & 73.39 & - & - \\
\hline 39.7 & - & 70.91 & - & - \\
\hline 39.8 & - & 66.08 & - & - \\
\hline 39.9 & - & 57.09 & - & - \\
\hline 40.0 & - & 64.43 & - & - \\
\hline 40.1 & - & 66.69 & - & - \\
\hline 40.2 & - & 67.41 & - & - \\
\hline 40.3 & - & 60.06 & - & - \\
\hline 40.4 & - & 70.02 & - & - \\
\hline 40.5 & - & 75.37 & - & - \\
\hline 40.6 & - & 60.64 & - & - \\
\hline 40.7 & - & 58.02 & - & - \\
\hline 40.8 & - & 63.69 & - & - \\
\hline 40.9 & - & 54.12 & - & - \\
\hline 41.0 & - & 58.15 & - & - \\
\hline 41.1 & - & 51.90 & - & - \\
\hline 41.2 & - & 67.04 & - & - \\
\hline 41.3 & - & 38.64 & - & - \\
\hline 41.4 & - & 47.74 & - & - \\
\hline 41.5 & - & 62.55 & - & - \\
\hline 41.6 & - & 50.76 & - & - \\
\hline 41.7 & - & 57.58 & - & - \\
\hline 41.8 & - & 50.40 & - & - \\
\hline 41.9 & - & 54.17 & - & - \\
\hline 42.0 & - & 50.21 & - & - \\
\hline 42.1 & - & 88.56 & - & - \\
\hline 42.2 & - & 80.86 & - & - \\
\hline
\end{tabular}




\begin{tabular}{|c|c|c|c|c|}
\hline \multirow[b]{2}{*}{ River km } & \multicolumn{4}{|c|}{ Jacquet } \\
\hline & $\tau_{b \text { field }}$ & $\tau_{b \text { gis }}$ & $\tau^{*}$ field & $\tau_{\text {gis }}^{*}$ \\
\hline 42.3 & - & 74.56 & - & - \\
\hline 42.4 & - & 59.01 & - & - \\
\hline 42.5 & - & 79.79 & - & - \\
\hline 42.6 & - & 68.52 & - & - \\
\hline 42.7 & - & 79.43 & - & - \\
\hline 42.8 & - & 75.11 & - & - \\
\hline 42.9 & - & 73.76 & - & - \\
\hline 43.0 & - & 60.78 & - & - \\
\hline 43.1 & - & 86.63 & - & - \\
\hline 43.2 & - & 149.46 & - & - \\
\hline 43.3 & - & 133.61 & - & - \\
\hline 43.4 & - & 149.31 & - & - \\
\hline 43.5 & - & 145.40 & - & - \\
\hline 43.6 & - & 153.67 & - & - \\
\hline 43.7 & - & 85.86 & - & - \\
\hline 43.8 & - & 85.80 & - & - \\
\hline 43.9 & - & 81.93 & - & - \\
\hline 44.0 & - & 74.46 & - & - \\
\hline 44.1 & - & 80.07 & - & - \\
\hline 44.2 & - & 82.56 & - & - \\
\hline 44.3 & - & 67.24 & - & - \\
\hline 44.4 & - & 78.97 & - & - \\
\hline 44.5 & - & 86.25 & - & - \\
\hline 44.6 & - & 66.86 & - & - \\
\hline 44.7 & - & 56.54 & - & - \\
\hline 44.8 & - & 61.88 & - & - \\
\hline 44.9 & - & 65.41 & - & - \\
\hline 45.0 & - & 62.87 & - & - \\
\hline 45.1 & - & 75.60 & - & - \\
\hline 45.2 & - & 75.58 & - & - \\
\hline 45.3 & - & 66.62 & - & - \\
\hline 45.4 & - & 66.60 & - & - \\
\hline 45.5 & - & 72.42 & - & - \\
\hline 45.6 & - & 38.27 & - & - \\
\hline 45.7 & - & 41.42 & - & - \\
\hline 45.8 & - & 43.13 & - & - \\
\hline 45.9 & - & 40.17 & - & - \\
\hline 46.0 & - & 38.64 & - & - \\
\hline 46.1 & - & 66.35 & - & - \\
\hline 46.2 & - & 68.33 & - & - \\
\hline 46.3 & - & 75.75 & - & - \\
\hline 46.4 & - & 79.98 & - & - \\
\hline 46.5 & - & 69.02 & - & - \\
\hline 46.6 & - & 70.55 & - & - \\
\hline 46.7 & - & 28.83 & - & - \\
\hline 46.8 & - & 39.67 & - & - \\
\hline 46.9 & - & 26.56 & - & - \\
\hline
\end{tabular}




\begin{tabular}{|c|c|c|c|c|}
\hline \multirow[b]{2}{*}{ River km } & \multicolumn{4}{|c|}{ Jacquet } \\
\hline & $\tau_{b \text { field }}$ & $\tau_{b \text { gis }}$ & $\tau^{*}$ field & $\tau_{\text {gis }}^{*}$ \\
\hline 47.0 & - & 27.73 & - & - \\
\hline 47.1 & - & 19.29 & - & - \\
\hline 47.2 & - & 25.60 & - & - \\
\hline 47.3 & - & 34.77 & - & - \\
\hline 47.4 & - & 20.35 & - & - \\
\hline 47.5 & - & 22.82 & - & - \\
\hline 47.6 & - & 20.21 & - & - \\
\hline 47.7 & - & 21.24 & - & - \\
\hline 47.8 & - & 41.07 & - & - \\
\hline 47.9 & - & 98.56 & - & - \\
\hline 48.0 & - & 108.26 & - & - \\
\hline 48.1 & - & 97.83 & - & - \\
\hline 48.2 & - & 108.96 & - & - \\
\hline 48.3 & - & 132.04 & - & - \\
\hline 48.4 & - & 33.90 & - & - \\
\hline 48.5 & - & 31.15 & - & - \\
\hline 48.6 & - & 32.58 & - & - \\
\hline 48.7 & - & 38.23 & - & - \\
\hline 48.8 & - & 22.71 & - & - \\
\hline 48.9 & - & 25.85 & - & - \\
\hline 49.0 & - & 21.44 & - & - \\
\hline 49.1 & - & 35.28 & - & - \\
\hline 49.2 & - & 20.22 & - & - \\
\hline 49.3 & - & 12.22 & - & - \\
\hline 49.4 & - & 11.38 & - & - \\
\hline 49.5 & - & 17.81 & - & - \\
\hline 49.6 & - & 25.73 & - & - \\
\hline 49.7 & - & 25.03 & - & - \\
\hline 49.8 & - & 24.83 & - & - \\
\hline 49.9 & - & 34.38 & - & - \\
\hline 50.0 & - & 24.11 & - & - \\
\hline 50.1 & - & 18.94 & - & - \\
\hline 50.2 & - & 26.64 & - & - \\
\hline 50.3 & - & 28.26 & - & - \\
\hline 50.4 & - & 20.35 & - & - \\
\hline 50.5 & - & 26.13 & - & - \\
\hline 50.6 & - & 25.31 & - & - \\
\hline 50.7 & - & 25.13 & - & - \\
\hline 50.8 & - & 20.89 & - & - \\
\hline 50.9 & - & 19.14 & - & - \\
\hline 51.0 & - & 32.19 & - & - \\
\hline 51.1 & - & 30.76 & - & - \\
\hline 51.2 & - & 20.16 & - & - \\
\hline 51.3 & - & 17.74 & - & - \\
\hline 51.4 & - & 25.84 & - & - \\
\hline 51.5 & - & 26.04 & - & - \\
\hline 51.6 & - & 31.58 & - & - \\
\hline
\end{tabular}




\begin{tabular}{|c|c|c|c|c|}
\hline \multirow[b]{2}{*}{ River km } & \multicolumn{4}{|c|}{ Jacquet } \\
\hline & $\tau_{b \text { field }}$ & $\tau_{b \text { gis }}$ & $\tau^{*}$ field & $\tau_{\text {gis }}^{*}$ \\
\hline 51.7 & - & 42.78 & - & - \\
\hline 51.8 & - & 47.78 & - & - \\
\hline 51.9 & - & 58.15 & - & - \\
\hline 52.0 & - & 50.12 & - & - \\
\hline 52.1 & - & 40.71 & - & - \\
\hline 52.2 & - & 36.95 & - & - \\
\hline 52.3 & - & 35.85 & - & - \\
\hline 52.4 & - & 40.65 & - & - \\
\hline 52.5 & - & 35.93 & - & - \\
\hline 52.6 & - & 33.33 & - & - \\
\hline 52.7 & - & 39.67 & - & - \\
\hline 52.8 & - & 37.03 & - & - \\
\hline 52.9 & - & 50.77 & - & - \\
\hline 53.0 & - & 33.27 & - & - \\
\hline 53.1 & - & 39.66 & - & - \\
\hline 53.2 & - & 37.65 & - & - \\
\hline 53.3 & - & 39.52 & - & - \\
\hline 53.4 & - & 8.83 & - & - \\
\hline 53.5 & - & 2.73 & - & - \\
\hline 53.6 & - & 2.75 & - & - \\
\hline 53.7 & - & 3.87 & - & - \\
\hline 53.8 & - & 6.26 & - & - \\
\hline 53.9 & - & 1.88 & - & - \\
\hline 54.0 & - & 2.47 & - & - \\
\hline 54.1 & - & 2.97 & - & - \\
\hline 54.2 & - & 1.67 & - & - \\
\hline 54.3 & - & 2.57 & - & - \\
\hline 54.4 & - & 2.72 & - & - \\
\hline 54.5 & - & 2.44 & - & - \\
\hline 54.6 & - & 2.60 & - & - \\
\hline 54.7 & - & 3.16 & - & - \\
\hline 54.8 & - & 7.25 & - & - \\
\hline 54.9 & - & 6.61 & - & - \\
\hline 55.0 & - & 6.31 & - & - \\
\hline 55.1 & - & 6.09 & - & - \\
\hline 55.2 & - & 3.07 & - & - \\
\hline 55.3 & - & 4.82 & - & - \\
\hline 55.4 & - & 6.63 & - & - \\
\hline 55.5 & - & 6.24 & - & - \\
\hline 55.6 & - & 4.40 & - & - \\
\hline 55.7 & - & 4.34 & - & - \\
\hline 55.8 & - & 3.85 & - & - \\
\hline 55.9 & - & 5.72 & - & - \\
\hline 56.0 & - & 4.61 & - & - \\
\hline 56.1 & - & 5.23 & - & - \\
\hline 56.2 & - & 5.39 & - & - \\
\hline 56.3 & - & 4.83 & - & - \\
\hline
\end{tabular}

